DOE/ER-0734

\title{
Energy Materials
}

Coordinating Committee

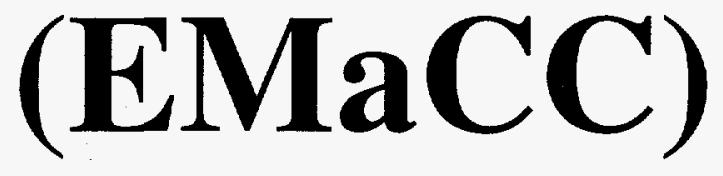

Fiscal Year 1997

July 31, 1998

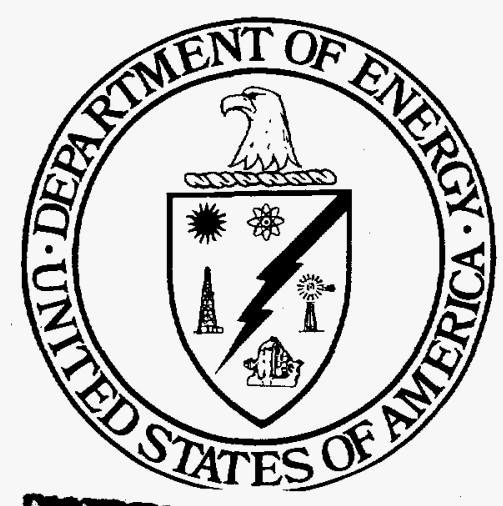

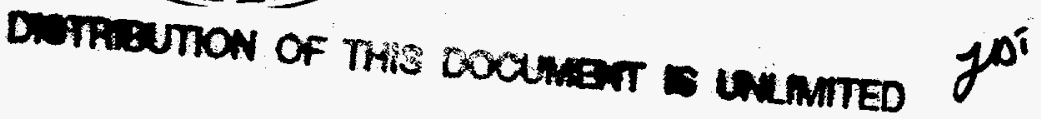

\section{Annual Technical Report}

U.S. Department of Energy

Office of Energy Research

Office of Basic Energy Sciences

Division of Materials Sciences 
This report has been reproduced directly from the best available copy.

Available to DOE and DOE Contractors from the Office of Scientific and Technical Information, P.O. Box 62, Oak Ridge, TN 37831; prices available from (423) 576-8401.

Available to the public from the U.S. Department of Commerce, Technology Administration, National Technical Information Service, Springfield, VA 22161, (703) $487-4650$. 


\section{DISCLAIMER}

This report was prepared as an account of work sponsored by an agency of the United States Government. Neither the United States Government nor any agency thereof, nor any of their employees, makes any warranty, express or implied, or assumes any legal liability or responsibility for the accuracy, completeness, or usefulness of any information, apparatus, product, or process disclosed, or represents that its use would not infringe privately owned rights. Reference herein to any specific commercial product, process, or service by trade name, trademark, manufacturer, or otherwise does not necessarily constitute or imply its endorsement, recommendation, or favoring by the United States Government or any agency thereof. The views and opinions of authors expressed herein do not necessarily state or reflect those of the United States Government or any agency thereof. 


\section{DISCLAIMER}

Portions of this document may be illegible in electronic image products. Images are produced from the best available original document. 


\section{DOE/ER-0734 \\ Energy Materials \\ Coordinating Committee (EMaCC)}

Fiscal Year 1997

July 31, 1998

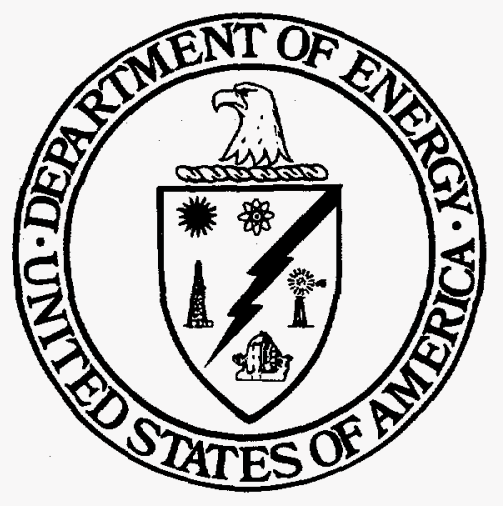

DISTFIBUTION OF THIS DOCUMENT IS LALMMTED

MASTER

\section{Annual Technical Report}

U.S. Department of Energy

Office of Energy Research

Office of Basic Energy Sciences

Division of Materials Sciences

Germantown, MD 20874-1290 
TABLE OF CONTENTS

Page

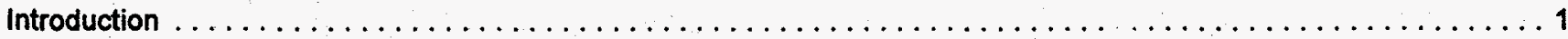

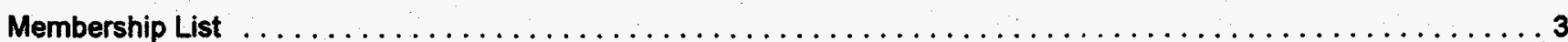

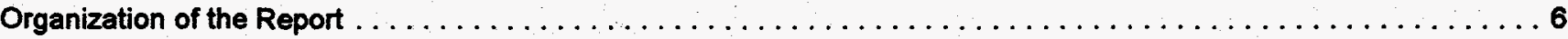

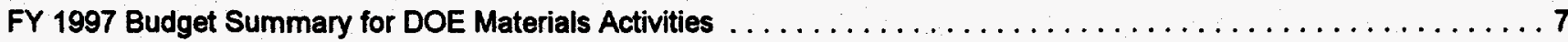

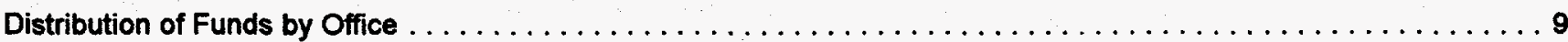

PROGRAM DESCRIPTIONS

OFFICE OF ENERGY EFFICIENCY AND RENEWABLE ENERGY $\ldots \ldots \ldots \ldots \ldots$

Office of Building Technology, State and Community Programs $\ldots \ldots \ldots \ldots \ldots \ldots \ldots \ldots$

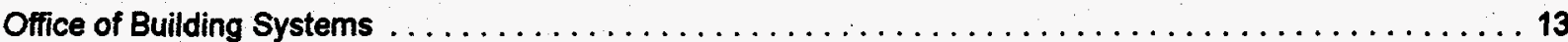

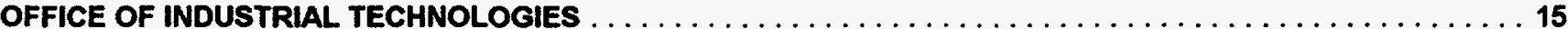

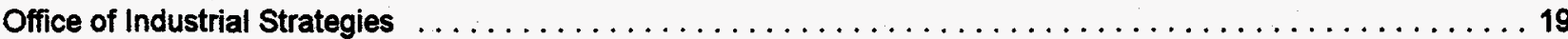

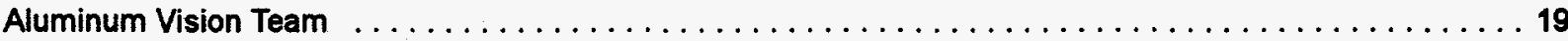

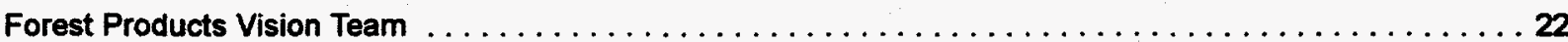

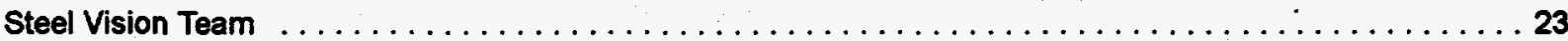

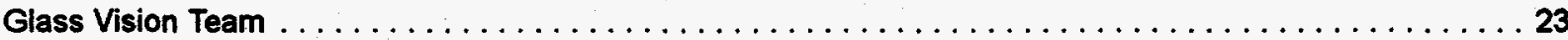

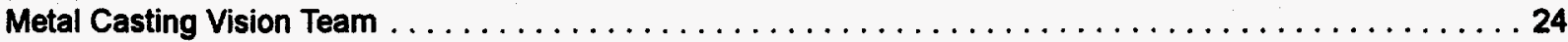

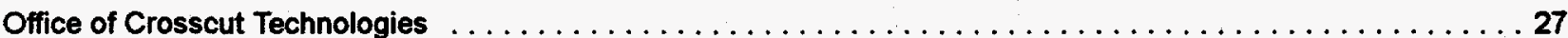

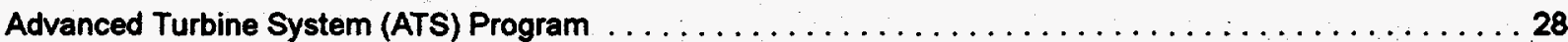

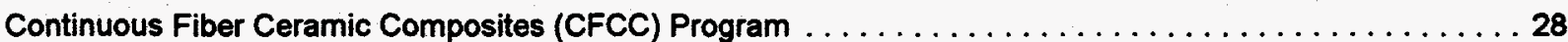

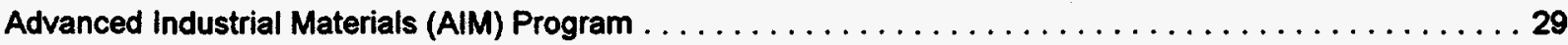

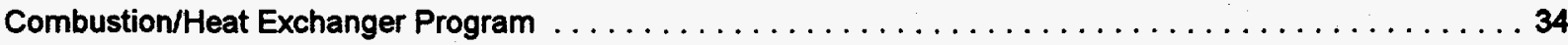

OFFICE OF TRANSPORTATION TECHNOLOGIES $\ldots \ldots \ldots \ldots \ldots \ldots \ldots \ldots$

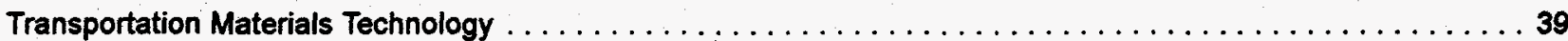

Automotive Materials Technology . . . . . . . . . . . . . . . . . . . . . . . . 39

Propulsion Systems Materials . . . . . . . . . . . . . . . . . . . . . . . . . 39

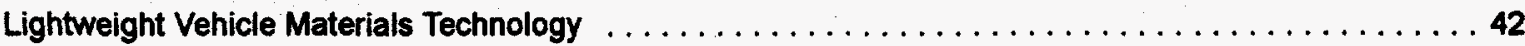

Electric Drive Vehicle Technology $\ldots \ldots \ldots \ldots \ldots \ldots \ldots \ldots \ldots \ldots \ldots \ldots \ldots$

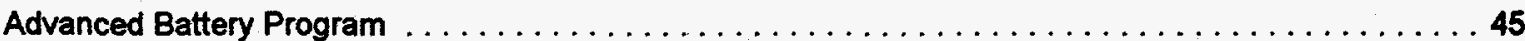

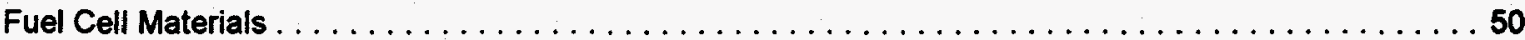

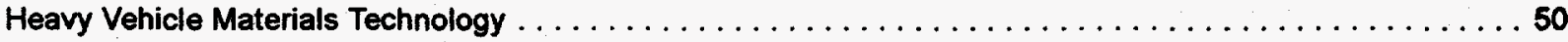




\section{TABLE OF CONTENTS (continued)}

\section{OFFICE DF ENERCY EFFICIENCY AND RENEWABLE ENERGY (continUEd)}

Office of Utility Technologies

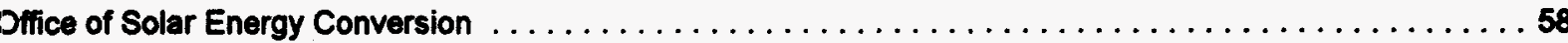

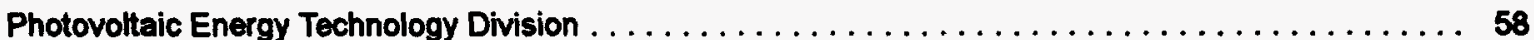

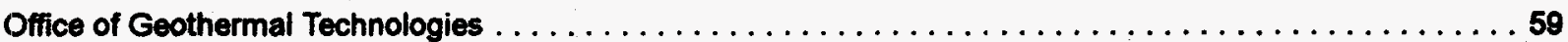

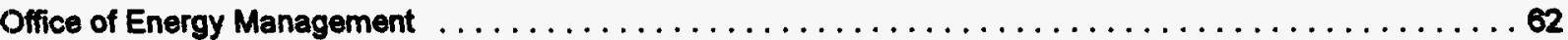

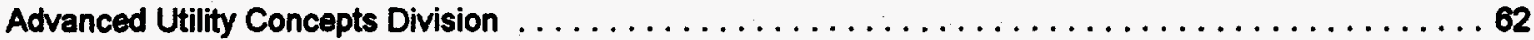

High Temperature Superconductivity for Electric Systems $\ldots \ldots \ldots \ldots \ldots \ldots \ldots \ldots \ldots \ldots 2$

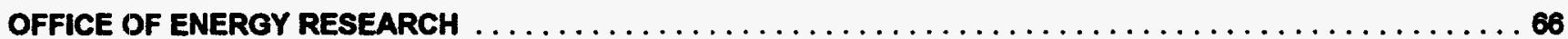

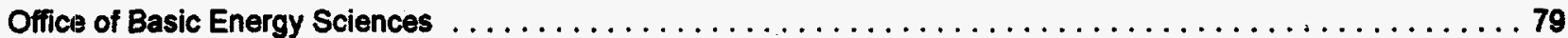

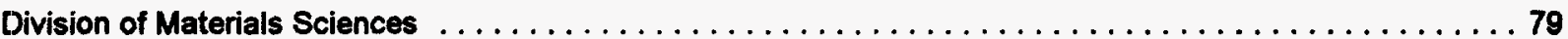

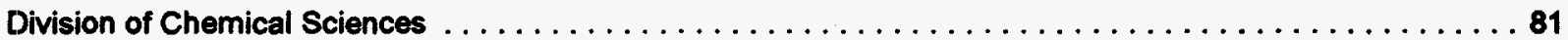

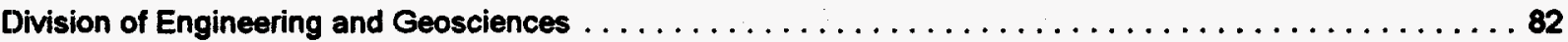

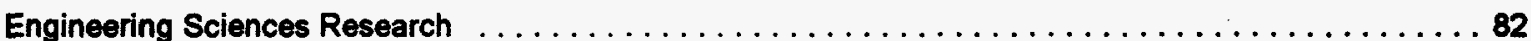

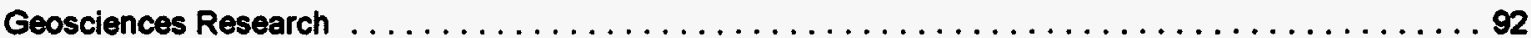

Office of Computational and Technology Research $\ldots \ldots \ldots \ldots \ldots \ldots \ldots \ldots \ldots \ldots \ldots \ldots \ldots$

Division of Advanced Energy Projects and Technology Research $\ldots \ldots \ldots \ldots \ldots \ldots \ldots \ldots \ldots \ldots 9 . \ldots 9$

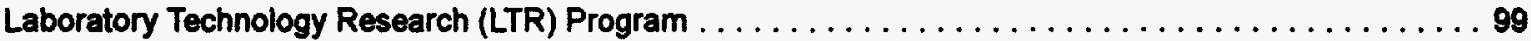

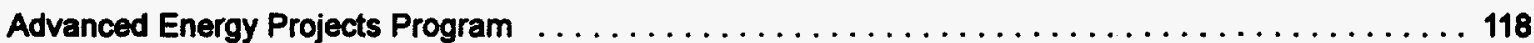

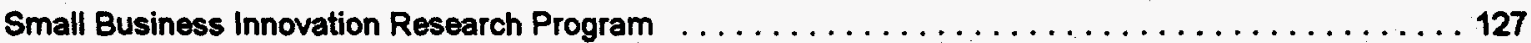

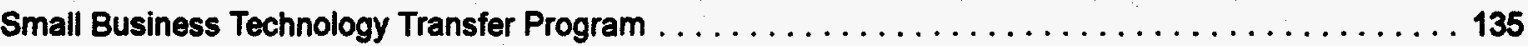

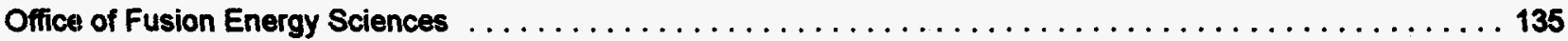

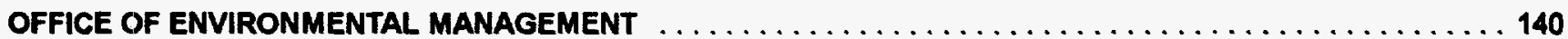

OFFICE OF NUCLEAR ENERGY, SCIENCE AND TECHNOLOGY $\ldots \ldots \ldots \ldots \ldots \ldots \ldots \ldots \ldots \ldots \ldots \ldots$

Office of Engineering and Technology Development $\ldots \ldots \ldots \ldots \ldots \ldots \ldots \ldots \ldots \ldots \ldots \ldots \ldots \ldots \ldots$

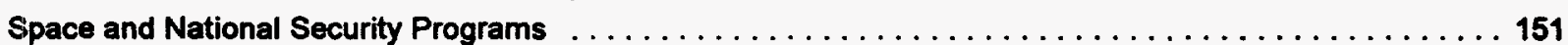

Office of Naval Reactors . . . . . . . . . . . . . . . . . . . . . . . . . . . . . . . . . . 152

OFFICE OF CIVILIAN RADIOACTIVE WASTE MANAGEMENT $\ldots \ldots \ldots \ldots \ldots \ldots \ldots \ldots \ldots \ldots \ldots \ldots \ldots$

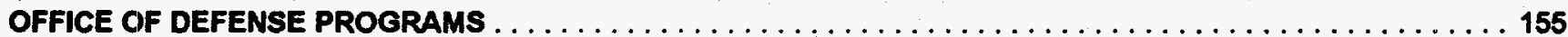

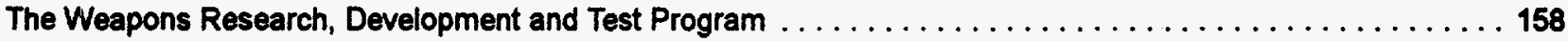

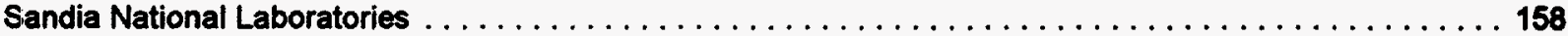

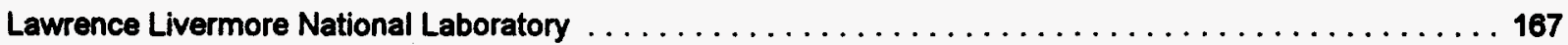

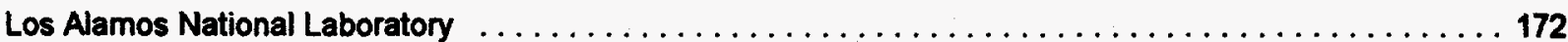


TABLE OF CONTENTS (continued)

OFFICE OF FOSSIL ENEROY ...................................................... Page

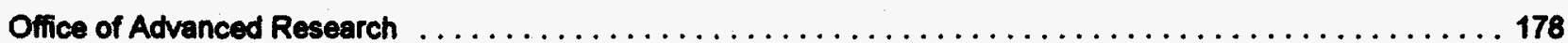

Fossil Energy AR\&TD Materials Program $\ldots \ldots \ldots \ldots \ldots \ldots \ldots \ldots \ldots \ldots \ldots \ldots \ldots \ldots \ldots$

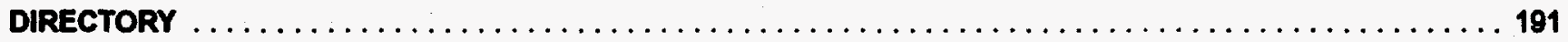

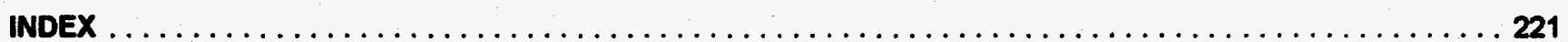




\section{INTRODUCTION}

The DOE Energy Materials Coordinating Committee (EMaCC) serves primarily to enhance coordination among the Department's materials programs and to further effective use of materials expertise within the Department. These functions are accomplished through the exchange of budgetary and planning information among program managers and through technical meetings/workshops on selected topics involving both DOE and major contractors. In addition, EMaCC assists in obtaining materials-related inputs for both intra- and interagency compilations.

Six topical subcommittees have been established to focus on materials areas of particular importance to the Department; the subcommittees and their respective chairpersons are:

Electrochemical Technologies - Richard Kelly, ER-132, (301) 903-6051

Metals - Sara Dillich, EE-22, (202) 586-7925

Radioactive Waste Containers - Helen Farrell, ER-131, (301) 903-5998

Semiconductors - Jerry Smith, ER-132, (301) 903-4269

Structural Ceramics - Charles Sorrell, EE-232, (202) 586-1514

Superconductivity - James Daley, EE-142, (202) 586-1165

Membership in the EMaCC is open to any Department organizational unit; participants are appointed by Division or Office Directors. The current active membership is listed on pages 3-5.

Six meetings were scheduled for 1998 . The dates, themes and speakers are as follows:

November 13, 1997

January 15, 1998

\section{Subcommittee on Environmental Management Speaker: Helen Farrell}

The minutes of the September 9, 1997, EMaCC meeting were accepted. Organizational details regarding EMaCC subcommittees were discussed. Helen Farrell made a presentation on the FY 1998 Environmental Management Science Program (EMSP) Solicitation. The announcement of the solicitation was said to be imminent and that there might be as much as $\$ 20$ million for new awards in FY98. A draft report from the R\&D Council subcommittee on Technical Coordinating Committees (TCC) was also discussed.

\section{Subcommittee on Electrochemical Technologies \\ Speaker: Professor Philip N. Ross, Lawrence Berkeley National Laboratory}

JoAnn Milliken welcomed the speaker and members; Richard Kelley introduced the guest speaker, Professor Philip N. Ross, who spoke on Surface Electrochemistry-Past, Present and Future. Dr. Ross traced the history of studies of the electrochemical interface through the development of electron-based spectroscopic analysis to the current in-situ photon-in photon-out methods such as Surface X-ray Scattering (SXS) and Surface-Enhanced Raman Spectroscopy (SERS). Progress in understanding a number of electrode processes such as potential-dependent reconstruction of Au(hkl) surfaces were discussed as was progress towards a carbon monoxide tolerant electrode for fuel cell. JoAnn Milliken described recent advances in the Automotive Fuel Cell Program. Significant accomplishments include the development of a highly efficient direct-hydrogen fuel cell stack system by International Fuel Cells, Inc., and the demonstration of technical feasibility of gasoline-powered PEM fuel cells. The latter achievement is important for the development of fuel cell systems powered by hydrogen generated by on-board fuel processing of gasoline. Utilizing the existing fuel infrastructure will enable early introduction of automotive fuel cells since a hydrogen fueling infrastructure is currently unavailable. Neil Rossmeissl spoke on materials issues in hydrogen research. The emphasis was on hydrogen storage and also hydrogen 
production, which is a high temperature $\left(800-1200^{\circ} \mathrm{C}\right)$ process. The minutes of the November 13, 1997, EMaCC meeting were accepted.

\section{Subcommittee on Metals \\ Speakers: Dr. Michael Kassner, Oregon State University \\ Dr. Phil Maziasz, Oak Ridge National Laboratory}

Sara Dillich welcomed the speakers on behalf of the Metals Subcommittee and gave a brief overview of planned solicitations/activities of the Office of Industrial Technologies. Dr. Michael Kassner spoke on the Metal Forming Project of the DOE Center for Excellence for the Synthesis and Processing of Advanced Materials. The object of the Metal Forming Project (one of eight Center projects) is to develop a scientific understanding of the phenomena relating to forming of aluminum alloys for industrial (especially automotive) applications. Dr. Phil Maziasz spoke on Achieving Perfect Microstructures for dramatically improving creep-strength of stainless steels. This summarized the results of a Cooperative Research and Development Agreement (CRADA) between ORNL utilizing its alloy R\&D and process optimization expertise and Solar Turbines, Inc., as the end-user, and Allegheny-Teledyne as the materials (foil) producer. Dr. Kassner and the Metal Forming project are supported by OER/BES/DMS. Dr. Maziasz's research is supported by the FEIARTD program.

May 21, 1998

\author{
Subcommittee on Superconductivity \\ Speakers: Russell Eaton, DOE Golden Field Office \\ Maribel Soto, Office of Naval Research Superconductivity Programs \\ X-D Xiang, Lawrence Berkeley National Laboratory \\ Bill McCallum, Ames Laboratory
}

\begin{abstract}
JoAnn Milliken called the meeting to order and Chris Platt welcomed our speakers and guests which included Don Gubser from the Naval Research Laboratories. Russell Eaton spoke on the status of the Superconductivity Partnership Initiative which is sponsored by the Superconductivity for Electric Systems Program, Maribel Soto presented a summary of work supported in the Office of Naval Research Superconductivity Programs, X-D Xiang presented work on the Combinatorial Approach to Study of Superconductors and Other Related Oxide Electronic Materials and Bil McCallum described progress toward understanding the Light Rare-Earth Barium Copper Oxide Superconductors.
\end{abstract}

Jully 16, 1998

\section{Subcommittee on Semiconductors/Photovoltaics}

September 10, 1998

The EMaCC reports to the Director of the Office of Energy Research in his or her capacity as overseer of the technical programs of the Department. This annual technical report is mandated by the EMaCC terms of reference. This report summarizes EMaCC activities for FY 1997 and describes the materials research programs of various offices and divisions within the Department.

The Chairman of EMaCC for FY 1997 was Dr. Yok Chen. The compilation of this report was performed by Dr. Tim Fitzsimmons, EMaCC Executive Secretary for FY 1998, with the assistance of FM Technologies, Inc.

Dr. JoAnn Milliken

Office of Transportation Technologies

EmaCC Chair, FY 1998 


\section{MEMBERSHIP LIST \\ DEPARTMENT OF ENERGY \\ ENERGY MATERIALS COORDINATING COMMITTEE}

\begin{tabular}{|c|c|c|}
\hline ORGANIZTIONI & REPRESEMTAYV. & $9 \% 10 N=1 \%$ \\
\hline \multicolumn{3}{|c|}{ 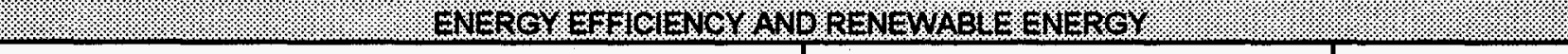 } \\
\hline \multicolumn{3}{|c|}{ Building Technology, State and Community Programs } \\
\hline Building Systems & Arun Vohra, EE-41 & 202/586-2193 \\
\hline \multicolumn{3}{|l|}{ Industrial Technologies } \\
\hline $\begin{array}{l}\text { Industrial Process Systems } \\
\text { Industrial Crosscut Technologies }\end{array}$ & $\begin{array}{l}\text { Sara Dillich, EE-22 } \\
\text { Toni Maréchaux, EE-22 } \\
\text { Brian Volintine, EE-22 } \\
\text { Charlie Sorrell, EE-23 } \\
\text { Debbie Haught, EE-23 } \\
\text { Pat Hoffman, EE-23 }\end{array}$ & $\begin{array}{l}202 / 586-7925 \\
202 / 586-8501 \\
202 / 586-1739 \\
202 / 586-1514 \\
202 / 586-2211 \\
202 / 586-6074\end{array}$ \\
\hline \multicolumn{3}{|l|}{ Transportation Technologies } \\
\hline $\begin{array}{l}\text { Automotive Propulsion System Materials } \\
\text { Automotive Lightweight Vehicle Materials } \\
\text { Advanced Battery Systems } \\
\text { Fuel Cell Systems } \\
\text { Heavy Vehicle Propulsion System Materials } \\
\text { High Strength Weight Reduction Materials } \\
\text { High Temperature Materials Laboratory }\end{array}$ & $\begin{array}{l}\text { Thomas Sebestyen, EE-32 } \\
\text { Joseph Carpenter, EE-32 } \\
\text { Ray Sutula, EE-32 } \\
\text { JoAnn Milliken, EE-32 } \\
\text { Sidney Diamond, EE-34 } \\
\text { Sidney Diamond, EE-34 } \\
\text { Sidney Diamond, EE-34 }\end{array}$ & $\begin{array}{l}202 / 586-9727 \\
202 / 586-1022 \\
202 / 586-8064 \\
202 / 586-2480 \\
202 / 586-8032 \\
202 / 586-8032 \\
202 / 586-8032\end{array}$ \\
\hline \multicolumn{3}{|l|}{ Utility Technologies } \\
\hline $\begin{array}{l}\text { Wind/Hydro/Ocean Technologies } \\
\text { Geothermal Technology } \\
\text { Photovoltaic Technology } \\
\text { Advanced Utility Concepts }\end{array}$ & $\begin{array}{l}\text { William Richards, EE-121 } \\
\text { Raymond LaSala, EE-122 } \\
\text { Richard King, EE-131 } \\
\text { James Daley, EE-142 } \\
\text { Christine Platt, EE-142 } \\
\text { Chris Kang, EE-142 }\end{array}$ & $\begin{array}{l}202 / 586-5410 \\
202 / 586-4198 \\
202 / 586-1693 \\
202 / 586-1165 \\
202 / 586-8943 \\
202 / 586-4563\end{array}$ \\
\hline
\end{tabular}




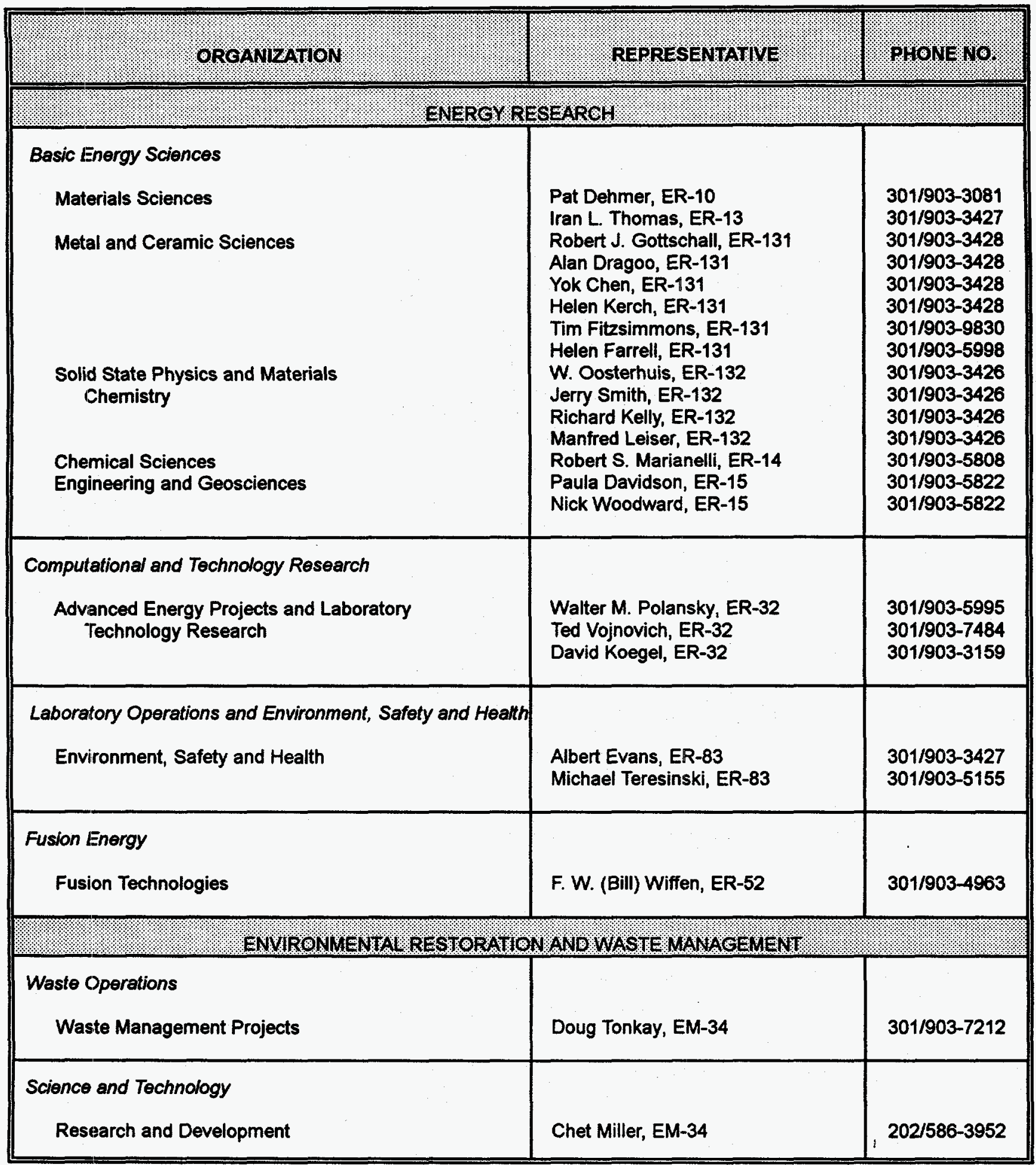




\begin{tabular}{|c|c|c|}
\hline ORGANIZATION & REPRESENTATIVE & 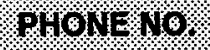 \\
\hline \multicolumn{3}{|c|}{ 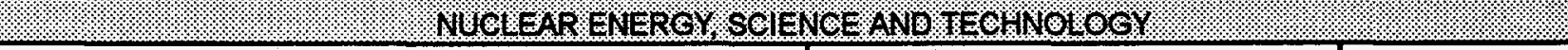 } \\
\hline Disposition Technologies & $\begin{array}{l}\text { William Van Dyke, NE-40 } \\
\text { Beverly Cook, NE-40 }\end{array}$ & $\begin{array}{l}301 / 903-4201 \\
301 / 903-4021\end{array}$ \\
\hline Space and Defense Power Systems & $\begin{array}{l}\text { William Barnett, NE-50 } \\
\text { John Dowicki, NE-50 }\end{array}$ & $\begin{array}{l}301 / 903-3097 \\
301 / 903-7729\end{array}$ \\
\hline Naval Reactors & $\begin{array}{l}\text { David I. Curtis, NE-60 } \\
\text { Tom Kennedy, NE-60 }\end{array}$ & $\begin{array}{l}703 / 603-5561 \\
703 / 603-1754\end{array}$ \\
\hline Reactor Programs & $\begin{array}{l}\text { John Warren, NE- } 80 \\
\text { Bob Lange, NE- } 80\end{array}$ & $\begin{array}{l}301 / 903-6491 \\
301 / 903-2915\end{array}$ \\
\hline \multicolumn{3}{|c|}{ CUULANRABIOACUNE WASTEMANAGEMENT } \\
\hline Analysis and Verification & Alan Berusch, RW-37 & $202 / 586-9362$ \\
\hline \multicolumn{3}{|c|}{ OEEEESSEROGRAMS. } \\
\hline \multicolumn{3}{|l|}{ Research and Advanced Technology } \\
\hline Research and Technology Development & Bharat Agrawal, DP-16 & $301 / 903-2057$ \\
\hline Inertial Confinement Fusion & Carl B. Hilland, DP-18 & $301 / 903-3687$ \\
\hline \multicolumn{3}{|c|}{ FOSSILENERGY. } \\
\hline Advanced Research & Fred M. Glaser & $301 / 903-2786$ \\
\hline
\end{tabular}




\section{ORGANIZATION OF THE REPORT}

The FY 1997 budget summary for DOE Materials Activities is presented on page 7. The distribution of these funds between DOE laboratories, private industry, academia and other organizations is presented in tabular form on page 9.

Following the budget summary is a set of detailed program descriptions for the FY 1997 DOE Materials activities. These descriptions are presented according to the organizational structure of the Department. A mission statement, a budget summary listing the project titles and FY 1997 funding, and detailed project summaries are presented for each Assistant Secretary office and the Office of Energy Research. The project summaries also provide DOE, laboratory, academic and industrial contacts for each project, as appropriate. 


\section{FY 1997 BUDGET SUMMARY FOR DOE MATERIALS ACTIVITIES}

(These numbers represent materials-related activities only. They do not include those portions of program budgets which are not materials related.)

OFFICE OF BUILDING TECHNOLOGY, STATE AND COMMUNITY PROGRAMS

FY 1997

Office of Building Systems

$\$ 1,090,000$

$1,090,000$

OFFICE OF INDUSTRIAL TECHNOLOGIES

$\$ 32,597,505$

Office of Industrial Strategies

$10,398,309$

Aluminum Vision Team

$5,071,000$

Forest Products Vision Team

Steel Vision Team

$1,084,012$

455,000

Glass Vision Team

$1,228,000$

Metal Casting Vision Team

$2,560,297$

Office of Crosscut Technologies

$22,199,196$

Advanced Turbine System (ATS) Program

$7,350,000$

Continuous Fiber Ceramic Composites (CFCC) Program

$8,400,000$

Advanced Industrial Materials (AIM) Program

Combustion/Heat Exchanger Program

$5,793,000$

630,000

OFFICE OF TRANSPORTATION TECHNOLOGIES

Transportation Materials Technology

$\$ 24,249,000$

Automotive Materials Technology

$24,249,000$

$17,483,000$

Propulsion Systems Materials

$5,483,000$

Lightweight Vehicle Materials Technology

$12,000,000$

Electric Drive Vehicle Technologies

$3,397,000$

Advanced Battery Programs

$2,997,000$

Fuel Cell Materials

400,000

Heavy Vehicle Materials Technology

$3,369,000$

OFFICE OF UTILITY TECHNOLOGIES

$\$ 38,810,000$

Office of Solar Energy Conversion

$18,460,000$

Photovoltaic Energy Technology Division

$18,460,000$

600,000

Office of Geothermal Technologies

$19,750,000$

Office of Energy Management

$19,750,000$

Advanced Utility Concepts Division

$19,750,000$ 
FY 1997 BUDGET SUMMARY FOR DOE MATERIALS ACTIVITIES (continued)

FY 1997

OFFICE OF ENERGY RESEARCH

$\$ 431,936,392$

Office of Basic Energy Sciences

$344,107,192$

Division of Materials Sciences

Division of Chemical Sciences

$332,060,000$

$5,143,000$

Division of Engineering and Geosciences

$6,904,192$

Engineering Sciences Research

$3,946,973$

Geosciences Research

$2,957,219$

Office of Computational and Technology Research

Division of Advanced Energy Projects and Technology Research

Laboratory Technology Research (LTR) Program

Advanced Energy Projects Program

Small Business Innovation Research Program

Small Business Technology Transfer Program

Office of Fusion Energy Sciences

$76,651,200$

$76,651,200$

$8,062,000$

$5,640,000$

$58,849,611$

$4,099,589$

$11,178,000$

OFFICE OF ENVIRONMENTAL MANAGEMENT

$\$ 6,870,939$

OFFICE OF NUCLEAR ENERGY, SCIENCE AND TECHNOLOGY

Office of Engineering and Technology Development

Space and National Security Programs

Office of Naval Reactors

$\$ 65,080,000$

$2,080,000$

$2,080,000$

$63,000,000^{1}$

OFFICE OF CIVILIAN RADIOACTIVE WASTE MANAGEMENT

$\$ 15,400,000$

\section{OFFICE OF DEFENSE PROGRAMS}

The Weapons Research, Development and Test Program

$\$ 96,633,600$

Sandia National Laboratories

Lawrence Livermore National Laboratory

$23,183,600$

$20,250,000$

Los Alamos National Laboratory

$53,200,000$

OFFICE OF FOSSIL ENERGY

$\$ 4,914,000$

Office of Advanced Research

Fossil Energy AR\&TD Materials Program

$4,914,000$

$\underline{4.914,000}$

TOTAL

'This excludes $\$ 47$ million for the cost of irradiation testing in the Advanced Test Reactor (ATR). 
FY 1997 Budget Summary for DOE Materials Activities

The distribution of these funds between DOE laboratories, private industry, academia and other organizations is listed below.

\begin{tabular}{|c|c|c|c|c|c|}
\hline ofilces & $160010 \%$ ories & monotro & Academills & Other & $10 \%$ \\
\hline $\begin{array}{l}\text { Office of Building } \\
\text { Technology, State and } \\
\text { Community Programs }\end{array}$ & $\$ 1,090,000$ & $\$ 0$ & $\$ 0$ & $\$ 0$ & $\$ 1,090,000$ \\
\hline $\begin{array}{l}\text { Office of Industrial } \\
\text { Technologies }\end{array}$ & $\$ 13,722,000$ & $\$ 15,617,208$ & $\$ 3,258,297$ & \$o & $\$ 32,597,505$ \\
\hline $\begin{array}{l}\text { Office of Transportation } \\
\text { Technologies }\end{array}$ & $\$ 17,925,000$ & $\$ 2,940,000$ & $\$ 3,084,000$ & $\$ 300,000$ & $\$ 24,249,000$ \\
\hline $\begin{array}{l}\text { Office of Utility } \\
\text { Technologies }\end{array}$ & $\$ 29,310,000$ & $\$ 9,500,000$ & \$o & $\$ 0$ & $\$ 38,810,000$ \\
\hline Office of Energy Research & $\$ 331,608,800$ & $\$ 65,199,200$ & $\$ 34,486,863$ & $\$ 641,529$ & $\$ 431,936,392$ \\
\hline $\begin{array}{l}\text { Office of Environmental } \\
\text { Management }\end{array}$ & $\$ 4,965,355$ & $\$ 250,000$ & $\$ 1,448,252$ & $\$ 207,332$ & $\$ 6,870,939$ \\
\hline $\begin{array}{l}\text { Office of Nuclear Energy, } \\
\text { Science and Technology }\end{array}$ & $\$ 65,080,000$ & $\$ 0$ & \$o & \$o & $\$ 65,080,000$ \\
\hline $\begin{array}{l}\text { Office of Civilian } \\
\text { Radioactive Waste } \\
\text { Management }\end{array}$ & $\$ 15,400,000$ & $\$ 0$ & so & \$o & $\$ 15,400,000$ \\
\hline Office of Defense Programs & $\$ 96,633,600$ & $\$ 0$ & $\$ 0$ & $\$ 0$ & $\$ 96,633,600$ \\
\hline Office of Fossil Energy & $\$ 3,979,000$ & $\$ 558,000$ & $\$ 357,000$ & $\$ 20,000$ & $\$ 4,914,000$ \\
\hline Totals & $\$ 579,713,755$ & $\$ 94,064,408$ & $\$ 42,634,412$ & $\$ 1,168,861$ & $\$ 717,581,436$ \\
\hline
\end{tabular}




\section{OFFICE OF ENERGY EFFICIENCY AND RENEWABLE ENERGY}

The Office of Energy Efficiency and Renewable Energy seeks to develop the technology needed for the Nation to use its existing energy supplies more efficiently, and for it to adopt, on a large scale, renewable energy sources. Toward this end, the Office conducts long-term, high-risk, high-payoff R\&D that will lay the groundwork for private sector action.

A number of materials R\&D projects are being conducted within the Energy Efficiency and Renewable Energy program. The breadth of this work is considerable, with projects focusing on coatings and films, ceramics, solid electrolytes, elastomers and polymers, corrosion, materials characterization, transformation, superconductivity and other research areas. The level of funding indicated refers only to the component of actual materials research. 
The Office of Energy Efficiency and Renewable Energy conducts materials research in the following offices and divisions:

FY 1997

OFFICE OF BUILDING TECHNOLOGY, STATE AND COMMUNITY PROGRAMS

$\$ 1,090,000$

Office of Building Systems

$1,090,000$

OFFICE OF INDUSTRIAL TECHNOLOGIES

$\$ 32,597,505$

Office of Industrial Strategies

$10,398,309$

Aluminum Vision Team

$5,071,000$

Forest Products Vision Team

$1,084,012$

Steel Vision Team

455,000

Glass Vision Team

$1,228,000$

Metal Casting Vision Team

$2,560,297$

Office of Crosscut Technologies

$22,199,196$

Advanced Turbine System (ATS) Program

$7,350,000$

Continuous Fiber Ceramic Composites (CFCC) Program

$8,400,000$

Advanced industrial Materials (AIM) Program

$5,793,000$

Combustion/Heat Exchanger Program

656,196

OFFICE OF TRANSPORTATION TECHNOLOGIES

$\$ 24,249,000$

Transportation Materials Technology

$24,249,000$

Automotive Materials Technology

$17,483,000$

Propulsion Systems Materials

$5,483,000$

Lightweight Vehicle Materials Technology

$12,000,000$

Electric Drive Vehicle Technologies

$3,397,000$

Advanced Battery Programs

Fuel Cell Materials

$2,997,000$

400,000

Heavy Vehicle Materials Technology

$3,369,000$

OFFICE OF UTILITY TECHNOLOGIES

$\$ 38,810,000$

Office of Solar Energy Conversion

$18,460,000$

Photovoltaic Energy Technology Division

$18,460,000$

600,000

Office of Geothermal Technologies

$9,750,000$

Advanced Utility Concepts Division

$19,750,000$

High Temperature Superconductivity for Electric Systems

$19,750,000$ 
OFFICE OF BUILDING TECHNOLOGY, STATE AND COMMUNITY PROGRAMS

Office of Building Technology, State and Community Programs - Grand Total

FY 1997

$\$ 1,090,000$

Office of Building Systems

$\$ 1,090,000$

Materials Properties, Behavior, Characterization or Testing

$\$ 1,090,000$

Development of Non-HCFC Foam Insulations

250,000

Evacuated Panel Insulation

250,000

Existing Materials Performance

110,000

Development of Sustainable Insulations

250,000

Standard Procedures for Measuring Solar Reflectivity of Roofs and Pavements

230,000 


\section{OFFICE OF BUILDING TECHNOLOGY, STATE AND COMMUNITY PROGRAMS}

\section{OFFICE OF BUILDING SYSTEMS}

The goal of this Office is to provide a scientific and technical basis (including model standards) for reducing the use of energy in residential and commercial buildings by 35 percent by the year 2000 from that used in 1975, while maintaining existing levels of human comfort, health and safety. The Division's primary objectives are to support research that advances the scientific and technical options for increased energy efficiency in buildings, to promote the substitution of abundant fuels for scarce fuels in buildings, and to promulgate standards for increased efficiency of energy use. To accomplish a portion of this, the Building Materials program seeks to: (1) develop new and improve existing insulating materials; (2) develop and verify analytical models that are useful to building designers and researchers for predicting the thermal performance characteristics of materials; (3) develop methods for measuring the thermal performance characteristics; and (4) provide technical assistance and advice to industry and the public. The DOE contact is Arun Vohra, (202) 586-2193.

\section{MATERIALS PROPERTIES, BEHAVIOR, CHARACTERIZATION OR TESTING}

\section{DEVELOPMENT OF NON-HCFC FOAM INSULATIONS \\ $\$ 250,000$ \\ DOE Contact: Arun Vohra, (202) 586-2193 \\ ORNL Contact: Ken Wilkes, (423) 574-5931}

This project is for the development of foam insulations that use alternative blowing agents as drop-in replacements for the CFC blowing agents that were previously used in the manufacture of foam insulation products and for the HCFC blowing agents that are currently being used. Prototype foam insulation boards and refrigerator panels were sent to ORNL for testing and evaluation. Tests are being conducted to determine thermal properties and aging characteristics. Models are being developed for aging processes, including the effects of facing materials.

Keywords: CFC, Foam Insulation, Insulation Sheathing, Roofs, HCFC, Refrigerators

\section{EVACUATED PANEL INSULATION $\$ 250,000$ \\ DOE Contact: Arun Vohra, (202) 586-2193 \\ ORNL Contact: Ken Wilkes, (423) 574-5931}

This project is for the development of an advanced technology super insulation concept. A filler layer of powder, fiber or foam is encapsulated in a vacuum barrier and a soft vacuum is drawn on the powder filler. Current technology produces R-30 and R-40 per inch panels. More efficient and/or less expensive fillers and longer life encapsulating materials are being developed. Initial applications are to the walls and doors of refrigerators/freezers. Other applications, including building envelopes, are being developed.

Keywords: Insulation, Vacuum, Heat Transfer, Refrigerators

\section{EXISTING MATERIALS PERFORMANCE $\$ 110,000$ \\ DOE Contact: Arun Vohra, (202) 586-2193 \\ LBL Contact: Dariush Arasteh, (510) 486-6844}

This project is for the development of accurate and reproducible data for use by the building materials community, improved test procedures to determine the thermal properties of existing, as well as advanced, insulations, interacting with the building materials research community, manufacturers, trade associations, professional societies, compliance groups and local government, and making and disseminating recommendations on appropriate usage of thermal insulation to conserve energy.

Keywords: Insulation, Buildings

\section{DEVELOPMENT OF SUSTAINABLE INSULATIONS \\ $\$ 250,000$ \\ DOE Contact: Arun Vohra, (202) 586-2193 \\ ORNL Contact: Ken Wilkes, (423) 574-5931}

This project is for the identification and development of low-cost sustainable insulation materials and systems for use in the building envelope. A survey and evaluation of information is being conducted to identify potentially applicable materials, known properties, deficiencies in knowledge of properties, level of availability, climatic and geographic range of applicability, environmental benefits and concerns, and costs of materials, transportation and any required treatment or processing. Laboratory evaluations of 
candidate materials will focus on thermal performance and other characteristics.

Keywords: Insulation, Sustainability, Building Envelope

5. STANDARD PROCEDURES FOR MEASURING SOLAR REFLECTIVITY OF ROOFS AND PAVEMENTS

$\$ 230,000$

DOE Contact: Mark Decot, (202) 586-6501

LBL Contact: Hashem Akbari, (510) 486-4287

ORINL Contact: Jeff Christian, (423) 574-5207

Reflectivity of exterior building materials used for pavement and roofing has been demonstrated to affect heating and cooling costs in buildings where they are applied. The reflectivity of these surfaces also has an effect on creating urban heat islands where ambient air temperature has an additional indirect effect on heating and cooling costs in buildings. Exterior surface reflectivity also has an effect on urban smog formation and indoor air quality. This research on procedures for measuring reflectivity and characterizing effects or urban heat islands is being conducted in cooperation with ASTM, the Lawrence Berkeley Laboratory, Oak Ridge National Laboratory, Cool Roof Rating Council, Environmental Protection Agency and other Cool Communities partners.

Keywords: Solar Reflectivity, Building Materials, Heat Islands, Smog, Energy Efficiency 
OFFICE OF INDUSTRIAL TECHNOLOGIES

FY 1997

Office of Industrial Technologies - Grand Total

$\$ 32,597,505$

Office of Industrial Strategies

$\$ 10,398,309$

Aluminum Vision Team

$\$ 5,071,000$

Device or Component Fabrication, Behavior or Testing

$\$ 1,935,000$

Aluminum Bridge Deck System

360,000

InLine Sensors for Electrolytic Aluminum Cells

254,000

Detection and Removal of Molten Salts from Molten Aluminum

294,000

High-Efficiency, High-Capacity, Low-NO ${ }_{x}$ Aluminum Melting Using OxygenEnhanced Combustion

527,000

Technology for Converting SPL to Useful Glass Fiber Products

500,000

Materials Properties, Behavior. Characterization or Testing

$\$ 970,000$

Molten Aluminum Explosion Prevention

100,000

Innovative Vertical Flotation Melter

300,000

Aluminum Pilot Cell

570,000

Materials Preparation, Synthesis, Deposition, Growth or Forming

Recycling Aluminum Salt Cake

$2,166,000$

Wettable Ceramic-Based Drained Cathode Technology for Aluminum Electrolysis Cells

Aluminum Spray Forming

500,000

666,000

$1,000,000$

Forest Products Vision Team

$\$ 1,084,012$

Materials Properties, Behavior. Characterization or Testing

$\$ 1,084,012$

Corrosivity Monitoring of Kraft Recovery Boilers

$1,084,012$

Steel Vision Team

$\$ 455,000$

Device or Component Fabrication. Behavior or Testing

$\$ 455,000$

Intermetallic Alloy Development Related to the Steel Industry

455,000

Glass Vision Team

$\$ 1,228,000$

Materials Preparation, Synthesis, Deposition, Growth or Forming

$\$ 364,000$

Chemical Vapor Deposition Ceramic Synthesis

364,000

Materials Properties, Behavior, Characterization or Testing

$\$ 864,000$

Development of Improved Refractories

364,000

Synthesis and Design of $\mathrm{MOSi}_{2}$ Intermetallic Materials

500,000 
OFFICE OF INDUSTRIAL TECHNOLOGIES (Continued)

FY 1997

Office of Industrial Strategies (continued)

Metal Casting Vision Team

$\$ 2,560,297$

Materials Preparation, Synthesis, Deposition, Growth or Forming

$\$ 1,333,502$

Assessment of Fast Shot Transition Point on Filling Patterns and Casting

Quality for Pressure Die Castings

122,000

Unconventional Methods for Yield Improvement through Directional

Solidification in Steel Castings

200,000

Plasma Refining Process Development

Heat Transfer at the Mold/Metal Interface in Permanent Mold Casting of Aluminum Alloys

Clean Cast Steel: 1) Flow of Steel in Gating Systems; 2) Control Ladle Temperature

176,000

155,921

Thin Section Steel Castings

Clean Metal Processing (Aluminum)

Advanced Lost Foam Casting Technology

220,000

88,581

169,000

202,000

Materials Properties, Behavior, Characterization or Testing

$\$ 1,053,185$

High Speed Milling and Pulsed ECM

Design Parameters for Lead Free Copper-Based Engineering Alloys in Permanent Molds

Process Parameters for Lead-Free Copper-Based Engineering Alloys in Permanent Molds

Impurity Limits in Aluminum Bronzes

Characterization of and Procedures to Eliminate Macro-Inclusion During Foundry Processing

Determination of Residual Stress and Softening Effects on the Life of Die Casting Dies

Development of Database Design Rules for Cast, High Alloy Steel Components

Semi-solid Metals Processing Consortium

Mechanical Properties Structure Correlation for Commercial Specifications of Cast Particulate Metal Matrix Components

Mechanical Properties of Squeeze and Semi-solid Cast A356

Ferrite Measurements in Duplex Stainless Steel Castings

Technology for the Production of Clean, Thin Wall, Machinable Gray and Ductile Iron Castings

Relationship Between Casting Distortion, Mold Filling and Interfacial Heat Transfer in Sand Molds

Device or Component Fabrication. Behavior or Testing 
OFFICE OF INDUSTRIAL TECHNOLOGIES (Continued)

FY 1997

Office of Crosscut Technologies

$\$ 22,199,196$

Advanced Turbine System (ATS) Program

$\$ 7,350,000$

Device or Component Fabrication. Behavior or Testing

$\$ 4,000,000$

Ceramic Components for Stationary Gas Turbines in Cogeneration Service

$4,000,000$

Materials Properties, Behavior, Characterization or Testing

$\$ 350,000$

Long-Term Testing of Ceramic Components for Stationary Gas Turbines

350,000

Materials Preparation, Synthesis, Deposition, Growth or Forming

ATS Materials Base Technology Support

$\$ 3,000,000$

$3,000,000$

Continuous Fiber Ceramic Composites (CFCC) Program

$\$ 8,400,000$

Materials Preparation, Synthesis, Deposition, Growth or Forming

$\$ 6,400,000$

CFCC Program - Industry Tasks

$6,400,000$

Materials Properties, Behavior: Characterization or Testing

$\$ 2,000,000$

Continuous Fiber Ceramic Composites (CFCC) Supporting Technologies

$2,000,000$

Advanced Industrial Materials (AIM) Program

$\$ 5,793,000$

Materials Preparation, Synthesis, Deposition, Growth or Forming

$\$ 3,302,000$

Intermetallic Alloy Development and Technology Transfer of Intermetallic Alloys

Development of Weldable, Corrosion Resistant Iron-Aluminide Alloys

515,000

Composites and Coatings Through Reactive Metal Infiltration

Conducting Polymers: Synthesis and Industrial Applications

Membrane Systems for Efficient Separation of Light Gases

Microwave and Plasma Processing

Uniform Droplet Processing

Advanced Materials/Processes

290,000

443,000

250,000

309,000

275,000

440,000

780,000

Materials Properties, Behavior, Characterization or Testing

$\$ 1,375,000$

Materials for Recovery Boilers

Metals Processing Laboratory User (MPLUS) Center

940,000

435,000

Device or Component Fabrication. Behavior or Testing

$\$ 610,000$

Gel Casting Technology

110,000

Microwave Joining of SiC

110,000

Selective Inorganic Thin Films

350,000

High Temperature Particle Filtration Technology

40,000 
Office of Industrial Technologies

OFFICE OF INDUSTRIAL TECHNOLOGIES (Continued)

FY 1997

Office of Crosscut Technologies (continued)

Advanced Industrial Materials (AIM) Program (continued)

Materials Structure and Composition

Metallic and Intermetallic Bonded Ceramic Composites Processing of Polymers in a Magnetic Field

Combustion/ Heat Exchanger Program

Materials Properties, Behavior. Characterization or Testing

Advanced Heat Exchanger Material Technology Development

Device or Component Fabrication. Behavior or Testing

High Pressure Heat Exchanger System (HiPHES) Energy Production High Pressure Heat Exchanger System (HiPHES) for Ethylene Production
$\$ 506,000$

165,000

341,000

$\$ 656,196$

$\$ 630,000$

630,000

\$ 26,196

0
26,196

18 


\section{OFFICE OF INDUSTRIAL TECHNOLOGIES}

The mission of the Office of Industrial Technologies (OIT) is to support the development and deployment of advanced energy efficiency, renewable energy and pollution prevention technologies for industrial applications. OIT's R\&D portfolio is driven by needs the Industries of the Future: chemicals, forest products, steel, aluminum, metalcasting and glass. These industries account for over half of all manufacturing energy use and account for 75 to 90 percent of most manufacturing wastes.

The Industries of the Future strategy uses industry-developed visions and technology roadmaps to outline the technology that will be needed in order to reach their goals. Through this process, government-funded research is brought to a sharp focus to benefit U.S. industry. OIT's R\&D portfolio includes process R\&D directly related to specific industries of the future and crosscutting R\&D which is applicable to multiple industries. Technology Access programs assist in delivering state-of-the-art and emerging technologies to industry customers.

\section{OFFICE OF INDUSTRIAL STRATEGIES}

The Industries of the Future (specific) mechanism cost-shares with industry and other organizations technology development identified in industry-wide developed visions and roadmaps. These technologies, specific to industry processes, are chosen based on their ultimate impact on energy and waste reduction, high priority and high risk to meet roadmap targets, widespread industry applicability and pre-competitive nature. Materials research addresses the need for industrial processes to run at increased temperatures with longer service lives, reduced downtime, and lower capital costs.

ALUMINUM VISION TEAM - The DOE Aluminum Team leader is Hank Kenchington, (202) 586-1878

\section{DEVICE OR COMPONENT FABRICATION, BEHAVIOR OR TESTING}

\section{ALUMINUM BRIDGE DECK SYSTEM $\$ 360,000$ \\ DOE Contact: Sara Dillich, (202) 586-7925 \\ ORNL Contact: Wayne Hayden, (423) 5746936}

The project objective is to develop and refine a bridge deck panel system consisting of aluminum multi-void extrusions joined to make panel sections. The desired results are to renovate deficient bridges and build new bridges throughout the U.S. using the aluminum bridge deck system. The project is being cost-shared under a Cooperative Research and Development Agreement between Reynolds Metals Company, Inc. and Oak Ridge National Laboratory (ORNL). The experimental plan has been established and ORNL is conducting work related to panel welding and NDE procedures, alternative welding procedures for onsite repairs, fatigue characterization of mechanically fastened aluminum joints, wear testing of composite paving surfaces, and environmental fatigue characterization of composite paving surfaces.

Keywords: Aluminum, Bridge Decks, Extrusions

\section{INLINE SENSORS FOR ELECTROLYTIC ALUMINUM CELLS \\ $\$ 254,000$ \\ DOE Contact: Sara Dillich, (202) 586-7925 \\ ORNL Contact: Jack Young, (423) 5744922}

Through an existing Cooperative Research and Development Agreement (CRADA) with industrial partners, Oak Ridge National Laboratory (ORNL), will develop a sensor for use in both conventional and advanced inert anode aluminum production cells. Fiber optic probes and laser-based Raman spectra analytical techniques are being investigated to measure soluble alumina in cryolite. Sensors for measurement of bath ratio and bath temperature will be investigated in future stages of the project. Dynamic process and thermal modeling will be developed in concert with these sensors to enable utility power load leveling through thermal cycling of the production cells without loss of productivity. A Raman cell for laboratory use has been designed and fabricated. Identifying a material that can endure cryolite melts is another barrier to developing a reliable sensor. Thus, research to date has focused on the development of coating materials for a silica probe, and three coating materials (CVD diamond, hot-pressed PBN and TBN) that appear to survive in cryolite melts during preliminary testing have been identified. Investigations are continuing into probe tip fabrication and coating, immersion tests in molten salts, and Raman characterization of cryolite.

Keywords: Sensor, Raman Probe, Fiber Optic Probe, Cryolite, Alumina 


\section{DETECTION AND REMOVAL OF MOLTEN SAL.TS FROM MOLTEN ALUMINUM $\$ 294,000$ DOE Contact: Sara Dillich, (202) 586-7925}

In a one-year effort beginning in September 1997, Selee Corporation and Alcoa Technical Center will conduct a program to detect and reduce chloride salts in molten aluminum. Selee Corporation has invented a simple electrical probe that senses the presence of salts in molten aluminum. Although consistent results have been seen in laboratory and plant tests, this salt detector needs to be calibrated. That is, its response must be correlated to the specific level of salts in the metal so that the response can be accurately interpreted. Selee has also invented a filter which selectively removes liquid salts from the liquid metal. This has been demonstrated in laboratory tests, but tests in real casting conditions must be carried out to determine efficiency and capacity of the filter. Using the experimental casting facility at the Alcoa Technical Center, these two devices will be exposed to various levels of chlorine and metal flow rates using commercial alloys. The response of the probe will be correlated with chlorine levels over a wide range of conditions. At the same time, the efficiency of the salt filter will be assessed. By monitoring the efficiency of the filter as a function of chlorine and time in casting, the adsorptive capacity of filter media can be determined. The goal of this project is to develop and demonstrate the technology at commercial-scale in one year. Commercial implementation by the domestic aluminum industry should be realized soon after, probably within another year.

Keywords: Molten Aluminum, Salts, Filter, Probe

9. HIGH-EFFICIENCY, HIGH-CAPACITY, LOW-NO ALUMINUM MELTING USING OXYGENENHANCED COMBUSTION $\$ 527,000$

DOE: Contact: Ramesh Jain, (202) 586-2381

Air Products \& Chemicals, inc. along with Argonne National Laboratory, Roth Brothers, and Brigham Young University will develop and demonstrate a novel, high-efficiency, high-capacity, low-NO , combustion system integrated with an innovative low-cost, on-site vacuum-swing-absorption (VSA) oxygen generation. This integrated burner/oxygen supply system will offer enhanced productivity, high-energy efficiency, low operating costs, and low $\mathrm{NO}_{x}$ emissions.

This two-year project, which began in September 1997, will be conducted in two phases. The first phase includes the design and construction of a low-NO burner at the optimum 35-50 percent combined total oxidizer stream using both the product and the exhaust streams from the VSA. The second phase includes the integration of the VSA to meet the average demand through proprietary storage, versus the current, less efficient practice of sizing to meet peak demand. The successful demonstration of this project will provide the U.S. aluminum industry with a cost-effective, energy-efficient, environmentally-friendly modification for current melting furnaces.

Keywords: Aluminum Melting, Combustion, Burner

\section{TECHNOLOGY FOR CONVERTING SPL TO USEFUL GLASS FIBER PRODUCTS $\$ 500,000$ DOE Contact: Sara Dillich, (202) 586-7925}

Vortec Corporation, assisted by Alumax Primary Aluminum Corp., Hoogovens Technical Services, Inc., and the New York State College of Ceramics at Alfred University, will perform a pilot-scale experimental testing project to evaluate the feasibility of converting SPL (spent potliner) from aluminum smelting plants to commercial quality glass fiber and aluminum fluoride products using Vortec's Cyclone Melting System (CMS ${ }^{\mathrm{MM}}$ ) technology. The project, initiated in September 1997, will be performed during a 20-month period and will include the following activities:

1. Design, fabrication, and installation of pilot-scale glass fiberizing and flue gas filtration and analysis equipment into Vortec's existing pilot-scale CMS $\mathrm{mm}$ testing facility

2. Pilot-scale SPL vitrification test to produce glass fibers

3. Testing and analysis of the fibers from the pilot-scale test with respect to commercial quality specifications

4. Testing and analysis of fibers with respect to human health considerations

5. Sampling and analysis of flue gas from the pilot-scale CMS ${ }^{\mathrm{TM}}$ during testing

6. Preliminary design of a commercial-scale air pollution system for aluminum fluoride production.

Keywords: Potliner, Aluminum Smelting, Glass Fiber, Alurninum Fluoride 
MATERIALS PROPERTIES, BEHAVIOR, CHARACTERIZATION OR TESTING

\section{MOLTEN ALUMINUM EXPLOSION PREVENTION \\ $\$ 100,000$ \\ DOE Contact: Ramesh Jain, (202) 586-2381 \\ ORNL Contact: Rusi P. Taleyarkhan, 4235764735}

The goal of this project is to improve industry's understanding of the conditions that trigger aluminumwater explosions and the reasons and extent to which certain coatings prevent those explosions. Project partners (ORNL, The Aluminum Association, Alcoa) will achieve this goal through developing a basic understanding of entrapment of heat transfer over submerged coated and uncoated surfaces. Partners have designed and developed the Steam Explosion Triggering Studies (SETS) facility, an experimental test site where the fundamental issues of explosions will be investigated with emphasis on triggering events. Solid tungsten, an element that has thermophysical properties similar to those of liquid aluminum, will be used during the experiments to allow the apparatus to be instrumented and the phenomena associated with the breakdown of steam film and triggering investigated without the hazards associated with experiments performed with large amounts of liquid aluminum. The initial coping assessment and the preliminary testing to verify the project's approach and direction have been completed. In addition, feedback has been provided to industry testing programs. Suppression capability data for various coatings with different curing times and their application criteria has been obtained, as well as the suppression capability data for various coatings based on the evolution of non-condensable gases and wettability.

Keywords: Explosions, Molten Aluminum, Water

\section{INNOVATIVE VERTICAL FLOATATION MELTER $\$ 300,000$ \\ DOE Contact: Ramesh Jain, (202) 586-2381}

The vertical floatation melter (VFM) is being developed by Energy Research Company, Gillespe and Powers, IMCO, and Stein, Atkinson and Stordy with support from the Office of Industrial Technologies. This technology represents a significantly cleaner and more efficient alternative for processing aluminum scrap. In the new process, the scrap is first dried and de-coated in a rotary kiln dryer that completely removes organics such as oil, paint, and plastics. The heat content of the organics volatizing from the scrap will supply supplementary heat to the de-coater. The dried and de-coated scrap is then melted in the opposed flow
VFM, where particles of varying sizes and surface areas are kept in suspension at different levels of the melter, designed with varying velocities to achieve the desired drag forces. The scrap pieces reach an equilibrium in which the scrap weight equals the gas drag force, and the scrap is suspended for 15 to 30 seconds, allowing sufficient residence time for it to melt. The melting particles experience changes in their aerodynamic shape until they reach the liquid state and fall into a molten metal bath. This process also has applications in the glass and steel industries.

Keywords: Floatation Melter, Aluminum Scrap

\section{ALUMINUM PILOT CELL $\$ 570,000$ DOE Contact: Sara Dillich, (202) 586-7925}

The Department of Energy, Office of Industrial Technologies is currently sponsoring a project with the Aluminum Company of America (Alcoa) to demonstrate, through pilot cell tests, viability of an advanced retrofit technology for alumina reduction based on inert, cermet anodes and wettable $\mathrm{TiB}_{2}-\mathrm{G}$ cathodes. Phase $I$ of the Alcoa project developed a retrofit commercial cell conceptual design and assessed its economic and environmental impact. Phase II is conducting tests in a pilot-scale cell and an evaluation of lower cost/higher quality fabrication of inert anodes. The objectives of Phase II are to construct, operate, and autopsy two pilot-scale cells; the first based on best available technology and the second optimized as a result of the knowledge gained from the first. These tests will also feature Bayer process improvements, and advanced cell design and control systems. Anodes will be fabricated by isostatic pressing and sintering of metal and oxide powders. Innovative fabrication methods for anode-collector bar assembly are also being investigated.

Keywords: Alumina Reduction, Aluminum Production, Inert Anode, Wettable Cathodes

\section{MATERIALS PREPARATION, SYNTHESIS, DEPOSITION, GROWTH OR FORMING}

\section{RECYCLING ALUMINUM SALT CAKE $\$ 500,000$ \\ DOE Contact: Sara Dillich, (202) 586-7925 \\ ANL Contact: John Hryn, (630) 252-5894}

Salt cake recovery is the most energy and cost intensive unit operation in the recovery of salt cake constituents. In this project, Argonne National Laboratory (ANL) is developing a salt recovery process based on electrodialysis (ED). Laboratory scale experiments and 
economic analysis has indicated that, for conditions consisterit with salt cake recycling, the ED technology is more cost-effective for salt recovery than alternative technologies (e.g., evaporation with vapor recompression). Increasing the market value of NMP is critical for cost-effective salt cake recycling. Impurities constitute about 10 percent of NMP and lower its market value. Research is investigating hydrometallurgical processes to purify NMP, since higher NMP purity results in higher market value for refractory aggregate and other potential alumina markets. Markets which will require lower development costs, such as alternative alumina units for the blast furnace in ironmaking, are also being explored.

Keywords: Aluminum, Salt Cake, Recycling, Electrodialysis

\section{WETTABLE CERAMIC-BASED DRAINED CATHODE TECHNOLOGY FOR ALUMINUM ELECTROLYSIS CELLS $\$ 666,000$ DOE Contact: Sara Dillich, (202) 586-7925}

Reynolds Metals Company, Kaiser Mead, and Advanced Refractory Technologies (ART) will collaborate to develop and evaluate ceramic-based materials, technology, and the necessary engineering packages to retrofit existing reduction cells as a means to improve the performance of the Hall Héroult cell. ART will produce $\mathrm{TiB}_{2}$-based tiles or coatings that will be used as the "drained" lining in two 70 kA prebake cells. The durability of the candidate materials and the performance of the drained cathode design will be evaluated during a one-month test using $12 \mathrm{kA}$ pilot reduction cells. This four-year project, initiated in September 1997, will include the following activities:

1. Development and evaluation of candidate $\mathrm{TiB}_{2}-$ carbon materials (tiles and coating)

2. Development and evaluation of proprietary carbon materials

3 Development of the drained cathode design

4. Evaluation of the best candidate materials and the drained cathode design in the $12 \mathrm{kA}$ pilot cell

5. Design and construction of a $70 \mathrm{kA}$ prebake cell retrofitted with a drained cathode using $\mathrm{TiB}_{2}$-based and or the proprietary materials

6. Startup and operation of two $70 \mathrm{kA}$ prebake cells retrofitted with a drained cathode and $\mathrm{TiB}_{2}$ and or the proprietary materials

Keywords: Cathode, Aluminum Production, Titanium Diboride

\section{ALUMINUM SPRAY FORMING $\$ 1,000,000$ DOE Contact: Sara Dillich, (202) 586-7925}

This project, conducted by the Aluminum Company of America (Alcoa), will translate current bench-scale spray forming technologies into a cost-effective process for the replacement of the energy-intensive ingot casting method. A unique linear spray nozzle system has been designed which has the potential for achieving the desired production rates of 1500 to $3000 \mathrm{lb}$. $/ \mathrm{hr} / \mathrm{in}$ in a single pass operation. Other processing targets include \pm 2 percent profile flatness, less than 1-inch edge trimming; surface porosity of less than 4 percent not interconnected, and overspray less than 5 percent. Thermomechanical processing studies, microstructural characterization of deposits, and mathematical and numerical modeling are in progress. Investigations are focusing on as-sprayed microstructure and thermomechanical properties of automotive alloy 6111 . An Advanced Development Unit, capable of operating in both an experimental and a semi-production mode, is being designed and constructed to investigate the commercial viability of the spray forming process to produce aluminum sheet. The unit will be used to determine costs as well as processing and safety procedures for steady state operations.

Keywords: Aluminum, Spray Forming, Sheet

FOREST PRODUCTS VISION TEAM - The DOE Forest Products team leader is Valri Robinson, (202) 586-0937

\section{MATERIALS PROPERTIES, BEHAVIOR, CHARACTERIZATION, OR TESTING}

\section{CORROSIVITY MONITORING OF KRAFT RECOVERY BOILERS \\ $\$ 1,084,012$ \\ DOE Contact: Charles A. Sorrell, (202) 586-1514 \\ IPST Contact: Preet Singh, (404) 894-6641}

The focus of this project is to develop an extensive corrosion kinetics database as well as a device to measure conditions which control corrosion in an operating recovery boiler. The benefit of such an approach will allow operators to predict or explain the impact of decisions prior to damaging boiler components. The project will be divided into four phases. Phase I will establish the feasibility of the project concept., Phase II will involve detailed studies on the most promising candidates for corrosion measurements, Phase III consists of small scale experiments conducted in a laboratory furnace to test the efficacy of the measurement system developed in Phase II, and in the final Phase IV, the measurement 
device and corrosion probes will be installed in a operating boiler for comparison.

Keywords: Recovery Boilers, Corrosion, Pulp and Paper

STEEL VISION TEAM - The DOE Steel team leader is Scott Richlen, (202) 586 - 2078

\section{DEVICE OR COMPONENT FABRICATION, BEHAVIOR OR TESTING}

\section{INTERMETALLIC ALLOY DEVELOPMENT RELATED TO THE STEEL INDUSTRY $\$ 455,000$ \\ DOE Contact: Charles A. Sorrell, (202) 586-1514 \\ ORNL Contacts: M. L. Santella, (423) 574-4805, V. K. Sikka, (423) 574-5112, and P. Angelini (423) $574-4565$}

The objective of this project is to develop and apply the excellent oxidation and carburization resistance and higher strength of intermetallic alloys including nickel aluminides $\left(\mathrm{Ni}_{3} \mathrm{Al}\right)$ to Steel industry related manufacturing applications. Progress in bringing technologies to development and commercialization in FY 1997 focused on furnace transfer rolis for use in the heat treating of steel slabs: 1) Two types of furnace roll designs have been fabricated and are being tested at Bethlehem Steel; both types utilize a welded connection between a trunnian and a roll body, 2) Technology for joining thick sections of $\mathrm{Ni}_{3} \mathrm{Al}$ to dissimilar metals was developed, and two rolls are being tested utilizing HK or HP steel trunnians weided to $\mathrm{Ni}_{3} \mathrm{Al}$ roll bodies, 3) After working with various companies on materials and process development of $\mathrm{Ni}_{3} \mathrm{Al}$ two companies have been licensed, including Alloy Engineering and Casting Company, Sandusky International to produce $\mathrm{Ni}_{3} \mathrm{Al}$ materials and components.

Keywords: Nickel Aluminides, Processing, Steel, Metalcasting, Aluminum, Heat Treating, Welding
GLASS VISION TEAM - The DOE Glass team leader is Theo Johnson, (202) 586- 6937

\section{MATERIALS PREPARATION, SYNTHESIS, DEPOSITION, GROWTH OR FORMING}

\section{CHEMICAL VAPOR DEPOSITION CERAMIC SYNTHESIS $\$ 364,000$ (funded by the OIT Glass Vision team) DOE Contact: Charles A. Sorrell, (202) 586-1514 Sandia National Laboratories - Livermore Contact: M. D. Allendorf, (415) 294-2895}

Comprehensive models, including detailed gas-phase and surface chemistry coupled with reactor fiuid mechanics, are required to optimize and scale-up chemical vapor deposition \pm (CVD) processes. The objective of this project is to use the unique diagnostic and modeling capabilities at the Sandia National Laboratories - California to understand and develop new techniques for chemical vapor deposition (CVD). A research reactor, originally constructed with DOE-OIT funding, is being used to determine identities and amounts of gaseous phase species present during CVD. Research efforts are focused on development of CVD processes for oxide fiber-preforms and plate glass surfaces for the improvement of properties. In FY1997 a CRADA was developed with Libby- Owens-Ford Co. on developing new CVD techniques for depositing coatings on glass. With respect to this project: (1) a database was developed of thermodynamic properties for the deposition of coatings on glass, (2) experimental techniques were developed for identifying reactions of the glass-coating precursors, and (3) the kinetics of several reactions were measured. In the task on composite and the fiber coating efforts: (1) an analytical model was completed to predict deposition of coatings on ceramic fiber preforms, and (2) a model to quantitatively predict boron nitride coating rates in chemical reactors was optimized.

Keywords: Chemical Vapor Deposition, Gas-Phase Chemistry, Modeling, Fibers, Flat Glass 
MATERIALS PROPERTIES, BEHAVIOR, CHARACTERIZATION OR TESTING

\section{DEVELOPMENT OF IMPROVED REFRACTORIES \\ $\$ 364,000$}

DOE Contact: Charles A. Sorrell, (202) 586-1514

Oak Ridge National Laboratory Contact:

A. A. Wereszczak (423) 574-7601, and

Peter Angelini (423) 574-4565

Refractories are critical for various industrial processes. For example, glass melting furnaces are fabricated with various types of refractories which enable the furnaces to be operated at very high temperatures, and steel or aluminum smelting and melting vessels are lined with refractories. The goal of this project is to develop improved refractories and to determine critical mechanical and thermophysical and mechanical properties. In FY 1997, work was focused on determining high temperature creep and corrosion behavior of refractories for use in oxifuel fired glass making furnaces. Partners in this activity include the Oak Ridge National Laboratory, Alfred University's Center for Glass Research (CGR) Satellite Center at the University of Missouri-Rolia, and an industrial technical team representing glass and refractories manufacturers.

Keywords: Refractories, Glass, Furnace, Oxi-fuel, High Temperature, Mechanical Thermophysical, Properties, Corrosion

21. SYNTHESIS AND DESIGN OF MOSI INTERMETALLIC MATERIALS

$\$ 500,000$

DOE Contact: Charles A. Sorrell, (202) 586-1514

Los Alamos National Laboratory Contacts: J. J. Petrovic, (505) 667-0125 and Richard Castro (505) 667-5191

The objective of this project is to develop $\mathrm{MoSi}_{2}$-based composites that will combine good room temperature fracture toughness with excellent oxidation resistance and high-temperature strength for industrial applications. Activities in FY 1997 included various major tasks. A CRADA with Johns Manville Corporation on the use of $\mathrm{MOSi}_{2}$ for glass industry applications is continuing. The corrosion behavior of $\mathrm{MoSi}_{2}$ materials in molten fiberglass has been initially evaluated, and is similar to AZS refractory. Maximum corrosion rates occur at the glass-air interface. Efforts have been initiated with IGT to test $\mathrm{MoSi}_{2}$ materials in a gas radiant tube environment. This will be a 500 hour test at $1800^{\circ} \mathrm{F}$ under gas combustion conditions.

Keywords: Composites, Intermetallics, Molydisilicides, Coatings

METAL CASTING VISION TEAM - The DOE Metalcasting team leader is Harvey Wong, (202) $586-9235$

MATERIALS PREPARATION, SYNTHESIS,

22. ASSESSMENT OF FAST SHOT TRANSITION POINT ON FILLING PATTERNS AND CASTING QUALITY FOR PRESSURE DIE CASTINGS $\$ 122,000$ DOE Contact: Toni Maréchaux, (202) 586-8501

Principal Investigator: Jerald Brevick, Ohio State University (614) 292-0177

The objective of this project is to evaluate common approaches to cavity filling, compare the results of current software metal flow models with fluid flow observed on high-speed video, and compare the location, size and total volume of contained gas porosity.

Keywords: Metalcasting, Metal Flow

\section{UNCONVENTIONAL METHODS FOR YIELD IMPROVEMENT THROUGH DIRECTIONAL SOLIDIFICATION IN STEEL CASTINGS $\$ 200,000$ \\ DOE Contact: Toni Maréchaux, (202) 586-8501 \\ Principal Investigator: Christoph Beckermann, University of lowa, (319) 335-5681}

This project is designed to increase yield through the use of solidification software to simulate imposed thermal gradients and evaluate their effect on yield.

Keywords: Metalcasting, Metal Flow

\section{PLASMA REFINING PROCESS DEVELOPMENT $\$ 176,000$ \\ DOE Contact: Toni Maréchaux, (202) 586-8501 \\ Principal Investigator: Carl Lundin, University of Tennessee, (423) $974-5310$}

The objective of this project is to improve the weldability and corrosion resistance of high alloy castings; to demonstrate reductive alloying in a plasma furnace to 
minimize oxidation losses of chromium and other elements; and to decarburize stainless steels efficiently.

Keywords: Metalcasting, Corrosion, Welding, Stainless Steel

25. HEAT TRANSFER AT THE MOLDIMETAL INTERFACE IN PERMANENT MOLD CASTING OF ALUMINUM ALLOYS

$\$ 155,921$

DOE Contact: Toni Maréchaux, (202) 586-8501

Principal Investigator: Robert Pehlke, University of Michigan, (313) 764-7489

The objective of this project is to achieve enhanced dimensional control in permanent mold castings, decreased cycle time and accurate control of heat transfer. It is designed to increase die life and enable thinner section sizes.

Keywords: Metalcasting, Aluminum, Permanent Mold Casting

26. CLEAN CAST STEEL: 1) FLOW OF STEEL IN GATING SYSTEMS; 2) CONTROL LADLE TEMPERATURE

$\$ 220,000$

DOE Contact: Toni Maréchaux, (202) 586-8501

Principal Investigator: Charles Bates, University of Alabama - Birmingham, (205) 975-8011

The objective of this project is: (1) to evaluate the effect of the flow of steel in gatings systems on steel casting quality; (2) to evaluate the effect of ladle temperature homogenization on steel casting quality.

Keywords: Metalcasting, Steel, Gatings

\section{THIN SECTION STEEL CASTINGS} $\$ 88,581$

DOE Contact: Toni Maréchaux, (202) 586-8501

Principal Investigator: Robert C. Voigt, Pennsylvania State University, (814) $863-7290$

The objective of this project is to develop a fundamental understanding of the key technologies needed to develop lighter weight, thinner section steel castings.

Keywords: Metalcasting, Steel

\section{CLEAN METAL PROCESSING (ALUMINUM)} $\$ 169,000$

DOE Contact: Toni Maréchaux, (202) 586-8501

Principal Investigator: Diran Apelian, Worcester

Polytechnic Institute, (508) 831-5992

The objective of this project is to investigate and develop implementable metal cleanliness assessment methods, melt contamination avoidance, and augmentation of the fundamental knowledge base of phase separation technology.

Keywords: Metalcasting, Aluminum, Phase Separation

\section{ADVANCED LOST FOAM CASTING TECHNOLOGY \\ $\$ 202,000$}

Principal Investigator: Charles Bates, University of Alabama - Birmingham, (205) 975-8011

The objective of this project is to perform research to advance the theory and application of lost foam casting including: making castings under vacuum; to extend the technology to allow bronze and steel alloy casting; coating improvements; and flow, fill and solidification experiments.

Keywords: Metalcasting, Lost Foam Casting

\section{MATERIALS PROPERTIES, BEHAVIOR, CHARACTERIZATION, OR TESTING}

\section{HIGH SPEED MILLING AND PULSED ECM $\$ 126,000$ \\ DOE Contact: Toni Maréchaux, (202) 586-8501 \\ Principal Investigator: Taylan Altan, Ohio State University}

The objective of this project is to determine the influence of HSM and PECM on residual stresses in the die surface and its resistance to thermal fatigue and to develop guidelines for machining $\mathrm{H}-13$ at a fully heat treated state. This will test the findings and determine time and cost savings.

Keywords: Metalcasting, Residual Stress, Machining 


\section{DESIGN PARAMETERS FOR LEAD FREE COIPPER-BASED ENGINEERING ALLOYS IN PERMANENT MOLDS \\ $\$ 88,000$ \\ DOE Contact: Toni Maréchaux, (202) 586-8501 \\ Principal Investigator: Yemi Fasoyinu, Materials Technology Läboratory, (613) 996-0325}

The three year project objectives are to: determine the tensile, fracture toughness, impact and fatigue properties of 12 copper-base alloys for use in more demanding engineering applications; determine the dry and lubricating sliding wear and slurry wear resistance; carry out corrosion studies (salt spray, atmospheric and marine); and determine pattern makers shrinkage and metal core taper allowance in permanent mold.

Keywords: Metalcasting, Copper Alloys, Corrosion

32. PROCESS PARAMETERS FOR LEAD-FREE COPPER-BASED ENGINEERING ALLOYS IN PERMANENT MOLDS

$\$ 61,000$

DOE Contact: Toni Maréchaux, (202) 586-8501

Principal Investigator: Kumar Sadayappan, Materials Technology Laboratory, (613) 992-0741

The objective of this project is to develop process parameters such as evaluation of mold materials, improvement in casting fluidity, and grain refinement; to perform wrater and computer modeling to explain mold filling and to evaluate high phosphorous lead-free brass for plumbing applications.

Keywords: Metalcasting, Copper Alloys, Metal Flow

\section{IMPURITY LIMITS IN ALUMINUM BRONZES $\$ 57,000$}

DOE Contact: Toni Maréchaux, (202) 586-8501

Principal Investigator: Yemi Fasoyinu, Materials Technology Laboratory, (613) 992-5475

The objective of this project is to study the effect of impurity elements on the mechanical properties, weldability and heat treatment of two common aluminum bronze alloys $\mathrm{C} 95800$ and $\mathrm{C95400}$. The impurity elements are $\mathrm{Pb}, \mathrm{Zn}, \mathrm{Sn}, \mathrm{Bi}, \mathrm{Se}, \mathrm{Si}, \mathrm{Cr}$ and $\mathrm{Be}$. These will be added as single elements, and in two element and three element combinations.

Keywords: Metalcasting, Bronze, Mechanical Properties

\section{CHARACTERIZATION OF AND PROCEDURES TO ELIMINATE MACRO-INCLUSION DURING FOUNDRY PROCESSING $\$ 43,000$ DOE Contact: Toni Maréchaux, (202) 586-8501 Principal Investigator: Alan Cramb, Carnegie Melion University, (412) 268-3517}

An inclusions atlas has been developed along with a set of standards to evaluate the cleanliness of steel castings. The atlas has been made available on the world wide web.

Keywords: Metalcasting, Steel, Macro-inclusions

\section{DETERMINATION OF RESIDUAL STRESS AND SOFTENING EFFECTS ON THE LIFE OF DIE CASTING DIES $\$ 108,000$ \\ DOE Contact: Toni Maréchaux, (202) 586-8501 \\ Principal Investigator: Jack Wallace, Case Western Reserve University, (216) 368-4222}

The objective of this project is to evaluate measurement methods and develop ways of reducing losses in die life caused by softening of the steel and build-up of residual stress.

Keywords: Metalcasting, Residual Stress, Die Casting

\section{DEVELOPMENT OF DATABASE DESIGN RULES FOR CAST, HIGH ALLOY STEEL COMPONENTS $\$ 79,000$ DOE Contact: Toni Maréchaux, (202) 586-85011 Principal Investigator: Martin Prager, Materials Properties Council, (215) 705-7694}

The objective of this project is to develop design data, screening tests and an atlas of micrographs.

Keywords: Metalcasting, Steel, Design Rules

\section{SEMI-SOLID METALS PROCESSING CONSORTIUM \\ $\$ 54,000$ \\ DOE Contact: Toni Maréchaux, (202) 586-8501 \\ Principal Investigator: Diran Apelian, Worcester Polytechnic Institute, (508) 831-5992}

The objective of this project is to characterize semi-solid materials from a microstructure and rheology point of view, to better understand thixotropic flow behavior, and to develop. new and enhanced alloys.

Keywords: Metalcasting, Semi-Solid, Rheology 
38. MECHANICAL PROPERTIES STRUCTURE CORRELATION FOR COMMERCIAL SPECIFICATION OF CAST PARTICULATE METAL MATRIX COMPONENTS $\$ 46,000$

DOE Contact: Toni Maréchaux, (202) 586-8501

Principal Investigator: Pradeep Rohadgi, University of Wisconsin - Milwaukee, (414) 229-4987

The objective of this project is to establish procedures for mechanical testing and structural characterization and to provide comparative data and composites for quality assurance.

Keywords: Metalcasting, Metal Matrix Composite, Mechanical Testing

39. MECHANICAL PROPERTIES OF SQUEEZE AND SEMI-SOLID CAST A356

$\$ 46,000$

DOE Contact: Toni Maréchaux, (202) 586-8501

Principal Investigator: Robert Aikin, Case Western Reserve University, (216) 368-4221

The objective of this project is to develop a mechanical properties database for A356 castings produced by the processes of squeeze casting and semi-solid casting.

Keywords: Metalcasting, Aluminum, Squeeze Casting, Semi-solid Casting

40. FERRITE MEASUREMENTS IN DUPLEX STAINLESS STEEL CASTINGS

$\$ 50,000$

DOE Contact: Toni Maréchaux, (202) 586-8501

Principal Investigator: Carl Lundin, University of Tennessee, (423) $974-5310$

The objective of this project is to develop suitable methods for non-destructively measuring ferrite amounts for the surface of castings.

Keywords: Metalcasting, Non-destructive Evaluation, Stainless Steel

41. TECHNOLOGY FOR THE PRODUCTION OF CLEAN, THIN WALL, MACHINABLE GRAY AND DUCTILE IRON CASTINGS

$\$ 201,853$

DOE Contact: Toni Maréchaux, (202) 586-8501

Principal Investigator: Charles Bates, University of Alabama - Birmingham, (205) 975-8011

This project will focus on identifying the phases and compounds which degrade properties and machinability. It will then determine methods for eliminating objectionable inclusions.

Keywords: Metalcasting, Gray Iron, Cast Iron, Inclusions

\section{RELATIONSHIP BETWEEN CASTING} DISTORTION, MOLD FILLING AND INTERFACIAL HEAT TRANSFER IN SAND MOLDS

$\$ 93,332$

DOE Contact: Toni Maréchaux, (202) 586-8501

Principal Investigator: Thomas Piwonka, University of Alabama - Tuscaloosa, (205) 348-1589

The objective of this project is to determine the effect of interfacial heat transfer coefficients and gap formation in iron and aluminum sand mold castings on casting dimensional accuracy.

Keywords: Metalcasting, Iron, Aluminum, Sand Mold

\section{DEVICE OR COMPONENT FABRICATION, BEHAVIOR OR TESTING}

\section{INTELLIGENT CONTROL OF THE CUPOLA FURNACE \\ $\$ 173,610$ \\ DOE Contact: Toni Maréchaux, (202) 586-8501 \\ Principal Investigator: Kevin Moore, Idaho State University, (208) 236-4188}

The objective of this project is to develop a controller for the cupola process using intelligent and conventional control methods.

Keywords: Metalcasting, Cupola, Intelligent Control

\section{OFFICE OF CROSSCUT TECHNOLOGIES}

The Office of Crosscut Technologies funds cost-shared research with industry and other organizations on technology development beneficial to and of high priority for many industries. Power generation equipment, combustion equipment, advanced materials and sensors and controls are being pursued. The three planning units that fund materials research include the Advanced Turbine Systems Program (ATS), Continuous Fiber Ceramic Composites (CFCC) Program, Advanced Industrial Materials (AIM) Program and the Combustion (Heat Exchanger) Program. 


\section{ADVANCED TURBINE SYSTEM (ATS) PROGRAM}

The Advanced Turbine Systems (ATS) Program will develop and demonstrate the next generation of gas turbines for both utility and industrial applications, including cogeneration and combined heat and power. The goals of the ATS program are to improve the efficiency ( $15 \%$ increase) and environmental performance ( $80 \%$ reduction in emissions) of gas turbines while reducing the cost of electricity by $10 \%$. The DOE program manager is Patricia Hoffman, (202) 586-6074.

\section{DEVICE OR COMPONENT FABRICATION, BEHAVIOR OR TESTING}

\section{CERAMIC COMPONENTS FOR STATIONARY GAS TURBINES IN COGENERATION SERVICE $\$ 4,000,000$ \\ DOE Contact: Pat Hoffman, (202) 586-6074 \\ Solar Contact: Jeff Price, (619) 544-5538}

The performance of stationary gas turbines is limited by the temperature and strength capabilities of the metallic structural materials in the engine hot section. To realize the benefits of higher temperature, uncooled ceramics with superior high temperature strength and durability with lower emissions signature will be substituted for metallic parts in the engine hot section. The ceramic parts cornprise the first stage ceramic blades, first stage ceramic nozzles and ceramic composite combustor liners. This project will design and test these components for a stationary $4.0 \mathrm{Mw}$ gas turbine for cogeneration service. The project will culminate in a 4000 -hour field demonstration of the engine.

Keywords: Structural Ceramics, Ceramic Composites, Cogeneration, Gas Turbines

MATERIALS PROPERTIES, BEHAVIOR, CHARACTERIZATION OR TESTING

\section{LONG-TERM TESTING OF CERAMIC COMPONENTS FOR STATIONARY GAS TURBINES \\ $\$ 350,000$ \\ DOE Contact: Pat Hoffman, (202) 586-6074 \\ ORNL Contact: Matt Ferber, (423) 576-0818}

Compared to aircraft turbines, the service life requirements for land-based Advanced Turbine Systems (ATS) significantly affect the objectives of respective materials development programs. Land-based turbines generally operate under longer maintenance intervals and endure a high percentage of time under full-load conditions. In addition to cyclic fatigue, creep damage becomes the major consideration for both metallic and ceramic systems. This program characterizes the long-term properties of advanced materials systems under the ATS materials/ manufacturing program.

\section{Keywords: Structural Ceramics, Creep Damage, Gas Turbines}

\section{MATERIALS PREPARATION, SYNTHESIS, DEPOSITION, GROWTH OR FORMING}

\section{ATS MATERIALS BASE TECHNOLOGY SUPPORT \\ $\$ 3,000,000$ \\ DOE Contact: Pat Hoffman, (202) 586-6074 \\ ORNL Contact: Mike Karnitz, (423) 576-5150}

Gas turbine manufacturers have stated a need for a turbine inlet temperature of greater than $2600^{\circ} \mathrm{F}$ in order to achieve higher efficiencies. New materials developments are necessary to achieve these temperatures for extended operating periods. Advanced casting techniques, metallurgy and coating science will be applied to gas turbines to allow higher operating temperature for increased efficiency while producing fewer emissions. The goals of these projects are improved turbine airfoil castings and reliable, higher performance thermal barrier coatings that will allow for increased turbine inlet temperature.

Keywords: Gas Turbines, Castings, Thermal Barrier Coatings

\section{CONTINUOUS FIBER CERAMIC COMPOSITES (CFCC) PROGRAM}

The Continuous Fiber Ceramic Composites (CFCC) Program operates as a collaborative effort between industry, national laboratories, universities and the government to develop advanced ceramic composite materials to a point at which the industry will assume full risk of further development. There are currently six industrial teams developing more than $\mathbf{2 0}$ industrial applications for continuous fiber ceramic composite materials. The National Laboratories along with Universities are developing supporting technologies (e.g. material design, processing methods, manufacturing techniques) and conducting performance evaluations. The DOE program managers are Merrill Smith, (202) 586-3646 and Debbie Haught, (202) 586-2211. 
MATERIALS PREPARATION, SYNTHESIS, DEPOSITION, GROWTH OR FORMING

\section{CFCC PROGRAM - INDUSTRY TASKS $\$ 6,400,000$ \\ DOE Contact: Merrill Smith, (202) 586-3646}

The goal of the CFCC Program is to develop, in U.S. industry, the primary processing methods for the reliable and cost-effective fabrication of continuous fiber ceramic composite components for use in industrial applications such as gas turbine components, heat exchangers, and hot gas filters. The first phase, completed in 1994, established performance requirements of applications and assessed feasibility of potential processing systems. Phase two, process engineering and component development, is in progress. Industrial participants include Dow Corning, Du Pont Lanxide Composites, Amercom, General Electric, McDermott Technologies, and Textron.

Keywords: Ceramic Composites, Continuous Fiber

MATERIALS PROPERTIES, BEHAVIOR, CHARACTERIZATION OR TESTING

\section{CONTINUOUS FIBER CERAMIC COMPOSITES (CFCC) SUPPORTING TECHNOLOGIES $\$ 2,000,000$ \\ DOE Contact: Debbie Haught (202) 586-2211 \\ ORNL Contact: Mike Karnitz, (423) 574-5150}

This project provides basic or generic support to the industry teams conducting CFCC research. Tasks include: composite design, materials characterization, test methods development, database generation, codes and standards, and life prediction.

Keywords: Ceramic Composites, Material Characterization, Test Methods

\section{ADVANCED INDUSTRIAL MATERIALS (AIM) PROGRAM}

New or improved materials can save significant energy and improve productivity by enabling systems to operate at higher temperatures, last longer, and reduce capital costs. The Advanced Industrial Materials program is a crosscutting program with emphasis on industrial needs of the Industries of the Future initiative and of crosscutting industries including carbon products, forging, heat treating, and welding. Efforts in FY 1996 were focused on partnerships between industry and the National Laboratories for commercialization of new materials and processes. The program manager is Charles A. Sorrell, (202) 586-1514.
MATERIALS PREPARATION, SYNTHESIS, DEPOSITION, GROWTH OR FORMING

\section{INTERMETALLIC ALLOY DEVELOPMENT AND TECHNOLOGY TRANSFER OF INTERMETALLIC ALLOYS $\$ 515,000$ \\ DOE Contact: Charles A. Sorrell, (202) 586-1514 \\ ORNL Contacts: M. L. Santella, (423) 574-4805 and V. K. Sikka, (423) 574-5112}

The objective of this project is to develop and apply the excellent oxidation and carburization resistance and higher strength of intermetallic alloys including nickel aluminides to Industries of the Future-related manufacturing applications. Progress in bringing technologies to development and commercialization in FY 1997 included: (1) research on $\mathrm{Ni}_{3} \mathrm{Al}$ welding technology applicable to, for example, furnace transfer rolls, obtaining materials properties of intermetallic and metallic alloys, modeling of stresses in structural components, continuation of exposure of furnace fixtures in continuous carburization heat treating furnaces (continue to show exceptional corrosion resistance), (2) evaluating technology for joining thick sections of $\mathrm{Ni}_{3} \mathrm{Al}$ to dissimilar metals, (3) testing components in various chemical industry processes, (4) completion of the CRADA with GM Saginaw on the development of $\mathrm{Ni}_{3} \mathrm{Al}$ for heat treating fixtures, and (5) licensed two companies, including Alloy Engineering and Casting Company, Sandusky International, to produce $\mathrm{Ni}_{3} \mathrm{Al}$ materials and components.

Keywords: Nickel Aluminides, Processing, Steel, Metalcasting, Aluminum, Heat Treating, Welding

\section{DEVELOPMENT OF WELDABLE, CORROSION RESISTANT IRON-ALUMINIDE ALLOYS $\$ 290,000$ \\ DOE Contact: Charles A. Sorrell, (202) 586-1514 ORNL Contact: P. J. Maziasz, (423) 574-5082 \\ Univ. of Cincinnati Contacts: A. Jordan and \\ O. N. C. Uwakweh (513) 556-3108}

The objectives of this project are to develop FeAl alloys with improved weldability and mechanical and corrosion properties for use in structural applications; and to develop the potential for weldable FeAl alloys for use in weld-overlay cladding applications. Several developments were made in FY 1997. New industrial tests of cast FeAl alloys showed superior oxidation resistance in air $+5 \%$ water vapor at $1100 \mathrm{C}$ up to $500 \mathrm{~h}$, surprising caburization resistance in both oxidizing $\left(\mathrm{H}_{2} 5.5 \% \mathrm{CH}_{4}\right.$ $\left.4.5 \% \mathrm{CO}_{2}\right)$ and reducing $\left(\mathrm{H}_{2}-1 \% \mathrm{CH}_{4}\right)$ atmospheres, and the expected outstanding sulfidation resistance at 
$816^{\circ} \mathrm{C}$. Testing of the material in various applications is continuing (neutral salt heat treating baths for steels, and molten carbonate salt environments for fuel cells). Cast grate bars and pallet tips used in an industrial calcination furnace continue to show oxidation/ sulfidation resistance. Crack-free welds were successfully made on hot-extrusion (fine grained ingot)produced FeAl alloys with no pre heat or post heat. For the first time, crack free autogenous welds were also made on cast FeAl alloys with pre and post-heat.

Keywords: Iron Aluminides, Coatings, Claddings, Thermophysical Properties

\section{COMPOSITES AND COATINGS THROUGH REACTIVE METAL INFILTRATION $\$ 443,000$ \\ DOE Contact: Charles A. Sorrell, (202) 586-1514 \\ Sandia National Laboratories Contact: R. E. Loehman, (505) 844-2222 (includes effort on coating technology at Stanford Research Institute)}

Ceramic-metal composites have advantages as engineering materials because of their high stiffness-tci-weight ratios, good fracture toughness, and because thieir electrical and thermal properties can be varied through control of their composition and microstructure. Reactive metal infiltration is a promising new route to synthesize and process a wide range of ceramic and metal-matrix composites to near-net-shape with control of both composition and microstructure. In FY 1997 a detailed mechanistic model was developed for composite formation that explains the observed microstructure and kinetics as a function of time and temperature. This new model has led to a process diagram showing the conditions where reactive metal penetration (RMP) is a practical process. The process has also been used to optimize composites of $\mathrm{AL}_{2} \mathrm{O}_{3}-\mathrm{MoSi}_{2}, \mathrm{Al}_{2} \mathrm{O}_{3}-\mathrm{Mo}\left(\mathrm{Si}_{0.93} \mathrm{Al}_{1,43}\right)$, and $\mathrm{Al}_{2} \mathrm{O}_{3}-\mathrm{Mo}\left(\mathrm{Si}_{0.93} \mathrm{Al}_{1.43}\right)-\mathrm{MO}_{3} \mathrm{Al}_{8}$ families, and then evaluating their properties.

The effort on coating technology at Stanford University emphasized Al coatings on steel. Coupon specimens exhibited excellent corrosion resistance in $1000 \mathrm{hr}$ salt spray.

Keywords: Metal Matrix Composites, Reactive Metal Infiltration, Ceramics, Inorganic Coatings, Corrosion

\section{CONDUCTING POLYMERS: SYNTHESIS AND INDUSTRIAL APPLICATIONS $\$ 250,000$ \\ DOE Contact: Charles A. Sorrell, (202) 586-1514 \\ Los Alamos National Laboratory Contact:

$$
\text { S. Gottesfeld, (505) 667-0853 }
$$

The process of separating pure components out of a mixture of gases is of great industrial importance. Current gas separation technologies have major shortcomings, including poor energy efficiency and the generation of secondary pollution. In FY 1997, the use of conducting polymers for electrochemical reactors (ECRS) based on polymeric electrolytes was addressed. The objective of this effort is to develop and test electrochemical reactors for the chlor-alkali industry, based on polymer membrane/electrode assemblies and on oxygen or air electrodes. In FY 1997, operation of a chlor-alkai cell at target cell operating conditions was demonstrated. The system used an oxygen cathode and a commercial chlor-alkali membrane of high current efficiency $(>95 \%)$.

Keywords: Electrically Conducting Polymers, Gas Separation, Capacitors

\section{MEMBRANE SYSTEMS FOR EFFICIENT SEPARATION OF LIGHT GASES $\$ 309,000$}

DOE Contact: Charles A. Sorrell, (202) 586-1514

Los Alamos National Laboratory Contact:

$$
\text { D. J. Devlin, (505) 667-9914 }
$$

Ethylene and Propylene are two of the largest commodity chemicals in the U.S. and are major building blocks for other chemicals. More energy-efficient processes are necessary. The main technical objective of this project is the development and precise control of the pore structure of membrane material. Membranes must have specially shaped channels in the 2 to 4 nanometer range. In FY 1997, a method for developing carbon pores for capillary condensation of hydrocarbons was devised. The use of oblique angle sputter techniques to develop thin films with controlled pore size has been demonstrated. Separation of butane gases form streams containing methane, argon, and hydrogen has been demonstrated. The effort will continue in FY 1998 as a CRADA with Amoco.

Keywords: Sputtering, Separations, Olefins, Hydrogen, Methane, Membranes 


\section{MICROWAVE AND PLASMA PROCESSING $\$ 275,000$}

DOE Contact: Charles A. Sorrell, (202) 586-1514

Los Alamos National Laboratory Contact: M. Trkula, (505) 667-0591

The project focuses on developing coating technologies to obtain erosion, and corrosion resistant, thermodynamically stable, and adherent coatings on die materials used to cast aluminum and other metals. Low temperature organometallic chemical vapor deposition combined with immersion ion processing is being developed as the coating technology. In FY 1997, initial thin film AIN, and amorphous $\mathrm{B}_{4} \mathrm{C}$ were successfully deposited on steel. Characterization included coating thickness, composition, mechanical and tribological properties.

Keywords: Coatings, Chemical Vapor Deposition, Ion Processing, Erosion, Corrosion

\section{UNIFORM DROPLET PROCESSING $\$ 440,000$}

DOE: Contact: Charles A. Sorrell, (202) 586-1514

ORNL Contact: Craig A. Blue (423) 574-4351, and Vinod Sikka, (423) 574-5123

Massachusetts Institute of Technology Contact: J-H Chun,(617) 253-1759

Northeastern University Contact: T. Ando, (617) $373-3811$

The purpose of this project is to adapt the uniform droplet process to higher melting materials e.g., intermetallic alloys, stainless, steel, superalloys; to provide superior metal powders for the powder metallurgy industry; and to develop methods for spray coating or casting of high temperature materials, including aluminide intermetallics. Spray forming of metallic systems is being investigated. Participants in the research include Oak Ridge National Laboratory, Massachusetts Institute of Technology, Northeastern University and powder metal companies. In FY 1997, (1) a system able to operate at temperatures up to 1500 $C$ was assembled and initial testing begun, (2) additional materials wee produced on the intermediate temperature system $\left(1250^{\circ} \mathrm{C}\right.$ ) (including copper and bronze), and 3) a license of the technology was taken by Uniform Metals Technology for production of copper and bronze uniform droplet materials for filter applications in chemical systems.

Keywords: Powder, Near Net Shape Forming, Aluminum, Alloys, Steel, Copper, Intermetallic Alloys

\section{ADVANCED MATERIALS/PROCESSES} $\$ 780,000$

DOE Contact: Charles A. Sorrell, (202) 586-1514

ORNL Contact: P. Angelini, (423) 574-4459,

P. S. Sklad, (423) 574-5069, and C. T Liu, (423) 574-4459

The goals of this project are to develop new and improved materials. Many metallic and ordered intermetallic alloys possess unique properties and have the potential to be developed as new materials for energy related applications. In FY 1997, (1) evaluated the parallelization of a casting program in order to provide capability for increased throughput and more realistic analyses, (2) developed infra-red technology for depositing coatings, surfacing and heating substrate materials, (3) developed initial corrosion resistant Iron-Chromium-Silicon alloys which are applicable in various glass industry applications, (4) determined the initial weldability of $\mathrm{Ni}_{3} \mathrm{Si}$ and made significant compositional changes to the alloy.

Keywords: Intermetallics, Ordered Alloys, $\mathrm{TiAl}_{1} \mathrm{Ni}_{3} \mathrm{Al}$, $\mathrm{Ni}_{3} \mathrm{Si}$, Metalcasting, Glass, Alloys

\section{MATERIALS PROPERTIES, BEHAVIOR,} CHARACTERIZATION OR TESTING

\section{MATERIALS FOR RECOVERY BOILERS $\$ 940,000$}

DOE Contact: Charles A. Sorrell, (202) 586-1514

ORNL Contact: James R. Keiser, (423) 574-4453

The purpose of this project is to determine the cause of failure of composite tubes used in Kraft Black Liquor recovery boilers during pulp and paper making, and to develop new materials to eliminate failures. The project consists of three efforts: (1) to obtain operating data and failure analyses from pulp and paper companies, boiler manufacturers and composite tube manufacturers, (2) to determine residual stresses in new and used composite tubes and microstructural characteristics of tubes as related to stresses and failure mechanisms, and (3) to develop new materials and/or fabrication methods for improvements in boiler efficiency, service life, and safety. Participants include Oak Ridge National Laboratory, Institute of Paper Science and Technology, and 11 industrial collaborators. In FY 1997: (1) analyses of tube specimens from many mills showed cracks have common characteristics, (2) temperature and strain gauges installed in the floor of a recovery boiler indicate that occasional temperature excursions do occur (10 to $200^{\circ} \mathrm{C}$ above normal operating temperature), (3) extended and verified a model showing stress in tubes versus materials properties and boiler operating 
conditions (developed a response surface indicating that alloy 825 and 625 may be more optimum alloys for use as cladding), (4) laboratory stress corrosion results (focusing on boiler conditions during start-up or cool-down) identified various conditions under which currently used cladding of $304 \mathrm{~L}$ would crack, and (5) the research received the Best Paper Award for 1996 from the Technical Association of the Pulp and Paper Industry (TAPPI)

Keywords.: Recovery Boilers, Composite Tubes, Pulp and Paper, Alloys, Stresses, Neutron Residual Stress, Measurements

\section{METALS PROCESSING LABORATORY USER (MPLUS) CENTER \\ $\$ 435,000$ (includes $\$ 50 \mathrm{~K}$ from OIT Glass Vision team) \\ DOE Contact: Charles A. Sorrell, (202) 586-1514 \\ Oak Ridge National Laboratory Contact: \\ M. Mackiewicz-Ludtka, (423) 576-4652 and \\ H. W. Hayden, (423) 574-6936}

The Metals Processing Laboratory User (MPLUS) Center was officially designated as a DOE User Facility in February, 1996. Its primary purpose is to assist U.S. industry and academia in improving energy efficiency and enhancing U.S. competitiveness. MPLUS is designed to provide U.S. Industries with access to the specialized technical expertise and capabilities to solve metals-processing issues that limit the development and implementation of emerging materials and materials processing technologies. MPLUS includes the following primary user centers: Metals Processing, Metal Joining, Metals Characterization and Metals Process Modeling. As of September 30, 1997, a total of 76 MPLUS Proposals were received from 60 companies and universities representing 26 states. Twelve organizations submitted 2 or more proposals for different projects. Of the 76 proposals, 53 were reviewed, and 31 of these 53 User projects were initiated. Ten (10) MPLUS projects were completed, and the 23 proposals were either (a) accepted contingent on legal approval, (b) under development, or c) being modified. A total of 546 user days were logged during FY 1997. Projects crosscut all of the seven industries in the Industries of the Future initiative; other crosscutting industries including forging, heat treating, and welding; and crosscutting programs.

Keywords: Industry, User Center, Metals, Materials, Processing, Joining, Properties, Characterization, Modeling, Process

\section{DEVICE OR COMPONENT FABRICATION, BEHAVIOR OR TESTING}

\author{
59. GEL CASTING TECHNOLOGY \\ $\$ 110,000$ \\ DOE Contact: Charles A. Sorrell, (202) 586-1514 \\ ORNL Contact: M. A. Janney, (423) 576-5183
}

Gelcasting is an advanced powder forming process. It can be used to form ceramic or metal powders into simple or complex, near net shapes. The sol-gel process is being developed in order to produce aluminum oxide tubes for use in high-intensity industrial lighting, and $\mathrm{H} 13$ steel dies. For the lighting application the sol-gel process will produce identical materials at lower temperatures and in far less time than do conventional methods which involve prolonged high temperature sintering with sintering aids. In FY 1997 , the effort relative to the CRADA with OSRAM demonstrated: (1) ability to make complex shape optical quality $\mathrm{Al}_{2} \mathrm{O}_{3}$, (2) ability to use meltable cores in gel casting to make complex hollow shapes. In additional FY 1997 efforts the ability to machine gel cast metal parts was also completed. Technology was developed to gel cast various metal alloys including, $H 13,174 \mathrm{ph}$, and nickel superalloys.

Keywords: Gel Casting, Sol Gel, Aluminum Oxide, Lighting Tubes, $\mathrm{H} 13$ Steel, Dies

\section{MICROWAVE JOINING OF SIC} $\$ 110,000$

DOE Contact: Charles A. Sorrell, (202) 586-1514

FM Technologies, Inc. Contact: R. Silberglitt, (703) $425-5111$

The objective of this project is to develop and optimize a joining method that can be applied to large scale fabrication of components such as radiant burner tubes and high temperature, high pressure heat exchangers. Microwave joining of both reaction bonded silicon carbide and sintered silicon carbide has been demonstrated for tubes up to $5 \mathrm{~cm}$ in diameter. Joints are leaktight at service temperature, and have adequate mechanical strength for desired applications. In FY 1997 the effort included: (1) joining of continuous fiber-reinforced (CFCC) SiC/SiC composite and sintered $\mathrm{SiC}$ specimens with $\mathrm{SiC}$ formed in situ from pyrolysis of either polysiloxane (silicone resin) or allyhydridopolycarbosilane (AHPCS) precursors, (2) determining the maximum shear strength of joints (microwave processing resulted in joints of comparable strength to those processed conventionally, and (3) joining and 
testing (high temperature strength) $8^{\text {" long by } 1 " O D}$ sintered SiC specimens (under the HiPHES project).

Keywords: Microwave Processing, Microwave Joining, SiC, Tubes

\section{SELECTIVE INORGANIC THIN FILMS $\$ 350,000$}

DOE Contact: Charles A. Sorrell, (202) 586-1514

Sandia National Laboratories contact:

T. M. Nenoff, (505) 844-0340

The purpose of this research is to develop a new class of inorganic membranes for light gas separation and use this technology to improve separation efficiencies currently available with polymer membranes, particularly for light alkanes. The approach is to nucleate and crystallize zeothlitic phases from sol-gel derived amorphous coatings, using porous filters and gas membranes as supports for these films. In FY1997 efforts included: (1) initiation of a CRADA with Amoco on the feasibility of using shape selective molecular sieve membranes to enrich p-xylene from mixtures, (2) fabrication of cesium phosphate molecular sieve membranes on porous zinc oxide wafers, (3) production of zinc oxide phosphates with larger pores of the $\mathrm{M}_{3} \mathrm{Zn}\left(\mathrm{PO}_{4}\right)_{3}$ structure type, and (4) formation of methylammonium zinc oxide phosphate phase that remains microporous after the water template is removed.

Keywords: Coatings, Sol-Gel Processing

\section{HIGH TEMPERATURE PARTICLE FILTRATION TECHNOLOGY \\ $\$ 40,000$ (project also includes additional effort from the CFCC program) \\ DOE Contact: Charles A. Sorrell, (202) 586-1514 \\ Oak Ridge National Laboratory Contact: T. Besmann, (423) 574-6852}

The objective of this project is to develop high temperature materials for high temperature filtration needs. High temperature filters are critical in many chemical and other industrial processes. The effort includes bench-scale testing and analyses of compatibility of materials in various environments. The current focus is on filtration technology for the $k$, dimethyldichlorosilane process. In FY 1997, the CRADA with Dow Corning continued. Modification to laboratory furnaces were made for bench scale testing of filter specimens. A large number of filter specimens was obtained and each filter was tested for $24 \mathrm{~h}$ under conditions simulating the chemical environment of interest.

Keywords: High Temperature, Filtration, Chemicals, Compatibility

\section{MATERIALS STRUCTURE AND COMPOSITION}

\section{METALLIC AND INTERMETALLIC BONDED CERAMIC COMPOSITES \\ $\$ 165,000$}

DOE Contact: Charles A. Sorrell, (202) 586-1514

ORNL Contacts: P. F. Becher, (423) 574-5197 and

T. N. Tiegs, (423) 574-5173

Southern Illinois University: R. Koc, (618) $453-7005$

To improve the reliability of ceramic components, new approaches to increasing the fracture toughness of ceramics over an extended temperature range are needed. One method is the incorporation of ductile phases into ceramic matrix alloys for local plastic deformation during crack-bridging processes. This objective of this program is to develop ceramic composites with high fracture toughness for intermediate temperature use in wear, tribological and engine applications. In FY 1997 various specimens were tested in a number of environments and a data information package was prepared.

The effort on ceramic powder processing has the objective of developing new synthesis methods using carbothermic reduction of carbon-coated precursors for producing high purity, submicron metal carbide, metal nitride and metal boride systems. During FY1997 efforts included: (1) determining carbon content effects of resulting TiC composites and the applicability of producing $\mathrm{TiB}_{2}$ powders, (2) preparation of TiC powder, and (3) fabrication of specimens at numerous sites and subsequent testing of composite specimens.

Keywords: Ceramics, Composites, Nickel Aluminide, Powder

\section{PROCESSING OF POLYMERS IN A MAGNETIC FIELD \\ $\$ 341,000$ \\ DOE Contact: Charles A. Sorrell, (202) 586-1514 \\ Los Alamos National Laboratory Contacts: \\ M. E. Smith, (505) 665-6858, and \\ B. C. Benicewicz, (505) 665-0101}

The purpose of this project is to demonstrate the utility of magnetic fields, to beneficially modify or control the physical, optical and electrical properties of materials through the application of magnetic fields during 
polymerization processing and solidification. Researchers at Los Alamos National Laboratory, in collaboration with an industrial partner, have demonstrated that using high (10-20 Tesla) magnetic fields to orient liquid crystal polymers during processing can lead to substantial improvements in mechanical properties. In FY 1997, (1) successfully produced polymer composite plaques (approximately $8^{\prime \prime} \times 8^{\prime \prime} x$ 0.125 ") of excellent uniformity as determined by visual inspection and mechanical property measurements, (2) demonstrated feasibility of using magnetic fields in the 1 to 2 Tesla range as provided with commercially available magnets, and (3) determined the nature of the molecular packing structures as aligned in the magnetic field by the use of nuclear magnetic resonance spectroscopy.

Keywords: Organic Polymers, Magnetic Processing, Mechanical Properties

\section{COMBUSTION/HEAT EXCHANGER PROGRAM}

The goal of the Combustion Program activities is to maximize efficiency and minimize emissions at the lowest practical cost. The program is designed to move superior combustion concepts for the laboratory through industry host site demonstration resulting in commercialization. The DOE program manager is Gideon Varga, (202) 586-0082.

\section{MATERIALS PROPERTIES, BEHAVIOR, CHARACTERIZATION OR TESTING}

\section{ADVANCED HEAT EXCHANGER MATERIAL TECHNOLOGY DEVELOPMENT $\$ 630,000$ \\ DOE Contact: G. Varga, (202) 586-0082 \\ ORNL Contact: M. Karnitz, (423) 574-5150}

This project conducts research to evaluate advanced ceramic materials, fabrication processes and joining techniques. The effects of hot, corrosive environments on candidate ceramic and ceramic composite materials continue to be investigated. Also under investigation is the performance of advanced ceramic materials subjected to the processing environments encountered in steam cracking for ethylene production.

Keywords: Structural Ceramics, Corrosion-Gaseous, Industrial Waste Heat Recovery, Ethylene

\section{DEVICE OR COMPONENT FABRICATION, BEHAVIOR OR TESTING}

\section{HIGH PRESSURE HEAT EXCHANGER SYSTEM (HIPHES) ENERGY PRODUCTION $\$ 0$ \\ DOE Contact: Gideon Varga, (202) 586-0082 \\ Solar Turbines Contact: B. Harkins, (619) 544-5398}

The High Pressure Heat Exchanger System (HiPHES) uses exhaust heat from a hazardous waste incinerator to drive a power turbine. Under this concept, a ceramic heat exchanger replaces the combustor in the gas generator section of a combustion turbine. The testing of a prototype high pressure ceramic heat exchanger for more than 800 hours at $1800^{\circ} \mathrm{F}$ and 100 psi solved critical issues of joining, system assembly, and repair. This included long term exposure in a dust-laden slip stream of a working hazardous waste incinerator. An optimal system comprises both monolithic ceramics and ceramic matrix composites. Uncertainties in various market forces for waste incineration has postponed a 4 Mw demonstration. The technology has been transferred to DOE's Advanced Turbine Systems (ATS) program.

Keywords: Ceramic Composites, Heat Exchangers, Waste Incineration

\section{HIGH PRESSURE HEAT EXCHANGER SYSTEM (HIPHES) FOR ETHYLENE PRODUCTION $\$ 26,196$ \\ DOE Contact: Gideon Varga, (202) 586-0082 \\ Stone \& Webster Engineering Corp. Contact: Joe Gondolfe, (281) 368-4379}

In this project, advanced ceramics are replacing the alloys conventionally used in ethylene production reactors. Ethylene production technology is mature, with technological advances resulting in gains of much less than 1 percent. Pilot runs on this project have demonstrated a 10 percent increase in ethylene production due to an increase in desirable yield and a prolonged run time between decoking cycles, achieved under controlled experimental conditions..

Keywords: Structural Ceramics, Ethylene, Heat Exchangers 


\section{OFFICE OF TRANSPORTATION TECHNOLOGIES}

FY 1997

Office of Transportation Technologies - Grand Total

$\$ 24,249,000$

Transportation Materials Technology

$\$ 24,249,000$

Automotive Materials Technology

$\$ 17,483,000$

Propulsion Systems Materials

$\$ 5,483,000$

Materials Preparation, Synthesis, Deposition, Growth or Forming

$\$ 3,027,000$

Gelcasting: Scale-up and Commercialization

550,000

177,000

Optimization of Silicon Nitride Ceramics

in situ Toughened Silicon Nitride

Gas Turbine Engine Components Manufacturing Scale-Up and Demonstration

Advanced Automation Gelcasting Processes for Silicon Nitride Components

350,000

$1,200,000$

750,000

Materials Properties, Behavior, Characterization or Testing

$\$ 1,626,000$

Characterization and Life Prediction of Ceramic Recuperator Materials

Component Verification

High Frequency Fatigue

Tensile Stress Rupture Testing

Toughened Ceramics Life Prediction

Life Prediction Methodology

Environmental Effects in Toughened Ceramics

Nondestructive Evaluation

71,000

275,000

250,000

270,000

200,000

385,000

175,000

Technology Transfer and Management Coordination

$\$ 425,000$

Technical Project Management

425,000

Device or Component Fabrication. Behavior or Testing

$\$ 405,000$

Corrosion-Resistant Coatings

Ceramic-Metal Joining

Mechanical Reliability Assessment of Electronic Ceramics and Electronic Ceramic , Components

195,000

110,000

100,000

Lightweight Vehicle Materials Technology

$\$ 12,000,000$

Device or Component Fabrication, Behavior or Testing

$\$ 12,000,000$

Low-Cost High Performance Aluminum Alloy Sheet for Automotive Applications

Low-Cost High Performance Cast Light Metals for Automotive Applications

Advanced Materials and Processes for Automotive Applications

Northwest Alliance for Transportation Technologies (NATT)

Automotive-Related Graduate Fellowships

Materials and Processes for Propulsion System Applications

Technology Assessment and Evaluation

Glass Reinforced Composite Materials Joining, Durability and Enabling Technologies

Composite Material Design, Manufacturing and Demonstration

USAMP Cooperative Agreement

Carbon Fiber Based Composite Materials Technology

$1,250,000$

$1,300,000$

375,000

$2,500,000$

350,000

650,000

450,000

$1,850,000$

$1,425,000$

$1,000,000$

850,000 
OFFICE OF TRANSPORTATION TECHNOLOGIES (continued)

Transportation Materials Technology (continued)

Electric Drive Vehicle Technologies

$\$ 3,397,000$

Advanced Battery Program

$\$ 2,997,000$

Materials Preparation, Synthesis, Deposition, Growth or Forming

$\$ 883,000$

Advanced Electrode Research

300,000

Electrochemical Properties of Solid-Electrolytes

Preparation and Characterization of New Polymer Electrolytes

200,000

210,000

New Cathode Materials

Development of Novel Electrolytes for Rechargeable Lithium Cells

73,000

100,000

Materials Properties. Behavior, Characterization or Testing

$\$ 1,530,000$

Carbon Electrochemistry

Fabrication and Testing of Carbon Electrodes as Lithium Intercalation Anodes

Reactivity and Safety Aspects of Carbonaceous Anodes in Lithium-Ion Batteries

Battery Materials: Structure and Characterization

Polymer Electrolyte for Ambient Temperature Traction Batteries: Molecular

Level Modeling for Conductivity Optimization

Analysis and Simulation of Electrochemical Systems

Corrosion of Current Collectors in Rechargeable Lithium Batteries

Electrode Surface Layers

Microstructural Modeling of Highly Porous NiMH Battery Substrates

Device or Component Fabrication, Behavior or Testing

250,000

75,000

140,000

140,000

145,000

235,000

200,000

200,000

145,000

$\$ 584,000$

Development of a Thin-Film Rechargeable Lithium Battery for Electric Vehicles

Applied Research on Novel Cell Components for Advanced Capacitors

Sol-Gel Derived Metal Oxides for Electrochemical Capacitors

Optimization of Metal Hydride Properties in MH/NiOOH Cells for Electric

Vehicle Applications

Preparation of Improved, Low Cost Metal Hydride Electrodes for Automotive

Applications

71,000

115,000

123,000

90,000

185,000

Fuel Cell Materials

$\$ 400,000$

Materials Properties, Behavior, Characterization or Testing

$\$ 400,000$

Electrode Kinetics and Electrocatalysis

300,000

Poisoning of Fuel Cell Electrocatalyst Surfaces: NMR Spectroscopic Studies

100,000 
OFFICE OF TRANSPORTATION TECHNOLOGIES (continued)

FY 1997

Transportation Materials Technology (continued)

Heavy Vehicle Materials Technology

$\$ 3,369,000$

Materials Preparation. Synthesis, Deposition. Growth or Forming

\$ 998,000

Cost-Effective SRBSN/Microwave Annealing of Silicon Nitride

400,000

Continuous Sintering of Silicon Nitride Ceramics

148,000

Cost-Effective, High-Toughness Silicon Nitride

350,000

Characterization/Testing of Low CTE Materials

100,000

Low CTE Materials/Diesel Exhaust Insulation

Low Cost NZP Powder

Advanced Manufacturing of Diesel Engine Turborotors

Advanced Manufacturing of Ceramic Exhaust Valves for Diesel Engines

Insulating Structural Ceramics for High Efficiency, Low Emission Engines

Thick Thermal Barrier Coatings (TTBCs) for Low Emissions, High Efficiency

Diesel Engine Components

Materials for Low Emissions, High Efficiency Diesel Engine Components

Materials for Low Emissions, High Efficiency Diesel Engine Components

High Strength Materials for Diesel Engine Fuel Injectors

Materials Properties, Behavior, Characterization or Testing

770,000

Diesel Exhaust Catalyst Characterization

200,000

Life Prediction Verification

200,000

High Temperature Tensile Testing

250,000

Computed Tomography

120,000

On-Machine Inspection

Mechanical Properties of CMZP

Technology Transfer and Management Coordination

$\$ 1,065,000$

Technical Project Management

International Exchange Agreement (IEA)

565,000

200,000

Standard Reference Materials

200,000

Mechanical Property Standardization

100,000

Device or Component Fabrication, Behavior or Testing

$\$ 536,000$

Thick Thermal Barrier Seal Coatings

33,000

Characterization of Machined Ceramics

200,000

Advanced Machining/Manufacturing

223,000

Next-Generation Grinding Wheel

High Speed Grinding

Laser-Based NDE Methods

80,000

Grinding Machine Stiffness

0

Next Generation Grinding Spindle

0

Process Cost Model

Intelligent Grinding Wheel 


\section{OFFICE OF TRANSPORTATION TECHNOLOGIES}

The Office of Transportation Technologies seeks to develop, in cooperation with industry, advanced technologies that will enable the U.S. transportation sector to be energy efficient, shift to alternative fuels and electricity, and minimize the environrnental impacts of transportation energy use. Timely availability of new materials and materials manufacturing technologies is critical for the development and engineering of these advanced transportation technologies.

Transportation Materials Technologies R\&D is conducted by the Office of Advanced Automotive Technologies (OAAT) and the Office of Heavy Vehicle Technologies (OHVT) to address critical needs of automobiles and heavy vehicles, respectively. These activities are closely coordinated between the two offices to ensure non-duplication of efforts. Another important aspect of these activities is the partnership between the federal government laboratories and U.S. industry, which ensures that the R\&D is relevant and that federal research dollars are highly leveraged.

Within OAAT, the bulk of the materials R\&D is carried out through the Transportation Materials Technologies program, with additional specialty materials R\&D in the Electric Drive Vehicle Technologies program. The Transportation Materials Technologies program develops: (a) Automotive Propulsion System Materials to enable advanced propulsion systems for hybrid vehicles, and (b) Lightweight Vehicle Materials to reduce vehicle weight and thereby decrease fuel consumption. The program seeks to develop advanced materials with the required properties and the processes needed to produce them at the costs and volumes needed by the automotive industries. Improved materials for body, chassis, and power train are critical to attaining the challenging performance standards for advanced automotive vehicles. The DOE contacts are Thomas Sebestyen, (202) 586-9727, for automotive propulsion system materials and Joseph Carpenter, (202) 586-1022, for automotive lightweight vehicle materials. The Electric Drive Vehicle Technologies program includes the support of Advanced Battery Materials R\&D for electric and hybrid vehicle applications. The DOE contact is Ray Sutula, (202) 586-8064. The program also supports Fuel Cell R\&D, which includes materials for proton-exchange membrane (PEM) fuel cells. The DOE contact is JoAnn Milliken, (202) 586-2480.

Within OHVT, the Transportation Materials Technologies program focuses on two areas: (a) Heavy Vehicle Propulsion System Materials, and (b) High Strength Weight Reduction Materials. In collaboration with U.S. industry and universities, efforts in propulsion system materials focus on the materials technology critical to the development of the low emission, 55 percent efficient (LE-55) heavy-duty and multi-purpose Diesel engines, such as: manufacturing of ceramic and metal components for high-efficiency turbocharger and supercharger, thermal insulation, for reducing engine block cooling, lowering ring-liner friction and reducing wear; high-pressure fuel injection materials; and exhaust aftertreatment catalysts and particulate traps. In the area of high strength weight reduction materials, energy savings from commercial trucking is possible with high strength materials which can reduce the vehicle weight within the existing envelope so as to increase payload capacity, and thereby reducing the number of trucks needed on the highways. Increased safety can be obtained by new brake materials and by incorporating highly shock absorbent materials in truck structures for improved control and crashworthiness. The DOE contact is Sidney Diamond, (202) 586-8032.

To support mainly propuision system materials R\&D, the High Temperature Materials Laboratory (HTML) at the Oak Ridge National Laboratory is a modern research facility that houses in its six user centers, a unique collection of instruments for characterizing materials. It supports a wide variety of high-temperature ceramics and metals R\&D. The HTML enables scientists and engineers to solve materials problems that limit the efficiency and reliability of advanced energy-conversion systems by providing access to sophisticated state-of-the-art equipment (which few individual companies and institutions can afford to purchase and maintain) and highly trained technical staff. The DOE contact is Sidney Diamond, (202) 586-8032. 


\section{TRANSPORTATION MATERIALS TECHNOLOGY}

\section{AUTOMOTIVE MATERIALS TECHNOLOGY}

\section{PROPULSION SYSTEMS MATERIALS}

\section{MATERIALS PREPARATION, SYNTHESIS, DEPOSITION, GROWTH OR FORMING}

\section{GELCASTING: SCALE-UP AND COMMERCIALIZATION \\ $\$ 550,000$ \\ DOE Contact: T. M. Sebestyen, (202) 586-9727 \\ ORNL Contact: D. P. Stinton, (423) 574-4556 \\ ORNL Contact: S. D. Nunn, (423) 576-1668}

The purpose of this work is to develop gelcasting as an advanced, near-net-shape ceramic forming process capable of manufacturing cost-effective, reliable silicon nitride components with industrial partners. The project goals include improving the gelcasting chemical system to enhance control of processing parameters and molded part characteristics, and improving gelcasting compositions and machining methods to produce highprecision components with features which are machined in the ceramic body. Surface-preparation techniques and mold-release agents which enhance separation of the part from the mold and which yield high-quality surface finish will also be identified.

Keywords: Silicon Nitride, Ceramics, Gelcasting, Forming

\section{OPTIMIZATION OF SILICON NITRIDE CERAMICS \\ $\$ 177,000$}

DOE Contact: T. M. Sebestyen, (202) 586-9727

ORNL Contact: D. P. Stinton, (423) 574-4556

University of Michigan Contact: T. Y. Tien, (313) $764-9449$

The objective of this investigation is to synthesize silicon nitride ceramics with optimum flexural strength, fracture toughness, and creep resistance by using statistical experimental designs. The sintering conditions and the composition of the sintering additives can affect the microstructure of silicon nitride ceramics and the characteristics of the grain-boundary phase and, hence, the mechanical properties. It is believed that the mechanical properties of silicon nitride can be optimized by controlling the size and aspect ratio of b$\mathrm{Si}_{3} \mathrm{~N}_{4}$ and the nature of the grain-boundary phase. In a related study to optimize the surface finish of silicon nitride materials, the effect of annealing on bend strength of specimens is being investigated. It is believed that the strength of these materials can be further improved as well if surface grain growth could be prevented by using proper vapor environment during annealing.

Keywords: Physical/Mechanical Properties, Silicon Nitride, Toughened Ceramics

\section{0. in situ TOUGHENED SILICON NITRIDE} $\$ 350,000$ DOE Contact: T. M. Sebestyen, (202) 586-9727

ORNL Contact: T. N. Tiegs, (423) 574-5173

AlliedSignal Ceramic Components Contact: J. M. Wimmer, (310) 512-3183

The purpose of this effort is to develop an extensive property database for AS800 silicon nitride, to improve its high-temperature properties, and to develop advanced fabrication processes for thin-walled components. This work is being done to address cost and property requirements to accelerate the adoption of AS800 into engines, including hybrid electric vehicles.

Keywords: Physical/Mechanical Properties, Silicon Nitride, Toughened Ceramics

\section{GAS TURBINE ENGINE COMPONENTS MANUFACTURING SCALE-UP AND DEMONSTRATION \\ $\$ 1,200,000$}

DOE Contact: T. M. Sebestyen, (202) 586-9727

AlliedSignal Engines Contact: M. L. Easley, (602) 231-4242

AlliedSignal Ceramic Components Contact: J. M. Wimmer, (310) 512-3183

Kyocera Industrial Ceramics Contact: W. D. Carruthers, (360) 750-6215

This project facilitates introduction of monolithic ceramic components in turbine engines and gathering essential and substantial field experience with these engines. The objectives are to: (1) improve the manufacturing processes for ceramic turbine engine components (nozzle vanes and turbine blades/bladed disks) and (2) demonstrate these processes in the production environment.

Keywords: Nozzle Vane, Turbine Blade, Turbine Rotor, Silicon Nitride, Ceramics, Forming, Machining 


\section{ADVANCED AUTOMATION GELCASTING PROCESSES FOR SILICON NITRIDE COMPONENTS \\ $\$ 750,000$}

DCE Contact: T. M. Sebestyen, (202) 586-9727

ONR Contact: S. G. Fishman, (703) 696-0285

AlliedSignal Ceramic Components Contact:

$$
\text { D. D. Foley, (310) 512-5916 }
$$

This project is Enhancement \#2 of a DARPAONR Advanced Materials Partnership Program with the Advanced Structural Ceramics Virtual Company (Cooperative Agreement \#N00014-95-2-0006). The objectives of Enhancement \#2 are to: (1) custom design and build equipment system capable of automating the gelcasting process, (2) demonstrate capability to produce 500 to 1000 turbine wheels per month for a period of two months and (3) integrate the equipment onto the production floor.

Keywords: Silicon Nitride, Ceramics, Gelcasting, Forming, Automation

\section{MATERIALS PROPERTIES, BEHAVIOR, CHARACTERIZATION OR TESTING}

\section{CHARACTERIZATION AND LIFE PREDICTION OF CERAMIC RECUPERATOR MATERIALS $\$ 71,000$} DOE Contact: T. M. Sebestyen, (202) 586-9727

ORNL Contact: M. K. Ferber, (423) 576-0818

Contact: S. F. Duffy, (330) 678-7328

The purpose of this effort is to characterize the thermomechanical response, define and help establish (in conjunction with researchers at ORNL and design engineers at Teledyne Ryan) the requisite material database, as well as perform life-prediction estimates for Teledyne Ryans' ceramic recuperator. This effort supports the Hybrid Electric Vehicle (HEV) Program.

Keywords: Components, Design Codes, Life Prediction, Statistics, Weibull, Fracture, Structural Ceramics, Mechanical Properties

\section{COMPONENT VERIFICATION $\$ 275,000$}

DOE Contact: T. M. Sebestyen, (202) 586-9727

ORNL Contact: D. P. Stinton, (423) 574-4556

ORNL Contact: P. F. Becher, (423) 574-5157

The objectives of this effort are to: (1) develop test methodology to measure mechanical properties of ceramics from complex-shaped components (e.g., gas turbine blades, nozzles, and rotors) at elevated temperatures; and (2) generate a mechanical properties database for recuperator thin sheet ceramic composites being developed by Du Pont Lanxide Composites (DLC). The database will be used for the finite element analysis and life prediction of the recuperator components.

Keywords: Components, Property Characterization, Silicon Nitride, Toughened Ceramics

\section{HIGH FREQUENCY FATIGUE} $\$ 250,000$

DOE Contact: T. M. Sebestyen, (202) 586-9727

ORNL Contact: D. P. Stinton, (423) 574-4556

ORNL Contact: K. C. Liu, (423) 574-5116

The objective of this task is to develop the baseline information on tensile and cyclic fatigue behavior of structural ceramics at room and elevated temperatures and at frequencies up to $4 \mathrm{kHz}$. Material behavior models for design and life evaluation analysis of ceramic components are being developed. $A$ benefit of this task will be a baseline database of candidate ceramic materials for use by ceramic materials manufacturers and ceramic components designers, fabricators, and users.

Keywords: Cyclic Fatigue, High Temperature Properties, Toughened Ceramics, Silicon Nitride, Time-Dependent

\section{TENSILE STRESS RUPTURE TESTING} $\$ 270,000$

DOE Contact: T. M. Sebestyen, (202) 586-9727

ORNL Contact: D. P. Stinton, (423) 574-4556

ORNL Contact: K. C. Liu, (423) 574-5116

The objective of this task is to develop the baseline information on tensile stress rupture and timedependent creep behavior of structural ceramics at 
elevated temperatures. Another goal is to develop material behavior models to facilitate design analysis of high-temperature structural components and improve their reliability.

Keywords: High Temperature Properties, Silicon Nitride, Tensile Testing, Time-Dependent, Toughened Ceramics

\section{TOUGHENED CERAMICS LIFE PREDICTION $\$ 200,000$}

DOE Contact: T. M. Sebestyen, (202) 586-9727

ORNL Contact: D. P. Stinton, (423) 574-4556

NASA - Lewis Research Center Contact:"

$$
\text { J. A. Salem, (216) 433-3313 }
$$

The objective of this research is to develop and verify models and test methods for life prediction of brittle materials such as in situ toughened ceramics, glasses, and intermetallics. A reliability model for anisotropic brittle materials such as single-crystal intermetallics and semiconductors has been developed and will be verified.

\section{Keywords: Creep, Fracture Toughness, High Temperature Properties, Life Prediction, Silicon Nitride, Time-Dependent, Toughened Ceramics}

\section{LIFE PREDICTION METHODOLOGY $\$ 0$} DOE Contact: T. M. Sebestyen, (202) 586-9727 ORNL Contact: C. R. Brinkman, (423) 574-5106

AlliedSignal Engines Contact: N. Menon, (602) $231-1230$

The objective of this effort is to develop methodologies required to adequately predict the useful life of ceramic components in advanced heat engines. The Erica and Ceramic computer codes are being updated and verified via extensive mechanical property characterization, at ambient and high temperatures, of uni-and-multiaxial test specimens of AS800 silicon nitride.

Keywords: Creep, Failure Analysis, Failure Testing, Life Prediction, Nondestructive Evaluation, Silicon Nitride, Time-Dependent

\section{ENVIRONMENTAL EFFECTS IN TOUGHENED CERAMICS \\ $\$ 385,000$}

DOE Contact: T. M. Sebestyen, (202) 586-9727

ORNL Contact: M. K. Ferber, (423) 576-0818

University of Dayton Contact: N. L. Hecht,

(513) $229-4341$

The objectives of this task are to evaluate hightemperature fatigue behavior, develop life-prediction analysis, and measure the thermal-mechanical properties of as-sintered versus machined specimens of the latest-vintage $\mathrm{Si}_{3} \mathrm{~N}_{4}$ ceramics. Additional goals include a better understanding of the degradation mechanisms affecting heat engine materials and extension of the database for these candidate ceramic materials. A final objective is a better understanding of the effects of different machining methods on the mechanical behavior of these candidate ceramics. Currently, the latest-vintage AS-800, SN-281 and $\mathrm{SN}-282$ materials are being evaluated.

Keywords: Environmental Effects, Fatigue, Structural Ceramics, Tensile Testing, TimeDependent

\section{NONDESTRUCTIVE EVALUATION}

$\$ 175,000$

DOE Contact: T. M. Sebestyen, (202) 586-9727

ORNL Contact: D. P. Stinton, (423) 574-4556

ORNL Contact: W. A. Simpson, Jr.,

(423) $574-4421$

The objective of this program is to develop nondestructive evaluation techniques capable of detecting critical flaws in structural ceramic components. Acoustic nonlinearity is being used to monitor the initial microstructural state of structural ceramics and to assess changes in that state as a function of in-service degradation. This approach appears sensitive to changes occurring at the lattice level (dislocations, vacancies, microcracking, etc.) and may provide a means of detecting early-stage (i.e., incipient) degradation. In addition, advanced techniques are being developed to detect and characterize critical flaws of particular interest to the ceramic community, i.e. surface and near-surface flaws.

Keywords: NDE, Structural Ceramics, Ultrasonics 


\section{TECHNOLOGY TRANSFER AND MANAGEMENT COORDINATION}

\section{TECHNICAL PROJECT MANAGEMENT $\$ 425,000$ \\ DOE Contact: T. M. Sebestyen, (202) 586-9727 \\ ORNL Contact: D. P. Stinton, (423) 574-4556}

The objective of this effort is to help assess the materials and manufacturing technology needs for advanced automotive propulsion systems, formulate technical plans to meet these needs, and prioritize and implement: a long-range research and development program.

Keywords: Advanced Heat Engines, Coordination, Management, Structural Ceramics

\section{DEVICE OR COMPONENT FABRICATION, BEHAVIOR OR TESTING}

\section{COR'ROSION-RESISTANT COATINGS $\$ 195,000$ \\ DOE Contact: T. M. Sebestyen, (202) 586-9727 \\ ORNL Contact: D. P. Stinton, (423) 574-4556 \\ ORNL Contact: J. A. Haynes, (423) 576-2894}

The objectives of this research program are to develop a coating system to increase the durability of $\mathrm{Si}_{3} \mathrm{~N}_{4}$ and SiC ceramic materials in hostile combustion environments and to assess coating manufacturability which will lead to component demonstration and commercialization.

Keywords: Coatings, Chemical Vapor Deposition, CVD, Engines, Silicon Nitride, Structural Ceramics, Corrosion Resistance, Mullite

\section{CERAMIC-METAL JOINING}

$\$ 110,000$

DOE Contact: T. M. Sebestyen, (202) 586-9727

ORNL Contact: D.P. Stinton, (423) 574-4556

ORNL Contact: M. L. Santella, (423) 574-4805

The objective of this task is to develop a technology for producing strong, reliable joints between two ceramic subassemblies and between a ceramic and metallic subassembly. Experiments are being done to identify and understand the effects of chemical reactions that occur during active metal brazing on the mechanical properties of silicon nitride.

Keywords: Brazing, JoiningMelding, Metals, Structural Ceramics, Silicon Nitride
84. MECHANICAL RELIABILITY ASSESSMENT OF ELECTRONIC CERAMICS AND ELECTRONIC CERAMIC COMPONENTS $\$ 100,000$

DOE Contact: T. M. Sebestyen, (202) 586-9727

ORNL Contact: D.P. Stinton, (423) 574-4556

ORNL Contact: A. A. Wereszczak, (423) $574-7601$

The objectives of this task are to provide expertise and characterization facilities for the assessment and prediction of mechanical reliability of electronic ceramics (ECs) and electronic ceramic components (ECCs), and to utilize life-prediction algorithms to increase service reliability of ECs and ECCs.

Keywords: Components, Electronics, Failure Analysis, Failure Testing, Life Prediction, Mechanical Properties, Reliability

\section{LIGHTWEIGHT VEHICLE MATERIALS TECHNOLOGY}

\section{DEVICE OR COMPONENT FABRICATION, BEHAVIOR OR TESTING}

\section{LOW-COST HIGH PERFORMANCE ALUMINUM ALLOY SHEET FOR AUTOMOTIVE APPLICATIONS \\ $\$ 1,250,000$ \\ DOE Contact: Joseph Carpenter, (202) 586-1022 \\ ORNL Contact: Phil Sklad, (423) 574-5069 Laboratory Partners: ORNL, LANL, INEEL, PNNL Industry Partners: Reynolds Metals Company, American Society of Mechanical Engineers (ASME), Commonwealth Aluminum, ARCO Aluminum, Ravenswood Aluminum}

The objectives of this effort are: to develop and implement low-cost continuous casting technologies for production of high-quality aluminum sheet; to develop a non-heat treatable aluminum alloy sheet product for automotive applications, such as exterior body panels or structural components; and todemonstrate advanced aluminum alloys and forming process for the manufacture of sheet aluminum components.

Keywords: Aluminum, Sheet Forming, Extrusion, Automotive 
86. LOW-COST HIGH PERFORMANCE CAST LIGHT METALS FOR AUTOMOTIVE APPLICATIONS

$\$ 1,300,000$

DOE Contact: Joseph Carpenter, (202) 586-1022

ORNL Contact: Phil Sklad, (423) 574-5069

Laboratory Partners: LLNL, ORNL, SNL, INEEL, PNNL, ANL

Industry Partners: USAMP (Ford, GM, Chrysler), LEP (Ford, GM, Chrysler)

The objectives of this effort are: to optimize design knowledge and improve product capability for lightweight, high-strength, cast structural components; to develop a low-cost method for producing prototype tools for lightweight metals in metal mold processes such as die casting, injection molding, and stamping; to reduce the lead time for production of prototype tools; and to improve the energy efficiency and cost effectiveness of large-scale automotive aluminum die castings by extending die life and reducing die wear.

Keywords: Aluminum, Magnesium, Cast Metals, Rapid Prototyping, Automotive, Die Life, Die Wear, Die Castings

\section{ADVANCED MATERIALS AND PROCESSES FOR AUTOMOTIVE APPLICATIONS $\$ 375,000$ \\ DOE Contact: Joseph Carpenter, (202) 586-1022 \\ ORNL Contact: Phil Sklad, (423) 574-5069 \\ Laboratory Partners: Ames Laboratory, ORNL \\ University Partners: University of Wisconsin- Milwaukee \\ Industry Partners: USAMP (Ford, GM, Chrysler), The Electric Power Research Institute (EPRI)}

The objectives of this effort are: to develop low cost powder metallurgy (PM) manufacturing methods for particle reinforced aluminum (PRA) composite components; to advance PRA machining technology and PRA composite design methodologies; and to produce and evaluate the use of aluminum "ashalloys"-metal matrix composites that incorporate coal fly ash-in the commercial manufacture of cast automotive parts.

Keywords: Metal Matrix Composites, Powder Metallurgy, Aluminum, Particle Reinforced Aluminum
88. NORTHWEST ALLIANCE FOR TRANSPORTATION TECHNOLOGIES (NATT) $\$ 2,500,000$

DOE Contact: Joseph Carpenter, (202) 586-1022

PNNL Contact: Gary McVay, (509) 375-3762

Laboratory Partners: PNNL, Albany Research

Center

Industry Partners: Alcoa, Reynolds, MC-21

NATT is a PNNL initiative comprised of multiple regional industrial sectors brought together to improve U.S. industrial technologies. The principal focus is the development of technologies to achieve the 50 percent weight reduction required to meet PNGV's objectives. NATT partners will use their resources to design new lightweight metals shaping and connecting, and to lower material costs. Some specific objectives of this effort are: to lower the cost of titanium and demonstrate the feasibility of manufacturing a cost-competitivel performance enhanced product; to develop an alternative molten salt electrolyte to be used in the lowcost electrowinning of primary magnesium metal; to develop and optimize tailored aluminum blank fabrication and forming characteristics for high-volume, lowcost automotive panels and structures; to develop a new low-cost process for the efficient on-site stir-casting of aluminum metal matrix composites suitable for the production of automotive components and an efficient and economical machining process for finishing AlMMC castings; and to develop efficient, cost competitive technologies for sorting shredded aluminum automotive scrap.

Keywords: Titanium, Aluminum, Magnesium, Tailor Welded Blanks, Scrap Sorting, Metal Matrix Composite

\section{AUTOMOTIVE-RELATED GRADUATE FELLOWSHIPS \\ $\$ 350,000$ \\ DOE Contact: Joseph Carpenter, (202) 586-1022 \\ ORNL Contact: Arvid Pasto, (423) 574-5123}

The fellowship program, administered by the High Temperature Materials Laboratory (HTML) of Oak Ridge National Laboratory through Oak Ridge Associated Universities (ORAU), sponsors Master's and Ph.D degree students who are U.S. citizens and are interested in pursuing a career in the area of lightweight materials for automotive applications. Projects must be relevant to interest areas of the Office of Advanced Automotive Technologies (OAAT). The objectives of the program are to provide a mechanism for training researchers in state-of-the-art advanced 
characterization techniques using instruments at HTML and encourage research in areas of interest to OAAT and DOE.

Keywords: Graduate Fellowship, Lightweight Materials, Automotive Applications, Characterization Technique

\section{MATERIALS AND PROCESSES FOR PROPULSION SYSTEM APPLICATIONS $\$ 650,000$ \\ DOE Contact: Joseph Carpenter, (202) 586-1022 \\ ORNL Contact: Phil Sklad, (423) 574-5069 \\ Laboratory Partners: ORNL, SNL, LBNL Industry Partners: USAMP (Ford, GM, and Chrysler), National Center for Machining Sciences}

The objective of these efforts are: to develop a multiphysics computational model of the induction heating and hardening process in order to predict part performance; to develop science-based, closed-loop controllers applicable to a broad range of steels; to use these tools to develop steel components with optimized, strength-to-weight ratios; to develop a model and methodology, based on finite element techniques, that predicts changes in the size and shape of parts that are attributable to heat treatment (heat treat distortion), and thus to provide the ability to optimize designs before heat treatment; and to increase the quality of wearcoated engine blocks by using nondestructive evaluation techniques.

Keywords: Induction Hardening, Heat Treat Distortion, Nondestructive Evaluation, Steel

\section{TECHNOLOGY ASSESSMENT AND EVALUATION \\ $\$ 450,000$}

DOE Contact: Joseph Carpenter, (202) 586-1022

ORNL Contact: Phil Sklad, (423) 574-5069;

Dave Warren, (423)574-9693, Dick Ziegler, (423) 574-5149

Laboratory Partners: ORNL

The objective of these activities is: to provide assessment of the cost effectiveness of various technologies; to evaluate the ability of the industrial infrastructure to accommodate emerging technologies; and to provide guidance to program management as to appropriate investments for R\&D funding.

Keywords: Cost, Infrastructure
92. GLASS REINFORCED COMPOSITE MATERIALS JOINING, DURABILITY AND ENABLING TECHNOLOGIES $\$ 1,850,000$

DOE Contact: Joseph Carpenter, (202) 586-1022

ORNL Contact: Dave Warren (423)574-9693

Laboratory Partners: ORNL, LBNL

Industry and University Partners: USAMPI

Automotive Composites Consortium, University of Texas, University of Tennessee, Oak Ridge Institute of Science and Technology, Tennessee State University, Goodrich, Baydur Adhesives, University of Tulsa

The objective of this effort is to develop critical enabling technologies necessary for the implementation of advanced structural composite materials. These nclude long term durability test methodologies, durability-driven design guidelines, adhesive test methods, nondestructive inspection techniques and material models which can be used in designing automotive components. Specific technology thrust areas include the development of Mode I, Mode II, and Mixed Mode Fracture test methods and computer-based models for adhesively bonded joints. This work includes the characterization of bulk adhesives, sheet composite, and adhesive-adherend pairs using three composite adherends and three adhesives (2 epoxy and 1 urethane). Models are to simulate the fracture behavior of bonded joints under a wide range of mode mixes and define the fracture envelope. Composite research is to lead to the development of experimentally-based, durability-driven design guidelines to assure the longterm (15 year) integrity of polymeric composite automotive structures. The project will develop and demonstrate reliable attachment technologies for use in lightweight composite structures for automotive applications. Adhesive joint and composite research includes bulk material characterization, fracture, fatigue, creep, and creep fracture. This work also includes the development of NDE methods, advanced curing technologies and structural analysis models. Technology implementation is conducted through Automotive Composites Consortium (ACC) focal projects. An additional objective is to develop NDE technology to evaluate bonded joint integrity of automotive assemblies, such as a body-in-white.

Keywords: Polymer, Composites, Joining, Fracture, Durability, Automotive, Adhesives, NonDestructive Inspection 
93. COMPOSITE MATERIAL DESIGN, MANUFACTURING AND DEMONSTRATION $\$ 1,425,000$

DOE Contact: Joseph Carpenter, (202) 586-1022

ORNL Contact: Dave Warren, (423) 574-9693

Laboratory Partners: ORNL, LLNL, INEEL. Industry and University Partners: USAMPI Automotive Composites Consortium, University of Michigan, University of Santa Barbara, University of Cincinnati, Wayne State University, Stanford University, University of Nottingham, Michigan Materials and Processing Institute, Budd Company, Dow

The objective is to develop the design and manufacturing methodologies to allow safe, reliable, repeatable and cost- effective implementation of composite materials in automotive structures. Specific efforts include the following: develop and model slurry preforming processes applicable to the automotive industry. After initial development, optimize the processes for repeatabilty of glass fiber positioning at increased production rates. In cooperation with the ACC Energy Management working group, develop material and component models for composite materials in high energy impacts for prediction of passenger safety and optimization of component designs. Demonstrate key technologies through focal projects which incorporate advances from various projects into manufacturable, cost effective pre-production prototypes that meet or exceed the requirements of current production assemblies.

Keywords: Polymer, Composites, Crash, Energy Management, Processing, Automotive, Preforming, Molding

\section{USAMP COOPERATIVE AGREEMENT $\$ 1,000,000$}

DOE Contact: Joseph Carpenter, (202) 586-1022

ORO Contact: Harold Clark, (423) 576-0823

Industry Partner: US Automotive Materials

Partnership (Chrysler, Ford, GM), Aplicator, Budd

The objectives of this project are to define and conduct vehicle-related R\&D in materials and materials processing. Projects include Rapid Prototyping for Metal Mold Processes, Design and Product Optimization for Cast Light Metals, Powder Metallurgy of Particle Reinforced Aluminum, Non-Toxic Free Machining Steel, Slurry Process Scale-up, P4 Preforming, Full Field NDT of Adhesive Bonding, ACC Focal Project II and ACC Focal Project III. Projects will be conducted by multiorganizational teams involving USAMP members, automotive suppliers, universities, and private research institutions.

Keywords: Polymer Composites, Aluminum, Magnesium, Free Machining Steel, Glass Fiber Preforming, Adhesive Bonding, Slumy Preforming, Powder Metallurgy, MMC, Rapid Prototyping, NDT, Automotive

\section{CARBON FIBER BASED COMPOSITE} MATERIALS TECHNOLOGY $\$ 850,000$

DOE Contact: Joseph Carpenter, (202) 586-1022 ORNL Contact: Dave Warren, (423) 574-9693 Laboratory Partners: ORNL Industry Partners: USAMPIAutomotive Composites Consortium, Lambda Technologies, AKZO Fortafil Fibers, Amoco

The objective is to conduct materials research to lead to the development of low cost carbon fiber for automotive applications. Research includes investigation of alternate energy deposition methods, and alternate precursors for producing carbon fiber, as well as the development of improved thermal processing methods and equipment for fiber manufacture. This work examines the fiber architecture and manufacturing issues associated with carbon fiber usage to take advantage of this material's high strength and modulus, while minimizing the effects of its low strain to failure. Candidate resin systems are screened for potential of meeting automotive industry requirements.

Keywords: Polymer, Composites, Carbon Fiber

\section{ELECTRIC DRIVE VEHICLE TECHNOLOGY}

\section{ADVANCED BATTERY PROGRAM}

\section{MATERIALS PREPARATION, SYNTHESIS, DEPOSITION, GROWTH OR FORMING}

\section{ADVANCED ELECTRODE RESEARCH $\$ 300,000$ \\ DOE Contact: Ray Sutula, (202) 586-8064 \\ Lawrence Berkeley National Laboratory \\ Contact: E. J. Cairns, (510) 486-5028}

The objective of this project is to investigate the behavior of $S$ electrodes in Li/polymer electrolyte/ sulfur cells and improve their lifetime and performance. Interest in the Li/S couple stems from its high theoretical specific energy $(-2600 \mathrm{Wh} / \mathrm{kg})$ as well as its environmentally benign components. In principle, this system is well-suited to EV applications, however a practical Li/S battery showing promise for EVs has not 
been developed. By using lower-density acetylene black, greatly improved utilization of the sulfur active material in the range of $40 \%$ and higher was demonstrated.

Keywords: Batteries, Solid-State Cells, Electric Vehicles, Sulfur Electrode

\section{ELECTROCHEMICAL PROPERTIES OF SOLID- ELIECTROLYTES \\ $\$ 200,000$ \\ DOE Contact: Ray Sutula, (202) 586-8064 \\ Lawrence Berkeley National Laboratory \\ Contact: L. C. De Jonghe, (510) 486-6138}

The objective of this project is to fabricate and study novel composite electrolytes which combine the advantages of a protective thin-film single-ion conductor with a conventional elastomeric polymer electrolyte for EV applications. A study of the transport properties of PEO-NaTFSI (TFSI $=\mathrm{N}\left(\mathrm{CF}_{3} \mathrm{SO}_{2}\right)_{2}$ ) electrolytes was completed, and thin solid films of $\mathrm{Li}_{3 x} \mathrm{La}_{0.67-x} \mathrm{TiO}_{3}$ were prepared by hydraulically pressing powders under an inert atmosphere.

Keywords: Batteries, Solid-State Cells, Electric Vehicles, Polymeric Electrolytes

\section{PREPARATION AND CHARACTERIZATION OF NEW POLYMER ELECTROLYTES $\$ 210,000$ DOE Contact: Ray Sutula, (202) 586-8064 \\ Lawrence Berkeley National Laboratory \\ Contact: J. Kerr, (510) 486-6279}

The objectives of this project are to develop methods of preparation and purification of the comb-branch backbone structures to design new polymers for rapid ion transport in batteries and to measure lithium ion transference numbers as a function of polymer and $\mathrm{Li}$ salt structure. Polymer electrolytes containing oxymethylene-linked polyethylene glycol and polypropylene oxide were prepared.

Keywords: Batteries, Solid-State Cells, Electric Vehicles, Polymeric Electrolytes

99. NEW CATHODE MATERIALS $\$ 73,000$

DOE Contact: Ray Sutula, (202) 586-8064

State University of New York Contact:

M. S. Whittingham, (607) 777-4623

The objective of this project is to synthesize and evaluate oxides of tungsten, molybdenum, and first-row transition metals for alkali-metal intercalation electrodes which are useful as positive electrodes in advanced nonaqueous rechargeable batteries. Cycling studies on $\mathrm{Li}_{x} \mathrm{M}_{\mathrm{y}} \mathrm{MnO}_{2}(\mathrm{M}=\mathrm{Li}, \mathrm{Na}, \mathrm{K})$ showed that the highest capacity and longest life was obtained when $M=K$, which provided the largest interlayer spacing.

Keywords: Intercalation Electrodes, Rechargeable Batteries

\section{DEVELOPMENT OF NOVEL ELECTROLYTES FOR RECHARGEABLE LITHIUM CELLS $\$ 100,000$ \\ DOE Contact: Ray Sutula, (202) 586-8064 \\ Delaware State University Contact: K. Wheeler, (302) $739-4934$}

The objective of this project is to investigate alternative electrolytes for rechargeable lithium batteries. Families of chloroaluminate-based ionic liquids were considered. Electrochemical studies revealed that electrolytes containing imidazole and $\mathrm{AlCl}_{3}$ had a relatively large electrochemical window of $4 \mathrm{~V}$.

Keywords: Intercalation Electrodes, Rechargeable Batteries

\section{MATERIALS PROPERTIES, BEHAVIOR, CHARACTERIZATION OR TESTING}

\section{CARBON ELECTROCHEMISTRY $\$ 250,000$ DOE Contact: Ray Sutula, (202) 586-8064 Lawrence Berkeley National Laboratory Contact: K. Kinoshita, (510) 486-7389}

The objective of this project is to identify the critical parameters that control the reversible intercalation of $\mathrm{Li}$ in carbonaceous materials and to determine their maximum capacity for $\mathrm{Li}$ intercalation. The collaboration with Superior Graphite and LLNL continued with the focus to evaluate alternative graphitized carbons for the negative electrodes in Li-ion cells. The graphitized carbons obtained from Superior Graphite so far have demonstrated that high heat-treatment temperatures $\left(-2800^{\circ} \mathrm{C}\right)$ may not be required to obtain acceptable electrode materials for $\mathrm{Li}$-ion cells.

Keywords: Carbon, Li Batteries, Li intercalation 
102. FABRICATION AND TESTING OF CARBON ELECTRODES AS LITHIUM INTERCALATION ANODES

$\$ 75,000$

DOE Contact: Ray Sutula, (202) 586-8064

Lawrence Livermore National Laboratory

Contact: T. Tran, (510) 422-0915

The objectives of this work are to evaluate the performance of carbonaceous materials as hosts for lithium intercalation negative electrodes, and to develop reversible lithium intercalation negative electrodes for advanced rechargeable lithium batteries. The approach is to fabricate electrodes from various commercial carbons and graphites and evaluate them in small lithium-ion cells. Electrode performance will be correlated with carbon structure and properties in collaboration with LBNL. The Li intercalation capacities of petroleum needle cokes (190LS, Superior Graphite Co.) that were air milled and heat treated to $1800^{\circ}$, $2100^{\circ}$ or $2350^{\circ} \mathrm{C}$ were examined The highest $\mathrm{Li}$ intercalation capacity $\left(x=0.93\right.$ in $\left.\mathrm{Li}_{x} \mathrm{C}_{6}\right)$ was obtained with the sample that was heat treated at $2350^{\circ} \mathrm{C}$ and then air milled.

Keywords: Carbon, Li Batteries, Intercalation

\section{REACTIVITY AND SAFETY ASPECTS OF CARBONACEOUS ANODES IN LITHIUM-ION BATTERIES \\ $\$ 140,000$ \\ DOE Contact: Ray Sutula, (202) 586-8064 \\ University of Michigan Contact: Abbas Nazri, (810) 986-0737}

The objective of this research is to investigate the chemical, electrochemical and safety aspects of carbon anodes used in Li-ion batteries, and to identify the reaction products that form during charge discharge cycling. This project was a new initiative in FY 1997. Initial results indicate that a large amount of gaseous species is generated on graphitic carbons when mixed cyclic carbonate and alkyl carbonate-based electrolytes are used.

Keywords: Carbon, Li Batteries, Li intercalation, Electrolyte Decomposition
104. BATTERY MATERIALS: STRUCTURE AND CHARACTERIZATION

$\$ 140,000$

DOE Contact: Ray Sutula, (202) 586-8064

Brookhaven National Laboratory Contact: J. McBreen, (516) 282-4071

The objective of this research is to elucidate the molecular aspects of materials and electrode processes in batteries and to use this information to develop electrode and electrolyte structures with good performance and long life. Current efforts have included in situ extended $x$-ray absorption fine structure (EXAFS) studies of lithium manganese oxides and nickel oxide electrodes. The EXAFS study shows that midway through the charge there is considerable disorder in the $\mathrm{Li}_{x} \mathrm{NiO}_{2}$ material, but it reverts to a more ordered structure towards the end of charge. On the other hand, $\mathrm{LiMn}_{2} \mathrm{O}_{4}$ shows much less changes in the spinel structure during charge than $\mathrm{LiNiO}_{2}$.

Keywords: Electrodes, Batteries, EXAFS

\section{POLYMER ELECTROLYTE FOR AMBIENT TEMPERATURE TRACTION BATTERIES: MOLECULAR LEVEL MODELING FOR CONDUCTIVITY OPTIMIZATION $\$ 145,000$ DOE Contact: Ray Sutula, (202) 586-8064 Northwestern University Contact: M. A. Ratner, (708) 491-5371}

The goal of this research is to apply molecular dynamics (MD) and Monte Carlo simulations to understand the conduction process in polymer electrolytes, and its modification by such parameters as temperature, density, ion species, polymer chain basicity, and interionic correlations, The results of this study should be beneficial in the development of improved polymer electrolytes for rechargeable $\mathrm{Li}$ batteries for EV applications. A simple model was developed in which the polyelectrolyte species are semibound, i.e. they cannot diffuse long distances. this model suggests that more flexible polyelectrolytes will have smaller diffusion barriers and higher ionic conduction.

Keywords: Batteries, Electric Vehicles, Polymeric Electrolytes 


\section{ANALYSIS AND SIMULATION OF ELIECTROCHEMICAL SYSTEMS $\$ 235,000$ \\ DOE Contact: Ray Sutula, (202) 586-8064 \\ University of California, Berkeley Contact: J. Newman, (510) 642-4063}

The objective of this program is to improve the performance of electrochemical cells used in the interconversion of electrical energy and chemical energy by identifying the phenomena which control the performance of a system. These phenomena are incorporated into a mathematical model which can predict system behavior. The models aid in the recognition of important parameters that are crucial to the optimization of a given electrochemical system. A mathematical model has been developed which showed good agreement with data obtained by slow charge/discharge potential transients, cyclic voltammetry, and potential-step measurements using a nickel hydroxide-hydrogen thin film cell. These data compare well with output from the numerical model.

Keywords: Electrochemical Phenomena, Galvanostatic Charge/Discharge

\section{CORROSION OF CURRENT COLLECTORS IN RECHARGEABLE LITHIUM BATTERIES $\$ 200,000$ \\ DOE Contact: Ray Sutula, (202) 586-8064 \\ University of California, Berkeley Contact: J. W. Evans, (510) 642-3807}

The objective of this research is to investigate the corrosion behavior of current collectors for rechargeable Li batteries. It was observed that, after short-term normal cycle tests of $\mathrm{LiN}_{6} \mathrm{O}_{13}$ cells, only a small amount of corrosion pits appeared on Al collectors, but serious pitting corrosion occurred after overcharging.

Keywords: Current Collectors, Advanced Batteries

108. ELECTRODE SURFACE LAYERS $\$ 200,000$

DOE Contact: Ray Sutula, (202) 586-8064

Lawrence Berkeley National Laboratory Contact: F. R. McLarnon, (510) 486-4636

Advanced in situ and ex situ characterization techniques are being used to study the structure, composition, and mode of formation of surface layers on electrodes used in rechargeable batteries. The objective of this research is to identify film properties that improve the rechargeability, cycle-life performance, specific power, specific energy, stability, and energy efficiency of electrochemical cells. Sensitive techniques such as ellipsometry, light scattering, Raman spectroscopy and scanning electron microscopy are utilized to monitor the formation of surface layers on secondary battery electrodes. Quantitative analysis of the SER spectra of a $\mathrm{Ni} / \mathrm{Ni}(\mathrm{OH})_{2}$ electrode showed that the precursor $\alpha-\mathrm{Ni}(\mathrm{OH})_{2}$ phase is only partially converted into $\beta-\mathrm{Ni}(\mathrm{OH})_{2}$ during cycling. Cyclic voltammetry of $\mathrm{TiO}_{2}-$ modified $\mathrm{Ni}$ electrode shows that $\mathrm{TiO}_{2}$ addition does not significantly shift the $\mathrm{O}_{2}$-evolution potential.

Keywords: Ion Implantation, Electrodes, Rechargeable Batteries

109. MICROSTRUCTURAL MODELING OF HIGHLY POROUS NIMH BATTERY SUBSTRATES $\$ 145,000$

DOE Contact: Ray Sutula, (202) 586-8064

University of Michigan Contact:

Ann Marie Sastry, (313) 764-3061

The objective of this research is to develop predictive capability for determining performance of $\mathrm{MH} / \mathrm{NiOOH}$ secondary cells through microstructural modeling of the $\mathrm{NiOOH}$ electrode.

These studies should lead to improved energy densities in $\mathrm{MH} / \mathrm{NiOOH}$ batteries by determining optimal microstructures for $\mathrm{NiOOH}$ substrates. The study is focused on the effects of the microstructure of fibrous composite electrodes on thermal and electrical conductivity. strength, and lifetime. Studies on a variety of fibers, including carbon (7-12 $\mu \mathrm{m}$ diameter) and polypropylene $(\sim 10 \mu \mathrm{m}$ diameter) fibers, both coated with nickel and sinter-bonded, and pure sinter-bonded nickel fibers, were completed. A novel network generation approach has been validated with experimental resistivities in fibrous substrates, and a new mechanics technique has been developed to model the damage progression in the fibrous substrates, and damage simulations have been initiated.

Keywords: MH/NiOOH Batteries Modeling, Microstructural Characterization 


\section{DEVICE OR COMPONENT FABRICATION, BEHAVIOR OR TESTING}

\section{DEVELOPMENT OF A THIN-FILM RECHARGEABLE LITHIUM BATTERY FOR ELECTRIC VEHICLES \\ $\$ 71,000$ \\ DOE Contact: Ray Sutula, (202) 586-8064 \\ Oak Ridge National Laboratory Contact: \\ J. B. Bates, (615) 574-4143}

The objective of this research is to identify methods for depositing acceptable thin-film electrodes for rechargeable Li batteries. These methods are being applied to develop solid-state $\mathrm{Li} / \mathrm{Li}_{x} \mathrm{Mn}_{2} \mathrm{O}_{4}$ rechargeable thin-film Li batteries for EV applications. The batteries are expected to have several important advantages as power sources: high specific energy and energy density, long cycle lifetimes, and a wide temperature range of operation. Laboratory-scale solid-state cells with $\mathrm{LiMn}_{2} \mathrm{O}_{4}$ electrodes were fabricated with open circuit voltages (OCVs) between 2.98 and $4.03 \mathrm{~V}$, consistent with the cathode composition with $\mathrm{x}=1$ for $\mathrm{Li}_{x} \mathrm{Mn}_{2} \mathrm{O}_{4}$. Studies indicate that the cathode surface has undergone a phase change to the orthorhombic structure for $x>1$, and the cell resistance increased as a result of the initial discharge.

Keywords: Electric Vehicles, Thin-Film Batteries, Solid-State Electrodes

\section{APPLIED RESEARCH ON NOVEL CELL COMPONENTS FOR ADVANCED CAPACITORS $\$ 115,000$ DOE Contact: Ray Sutula, (202) 586-8064 \\ SAFT Research \& Development Center Contact: Guy Chagnon, (410) 771-3200}

The objective of this research is to evaluate the doublelayer capacitance of high-surface-area carbons, and to develop low-cost carbon electrodes for electrochemical double-layer capacitors that meet the DOE goal of $1600 \mathrm{~W} / \mathrm{kg}, 10 \mathrm{Wh} / \mathrm{kg}$ and $\$ 1 / \mathrm{kW}$. Cells with $140^{\circ} \mathrm{F}$ capacitance and 20 milliohms resistance, corresponding to high-performance capacitors delivering $6.1 \mathrm{Wh} / \mathrm{kg}$ and $3.9 \mathrm{Kw} / \mathrm{kg}$ were built and tested. An additional 10 cells were fabricated and tested at INEEL; results (typically 1.4-1.8 Wh/kg at about $63 \mathrm{~W} / \mathrm{kg}$ ) are documented in an INEEL report. This project has been completed.

Keywords: Electrochemical Capacitors, Carbon Electrodes

\section{SOL-GEL DERIVED METAL OXIDES FOR ELECTROCHEMICAL CAPACITORS $\$ 123,000$ DOE Contact: Ray Sutula, (202) 586-8064 University of Wisconsin - Madison Contact: Marc A. Anderson, (608) 262-2674}

The objective of this research is to improve the chemical and materials properties of the NiO/Ni system for electrochemical capacitors (ultracapacitors). Prototypes made from nickel oxide thin-film electrodes have been successfully fabricated with a total thickness of the cell (including outside packaging material) of less than 1 $\mathrm{mm}$. Five cells were tested at INEEL; results are documented in an INEEL report. This project has been completed.

Keywords: Electrochemical Capacitor, NiO Electrodes

\section{OPTIMIZATION OF METAL HYDRIDE PROPERTIES IN MHINIOOH CELLS FOR ELECTRIC VEHICLE APPLICATIONS $\$ 90,000$ \\ DOE Contact: Ray Sutula, (202) 586-8064 \\ University of South Carolina Contact: R. E. White, (803) $777-7314$}

The objective of this research is to optimize the alloy composition of metal hydride electrodes by microencapsulation of hydrogen storage alloys metal hydride electrodes for $\mathrm{MH} / \mathrm{NiOOH}$ batteries. Microencapsulation of the hydrogen storage alloys with electroless nickel or cobalt-nickel coatings was found to improve the cycle life by forming a conductive passive film on the surface which prevents the oxidation of the active materials.

Keywords: $\mathrm{MH} / \mathrm{NiOOH}$ Batteries, Hydrogen Storage, LaNi ${ }_{4.27} \mathrm{Sn}_{0.24}$ Alloy, Microencapsulation

\section{PREPARATION OF IMPROVED, LOW COST METAL HYDRIDE ELECTRODES FOR AUTOMOTIVE APPLICATIONS $\$ 185,000$ \\ DOE Contact: Ray Sutula, (202) 586-8064 \\ Brookhaven National Laboratory Contact: J. Reilly, (516) 344-4502}

The objective of this research is to increase the energy density of metal hydride electrodes for $\mathrm{MH} / \mathrm{NiOOH}$ batteries by preparing improved $A B_{5}$ and $A B_{2}$ electrodes. A second objective is to develop improved mathematical model for the electrochemical behavior of the $\mathrm{MH}_{\mathrm{x}}$ electrode. The presence of cobalt and $\mathrm{Al}$ in $\mathrm{AB}_{5}$ hydride electrodes was found to strongly inhibit corrosion by reducing the lattice expansion and contraction in the electrochemical charge-discharge 
process and, in the case of $\mathrm{Co}$, from the formation of a corrosion-resistant surface layer.

Keywords: $\quad \mathrm{MH} / \mathrm{NiOOH}$ Batteries $A b_{5}$ and $A b_{2}$ Electrodes, Hydrogen Storage, $X$-ray Absorption Spectroscopy

\section{FUEL CELL MATERIALS}

\section{MATERIALS PROPERTIES, BEHAVIOR,} CHARACTERIZATION OR TESTING

\section{ELECTRODE KINETICS AND ELECTROCATALYSIS $\$ 300,000$ \\ DOE Contact: JoAnn Milliken, (202) 586-2480 \\ Lawrence Berkeley National Laboratóny \\ Contact: P. N. Ross, (510) 486-6226}

Physically meaningful mechanistic models are essential for the interpretation of electrode behavior and are useful in directing the research on new classes of materials for electrochemical energy conversion and storage devices. The objective of this project is to develop an atomic-level understanding of the processes taking place in complex electrochemical reactions at electrode surfaces. Researchers are employing low energy electron diffraction (LEED) to study single crystals; high resolution electron microscopy (HREM) for carbon electrode materials; and $X$-ray absorption fine structure (EXAFS) for organometallic catalysts. Low Energy lon Scattering (LEIS) and Auger Electron Spectroscopy (AES) are being utilized to study the composition of sputtered and UHV-annealed polycrystalline Pt-based bulk alloys for hydrogen electrocatalysis. It was found that both the surface and bulk composition of $\mathrm{Pt}_{75} \mathrm{MO}_{25}$ alloy for hydrogen oxidation was the same.

Keywords: Spectrographic Analysis, Electrocatalysts, Electrooxidation

116. POISONING OF FUEL CELL ELECTROCATALYST SURFACES: NMR SPECTROSCOPIC STUDIES $\$ 100,000$

DOE: Contact: JoAnn Milliken, (202) 586-2480

Lawrence Berkeley National Laboratory

Contact: E. J. Cairns, (510) 486-5028

Platinum is the most active single-component catalyst for $\mathrm{CH}_{3} \mathrm{OH}$ electrooxidation in DMFCs; however, poisoning reactions at the surface render the anode ineffective under target operation conditions. The objective of this research is to obtain information on the nature of the poisoning intermediate(s) in $\mathrm{CH}_{3} \mathrm{OH}$ electrooxidation on Pt-based electrocatalysts by NMR. The unwanted coupling of the NMR sample to the coil was eliminated, thereby permitting the acquisition of meaningful NMR spectra of fuel-cell electrode surface species under open-circuit conditions and strongly suggesting the possibility of acquiring spectra under conditions of in situ electrode potential control.

Keywords: NMR, Electrooxidation, Fuel Cells

HEAVY VEHICLE MATERIALS TECHNOLOGY

MATERIALS PREPARATION, SYNTHESIS, DEPOSITION, GROWTH OR FORMING

\section{COST-EFFECTIVE SRBSN/MICROWAVE ANNEALING OF SILICON NITRIDE $\$ 400,000$ \\ DOE Contact: Sidney Diamond, (202) 586-8032 \\ ORNL Contact: D. R. Johnson, (423) 576-6832 \\ ORNL Contact: J. O. Kiggans, (423) 574-8863}

There are two major objectives of this research element. The first objective is the development of new sintered reaction-bonded silicon nitride (SRBSN) materials that will serve as cost-effective materials for use in suitable heavy-duty-diesel applications. The second is the investigation of microwave heating as a means for the nitridation of silicon for the fabrication of sintered reaction-bonded silicon nitride.

Keywords: Annealing, Cost-Effective Ceramics, Microwave Processing, Microwave Sintering, Silicon Nitride, SRBSN

\section{CONTINUOUS SINTERING OF SILICON} NITRIDE CERAMICS

$\$ 148,000$

DOE Contact: Sidney Diamond, (202) 586-8032

ORNL Contact: T. N. Tiegs, (423) 574-5173

Southern Illinois University Contact:

D. E. Wittmer, (618) 453-7006/7924

The objective of this effort is to investigate the potential of cost-effective sintering of $\mathrm{Si}_{3} \mathrm{~N}_{4}$ through the development of continuous sintering techniques and the use of lower cost $\mathrm{Si}_{3} \mathrm{~N}_{4}$ powders and sintering aids.

Keywords: Cost-Effective Ceramics, Silicon Nitride, Sintering 
119. COST-EFFECTIVE, HIGH-TOUGHNESS SILICON NITRIDE $\$ 350,000$

DOE Contact: Sidney Diamond, (202) 586-8032

ORNL Contact: D. R. Johnson, (423) 576-6832

ORNL Contact: T. N. Tiegs, (423) 574-5173

In silicon nitride, acicular or elongated grains can be generated by in situ growth and these can provide significant toughening on the same order as the whisker-toughened materials. Microstructural development to promote growth of in situ toughened microstructures in silicon nitride is the current emphasis of this project.

Keywords: Alumina, Composites, Silicon Carbide, SiAION, Toughened Ceramics

\section{ChARACTERIZATION/TESTING OF LOW CTE MATERIALS \\ $\$ 100,000$ \\ DOE Contact: Sidney Diamond, (202) 586-8032 \\ ORNL Contact: D. R. Johnson, (423) 576-6832 \\ ORNL Contact: D. P. Stinton, (423) 574-4556}

Insulated exhaust portliners are needed in advanced diesel engines to increase engine fuel efficiency by increasing the combustion temperatures and reducing the combustion heat that is lost through the head and into the water cooling system. Low-expansion materials have potential for this application due to their very low thermal conductivity, extraordinary thermal-shock resistance, and reduction of attachment stresses. Thermal-shock resistance is critical because the shape of the portliners requires that they be cast into the metallic cylinder head. Functioning exhaust portliners are inaccessible after they are cast into cylinder heads and, hence, must not require maintenance for the life of the head ( $\sim 1$ million miles). A contract has been placed with LOTEC to develop cost-effective processes for the fabrication of the portliners. LOTEC is investigating $\mathrm{Ba}_{1+x} \mathrm{Zr}_{4} \mathrm{P}_{6-2 x} \mathrm{Si}_{2 x} \mathrm{O}_{24}$ (BaZPS) and $\mathrm{Ca}_{1-x} \mathrm{Sr}_{2} \mathrm{Zr}_{4} \mathrm{P}_{6} \mathrm{O}_{24}$. ORNL is assisting with the characterization and evaluation of the LOTEC compositions.

Keywords: Physical/Mechanical Properties, Structural Ceramics, Ultra-low Expansion, Zirconia

\section{LOW CTE MATERIALS/DIESEL EXHAUST INSULATION \\ \$O}

DOE Contact: Sidney Diamond, (202) 586-8032

ORNL Contact: D.R. Johnson, (423) 576-6832

LOTEC, Inc. Contact: Santosh Limaye, (801) $277-6940$

The overall objective of this effort is to develop sodiumzirconium-phosphate (NZP) ceramic-based, "cast-inplace," diesel-engine portliners. Specific objectives are: (1) development and optimization of the overall insulation system, (2) refinement of the compliant layer formation process around the ceramic insulation system, (3) development and adaptation of costeffective powder and material fabrication processes; and (4) creation of a database of high-temperature properties (stability in diesel exhaust environment, thermal cycling, thermal shock, etc.). LOTEC will continue to develop and scale up production of sodiumzirconium-phosphate (NZP) materials developed at Penn State University.

Keywords: Structural Ceramics, Ultra-low Expansion, Zirconia

\section{LOW COST NZP POWDER $\$ 0$} DOE Contact: Sidney Diamond, (202) 586-8032 ORNL Contact: D.R. Johnson, (423) 576-6832 LOTEC, Inc. Contact: Santosh Limaye, (801) $277-6940$

The overall objective of this work is to develop a suitable technology for low-cost synthesis and processing of NZP materials. The two NZP materials of primary interest are BS-25 $\left(\mathrm{Ba}_{1.25} \mathrm{Zr}_{4} \mathrm{Si}_{0.5} \mathrm{P}_{5.5} \mathrm{O}_{24}\right)$ and CS-50 $\left(\mathrm{Ca}_{0.5} \mathrm{Sr}_{0.5} \mathrm{Zr}_{4} \mathrm{P}_{6} \mathrm{O}_{24}\right)$. Specific objectives to be accomplished are: (1) preliminary assessment of powder techniques of specialist vendors for costeffective NZP powder synthesis; (2) evaluation of NZP powder samples for phase and impurity content, particle size and distribution, surface area, thermal stability, dispersability, flowability, sinterability after green forming, and synthesis costs; (3) selection of up to two finalist powder suppliers based on results of initial evaluation, commercial viability of the process, and scale-up costs; (4) advanced evaluation of powders supplied by two companies based on results of material properties testing such as thermal expansion, strength, elastic modulus, etc.; and (5) metal-casting trials involving NZP prototype parts and testing of the 
prototypes for diesel-engine worthiness. A secondary objective will be to set up a hydrothermal (or other) lowcost powder synthesis facility at LoTEC as a parallel effort.

Keywords: Powder Characterization, Powders, Structural Ceramics, Ultra-low Expansion, Zirconia

\section{ADVANCED MANUFACTURING OF DIESEL ENGINE TURBOROTORS \\ $\$ 0$}

DOE Contact: Sidney Diamond, (202) 586-8032

ORNL Contact: D. R. Johnson, (423) 576-6832

Kyocera Contact: E. Kraft, (206) 750-6147

The objective of this program is to develop the costeffective manufacturing technology required for ceramic turbine rotors for use in turbochargers for heavy duty diesel truck and bus applications. A team, led by Kyocera and including Schwitzer U.S., Inc, and Caterpillar Inc., will develop and demonstrate production readiness for reliable, cost-affordable, turbochargers with ceramic turborotors. Program goals include a nominal order of magnitude reduction in cost over the present cost for small quantities, and process capability for critical component attributes which is adequate for the performance and reliability specifications of the application.

Keywords: Components, Cost-Effective Ceramics, Process Control, Silicon Nitride

\section{ADVANCED MANUFACTURING OF CERAMIC EXHAUST VALVES FOR DIESEL ENGINES \$O \\ DOE Contact: Sidney Diamond, (202) 586-8032 \\ ORNL Contact: A. E. Pasto, (423) 574-4956 \\ Norton Contact: Vimal Pujari, (508) 351-7929}

The objectives of this program are to design, develop, and demonstrate advanced manufacturing technology for the production of ceramic valves. A production manufacturing process for a ceramic exhaust valve for DDC's Series 149 diesel engine is being developed under this program. Specific objectives are to: (1) reduce manufacturing costs by at least an order of magnitude over current levels; (2) develop and demonstrate performance ratio values of 0.7 or less for all critical component attributes; and (3) to validate ceramic valve performance, durability, and reliability in rig and engine testing.

Keywords: Components, Cost-Effective Ceramics, Process Control, SiAlON
125. INSULATING STRUCTURAL CERAMICS FOR HIGH EFFICIENCY, LOW EMISSION ENGINES $\$ 0$

DOE Contact: Sidney Diamond, (202) 586-8032

ORNL Contact: D. R. Johnson, (423) 576-6832

Caterpillar Contact: Michael Haselkorn, (309) 578-2953

The overall objective of this new program is to develop a commercially viable, zirconia-toughened mullite cylinder-head insert for advanced diesel engines using an innovative tape cast and pressureless sintering process.

Keywords: Ceramics, Components, Diesel, Engines, Mullite, Zirconia

\section{THICK THERMAL BARRIER COATINGS (TTBCs) FOR LOW EMISSIONS, HIGH EFFICIENCY DIESEL ENGINE COMPONENTS SO}

DOE Contact: Sidney Diamond, (202) 586-8032

ORNL Contact: D. R. Johnson, (423) 576-6832

Caterpillar Contact: M. Brad Beardsley, (309) 578-8514

The objective of this new program is to develop durable, thick thermal barrier coating (TTBC) technologies for higher efficiency and lower-emission heavy duty diesel engines.

Keywords: Ceramics, Coatings and Films, Components, Diesel, Engines

127. MATERIALS FOR LOW EMISSIONS, HIGH EFFICIENCY DIESEL ENGINE COMPONENTS \$O

DOE Contact: Sidney Diamond, (202) 586-8032

ORNL Contact: D. R. Johnson, (423) 576-6832

Cummins Contact: Paul Becker, (812) $377-4701$

The goal of this new program is to develop advanced material applications in diesel engine components to enable the design of cleaner, more efficient engines. Advanced materials may include ceramics, intermetallic alloys, advanced metal alloys, or ceramic or metal coatings. Components may include in-cylinder components, valve-train components, fuel-system components, exhaust system components, and air handling systems.

Keywords: Alloys, Ceramics, Coatings and Films, Components, Diesel, Engines, Intermetallics 
128. MATERIALS FOR LOW EMISSIONS, HIGH EFFICIENCY DIESEL ENGINE COMPONENTS \$O

DOE Contact: Sidney Diamond, (202) 586-8032

ORNL Contact: D. R. Johnson, (423) 576-6832

Detroit Diesel Contact: Yuri Kalish,

(313) 592-7825

In this program, DDC will investigate the feasibility of using a smart-materials-based actuator in place of a solenoid for fuel injection actuation.

Keywords: Alloys, Ceramics, Coatings and Films, Components, Diesel, Engines, Intermetallics

129. HIGH STRENGTH MATERIALS FOR DIESEL ENGINE FUEL INJECTORS

$\$ 0$

DOE Contact: Sidney Diamond, (202) 586-8032

ORNL Contact: R. L. Beatty, (423) 574-4536

Cummins Contact: Thomas Yonushonis, (812) 377-7078

The objective of this new program is to develop materials for next-generation diesel fuel injectors.

Keywords: Ceramics, Cermets, Components, Diesel

MATERIALS PROPERTIES, BEHAVIOR, CHARACTERIZATION OR TESTING

\section{DIESEL EXHAUST CATALYST CHARACTERIZATION \\ $\$ 200,000$}

DOE Contact: Sidney Diamond, (202) 586-8032

ORNL Contact: D. R. Johnson, (423) 576-6832

ORNL Contact: L F. Allard, (423) 574-4981

The purpose of this work is to use analytical and highresolution electron microscopy to characterize the microstructures of emission control catalysts. Emphasis is placed on relating microstructural changes to performance of diesel oxidation catalysts.

Keywords: Catalyst Performance, Catalysts, Diesel, Microstructure, Chemical Analysis, Mechanical Properties, Scanning Electron Microscopy

\section{LIFE PREDICTION VERIFICATION}

$\$ 200,000$

DOE Contact Sidney Diamond, (202) 586-8032

ORNL Contact: D. R. Johnson, (423) 576-6832

ORNL Contact: A. A. Wereszczak, (423) 574-7601

The first goal of this research program is to generate engineering data from ambient to high-temperature mechanical testing of silicon nitride and SIAION. The second is to characterize the evolution and role of damage mechanisms using metallography, SEM, and TEM. Lastly, available analytical and numerical models will be utilized to predict the life of complex-shaped components and prototype engine parts (e.g., valves).

Keywords: Components, Engines, Failure Analysis, Failure Testing, High Temperature Service, Life Prediction, Mechanical Properties, Structural Ceramics, Tensile Testing, SiAION, Silicon Nitride

132. HIGH TEMPERATURE TENSILE TESTING $\$ 250,000$

DOE Contact: Sidney Diamond, (202) 586-8032

ORNL Contact: D. R. Johnson, (423) 576-6832

North Carolina A\&T State University Contact:

J. Sankar, (919) 334-7620

The objective of this research is to test and evaluate the long-term mechanical reliability of $\mathrm{Si}_{3} \mathrm{~N}_{4}$ at high temperatures. Microstructural/microchemical analysis of the fracture surfaces using scanning electron microscopy (SEM), transmission electron microscopy (TEM), and energy-dispersive spectral analysis (EDS) is an integral part of this effort

Keywords: Creep, Fracture, Microscopy, Silicon Nitride, Tensile Testing

\section{COMPUTED TOMOGRAPHY}

$\$ 120,000$

DOE Contact: Sidney Diamond, (202) 586-8032

ORNL Contact: D. R. Johnson, (423) 576-6832

Argonne National Lab Contact: W. A. Ellingson, (312) $972-5068$

The objective of this project has been redefined to study 3D X-ray CT densitometry reliability relative to detection of density variations in GS-44 with chopped carbon fibers. GS-44 with chopped carbon fibers is being developed as a material for valve guides as part of an effort with Caterpillar. Current processing technology is 
via cold isostatic pressing. Other, more-cost-effective processing methods may be assessed and a nondestructive method to establish carbon fiber distribution would be highly desirable.

Keywords: Carbon Fibers, Components, Computed Tomography, Diesel, Engine, Nondestructive Evaluation

134. ON-MACHINE INSPECTION $\$ 0$

DOE Contact: Sidney Diamond, (202) 586-8032

ORNL Contact: D. R. Johnson, (423) 576-6832

Caterpillar Contact: M. K. Haselkorn, (309) 578-6224

The primary objective of this new program is to establish a correlation between nondestructive evaluation techniques and the properties and performance of machined ceramic surfaces.

Keywords: Machining, Nondestructive Evaluation, Structural Ceramics

\section{MECHANICAL PROPERTIES OF CMZP} $\$ 0$ DOE Contact: Sidney Diamond, (202) 586-8032 ORNL Contact: D. R. Johnson, (423) 576-6832 Caterpillar Contact: M. K. Haselkorn, (309) 578-6624

The primary objective of this program is to determine the effect of long-term exposure to a diesel-engineexhaust environment of a particular low-expansion ceramic known as calcium magnesium zirconium phosphate (CMZP).

Keywords: CMZP, Diesel, Engine, Physical/Mechanical Properties, Stability

\section{TECHNOLOGY TRANSFER AND MANAGEMENT COORDINATION}

\section{TECHNICAL PROJECT MANAGEMENT $\$ 565,000$ \\ DOE Contact: Sidney Diamond, (202) 586-8032 \\ ORNL Contact: D. R. Johnson, (423) 576-6832}

The objective of this effort is to assess the materials technology needs for high-efficiency diesel engines, formulate technical plans to meet these needs, and prioritize and implement a long-range research and development program.

Keywords: AGT, Advanced Heat Engines, Coordination, Diesel, Management, Structural Ceramics

\section{INTERNATIONAL EXCHANGE AGREEMENT (IEA) $\$ 200,000$ \\ DOE Contact: Sidney Diamond, (202) 586-8032 \\ ORNL Contact: D. R. Johnson, (423) 576-6832 \\ ORNL Contact: M. K. Ferber, (423) 576-0818}

The purpose of this effort is to organize, assist, and facilitate international research cooperation on the characterization of advanced structural ceramic materials. A major objective of this research is the evolution of measurement standards. Participants in Annex II are the United States, Germany, Sweden, Japan, and Belgium. Current research is focused on Subtask 9, Thermal Shock, and Subtask 10, Ceramic Powder Characterization.

Keywords: IEA, Powder Characterization

\section{STANDARD REFERENCE MATERIALS $\$ 200,000$}

DOE Contact: Sidney Diamond, (202) 586-8032

ORNL Contact: D. R. Johnson, (423) 576-6832

NIST Contact: G. Onoda, (301) 975-4489

This objective of this project is to tighten and finalize procedures for the characterization of secondary properties of powders. There are four focus areas relating to the secondary properties: dispersion of powders from slurry preparation, slurry preparation, spray-dried powders, and green body evaluation.

Keywords: IEA, Reference Material, Powder Characterization

139. MECHANICAL PROPERTY STANDARDIZATION $\$ 100,000$

DOE Contact: Sidney Diamond, (202) 586-8032

ORNL Contact: D. R. Johnson, (423) 576-6832

NIST Contact: G. Quinn, (301) 975-5765

The purpose of this effort is to develop mechanical test standards in support of the Heavy Vehicle Propulsion System Materials Program.

Keywords: Mechanical Properties, Test Procedures 


\section{DEVICE OR COMPONENT FABRICATION, BEHAVIOR OR TESTING}

\section{THICK THERMAL BARRIER SEAL COATINGS $\$ 33,000$ DOE Contact: Sidney Diamond, (202) 586-8032 ORNL Contact: D. R. Johnson, (423) 576-6832 ORNL Contact: D. P. Stinton, (423) 574-4556}

The purpose of this exploratory research program was to assess the possibility for sealing the surface of porous thermal barrier coatings (TBCs) with a thin oxide coating prepared by chemical vapor deposition. $\mathrm{Al}_{2} \mathrm{O}_{3}$, $\mathrm{SiO}_{2}$, mullite, and $\mathrm{ZrO}_{2}$ were evaluated as candidate seal coating materials. The high-temperature stability of the sealed TBC structures was studied by performing cyclic oxidation experiments at ORNL and gas permeability measurements at Caterpillar.

Keywords: Coatings, Chemical Vapor Deposition, CVD, Diesel, Engines, Thermal Barrier Coatings

\section{CHARACTERIZATION OF MACHINED CERAMICS $\$ 200,000$}

DOE Contact: Sidney Diamond, (202) 586-8032

ORNL Contact: D. R. Johnson, (423) 576-6832

ORNL Contact: P. J. Blau, (423) 574-5377

The purpose of this task was to develop, in conjunction with U.S. industry, advanced technologies and the associated scientific and economic concepts necessary to reduce the costs for machining of structural ceramics for energy-efficient, low-emissions transportation systems. This effort was conducted by industry, other national laboratories, and in-house at ORNL. The ORNL research concerned two technical areas: 1) investigating the effects of machining practices on the durability of ceramics for valve and valve-seat applications; and 2) understanding and characterizing the detailed nature of machining-induced surface and subsurface damage and their evolution in advanced ceramic materials using a range of analytical tools.

Keywords: Cost-Effective Ceramics, Machining, Silicon Nitride, Structural Ceramics

\section{ADVANCED MACHINING/MANUFACTURING} $\$ 223,000$

DOE Contact: Sidney Diamond, (202) 586-8032

ORNL Contact: D. R. Johnson, (423) 576-6832

ORNL Contact: S. B. McSpadden, Jr., (423) $574-5444$

The objective of this effort is to develop and demonstrate optimized grinding processes for the production of difficult-to-machine components for use in diesel engines.

Keywords: Cost-Effective Ceramics, Machining, Silicon Nitride, Structural Ceramics

\section{NEXT-GENERATION GRINDING WHEEL} $\$ 0$

DOE Contact: Sidney Diamond, (202) 586-8032

ORNL Contact: P. J. Blau, (423) 574-5377

Norton Contact: Robert H. Licht, (508) $351-7815$

This effort is aimed at the engineering design and development of a next-generation, superabrasive grinding wheel specifically tailored for the cylindrical grinding of silicon nitride and other advanced structural ceramic parts for automotive and truck engine applications. The intent of this effort is to significantly reduce manufacturing cost of ceramic parts and to enhance the competitiveness of U.S. industry by providing an optimized grinding wheel for ceramics. The Phase I objectives to define requirements, and design, develop, and evaluate a next-generation grinding wheel for cost-effective cylindrical grinding of advanced ceramics have been met. The overall objectives of the Phase II effort are: (1) to scale up the manufacturing process for the Phase I experimental wheel composition in order to manufacture 356-mm- (14-in.-) diameter grinding wheels; and to validate the performance of the new wheels in cylindrical grinding of advanced ceramics at independent test sites.

Keywords: Cost-Effective Ceramics, Machining, Silicon Nitride, Structural Ceramics, Surface Characterization and Treatment

144. HIGH SPEED GRINDING $\$ 0$

DOE Contact: Sidney Diamond, (202) 586-8032

ORNL Contact: P. J. Blau, (423) 574-5377

Eaton Contact: Joseph A. Kovach, (216) 523-6766

The purpose of this effort is to develop a single step, rough finishing process suitable for producing highquality silicon nitride ceramic parts at high material 
removal rates and at substantially lower cost than traditional, multi-stage grinding processes. Initial implications from Phase I have suggested that HSLD grinding of $\mathrm{Si}_{3} \mathrm{~N}_{4}$ is technically feasible. Accordingly, the Phase II effort is focused on: (1) continued expansion of the HSLD science base; (2) further development of the enabling IHSLD technologies required for successful implementation; and (3) economic analysis of the HSLD production cost drivers.

Keywords: Cost-Effective Ceramics, Machining, Silicon Nitride, Structural Ceramics, Surface Characterization and Treatment

145. LASER-BASED NDE METHODS $\$ 80,000$

DOE Contact: Sidney Diamond, (202) 586-8032

ORINL Contact: D. R. Johnson, (423) 576-6832

Argonne National Lab Contact: J. G. Sun, (708) 252-5169

The primary objective of this program is to develop a laser-based, elastic optical scattering procedure which would provide a direct (near-real-time) method to detect machining-induced damage in monolithic ceramics. Median and lateral crack detection are of primary importance. The laser-based elastic optical scattering program is being executed in three steps. The first is to optimize the elastic scattering procedure by examining specimens machined using innovative machining techniques. The second step involves correlation of the elastic scattering results with mechanical properties in "real" machined ceramic specimens. The final step involves the development of a prototype instrument to be evaluated for on-line implementation in a production environment.

Keywords: Machining, Nondestructive Evaluation, Structural Ceramics

146. GRINDING MACHINE STIFFNESS \$O

DOE Contact: Sidney Diamond, (202) 586-8032

ORNL Contact: P. J. Blau, (423) 574-5377

University of Connecticut Contact: $\mathrm{Bi}$ Zhang, (203) 486-3576

The objective of this effort is to determine the minimum required grinding machine stiffness to meet acceptable quality requirements for ground silicon nitride ceramic parts.

Keywords: Machining, Silicon Nitride
147. NEXT GENERATION GRINDING SPINDLE $\$ O$

DOE Contact: Sidney Diamond, (202) 586-8032

ORNL Contact: P. J. Blau, (423) 574-5377

Eaton Contact: J. A. Kovach, (216) 523-6766

The objective of this effort is to design, develop, test, and demonstrate the operation of a next generation, high-stiffness, high-speed spindle to be used for centerless grinding of ceramic parts.

Keywords: Machining, Structural Ceramics

\section{PROCESS COST MODEL}

$\$ 0$

DOE Contact: Sidney Diamond, (202) 586-8032

ORNL Contact: S. G. Winslow, (423) 574-0965

AlliedSignal Ceramic Components Contact: J. M. Wimmer, (312) 512-3183

The objective of this effort was to refine and utilize a process cost model for the evaluation of various fabrication methods used to manufacture diesel engine and aerospace/industrial turbomachinery structural ceramic components and provide a report containing an analysis of the process cost modeling effort.

Keywords: Cost-Effective Ceramics, Cost Reduction, Modeling, Processing, Structural Ceramics

149. INTELLIGENT GRINDING WHEEL $\$ 0$

DOE Contact: Sidney Diamond, (202) 586-8032

ORNL Contact: P. J. Blau, (423) 574-5377

University of Massachusetts Contact:

Stephen Malkin, (413) 545-3687

The objective of this effort is to develop an "intelligent grinding wheel" for in-process monitoring of ceramic grinding processes. Such a wheel will be smart enough to monitor its "state" or "condition" during truing, dressing, and grinding; to identify the prevailing grinding mechanisms (ductile versus brittle); and to use this realtime information as a feedback signal for process control and optimization. In order to monitor the wheel working condition and the grinding processes in a realtime and on-line fashion, without additional instrumentation, both acoustic emission sensors and dynamic force sensors, together with the primary signal-processing electronics, will be embedded in the core of the grinding wheel.

Keywords: Cost-Effective Ceramics, Machining, Structural Ceramics 
OFFICE OF UTILITY TECHNOLOGIES

FY 1997

Office of Utility Technologies - Grand Total

$\$ 38,810,000$

Office of Solar Energy Conversion

$\$ 18,460,000$

Photovoltaic Eneray Technology Division

$\$ 18,460,000$

Materials Preparation, Synthesis, Deposition, Growth or Forming

$\$ 12,800,000$

Amorphous Silicon for Solar Cells

$3,370,000$

Polycrystalline Thin Film Materials for Solar Cells

$8,110,000$

Deposition of III-V Semiconductors for High-Efficiency Solar Cells

$1,320,000$

Materials Properties, Behavior. Characterization or Testing

$\$ 3,550,000$

Materials and Device Characterization

$\$ 3,550,000$

Device or Component Fabrication. Behavior or Testing

$\$ 2,110,000$

High-Efficiency Crystalline Silicon Solar Cells

$2,110,000$

Office of Geothermal Technologies

$\$ 600,000$

Materials Preparation. Synthesis. Deposition. Growth or Forming

Thermally Conductive Composites for Heat Exchangers

\$ 125,000

125,000

Materials Properties, Behavior, Characterization or Testing

$\$ 475,000$

Advanced High Temperature Geothermal Well Cements

Corrosion Mitigation at The Geysers

125,000

100,000

100,000

Thermally Conductive Cementitious Grouts for Geothermal Heat Pumps

150,000

Office of Energy Management

$\$ 19,750,000$

Advanced Utility Concepts Division

$\$ 19,750,000$

High Temperature Superconductivity for Electric Systems

$\$ 19,750,000$

Device or Component Fabrication, Behavior or Testing

$\$ 19,750,000$

Wire Technology

$5,000,000$

Systems Technology

$5,250,000$

Superconductivity Partnership Initiative

$9,500,000$ 


\section{OFFICE OF UTILITY TECHNOLOGIES}

\section{OFFICE OF SOLAR ENERGY CONVERSION}

\section{PHOTOVOLTAIC ENERGY TECHNOLOGY DIVISION}

The National Photovoltaics program sponsors high-risk, potentially high-payoff research and development in photovoltaic energy technology that will result in a technology base from which private enterprise can choose options for further development and competitive application in U.S. electrical markets. The objective of materials research is to overcome the technical barriers currently limiting the efficiency and cost of photovoltaic cells. Theoretical conversion efficiency of photovoltaic cells is limited by the portion of the solar spectrum to which the cell's semiconductor material can respond, and by the extent to which these materials can convert each photon to electricity. The practical efficiency is constrained by the arnount of light captured by the cell, the cell's uniformity, and a variety of loss mechanisms for the photogenerated carriers. Cost is affected by the expense and amount of materials required, the complexity of processes for fabricating the appropriate materials, and the complexity and efficiency of converting these materials into cells and modules.

\section{MATERIALS PREPARATION, SYNTHESIS, DEPOSITION, GROWTH OR FORMING}

\section{AMORPHOUS SILICON FOR SOLAR CELLS $\$ 3,370,000$ \\ DOE Contact Jeffrey Mazer: (202) 586-2455 \\ NREL Contact: Bolko von Roedern,} (303) 384-6480

This project performs applied research upon the deposition of amorphous silicon alloys to improve solar cell properties. Efficient solar energy conversion is hindered by improper impurities or undesired structure in the deposited films and the level of uniformity of the films over large $\left(4000 \mathrm{~cm}^{2}\right)$ areas. The films are deposited by plasma enhanced chemical vapor deposition (glow discharge), thermal chemical vapor deposition and sputtering. The long term goal of this effort is to develop the technology for 15 percent efficient photovoltaic modules with cost under $\$ 50 / \mathrm{m}^{2}$ and with 30-year lifetime. This will allow an entire system lifetime energy cost of under $\$ 0.06 / \mathrm{kWh}$. Achieving that goal will enable amorphous silicon to be a cost-effective utility-scale generator.

Keywords: Amorphous Materials, Coatings and Films, Semiconductors, Chemical Vapor Deposition, Sputtering, Solar Cells

151. POLYCRYSTALLINE THIN FILM MATERIALS FOR SOLAR CELLS

$\$ 8,110,000$

DOE Contact: Jeffrey Mazer, (202) 586-2455

NREL Contact: Kenneth Zweibel, (303) 384-6441

This project performs applied research upon the deposition of CulnS $e_{2}$ and CdTe thin films for solar cells. Research centers upon improving solar cell conversion efficiency by depositing more nearly stoichiometric films, by controlling interlayer diffusion and lattice matching in heterojunction structures and by controlling the uniformity of deposition over large $\left(4000 \mathrm{~cm}^{2}\right)$ areas. The films are deposited by chemical and physical vapor deposition, electrodeposition and sputtering. The long term goal of this effort is to develop the technology for 15 percent efficient photovoltaic modules with cost under $\$ 50 / \mathrm{m}^{2}$ and with 30 -year lifetime. This will allow an entire system lifetime energy cost of under $\$ 0.06 / \mathrm{kWh}$. Achieving this goal will enable polycrystalline thin film material to be a costeffective utility-scale generator.

Keywords: Coatings and Films, Semiconductors, Chemical Vapor Deposition, Physical Vapor Deposition, Electrodeposition, Sputtering, Solar Cells

\section{DEPOSITION OF III-V SEMICONDUCTORS FOR HIGH-EFFICIENCY SOLAR CELLS $\$ 1,320,000$ \\ DOE Contact: Jeffrey Mazer, (202) 586-2455 NREL Contact: John Benner, (303) 384-6496}

This project performs applied research upon deposition of III-V semiconductors for high efficiency solar cells, both thin film for flat plate applications and multilayer cells for concentrator applications. Research centers upon depositing layers precisely controlled in terms of composition, thickness and uniformity and studying the interfaces between the layers. The materials are deposited by chemical vapor deposition, liquid phase epitaxial growth and molecular beam epitaxial growth. The long term goal of this area is to develop 35 percent efficient concentrator cells and 24 percent efficient $100 \mathrm{~cm}^{2}$ one-sun cells for flat plate applications. 
Achieving these goals will enable systems using these technologies to be cost-effective utility-scale generators.

Keywords: Semiconductors, Chemical Vapor Deposition, Solar Cells

\section{MATERIALS PROPERTIES, BEHAVIOR, CHARACTERIZATION OR TESTING}

\section{MATERIALS AND DEVICE CHARACTERIZATION $\$ 3,550,000$ \\ DOE Contact: Jeffrey Mazer, (202) 586-2455}

NREL Contact: Larry Kazmerski, (303) 384-6600

This project measures and characterizes materials and device properties. The project performs surface and interface analysis, electro-optical characterization and cell performance and material evaluation to study critical material/cell parameters such as impurities, layer mismatch and other defects that limit performance and lifetime. Techniques that are used include deep level transient spectroscopy, electron beam induced current, secondary ion mass spectroscopy, scanning electron microscopy and scanning transmission electron microscopy.

Keywords: Semiconductors, Nondestructive Evaluation, Surface Characterization, Microstructure, Solar Cells

\section{DEVICE OR COMPONENT FABRICATION, BEHAVIOR OR TESTING}

\section{HIGH-EFFICIENCY CRYSTALLINE SILICON SOLAR CELLS \\ $\$ 2,110,000$ \\ DOE Contact: Jeffrey Mazer, (202) 586-2455 \\ NREL Contact: John Benner, (303) 384-649 \\ SNL Contact: Margie Tatro, (505) 844-3154}

This project performs applied research upon crystalline silicon devices to improve solar-to-electric conversion efficiency. The project employs new and improved dopant profiles, back-surface fields, and bulk passivation treatments to reduce electron-hole recombination at cell surfaces and in the bulk. Control of point defects in crystalline silicon is being studied by a variety of techniques, and is thoroughly discussed at the annual NREL-sponsored Silicon Defects Conference.

Additionally, improved light-trapping surface treatments for thin cells ( $\sim 50$ to 100 microns thick), and improved methods for inexpensive silver-paste contact screen printing are also under development. One of the major goals of this project is to develop a rapid-thermalprocessing (RTP)-based, screen-printed-contact, photolithography-free protocol that will yjeld 18 percent efficient $100 \mathrm{~cm}^{2}$ cells on multi-crystalline material in a commercial production environment.

Keywords: Semiconductors, Solar Cells, Crystal Silicon

\section{OFFICE OF GEOTHERMAL TECHNOLOGIES}

The primary goal of the geothermal materials program is to ensure that the private sector development of geothermal energy resources is not constrained by the availability of technologically and economically viable materials of construction. This requires the performance of intermediate and long-term high risk OGT-sponsored materials research and development.

\section{MATERIALS PREPARATION, SYNTHESIS, DEPOSITION, GROWTH OR FORMING}

\section{THERMALLY CONDUCTIVE COMPOSITES FOR HEAT EXCHANGERS $\$ 125,000$ \\ DOE Contact: R. LaSala, (202) 586-4198 \\ BNL Contact: M. L. Allan, (516) 344-3060}

This project is investigating thin thermally conductive polymer-based composites for use as corrosion and scale-resistant liner materials on carbon steel tubing used in shell and tube heat exchangers in binary geothermal processes or for bottoming cycles in multistage flash plants. Corrosion and scaling on the brine side of carbon steel tubing in shell and tube heat exchangers have been major problems in the operation of geothermal processes. Compared to the cost of high alloy steels, a considerable economic benefit could result from the utilization of a proven corrosion resistant composite material if sufficient heat transfer and antifouling properties can be achieved. The work consists of determination of the effects of compositional and processing variables on the thermal and fouling properties of the composite and measurements of the physical and mechanical properties after exposure to hot brine in the laboratory and in plant operations. The effects of antioxidant, SiC fillers and low surface energy additives on the fouling coefficient and scale adhesion are also being evaluated.

Fundamental work to elucidate the interactions that take place at the thermally conductive composite/ scale interface was performed. The results of these studies indicated that polymers containing ester, ketone or ether functional groups should not be used as liner materials because of their susceptibility to oxidation reactions with hot brine. This reaction led to formation of carboxylic acid groups which subsequently react with $\mathrm{Ba}$ and $\mathrm{Ca}$ in geothermal brines. The Ba- and Ca-complexed carboxylate salt derivatives not only acted to promote 
the rate of scale deposition, but also caused the development of high bond strength at the interfaces between the coating and scale. Based on these findings, the incorporation of antioxidants and the use of polyaryl type polymers were selected for field testing.

Field tests with flowing hypersaline brine under heat exchange conditions in conjunction with NREL are in progress to evaluate the following coatings.

\section{- Styrene/TMPTMASiC/antioxidant}

- StyrenerTMPTMASiC

- Styrene/TMPTMASiC/antioxidant over zinc phosphate

- StyrenerTMPTMAVSiC over zinc phosphate

- Polyphenylene sulfide over zinc phosphate

- Polyphenylene sulfide/SiC over zinc phosphate

Preliminary results indicate a trend for the coats containing antioxidants to have greater fouling resistance. If this behavior is sustained the coatings will represent a significant advancement in overcoming problems of both corrosion and scale resistance. Research is also underway to improve methods of attaching the lined heat exchanger tubes to tube sheets. The results from preliminary design, manufacturing and cost studies indicate that contingent upon the development of a method for joining the composite lined tubes to the tube sheets, reductions in the cost of heat exchangers up to $65 \%$ could be realized.

Keywords: Composites, Polymers, Corrosion, Heat Transfer, Heat Exchanger Tubes, ScaleResistant, Fabrication Technology, Fouling Coefficient

\section{MATERIALS PROPERTIES, BEHAVIOR,} CHARACTERIZATION OR TESTING

\section{ADVANCED HIGH TEMPERATURE GEOTHERMAL WELL CEMENTS $\$ 125,000$ \\ DOE Contact: R. LaSala, (202) 586-4198 \\ BNL. Contact: M. L. Allan, (516) 344-3060}

Lightweight ( $<1.2 \mathrm{~g} / \mathrm{cc}$ ), environmentally benign, chemically and thermally resistant well cements are needed to reduce the potential for lost circulation problems during well completion operations and to ensure long-term well integrity. Materials designed for temperatures $>400^{\circ} \mathrm{C}$ will be needed as higher temperature resources are developed. Cements resistant to brines containing high concentrations of $\mathrm{CO}_{2}$ at temperatures $>150^{\circ} \mathrm{C}$ are also needed. Emphasis is being placed on high temperature rheology, phase chemistry, and the mechanical, physical, and chemical resistance properties of the cured materials. Retarding admixtures required to maintain pumpability during placement operations are also being identified.

Cost-shared R\&D between BNL, Halliburton Services and Unocal to develop cementing materials produced by acid-base reactions between fly ash-blended calcium aluminate cements and phosphate-containing compounds was continued. Several candidate systems were evaluated. Studies of the cementing phases formed, microstructure developed, carbonation rate, and changes in strength and permeability after exposure to $\mathrm{CO}_{2}$ solutions at $300^{\circ} \mathrm{C}$ were completed. As a result, a formulation was tentatively selected for use in a fullscale test performed in FY 1997. The basic cement formulation consists of $23.7 \mathrm{wt} \%$ fly ash; $15.8 \mathrm{wt} \%$ calcium aluminate cements, 12.6 wt\% sodium polyphosphate, $29.1 \mathrm{wt} \% \mathrm{Al}_{2} \mathrm{O}_{3}$-shelled microspheres, and $18.8 \mathrm{wt} \%$ water. This formulation has a slurry density of approximately $1.2 \mathrm{~g} / \mathrm{cc}$, and after hydrothermal curing forms a strong, $\mathrm{CO}_{2}$-resistant cement. As an example, autoclave exposure for 120 days to a 4 wt $\% \mathrm{Na}_{2} \mathrm{CO}_{3}$ solution at $300^{\circ} \mathrm{C}$ produced no evidence of carbonation or strength retrogression. In contrast, Class $\mathbf{G}$ cement that is conventionally used for geothermal well completions was severely deteriorated. A production well in Indonesia was recently successfully completed with the developed calcium phosphate cement and use of this material in two more wells in 1998 is planned.

Keywords: Cements, Material Degradation, Strength, Drilling, Carbonation, Retarders, Well Completions

\section{CORROSION MITIGATION AT THE GEYSERS $\$ 100,000$ \\ DOE Contact: R. LaSala, (202) 586-4198 \\ BNL Contact: M. L. Allan, (516) 344-3060}

Increased $\mathrm{HCl}$ gas concentrations in the steam produced from geothermal wells at The Geysers in Northern California have resulted in severe corrosion problems in casings in the upper regions of wells where condensation may occur, in the well-head, transmission piping, turbines, and cooling towers. The objective of the program is to optimize and field test polymers, polymer matrix composites, and ceramic matrix composites for utilization as corrosion resistive liners on components exposed to low pH steam condensates at temperatures up to $-200^{\circ} \mathrm{C}$. The identification of need, performance of prototype and full-scale field evaluations, and subsequent economic studies are 
performed as cost-shared activities with firms active at The Geysers.

In FY 1997, a number of potential coating systems were developed by BNL and were investigated in laboratoryscale work. These included: (a) refractory oxides $\left(\mathrm{ZrO}_{2}\right.$ $\mathrm{Al}_{2} \mathrm{O}_{3}$, and $\mathrm{Y}_{2} \mathrm{O}_{3}$ ), (b) ceramic-sealed NiAl alloy composites, (c) fly ash-derived glass ceramics and (d) PPSsealed NiAl alloy composites. These materials were evaluated for use as corrosion/oxidation/abrasionresistant coatings for mild carbon steel, stainless steel, Ni-Cr steel and Ti-based alloys.

Keywords: Corrosion Protection, Polymers, Composites, Ceramics, Well Casing, Turbine Components, Piping, Acid Condensate

\section{ADVANCED COATING MATERIALS $\$ 100,000$ DOE Contact: R. LaSala, (202) $586-4198$ BNL Contact: M. L. Allan, (516) 344-3060}

Corrosion of plant components is a problem that is encountered in most geothermal processes, and low. cost solutions are needed in order to maintain the economic competitiveness of this large and environmentally benign energy source. The objective of this task is to optimize and field test polymers and polymer, ceramic, and metal composites, developed in other parts of the Geothermal Materials Development Program, as corrosion protective systems for use in brine dominated geothermal electric generation processes and for the biochemical treatment of plant wastes. Successful evaluations and subsequent technology transfer will result in reduced plant construction and operation costs, increased generation efficiencies and utilization factors, and enhanced environmental acceptance.

Thermal sprayed $\mathrm{WC}-12 \% \mathrm{Co}$ and $\mathrm{Cr}_{3} \mathrm{C}_{2}-\mathrm{NiCr}$ coatings were evaluated for corrosion and erosion protection of vent gas blowers. These coatings are currently undergoing field tests. Thermal sprayed ethylene tetrafluoroethylene and ethylene methacrylic acid polymers, spray-and-bake fluoropolymers and brushable ceramic-filled epoxy were investigated as coatings to protect mild steel and $316 \mathrm{~L}$ stainless steel from geothermal sludge, synthetic hypersaline brine and Thiolacillus ferrooxidans at $55^{\circ} \mathrm{C}$ in laboratory scale tests. All thermal spraying was performed at the State University of New York at Stony Brook. The coatings were selected on the basis of their predicted resistance to chemical attack and biodegradation, ease of largescale application, and economics. Long-term exposure tests in simulated environments were conducted and the coatings performance assessed. Residual adhesion after exposure was measured. Cathodic disbondment tests were also conducted to determine the possibility of using the coatings in conjunction with cathodic protection.

It was found that the tested coatings were resistant to chemical attack and biodegradation at the test temperature of $55^{\circ} \mathrm{C}$. The thermal sprayed ethylene methacrylic acid coatings protected $316 \mathrm{~L}$ stainless steel from corrosion in coupon tests. However, corrosion of mild steel substrates coated with ethylene methacrylic acid and ethylene tetrafluoroethylene occurred in Atlas cell tests that simulated a lined reactor operating environment, and this resulted in decreased adhesive strength. The ceramic-filled epoxy performed well with only slight substrate corrosion occurring after 18 weeks of exposure. This coating also displayed excellent abrasion resistance and is recommended for further testing in pilot-scale biochemical processing equipment.

Keywords: Corrosion Protection, Polymers, Composites, Biochemical Processes, Thermal Spraying, Adhesion, Cathode Protection

\section{THERMALLY CONDUCTIVE CEMENTITIOUS GROUTS FOR GEOTHERMAL HEAT PUMPS $\$ 150,000$}

DOE Contact: R. LaSala, (202) 586-4198

BNL Contact: M. L. Allan, (516) 344-3060

Ground head exchangers used with geothermal heat pumps (GHPs) rely on a backfill material to provide heat transfer between the polyethylene U-tube and surrounding formation. Critical properties of the backfill grout are thermal conductivity, cost, ease of placement, impermeability, shrinkage resistance, bonding to U-tube and formation, and durability. By increasing the thermal conductivity of the grouting material the required length of the heat exchanger can be decreased, and this results in decreased installation costs in addition to improved GHP performance.

In FY 1997 Brookhaven National Laboratory initiated research to develop high thermal conductivity cementitious grouts for geothermal heat pumps. This research is focused on cement-silica sand grouts. The effects of sand gradation and proportion on properties such as thermal conductivity, permeability, shrinkage, coefficient of thermal expansion, bond strength, leach resistance and durability have been investigated. Thermal conductivities between 2.4 and $2.8 \mathrm{~W} / \mathrm{mK}$ have been achieved, depending on sand type, content and water/cement ratio. This compares with 0.84 and $0.80 \mathrm{~W} / \mathrm{mK}$ for neat cement grouts with water/cement ratios of 0.6 and 0.8 , respectively. Conventional high solids bentonite grout has a thermal conductivity around $0.75-0.8 \mathrm{~W} / \mathrm{mK}$ and bentonite-sand grout can be 
expected to have a value around $1.46 \mathrm{~W} / \mathrm{mK}$. Cost analysis and the impact of the developed thermally conductive grouts on heat exchanger length design have been conducted in collaboration with the University of Alabama.

It is intended to conduct a field trial in FY98 to evaluate the developed grout under realistic working conditions, further examine bonding between grout, $U$-tube and surrounding formation, measure freeze-thaw resistance of the grouts and investigate non-destructive methods for detecting loss of bonding in any grouting material.

Keywords: Geothermal Heat Pumps, Cementitious Grouts, Backfill, Ground Heat Exchanger, Thermal Conductivity

\section{OFFICE OF ENERGY MANAGEMENT}

\section{ADVANCED UTILITY CONCEPTS DIVISION}

The Advanced Utility Concepts Division supports research and development of advanced energy storage and electrochemical conversion systems that will facilitate the substitution of renewable energy sources for fossil fuels-measures that will increase the reliability and efficiency of the energy economy. The goal is to provide reliable, inexpensive devices to mitigate the temporal and spatial mismatches between energy supply and energy demand.

\section{HIGH TEMPERATURE SUPERCONDUCTIVITY FOR ELECTRIC SYSTEMS}

\section{DEVICE OR COMPONENT FABRICATION, BEHAVIOR OR TESTING}

160. WIRE TECHNOLOGY

$\$ 5,000,000$

DOE. Contact: Jim Daley, (202) 586-1165

Argonne National Laboratory Contact:

U. Balachandran, (708) 252-4250

Brookhaven National Laboratory Contact: David Welch, (516) 282-3517

Los Alamos National Laboratory Contact:

Dean Peterson, (505) 665-3030

National Renewable Energy Laboratory

Contact: Richard Blaugher, (303) 384-6518

Oak Ridge National Laboratory Contact:

Riobert Hawsey, (615) 574-8057

Sandia National Laboratory Contact: Peter Roth, (505) 845-9301

American Superconductor Contact: G. N. Riley, (508) 836-4200

Intermagnetics General Corp. Contact:

Paradeep Haldar, (518) 782-1122
The wire technology goal is improvement in short wire samples $(1 \mathrm{~cm}$ to $10 \mathrm{~cm})$ through: improved powder synthesis, improved fundamental understanding of critical currents in high temperature superconductors, and investigation of new wire processing methods. Improvement in long wire length uniformity is included in the Systems Technology project below.

The wire development project is the key to eventual commercialization of superconductivity systems. Subtasks in the project are as follows:

a. Ink development and spray deposition - To develop high quality, low cost methods for the delivery of superconductor precursor materials in a commercially scalable thick-film process using ink-spray techniques.

b. Thallination and advanced substrate development - Continue to optimize the thallination parameters leading to high $J_{c}$ superconducting films and develop and evaluate a textured substrate to permit the synthesis of a bi-axially textured oxide film. To scale up the thallination apparatus to allow longer length development of superconducting samples leading eventually to a continuous thallination process.

c. Development of Thallium based conductors - The purpose of the TI-based conductor development project is to develop materials and processes which will lead to the practical production of wires and tapes capable of carrying high currents in the presence of typical operating magnetic fields at liquid nitrogen temperatures.

d. Practical conductor development for electrical power systems utilizing high $T_{c}$ oxides; characterization of aligned $\mathrm{Bi}(2223)$ in AG PIT tapes - The purpose of this project is to make detailed characterization of electrical magnetic properties, such as AC losses and critical currents, of cuprate conductors in order to make critical assessments of the conductors, as well as to provide pertinent data for the design of various electrical devices.

e. Development of high $\mathrm{I}_{c}$ and $\mathrm{J}_{c} \mathrm{BSCCO}$ conductors - The main part of the project is aimed at understanding the effects of optimal defect geometry and density on the high temperature, high field performance of Bi-2223 tapes. The defects are produced by the recoil of proton induced fission fragments in the Bi-2223 cores of the tapes, which result in splayed columnar defects. 
f. High rate deposition technology for long-length conductors - The purpose of this project is to develop metal-organic chemical vapor deposition processes to fabricate high-quality superconductor coatings on long-length substrates. Film composition, crystallinity, morphology, and superconducting properties as a function of chemical precursor, gas pressure, flow rate, substrate materials, and deposition temperatures will be systematically investigated.

9. High current YBCO coated-conductor development - The objectives of this project included: Development of continuous processing of both the IBAD buffer layer and the laser-deposited YBCO layers at lengths of one meter. Investigation of means to accelerate and economize the deposition of IBAD layer. Investigation of accelerated deposition of the YBCO layer.

h. Deposited conductors on textured metal substrates - The purpose of the project is to develop scalable processes for fabrication of conductors for high temperature, high field applications The objectives for this project are: To obtain proof-of-principle for the RABITS (Rolling-Assisted Biaxially Textured Substrate) approach to conductor fabrication by demonstrating high critical current densities in a reproducible manner. For this purpose, primarily pulsed laser deposition has been used for oxide buffer layers and $\mathrm{YBa}_{2} \mathrm{Cu}_{3} \mathrm{O}_{7}$.

Keywords: Superconductor, Thallium Conductor, Bismuth Conductor, Coated Conductor

161. SYSTEMS TECHNOLOGY

\section{$\$ 5,250,000$}

DOE Contact: Jim Daley, (202) 586-1165

Argonne National Laboratory Contact: U. Balachandran, (708) 252-4250

Brookhaven National Laboratory Contact: David Welch, (516) 282-3517

Los Alamos National Laboratory Contact: Dean Peterson, (505) 665-3030

National Renewable Energy Laboratory Contact: Richard Blaugher, (303) 384-6518

Oak Ridge National Laboratory Contact: Robert Hawsey, (615) 574-8057

Sandia National Laboratory Contact: Thomas Bickel, (505) 845-9301

American Superconductor Contact: G. N. Riley, (508) $836-4200$

Intermagnetics General Corp. Contact: Paradeep Haldar, (518) 782-1122

Oxford Instruments, Inc. Contact: K. R. Marken, (908) $541-1300$
Systems technology goals include: improved uniformity in long ( 10 meter to 1000 meter) high temperature superconductor (HTS) wires, development of high field (2-5 telsa) coils, and design of high efficiency electric power devices.

The electric power application project includes development of long length wire manufacture and coil manufacture. Some preliminary systems development is also done. Project subtasks are as follows:

a. AC-loss calorimeter system for HTS power transmission cables - The objective of this project is to develop an AC-loss calorimetric measurement system capable of determining the total AC-losses (hysteretic eddy current and coupling) of an HTS cable conductor operating in a 3-phase environment.

b. Practical conductor development for electrical power systems utilizing high $T_{c}$ oxides: characterization of electrical and magnetic properties - The purpose of this project is: to make detailed characterization of electrical and magnetic properties, such as ac losses and critical currents, of cuprate conductors in order to make critical assessments of the conductors, as well as to provide pertinent data for the design of various electrical devices.

c. Power applications of high temperature superconductors - To develop HTS components relating to electric power applications. Evaluate techniques and approaches to manufacture HTS coils and magnets for use in power-related applications such as transformers, motors, generators, fault current limiters, SMES and transmission cable. Manufacture long lengths of $\mathrm{Bi}-2223$ multi filament conductor and $\mathrm{Bi}-2212$ surface-coated conductor for use in the demonstration of prototype systems.

d. Long-length HTS conductors - The purpose of this project is to develop technology to fabricate longlength conductors with superconducting and mechanical properties suitable for commercial operation at temperature approaching $77 \mathrm{~K}$.

e. Resistive fault current limiter - The purpose of the project is to develop a resistive $100 \mathrm{~A}$ fault current limiter from sintered YBCO. The device would be an intermediate step in the development of a commercial $F C L(600 \mathrm{~A} / 12 \mathrm{kV})$ for distribution lines of an electric utility.

f. HTS transmission cable - The purpose of this project is to develop the technology necessary to proceed to commercialization of high temperature 
superconducting transmission cable. The objectives are to design and construct a low-cost, 2000 A AC, bare $1 \mathrm{~m}$ HTS cable prototype, and test its pertiormance.

g. Conductor, coil, and apparatus development for utility and commercial applications - The purpose of this project is to establish the technical and economic feasibility and benefits to society of HTS transformers of medium(30 MVA) to large rating. The objective is to design and begin the construction of a nominal 1 MVA HTS demonstration transformer incorporating the concepts developed.

h. $\quad A C$ wires and $A C$ coils for power applications The objective of this AC loss effort is to support the development of a high temperature superconductor developed for AC applications. The low level of loss observed in the experimental datal indicated that improvements in the $A C$ apparatus would be required to characterize long continuous lengths of conductor. The main concern was the variation in the field homogeneity for long sample lengths when the sample was exposed to $A C$ fields perpendicular to the wide face of the conductor.

i. High gradient magnetic separation - The objective is to design and build a prototype industrial HTS high gradient magnetic separation system. The copper coils used in conventional industrial magnetic separation systems consume large amounts of electrical power. Significant energy savings are possible if superconducting magnet systems are used.

Keywords: Long Length Conductor, Bearing, Flywheels, Superconducting Tape, Power Transmission Cable, Resistive Fault Current Limiter, Magnetic Separation, Transformer

\section{SUPERCONDUCTIVITY PARTNERSHIP INITIATIVE \\ $\$ 9,500,000$ \\ DOE Contact: Chris Platt, (202) 586-4563}

The Superconductivity Partnership Initiative (SPI) is an industry-led venture between the Department of Energy and four industrial consortia intended to accelerate the use of high temperature superconductivity in energy applications. Each SPI team includes a vertical integration of non-competing companies that represent the entire spectrum of the R\&D cycle. That is, the teams include the ultimate user of the technology-the electric utilities-as well as a major manufacturing company and a small company supplier of superconducting components. Each team also includes one or more national laboratories who perform specific tasks defined by the team. The SPI goal is to design cost-effective HTS systems for electricity generation, delivery and use. The funding amount below includes the Department's share of the SPI design activities, as well as parallel HTS technology development that directly supports the SPI teams. In FY 1997, projects are underway for a superconducting fault-current limiter (Lockheed-Martin), and $100 \mathrm{HP}$ motor (Rockwell Automation) . In addition, a transmission cable project, led by the Electric Power Research Institute and Pirelli Cable, was funded. All of these projects will incorporate high-temperature superconducting wire. Four Department of Energy National Laboratories are currently directly supporting the Superconductivity Partnership Projects: Argonne, Los Alamos, Oak Ridge, and Sandia.

Project subtasks are as follows:

a. Fault Current Limiter - The fault current limiter project undertook conceptual studies of various device designs, provided a market survey for current limiter applications, completed an energy benefit assessment, conducted a network interface assessment, determined conductor requirements, and analyzed the economic potential of fault current limiters. Fault current limiters can be used on transmission and distribution systems to improve system flexibility, reliability and performance.

Lockheed Martin Contact: Eddie Leung, (619) 974-1166

b. Motor - Electrical and mechanical design and thermal analysis was completed. In addition, the construction of the components for a motor prototype will be nearly completed, with assembly and testing. Superconducting motors can have a large impact on electrical energy utilization through reduced losses and size compared to conventional iron core motors. These reduced losses and the smaller size will be the driving force for the commercial introduction of superconducting motors in industrial applications.

Rockwell Automation Contact: David Driscoll, (216) 266-6002

c. High Temperature Superconducting Power Cable - The first phase of the contract calls for the development and fabrication of a 30-meter prototype $115 \mathrm{KV}$ HTS underground power transmission cable which will be tested at a utility 
test site. Additionally, the project will conclude

with design of a 3-phase, 100 meter cable system.

Electric Power Research Institute Contact:

Don Von Dollen, (415) 855-2679

Keywords: Motor, Fault Current Limiter, Transmission Cable 
Fundamentals of Thermal Plasma Processing

Multivariable Control of the Gas-Metal Arc Welding Process.

153,000

Metal Transfer in Gas-Metal Arc Welding

Thermal Plasma Chemical Vapor Deposition of Advanced Materials

124,000

157,975

Research on Combustion-Driven HVOF Thermal Sprays

96,893

Effect of Forced and Natural Convection on Solidification of Binary Mixtures

Materials Properties, Behavior, Characterization or Testing

Continuum Damage Mechanics - Critical States

An Investigation of History-Dependent Damage in Time-Dependent Fracture Mechanics

Intelligent Control of Thermal Processes

Elastic-Plastic Fracture Analysis Emphasis on Surface Flaws

Nondestructive Evaluation of Superconductors

Origins of Asymmetric Stress-Strain Response in Phase

Transformations

Modeling and Analysis of Surface Cracks

Development of Measurement Capabilities for the Thermophysical Properties of Energy-Related Fluids

High- $T_{c}$ Superconductor-Semiconductor Integration and Contact Technology

Thin Film Characterization and Flaw Detection

Transport Properties of Disordered Porous Media From the Microstructure

Inelastic Constitutive Equation: Deformation Induced Anistropy and the Behavior at High Homologous Temperature

Stress and Stability Analysis of Surface Morphology of Elastic and Piezoelectric Materials

Optical Techniques for Characterization of High Temperature Superconductors 


\section{OFFICE OF ENERGY RESEARCH (continued)}

Office of Basic Energy Sciences (continued)

Division of Engineering and Geosciences (continued)

Enqineering Sciences Research (continued)

Device or Component Fabrication, Behavior or Testing

An Analytical-Numerical Alternating Method for 3-D Inelastic Fracture and Integrity Analysis of Pressure-Vessels and Piping at

Elevated Temperatures

Pulse Propagation in Inhomogeneous Optical Waveguides

Flux Flow, Pinning and Resistive Behavior in Superconducting Networks

Geosciences Research

$\$ 2,957,219$

Materials Preparation. Synthesis, Deposition, Growth or Forming

$\$ 620,789$

Organic Anion-Mineral Surface Interactions During Diagenesis

Solution-reprecipitation of Calcite and Partitioning of Divalent Metals

129,999

Transition Metal Catalysis in the Generation of Petroleum and Natural Gas

109,313

Mineral Dissolution and Precipitation Kinetics: A Combined Atomic-Scale and Macro-Scale Investigation

Materials Structure and Composition

Reaction Mechanisms of Clay Minerals and Organic Diagenesis: An HRTEMIAEM Study

Infrared Spectroscopy and Hydrogen Isotope Geochemistry of Hydrous Silicate Glasses

Biomineralization: Systematics of Organic-directed Controls on Carbonate Growth Morphologies and Kinetics Determined By in situ Atomic Force Microscopy

Reactions and Transport of Toxic Metals in Rock-Forming Silicates at $25^{\circ} \mathrm{C}$

The Crystal Chemistry and Structural Analysis of Uranium Oxide Hydrates

Materials Properties, Behavior, Characterization or Testing

$\$ 1,817,172$

Oxygen and Cation Diffusion in Oxide Materials

Structure and Reactivity of Ferric Oxide and Oxyhydroxide Surfaces:

Quantum Chemistry and Molecular Dynamics

Cation Diffusion Rates in Selected Silicate Minerals

Grain Boundary Transport and Related Processes in Natural Fine-Grained Aggregates

Thermodynamics of Minerals Stable Near the Earth's Surface

New Method for Determining Thermodynamic Properties of Carbonate

Solid-Solution Minerals

Theoretical Studies of Metal Species in Solution and on Mineral Surfaces

Micromechanics of Failure in Brittle Geomaterials

Three-Dimensional Imaging of Drill Core Samples Using Synchrotron-Computed Microtomography

Shear Strain Localization and Fracture Evolution in Rocks

Dissolution rates and surface chemistry of feldspar glass and crystal

Transport Phenomena in Fluid-Bearing Rocks

Cation Chemisorption at Oxide Surfaces and Oxide-Water Interfaces:

$X$-Ray Spectroscopic Studies and Modeling 
OFFICE OF ENERGY RESEARCH (continued)

FY 1996

Office of Computational and Technology Research

$\$ 13,702,000$

Division of Advanced Energy Projects and Technology Research

$\$ 13,702,000$

Laboratory Technology Research (LTR) Program

$\$ 8,062,000$

Materials Preparation, Synthesis, Deposition, Growth or Forming

$\$ 2,887,000$

Lumeloid, A New Solar Energy Conversion Material (ANL94-42)

200,000

Cold Cathode Electron Emission from Diamond and Diamond-Like

Carbon Thin Films for Flat Panel Computer Displays (ANL95-02)

Giant Magnetoresistance Wire Sensor (ANL95-07)

High Performance Tailored Materials for Levitation and Permanent Magnetic Technologies (ANL97-02)

Synthesis and Crystal Chemistry of Technologically Important Ceramic

Membranes (ANL97-06)

Composite Metal-Hydrogen Electrodes for Metal-Hydrogen Batteries (BNL94-06)

Development of CdTe/CdZnTe Materials for Radiation Detectors (BNL94-09)

Corrosion Resistance of New Alloys for Biomedical Applications (BNL94-20)

Catalytic Production of Organic Chemicals Based on New Homogeneously

Catalyzed lonic Hydrogenation Technology (BNL97-05)

Novel Biocompatible "Smart" Contact Lens Material (LBL94-28)

Alloy Design of Neodymium ( $\mathrm{Nd}_{2} \mathrm{Fe}_{14}$ B) Permanent Magnets (ORL94-15)

Development of Aluminum Bridge Deck System (ORL94-56)

Manufacturing of Ni-Base Superalloys with Improved High-Temperature

Performance (ORL95-05)

New Thermoelectric Materials for Solid State Refrigeration (ORL95-10)

Polymer Multilayer (PML) Film Applications of Optics, Electrolytes, and Glazings (PNL.94-06)

Development of Mixed Metal Oxides (PNL94-28)

Development of Tape Calendaring Technology for Separation Membranes (PNL95-04)

Innovative Multilayer Thermal Barrier Coatings for Gas Turbine Engines (PNL95-07)

Interfacial Interactions of Biological Polymers with Model Surfaces (PNL97-21)

Highly Dispersed Solid Acid Catalysts on Mesoporous Silica (PNL97-28)

Device or Component Fabrication, Behavior or Testing

140,000

75,000

125,000

125,000

115,000

115,000

140,000

118,000

211,000

155,000

105,000

137,000

150,000

200,000

25,000

257,000

245,000

124,000

125,000

$\$ 3,074,000$

Application of High Performance Computing of Automotive Design and Manufacturing (ANL94-54)

Development of Rapid Prototyping Technology for Bioceramic Applications (ANL95-08)

Smooth Diamond Films for Friction and Wear Applications and Chemically

Protective Coatings (ANL97-05)

Microfabrication of a Multi-Axis Micro-Accelerometer Using High Aspect Ratio

Microfabrication (HARM) and Silicon Micromachining (BNL94-02)

Nondestructive X-Ray Scattering Characterization of High Temperature Superconducting Wires (BNL95-10)

Thin Film Lithium Batteries (BNL95-11)

New Catalysts for Direct Methanol Oxidation Fuel Cells (BNL95-14)

Development of Multi-Channel ASICs for CdZnTe Gamma Detectors Arrays (BNL97-06)

Microcircuits and Sensors for Portable, Low-Power Data Collection and Transmission (BNL97-07)

175,000

276,000

150,000

100,000

160,000

80,000

80,000

82,000

125,000 


\section{OFFICE OF ENERGY RESEARCH (continued)}

Office of Computational and Technology Research (continued)

Division of Advanced Energy Projects and Technology Research (continued)

Laboratory Technology Research Program (continued)

Device or Component Fabrication. Behavior or Testing (continued)

Rechargeable Zinc/Air Batteries for Consumer Applications (LBL94-43)

Micromagnetic Structures (LBL95-12)

Development of Zinc/Nickel Oxide Batteries for Electric Vehicle Applications (LBL95-27)

62,000

378,000

Catalytic Conversion of Chloro-Fluorocarbons Over Palladium-Carbon Catalysts (LBL95-45)

Ionically Conductive Membranes for Oxygen Separation (LBL97-03)

Light Emission Processes and Dopants in Sold State Light Sources (LBL97-13)

Combinatorial Discovery and Optimization of Novel Materials for Advanced

Electro-Optical Devices (LBL97-18)

Development of a Thin-Film Battery Powered Hazard Card and Other Microelectronic

Devices (ORL94-39)

Ion Implantation Processing Technologies (ORL94-72)

Rapid Prototyping of Ceramics (ORL94-95)

Development of a Thin Film Battery Powered Transdermal Medical Device (ORL95-11)

Rapid Prototyping of Bioceramics for Implants (ORL95-12)

Development of High-Temperature Superconducting Wire Using RABITS

Coated Conductor Technologies (ORL97-02)

100,000

Instrumentation and Facilities

$\$ 1,079,000$

Micro-Spectroscopy Facility for New Infrared Imaging Materials (BNL94-60)

Development of Environmentally Conscious Machining Fluids (ORL94-91)

Novel Methods for Fabrication Cost Reduction of Pressure Infiltration Cast Metal

Matrix Composite Components (ORL95-01)

Ultra-Precision Automated Measurement for Manufacturing (ORL95-08)

Neural Network Model (ORL95-90)

Microfabricated Instrumentation for Chemical Sensing in Industrial Process

Control (ORL97-08)

Modeling and Simulation of Advanced Sheet Metal Forming (PNL94-38)

91,000

204,000

192,000

75,000

248,000

99,000

170,000

Materials Properties, Behavior. Characterization of Testing

$\$ 1,022,000$

Next Generation Corrosion Inhibitors for Steel in Concrete (BNL95-12)

Prevention/Elimination of Metal-Water Explosions in Aluminum Casting Pits (ORL92-05)

50,000

In-Line Aluminum Sensors (ORL95-04)

The Role of Yttrium in Improving the Oxidation Resistance in Advanced Single

Crystal Nickel-based Superalloys for Turbine Applications (ORL95-07)

Atomic Scale Structure of Uitrathin Magnetic Multilayers and Correlation with

Resistance, Giant Magnetoresistance, and Spin-Dependent Tunneling (ORL97-03)

Processing/Property Relationships in Centrifugally Cast Al-Metal Matrix Composites

(MMC) (PNL94-02)

Bioactive and Porous Metal Coatings for Improved Tissue Regeneration (PNL95-23)

174,000

113,000

149,000

100,000

245.000

191,000 
OFFICE OF ENERGY RESEARCH (continued)

FY 1997

Office of Computational and Technology Research (continued)

Division of Advanced Energy Projects and Technology Research (continued)

Advanced Energy Projects Program

$\$ 5,640,000$

Device or Component Fabrication, Behavior or Testing

$\$ 2,553,000$

Composite Magnetostrictive Materials for Advanced Automotive Magnetomechanical Sensors

Energy Related Applications of Selective Line Emitters

Investigation of High Efficiency Multi Band Gap Multiple Quantum Well Solar Cells

A Novel Tandem Homojunction Solar Cell: An Advanced Technology for High

Efficiency Photovoltaics

Magnetically Enhanced Thermoelectric Cooling

Photochemical Solar Cells

Efficient Energy Up-Conversion of Infrared to Visible Light at Semiconductor Heterojunctions

Electrically Active Liquid Matrix Composites

Semiconductor Broadband Light Emitters

Materials Preparation, Synthesis, Deposition, Growth or Forming

449,000

266,000

225,000

255,000

250,000

150,000

268,000

300,000

390,000

Next Generation High-Temperature Structural Materials for Heat Exchangers and Heating Elements

Photorefractive Liquid Crystals: New Materials for Energy-Efficiency Imaging Technology

Tritiated Porous Silicon: A Standalone Power Source

Supported Molten Metal Catalysts: Development of a New Class of Catalysts

Combinatorial Synthesis of High $T_{c}$ Superconductors

Fabrication and Characterization of Micron Scale Ferromagnetic Features

Micro-Hollow Cathode Discharge Arrays: High Pressure, Nonthermal Plasma Sources

Rapid Melt and Resolidification of Surface Layers Using Intense, Pulsed lon Beams

Experimental and Theoretical Investigation of Dual-Laser Ablation for Stiochiometric Large-Area Multicomponent Film Growth

$\$ 2,178,000$

294,000

289,000

250,000

322,000

250,000

106,000

259,000

300,000

108,000

Materials Properties, Behavior, Characterization or Testing

$\$ 909,000$

Shape Memory Alloy Reinforcement of Metals

Exploitation of Room Temperature Molecule/Polymer Magnets for Magnetic and

405,000

Electromagnetic Interference Shielding and Electromagnetic Induction

Applications

212,000

Molecular Surface Modification as a Means of Corrosion Control

292,000 
OFFICE OF ENERGY RESEARCH (continued)

FY 1997

Office of Computational and Technology Research (continued)

Division of Advanced Energy Projects and Technology Research (continued)

Small Business Innovation Research Program

$\$ 58,849,611$

Materials, Preparation, Synthesis, Deposition, Growth or Forming

$\$ 17,920,148$

Phase I

$\$ 3,368,833$

Controlled Permeability Chemically Activated Fly Ash (CAFA) for Reactive Contaminant Barrier

Advanced Multilayer Braze Foil for $\mathrm{Si}_{3} \mathrm{~N}_{4}$ Joining

75,000

A Novel Reactive Joining Compound for High Temperature Applications

Fabrication of Active Braze Alloys for High Temperature Service

74,997

74,993

75,000

Diamond-Like Nanocomposites: Hard, Wear Resistant, Low Friction Coatings for Tribological Applications

74,869

High Growth Rate Cubic Boron Nitride Deposition

74,867

Development of Novel Boron-Based Multilayer Thin-Film

73,420

Nano-Layered Diboride Materials with Enhanced Hardness, Strength, and Toughness for Wear Applications

74,929

Advanced Plasma Surface Modification System

High-Flux, Low Energy, Ion Source for High Rate Ion-Assisted

Deposition of Hard Coatings

74,669

An Ion Source Design Useful for the Production of Tribiological Thin Films

Semi-Solid Thermal Transformation to Produce Semi-Solid Formable Alloys

75,000

74,996

A Simple Process to Manufacture Grain Aligned Permanent Magnets

75,000

74,840

A Novel Technique for the Enhancement of Coercivity in High Energy

Permanent Magnets

Controlled Atmosphere Plasma Spraying of NdFeB Magnet Materials

73,130

75,000

75,000

Stabilization of Nitride Magnet Material Via Sol-Gel Route

A Novel Process to Produce Nanostructured Permanent Magnetic Materials

75,000

Coke Resistant Catalyst for the Partial Oxidation Reforming of Hydrocarbon Fuels

75,000

74,987

CO Tolerant Doped-Metal Oxide Catalysts

Advanced Electrocatalysts for Direct Methanol Oxidation

A Combinatorial Approach to the Synthesis and Characterization of Novel

Anode Materials for Direct Methanol Fuel Cells

74,974

Novel Multifunctional Direct Methanol Fuel Cell Catalysts

Low Cost Deposition of Buffer Layers for Manufacturable YBCO HTS Conductors

74,582

75,000

75,000

75,000

75,000

Buffer Layers on Textured Nickel Using Commercially Viable CCVD Processing

Micromachined SiC Sensors For Harsh Environment Applications

75,000

Silicon Carbide Sensors for Harsh Environments

Development of Efficient and Practical Passive Solar Building Systems with

High Recycled Content Using the Preplaced Aggregate Concrete Technology

74,840

Heterogeneous Hydroformylation of Alkanes with Syngas

Advanced NZP-Ceramic Based Thermal Barrier Coatings with Enhanced

Oxidation and Thermal Shock Resistance

75,000

75,000

74,900 
OFFICE OF ENERGY RESEARCH (continued)

Office of Computational and Technology Research (continued)

Division of Advanced Energy Projects and Technology Research (continued)

Small Business Innovation Research Program (continued)

Materials, Preparation, Synthesis, Deposition, Growth or Forming (continued)

Phase I (continued)

Tubular SOFC with Deposited Nano-Scale YSZ Electrolyte

75,000

Integrated Bandpass Filter Contacts for TPV Cells

In-Situ Ultrahigh-Pressure Waterjet Peening of Nuclear Reactor Internals for the Prevention of Stress Corrosion Cracking

Thallium-Containing III-V Quaternary Compound Semiconductor for Use in Infrared Detection

High Speed Long Wavelength Infrared Detector Array/Preamplifier Development

Development of Cadmium Germanium Arsenide Crystals

AllnGaN Light Emitting Diodes for Spectroscopic Applications

An Easily Dispersed Reactive Coating for Surface Decontamination

High Quantum Efficiency Spin-polarized Photocathodes

Rapid Quench $\mathrm{Nb}_{3} \mathrm{Al}$ for High Field Accelerator Applications

Ultra-Lightweight Carbon-Carbon Cooling Structure For Pixel and Silicon Strip Detectors

Epitaxial Growth of SiC on Silicon for Radiation Hard Particle Detectors

Development of Scintillators and Waveshifters for Detection of lonizing Radiation

Low Viscosity Organic Insulation Systems For Improved Processing and Reduced Radiation Induced Gas Evolution

Radiation Resistant Joining Methods for Structural Applications in Fusion Energy Systems

Phase II (First Year)

An Attrition-Resistant Zinc Titante Sorbent for a Transport Reactor

A Light Scattering Based Sensor for On-Line Monitoring of Fiber Diameter Distribution During Fiberglass Manufacturing

High Rate Deposition of Transparent Conducting Zinc Oxide Using Activated Oxygen for Photovoltaic Manufacturing Cost Reduction 
OFFICE OF ENERGY RESEARCH (continued)

Office of Computational and Technology Research (continued)

Division of Advanced Energy Projects and Technology Research (continued)

Small Business Innovation Research Program (continued)

Materials. Preparation. Synthesis. Deposition. Growth or Forming (continued)

Phase II (Second Year)

Low Cost, Contamination-Tolerant Electrocatalysts for Low-Temperature Fuel Cells

A Low Cost, High Temperature Superconductor Wire Manufacturing Technology

750,000

750,000

A Low Cost Receiver Plate Manufacturing Process for High Concentration Photovoltaic Systems

An Intumescent Mat Material for Joining of Ceramics to Metals at High Temperatures

Development of Modulator Quality Rubidium Titanyl Arsenate Crystals for Remote Sensing Laser Systems

A Novel Method to Recycle.Thin Film Semiconductor Materials

An Improved Material and Low-Cost Fabrication Options for Candle Filters

An Integrated Catalyst/Collector Structure for Regenerative Proton-Exchange Membrane Fuel Cells

Nanostructured Interstitial Alloys as Catalysts for Direct Energy Applications

Environmentally Responsible Recycling of Thin-Film Cadmium Telluride Modules

Low-Cost, Large-Area, High-Resistivity Substrates for Gas Microstrip Detectors

An Economic Sorbent for the Removal of Mercury, Chlorine, and Hydrogen Chloride from Coal Combustion Flue Gases

680,000

750,000

750,000

600,000

750,000

719,147

750,000

750,000

749,973

750,000

Materials Properties, Behavior, Characterization or Testing

$\$ 12,202,888$

Phase I

$\$ \quad 971,422$

Nondestructive Measurements of Key Mechanical Properties of Alloy 718 Welded Structures Using Novel Stress-Strain Microprobe Technology

Processing For Surface Hardness: Novel Characterization Techniques for Dynamic Tribological Properties of Thin Films

A Novel Mass Spectrometer for Characterization of Electrochemical Processes

New Insulation Techniques for High Voltage, High Frequency Motors

Development of Carbon Products from the Waste Stream of the Super Critical Deashing Process in Coal Liquefaction

Sol-Gel Coatings as Corrosion Barriers for Carbonate Fuel Cell Components

Enhanced Flaw Detection by Time-Reversal Auto-Focusing of an Ultrasonic Array

High Resolution Cryogenic Calorimeter for Beta and Gamma Ray Detection

High Current Density High Repetition Rate Ferroelectric Cathode

High Current Capacity High Temperature Superconducting Film Based Tape for High Field Magnets

A Polycrystalline Pixel Diamond Film Particle Detector

Resistance Welding Vanadium Alloys

Low Cost Technique for Testing Ceramic Insulator Coatings

75,000

74,993

75,000

74,985

75,000

75,000

74,988

74,976

75,000

75,000

71,483

74,997

75,000 
OFFICE OF ENERGY RESEARCH (continued)

Office of Computational and Technology Research (continued)

Division of Advanced Energy Projects and Technology Research (continued)

Small Business Innovation Research Program (continued)

Materials Properties, Behavior, Characterization or Testing (continued)

Phase II (First Year)

$\$ 8,242,295$

Carbon Monoxide Tolerant Anodes for Proton Exchange Membrane

(PEM) Fuel Cells

Low Cost Advanced Bipolar Plates for Proton Exchange Membrane Fuel Cells Improved Bi-2223 Flux Pinning Through Chemical Doping

Low Cost Multifilament Composite Process

Template-Mediated Synthesis of Periodic Membranes for Improved Liquid-Phase Separations

Novel Fiber-Based Adsorbent Technology

Metal-Binding Silica Materials for Wastewater Cleanup

Superhard Nanophase Cutter Materials for Rock Drilling Applications

Evaluation and Constitutive Modeling of Unidirectional SiC/SiC Composites with Engineered SiC Fiber Coatings Subjected to Neutron Irradiation

Innovative Fabrication of SiC/SiC Composites with High Through-the-

Thickness Thermal Conductivity

High Numerical Aperture Scintillating Fibers

Phase II (Second Year)

750,000

720,000

750,000

750,000

750,000

750,000

750,000

750,000

748,520

750,000

743,775

$\$ 2,989,171$

Rotating, In-Plane Magnetization and Magneto-Optic Imaging of Cracks Under Coatings on Ferromagnetic Metals

Development of Laser Materials and Rugged Coatings as Components for Tunable Ultraviolet Laser Systems

Application of Raman Spectroscopy to Identification and Sorting of Post-Consumer Plastics for Recycling

A Sensor for Automated Plastics Sorting

Device or Component Fabrication, Behavior or Testing

Phase I

Hydrocarbon Gas Sensors Based on Wide Band-Gap Semiconductors

Shaft Weld Replacement with a Ceramic Locking Assembly Joint

A Novel Technology for $\mathrm{Si}_{3} \mathrm{~N}_{4}$-To Superalloy Joints With High Use Temperature Capability

Development of Economical Procedures for Producing and Processing Fine Grained SSM Feedstock via Mechanical Stirring

A New Semi-Solid Forming Process For Fabrication of High Volume Fraction (>15 vol\%) Metal/Metal Carbide Nanocomposites

Alternative Metal Forming Using Laser Engineered Net Shaping

Production of High Performance BSCCO-2223 Tapes Using Hydrostatic Pressure

Development of Long-length Fabrication Technology for High $\mathrm{T}_{c}$ Superconductors Operation in High Magnetic Fields at 77K
750,000

739,171

750,000

750,000

$\$ 28,726,575$

$\$ 2,095,557$

74,195

74,986

75,000

72,667

75,000

74,777

75,000

74,999 
OFFICE OF ENERGY RESEARCH (continued)

Office of Computational and Technology Research (continued)

Division of Advanced Energy Projects and Technology Research (continued)

Small Business Innovation Research Program (continued)

Device or Component Fabrication, Behavior or Testing (continued)

Phase I (continued)

Non-Linear Inductor for Power Electronics Protection

75,000

Novel Fabrication of Low Cost Performance Bipolar Plates

75,000

Corrosion Resistant Bipolar Plates for PEM Fuel Cells

74,989

Reduced Part Count Motor Fabrication

Removal of Particulate and $\mathrm{SO}_{x} / \mathrm{NO}_{x}$ Precursors in Integrated Gasification Combined Cycle Systems

Use of Novel, Low-Cost Additives to Improve Sorbent Efficiency for Control of Mercury Emissions in Coal-Fired Power Plant Flue Gases

Mixed Phase Positive Electrodes for Long Life AMTEC Modules

High Brightness LEDs Based on the (Al, Ga, In)N Materials System

Development of High Power RF Windows and Waveguide Components for the Next Linear Collider

Cost Reduction for Production of Superconducting Niobium Cavities

Electrical Discharge Machining Application to the Development of $\mathrm{mm}$-wave Accelerating Structures

Direct Adhesive Technology for Arbitrary Conductors

Controlled Processing for High-Performance Fine Filament Bi-2223 Conductors

Development of a High Field $\mathrm{NbTi}$ Superconductor Using an Approach Combining Artificial Flux Pinning With Conventional Thermomechanical Processing

Conventionally Processed NbTi Superconductors with Artificial Ferromagnetic Pinning Centers for High Magnetic Field (>8 T) Application

Liquid Core Optical Scintillating Fibers

High Performance Heat Pipe Cooling of Electron Cyclotron Heating Mirrors P12-2426

Reaction Bonding of Silicon Carbide Composites for Fusion Applications

Net Shape Gradient W-Cu Plasma Facing Components by Pressure Infiltration

Joining of Silicon Carbide for Fusion Applications

A Novel Divertor Design Based on a Tungsten Wire Brush Tile

Beryllium and Tungsten Brush Armor for Plasma Facing Components

Fabrication for Reliable Tungsten Brush Structures for Fusion Reactor Applications

74,900

75,000

74,996

75,000

75,000

75,000

74,355

74,000

74,839

75,000

74,993

74,997

74,973

74,971

74,945

74,975

75,000

75,000

75,000

75,000

Phase II (First Year)

$\$ 20,090,139$

Catalytic Membrane for High Temperature Hydrogen Separations

750,000

Advanced Coal Based Power System Components Using Reaction Bonded Silicon Carbide

A New Separation and Treatment Method for Soil and Groundwater Restoration

Continuous Analyzer for Monitoring Hydrogen Chloride and Chlorine During Site Cleanup Activity

Long-Life Electrical Neutron Generator

Passive Electronic Components from Nanostructured Materials

A Multicore Optical Fiber Sensor for Mass Transport and Particulates

Infrared Hollow Waveguide Organic Solvent Analyzer 
OFFICE OF ENERGY RESEARCH (continued)

\section{Office of Computational and Technology Research (continued)}

Division of Advanced Energy Projects and Technology Research (continued)

Small Business Innovation Research Program (continued)

Device or Component Fabrication, Behavior or Testing (continued)

Phase II (First Year) (continued)

Stratospheric Water Vapor Microsensor

Compact, Airborne Laser Multigas Sensor

Microwave Radiometer for Passively and Remotely Measuring Atmospheric Water Vapor

Advanced Water Sensor for Unmanned Aerial Vehicles

High-Gain Monocapillary Optics

High Performance X-Ray and Neutron Microfocusing Optics

Very Low Friction Small Radius Domed Cutters for Percussion Drill Bits

Development and Testing of a Jet Assisted Polycrystalline Diamond Drilling Bit

Advanced Low-Stress Bonding of Thermally Stable Polycrystalline Diamond Cutters

to Tungsten Carbide Substrates

Nanocrystalline Superhard, Ductile Ceramic Coatings for Roller Cone Bit Bearings

Solid-State Ultracapacitors for Electric Vehicles and Consumer Electronics

High Surface Area Non-Oxide Ceramic Electrodes for Ultracapacitors

Wrappable Inorganic Electrical Insulators for Superconducting Magnets

Joining of Tungsten Armor Using Functional Gradients

Carbon Thermostructure for Silicon-Based Particle Detectors

High Performance Optical Detectors for Calorimetry

Coplanar CdZnTe p-I-n, Gamma-Ray Detectors for Nuclear Spectroscopy

Large Room Temperature $C d_{1-x} Z n_{x} T_{e}$ Detectors

In-Situ Nondestructive Measurements of Key Mechanical Properties of Reactor Pressure Vessels Using Innovative SSM Technology

Oxidation Induction Time Technology for Electric Cable Condition Monitoring and Life-Assessment

750,000

600,443

738,746

750,000

539,595

517,510

750,000

750,000

749,968

749,707

750,000

750,000

750,000

750,000

750,000

750,000

745,571

750,000

600,000

600,000

Phase II (Second Year)

$\$ 6,540,879$

Advanced High Power Silicon Carbide Internally Cooled X-Ray

Chemical Microsensor Arrays as Integrated Chip Compatible Devices for Chemical Weapons Nonproliferation Inspection

A High Resolution Multi-hit Time to Digital Converter Integrated Circuit

A Helium-Cooled Faraday Shield Using Porous Metal Cooling

Low Cost Fabrication of Large Silicon Carbide/Silicon Carbide Composite Structures

Bandgap-Engineered Thermophotovoltaic Devices for High Efficiency Radioisotope Power

Rugged, Tunable Infrared Laser Sources

An Innovative Membrane and Process for Removal and Recovery of Natural Gas Liquids A Lower Cost Molten Carbonate Matrix

600,787

749,890

695,343

750,000

747,791

750,000

750,000

747,777 
OFFICE OF ENERGY RESEARCH (continued)

FY 1997

Office of Computational and Technology Research (continued)

Division of Advanced Energy Projects and Technology Research (continued)

Small Business Technology Transfer Program

$\$ 4,099,589$

Materials Preparation, Synthesis, Deposition, Growth or Forming

$\$ 2,299,868$

Phase I

$\$ 299,891$

Improved Beta-Alumina Fabrication Using Rapid Plasma Sintering

99,896

New High-Performance GaSb-Based Thermophotovoltaic (TPV) Devices

High Efficiency Magnet Refrigerators as Alternate Environmentally Safe Commercial Refrigeration Devices

Phase II (First Year)

100,000

Cabled Monofilament Subelements for Improved Multifilament Niobium Tin Performance and Reduced Cost

$\$ 499,977$

499,977

Phase II (Second Year)

$\$ 1,500,000$

Laser Processing of Thermal Sprayed Beryllium Plasma Facing Components

Amorphous Silicon/Crystalline Silicon Heterojunctions for Nuclear

Radiation Detector Applications

Low Loss Sapphire Windows for High Power Microwave Transmission

500,000

500,000

500,000

Device or Component Fabrication. Behavior or Testing

$\$ 1,799,721$

Phasel

$\$ 299,761$

Novel Thin Film Scintillator for Intermediate Energy Photons Detection and Imaging

Silicon Carbide Heat Exchanger for Advanced Coal-Based Power Systems

Advanced Ceramic Hot Gas Filters

99,965

100,000

Phase II (First Year)

$\$ 999,960$

High Speed Motor Alternators for Hybrid Electric Vehicle Energy Storage

A Flywheel Motor Alternator for Hybrid Electric Vehicles

499,960

500,000

Phase II (Second Year)

$\$ 500,000$

Environmentally Benign Manufacturing of Compact Disk Stampers

500,000 


\section{OFFICE OF ENERGY RESEARCH (continued)}

FY 1997

Office of Fusion Eneray Sciences

$\$ 11,178,000$

Materials Properties, Behavior, Characterization or Testing

$\$ 11,178,000$

Structural Materials Development

670,000

Modeling Irradiation Effects in Solids

50,000

Fusion Systems Materials

$3,270,000$

Structural Materials for Fusion Systems

Development of Radiation-hardened Ceramic Composites for Fusion Applications

960,000

28,000

Damage Analysis And Fundamental Studies for Fusion Reactor Materials Development

Development of Lithium-bearing Ceramic Materials for Tritium Breeding in Fusion Reactors

150,000

Post-irradiation Examination of Lithium-bearing Ceramic Materials for Tritium Breeding in Fusion Reactors

International Thermonuclear Experimental Reactor (Iter) Materials Development for

Plasma Facing Components

ITER Materials Evaluation

ITER Structural Materials Evaluation

Development of $\mathrm{Nb}_{3} \mathrm{~s}$ S Superconducting Wire for the ITER Magnet Program

Structural Materials Development for the Conduit of ITER Cable-in-Conduit-Conductors

200,000

200,000 


\section{OFFICE OF ENERGY RESEARCH}

The Office of Energy Research (ER) advances the science and technology foundation for the Department and the Nation to achieve efficiency in energy use, diverse and reliable energy sources, a productive and competitive economy, improved health and environmental quality, and a fundamental understanding of matter and energy. The Director of Energy Research is responsible for six major outlay programs: Basic Energy Sciences, Fusion Energy, Health and Environmental Research, High Energy and Nuclear Physics and Computational and Technology Research. The Director also advises the Secretary on DOE physical research programs, university-based education and training activities, grants, and other forms of financial assistance.

The Office of Energy Research conducts materials research in the following offices and divisions:

- Office of Basic Energy Sciences - Division of Engineering and Geosciences; Division of Materials Sciences; and Division of Chemical Sciences

- Office of Computational and Technology Research - Division of Advanced Energy Projects and Technology Research

Office of Health and Environmental Research - Division of Physical and Technology Research

Office of Fusion Energy - Division of Advanced Physics and Technology

Materials research is carried out through the DOE national laboratories, other federal laboratories, and grants to universities and industry.

\section{OFFICE OF BASIC ENERGY SCIENCES}

The Office of Basic Energy Sciences (BES) supports basic research in the natural sciences leading to new and improved energy technologies and to understanding and mitigating the environmental impacts of energy technologies. The BES program is one of the Nation's foremost sponsors of fundamental research in broad areas of materials sciences, chemical sciences, geosciences, biosciences, and engineering sciences. The BES program underpins the DOE missions in energy and the environment, advances energy-related basic science on a broad front, and provides unique national user facilities for the scientific community.

The program supports two distinct but interrelated activities: (1) research operations, primarily at U.S. universities and 11 DOE national laboratories and (2) user-facility operations, design, and construction. Encompassing more than 2,400 researchers in 200 institutions and 17 of the Nation's premier user facilities, the program involves extensive interactions at the interagency, national, and international levels. All research activities supported by BES undergo rigorous peer evaluation through competitive grant proposals, program reviews, and advisory panels. The challenge of the BES program is to simultaneously achieve excellence in basic research with high relevance to the Nation's energy future, while providing strong stewardship of the Nation's research performers and the institutions that house them to ensure stable, essential research communities and premier national user facilities.

\section{DIVISION OF MATERIALS SCIENCES}

The Division of Materials Sciences conducts a broad program of materials research to increase the understanding of phenomena and properties important to materials behavior that will contribute to meeting the needs of present and future energy technologies. The Division supports fundamental research in materials at DOE national laboratories and plans, constructs, and operates national scientific user facilities needed for materials research. In addition, the Division funds over $\mathbf{2 0 0}$ grants, mostly with universities, on a wide range of topics in materials research.

Fundamental materials research is carried out at twelve DOE laboratories: Ames Laboratory at lowa State University, Argonne National Laboratory, Brookhaven National Laboratory, Idaho National Engineering Laboratory, Lawrence Berkeley National Laboratory, Los Alamos National Laboratory, National Renewable Energy Laboratory, Oak Ridge National Laboratory, Pacific Northwest National Laboratory, and Sandia National Laboratories in New Mexico and California, and the Stanford Synchrotron Radiation Laboratory. The laboratories also conduct significant research 
activities fior other DOE programs such as Energy Efficiency, Fossil Energy, Nuclear Energy, Environmental Management and Defense Programs. The Division of Materials Sciences also funds a program consisting of 50 research projects at the University' of Illinois Frederick Seitz Materials Research Laboratory.

The performance parameters, economics, environmental acceptability and safety of all energy generation, conversion, transmission, and conservation technologies are limited by the discovery and optimization of the behavior and performance of materials in these energy technologies. Fundamental materials research seeks to understand the synergistic relationship between the synthesis, processing, structure, properties, behavior, performance of materials of importance to energy technology applications and recycling of materials. Such understanding is necessary in order to develop the cost-effective capability to discover technological and economically desirable new materials and costcompetitive and environmentally acceptable methods for their synthesis, processing, fabrication, quality manufacture and recycling. The materials program supports strategically relevant basic scientific research that is necessary to discover new materials and processes and to eventually find optimal synthesis, processing, fabricating, and manufacturing parameters for materials. Materials Science research enables sustainable development so that economic growth can be achieved while improving environmental quality.

Specific information on the Materials Sciences sub-program is contained in the DOE publication DOEfER-0703 Materials Sciences Programs FY 1996 (published June 1997). This 168-page publication contains program descriptions for 478 research programs that were funded in Fiscal Year 1996 by the Division of Materials Sciences. Five cross-cutting indices identify all 478 programs according to Principal Investigator(s), Materials, Techniques, Phenomena and Environment. Other contents include identification of the Division of Materials Sciences Staff structure and expertise; a bibliographical listing of $\mathbf{4 8}$ scientific workshop, topical, descriptive, Research Assistance Task Force and research facilities reports on select topics that identify materials sciences research needs and opportunities; a descriptive summary of the DOE Center of Excellence for the Synthesis and Processing of Advanced Materials; a descriptive summary and access information on 15 National Research User Facilities including synchrotron light sources, neutron beam sources, electron beam microcharacterization instruments, materials preparation and combustion research; and an analytical summary of research funding levels. Limited copies may be obtained by calling (301) 903-3427 and requesting DOE publication DOE/ER-0703. Project summaries are also available under the Division's home page on the Worldwide Web (uww.er.doe.gov/production/ bes/dms/portfolio.html).

\section{NATIONAL USER FACILITIES UNDER THE OFFICE OF BASIC ENERGY SCIENCES}

Basic Energy Sciences (BES) is responsible for the planning, construction, and operation of many of the Nation's most sophisticated research facilities, including third-generation synchrotron light sources and high-flux neutron sources as well as specialized facilities for microcharacterization, materials synthesis and processing, combustion research, and ion beam studies. These facilities are unmatched in the world in their breadth of capabilities and number of scientific users. BES facilities have enormous impact on science and technology, ranging from the structure of superconductors and biological molecules to the development of wear-resistant prostheses, from atomic-scale characterization of environmental samples to elucidation of geological processes, and from the production of unique isotopes for defense applications and cancer therapy to the development of new medical imaging technologies.

BES research facilities serve over 4,500 researchers from universities, industry, and government laboratories each year. These users conducted forefront research in physics, materials sciences, chemical sciences, earth sciences, structural biology, engineering, medical and other sciences. The costs for the construction and the safe, user-friendly operation of these world class facilities are substantially beyond the capability of individual academic and private industrial research laboratories. They are made available to all qualified users from academia, industry, and both DOE and non-DOE government laboratories, most generally without charge for non-proprietary research that will be published in the open literature.

The research facilities permit the Nation's science and technology enterprise to have access to research instruments that are required for world-competitive forefront research that would not otherwise be possible. Included amongst the numerous honors and distinctions to the research that has been carried out at the BES national user facilities was the 1994 Nobel Prize in Physics, shared by Dr. Clifford G. Shull, who carried out pioneering investigations in neutron scattering at Oak Ridge National Laboratory. All of the BES national user facilities have been constructed within cost, on schedule, and with rigorous compliance to all environmental, safety and health regulations. Further information about the National User Facilities can be found in "Scientific Research Facilities," published by the U.S. Department of Energy; available from the Office of Basic Energy Sciences, (301) 903-3081 


\section{DIVISION OF CHEMICAL SCIENCES}

The Division of Chemical Sciences supports research important to fossil chemistry, combustion, advanced fusion concepts, photoconversion, catalysis, separations chemistry, actinide and lanthanide chemistry, thermophysical properties of complex fluids, nuclear waste processing, and environmental remediation. Research related to materials is carried out in the areas of heterogeneous catalysis, electrochemical energy storage and conversion research and materials precursor chemistry. The operating budget for $F Y 1997$ for materials-related programs was $\$ 5,143,000$ and was allocated to 23 projects in heterogeneous catalysis, electrochemical energy storage and conversion research and materials precursor chemistry.

The program in catalysis emphasizes fundamental chemical, physical, materials and engineering aspects related to catalytic chemistry. Research into fundamental aspects of heterogeneous catalysis overlaps in several areas with complementary efforts in the Division of Materials Sciences. Among these areas are the synthesis of oxides having large surface areas and large pore volumes, but fairly small pores. This includes single and mixed oxides which are either crystalline or amorphous. Another area of overlap is the characterization of thin oxide films on metals. These materials not only have important relationships to industrial catalysts but also are intrinsically interesting and allow the types of detailed studies of ceramic type properties normally associated with single crystals. Structural studies on bimetallic crystals as model catalysts constitutes a second area of overlap. This area is closely tied to alloy physics. Finally, the reactive decomposition chemistry of chlorocarbons on single crystals has a strong relationship to corrosion and lubrication.

The Chemical Engineering Science program supports fundamental research in electrochemical energy storage and conversion focused on the non-automotive consumer market with emphasis on improvements in battery size, weight, life and recharge cycles. Areas of research include materials development and characterization, battery component development and interactions, characterizatioon methodologies and systems development and modeling. Although both primary and secondary battery systems are considered, the greatest emphasis is placed on rechargeable (i.e., secondary) battery systems. The program covers a broad spectrum of research including investigations of lithium cells, metal hydrides, fundamental studies of composite electrode structures, failure and degradation of active electrode materials, thin-film electrodes, electrolytes and interfaces. Characterization and methodologies include problems of electrode morphology, corrosion, separator/electrolyte stability, stable microelectrodes and the transport properties of electrode and electrolyte materials and surface films. Investigations in computational chemistry, modeling and simulations, including property predictions, phenomenological studies of reactions and interactions at critical interfaces, film formation, phase change effects on electrodes and characterization of crystalline and amorphous materials are also of interest.

Chemical Sciences-supported materials precursor chemistry centers on the chemistry of advanced materials precursors, including the synthesis of novel inorganic and organometallic and polymeric structures which could serve as precursors to ceramics and other advanced materials. The research is represented by the following areas: catalysis to link monomeric/polymer building blocks; the mechanisms of oligomerization steps; electronic theories to predict precursors for new ceramics; emerging advanced materials based on complex oxides; single source precursors to multicomponent oxides; the design of materials with tailored properties; and the synthesis and characterization of complex 3-dimensional structures.

The Division of Chemical Sciences manages several large scientific facilities. Four of these are user-oriented: the Combustion Research Facility at Sandia/California, the High Flux Isotope Reactor at Oak Ridge National Laboratory, the Stanford Synchrotron Radiation Laboratory at Stanford University and the National Synchrotron Light Source at Brookhaven National Laboratory. The National Synchrotron Light Source is operated in conjunction with the Division of Materials Sciences.

For information about specific programs the DOE contact is William S. Millman, (301) 903-3285. The reader also is referred to the Worldwide Web for the publication Summaries of FY 1997 Research in the Chemical Sciences ( $u w w . e r . d o e . g o v / p r o d u c t i o n / b e s / c h m h o m e . h t m l$ ) for summaries of all funded programs and descriptions of major user and other special facilities. 


\section{DIVISION OF ENGINEERING AND GEOSCIENCES}

Materials research in the Division of Engineering and Geosciences is sponsored by two different programs as described below.

The BES Engineering Research Program was started in 1979 to help resolve the numerous serious engineering issues impeding efforts to meet U.S. long-term energy needs. The program supports fundamental research on broad, generic topics in energy related engineering-topics not as narrowly scoped as those addressed by the shorter term engineering research projects sponsored by the various DOE technology programs. Special emphasis is placed on projects which, if successfully concluded, will benefit more than one energy technology.

The broad goals of the BES Engineering Research Program are: (1) to extend the body of knowledge underlying the current engineering practice so as to create new options for enhancing energy savings and production, for prolonging useful equipment life, and for reducing costs without degradation of industrial production and performance quality; and (2) to broaden the technical and conceptual base for solving future engineering problems in the energy technologies. The DOE contact for this program is Robert E. Price, (301) 903-5822.

\section{ENGINEERING SCIENCES RESEARCH}

A brief description of Engineering Sciences supported programs: is found in DOE/ER-0704, "Summaries of FY 1996 Engineering Research," which was published in June 1997. Limited copies may be obtained by calling (301) 903-5822.

\section{MATERIALS PREPARATION, SYNTHESIS, DEPOSITION, GROWTH OR FORMING}

\author{
163. FUNDAMENTALS OF THERMAL PLASMA \\ PROCESSING \\ $\$ 478,000$ \\ DOE Contact: Robert E. Price, (301) 903-5822 \\ Idaho National Engineering Laboratory \\ Contact: J. R. Fincke, (208) 526-2031
}

This project is the experimental portion of a coordinated experimental-theoretical research project on thermal plasma processing of materials. This work is primarily focused on the development of advanced diagnostic and computational techniques and their application to obtain a better and more detailed understanding of the fundamerital physical and chemical processes occurring in nonequilibrium thermal plasmas with entrained particles. The techniques thus developed and the information and insights they provide, can then be directly applied to process design, optimization, and scale-up. The diagnostic and computational techniques already developed under this project now represent the state of the art in this area.

During the next five years of this project, we propose to further extend and generalize these techniques to permit their application to several additional topics of timely importance in the thermal plasma processing of materials, namely (1) functionally gradient materials (FGMs), (2) reactive plasma spraying, and (3) plasma chemical synthesis of nanophase materials. These topics share some common features and physics which make it efficient and cost-effective to consider them together. They forma a natural progression and will be pursued sequentially in the above order, but with significant overlap.

\section{Keywords: Plasma Processing, Functionally Gradient Materials}

\section{MULTIVARIABLE CONTROL OF THE GAS- METAL ARC WELDING PROCESS $\$ 153,000$ DOE Contact: Robert E. Price, (301) 903-5822 MIT Contact: David E. Hardt, (617) 253-2429}

Continuing from last year we have been pursuing three related topics: development of a unique high bandwidth are-furnace, development of a "variable footprint" welding torch, and exploration of distributed parameter models, sensors and controllers. These topics are all motivated by the need to have greater control over the spatial distributions, owing to the limitations imposed by a lumped parameter modeling approach. The arc furnace work was completed this year, with demonstration of de-coupled temperature and flowrate control. A U.S. patent has been issued for this furnace concept and the attendant control system.

The work on the variable footprint torch is pursuing a Gas-Modulated Plasma Arc approach. Characteristics of the new hardware include decoupled heat and filler metal delivery, variable heat output distribution and modular construction for multi-functionality. A physically-based model is currently under development as an aid in designing an appropriate controller for the said torch. The model will be tested and verified upon completion of the torch, currently under in-house fabrication. 
In the area of distributed parameter control, we are considering both the basic modeling form along with a multivariable optimal control philosophy. Techniques are being developed for optimally locating and shaping (in space and time) heating/cooling sources (e.g., cooling passages in a mold). The theory for optimal location of measurements has been studied, and simulations and experiments were conducted to study the findings. As an example application, transient temperature control was implemented on a model used by Bethlehem Steel Corporation for a hot slab mill. The techniques being developed are being used as guidelines for developing new actuators (heaters, torches etc.) and sensors for a variety of industrial processes.

Keywords: Gas-Metal Arc, Welding

\section{METAL TRANSFER IN GAS-METAL ARC WELDING $\$ 124,000$ DOE Contact: Robert E. Price, (301) 903-5822 MIT Contacts: T. W. Eagar and J. Lang, (617) 253-3229}

Three projects have been undertaken, all aimed at improved control of the final properties of a weld.

The first project, now completed, was a study to model droplet detachment dynamics. Experimental data was generated using a specially developed GMAW system with laser imaging, high speed video, and electrode vibration mechanics. Simulations based on a lumped parameter model were also conducted and good results with the experiments attained.

The second project is to develop a semi-transferred plasma welding system. This system is presently under construction. It will consist of two independent plasmas. A transferred plasma is used for substrate heating, while a second non-transferred plasma is used to provide a spray coating stream. Each will be independently controlled with a separate power supply.

The third project is to model and predict the physics of the weld pool during GMAW. The first phase of the experimental component of this project has been completed. The theoretical part is currently under way. Present efforts are focused on determining the shape of the free surface of the molten metal and its influence in the fluid flow, and the influence of Marangoni flows due to compositional differences between the impinging droplet and the substrate.

Keywords: Gas-Metal Arc, Welding
166. THERMAL PLASMA CHEMICAL VAPOR DEPOSITION OF ADVANCED MATERIALS $\$ 157,975$ DOE Contact: Robert E. Price, (301) 903-5822 University of Minnesota Contact: J. Heberlein

The objectives of this program include the characterization of plasma reactors used for materials processing in particular for the deposition of diamond films and the generation of ultrafine particles.

For characterizing a particular diamond deposition reactor, a realistic model has been developed for liquid precursor injection into the plasma in front of the substrate. This three-dimensional model is based on a fluid dynamic description of the plasma jet and the injection gas streams, an energy transfer model including evaporation of the droplets, dissociation of the vapors, and recombination reactions according to chemical kinetics. A surface kinetics model describes the diamond film growth. Initial results show reasonable agreement with experiments.

The theoretical description of if reactors for ultrafine powder production has been completed, and temperature and velocity profiles for different reactor configurations and operating conditions provide a basis for future optimal reactor design.

In order to meet needs for spatially and temporally resolved measurements of the characteristics of turbulent plasma jets, a diagnostic capability has been established based on laser scattering techniques. Results of these measurements will be compared with findings obtained at INEL.

For determining transport coefficients of gas mixtures at plasma temperatures, the influence of different interaction potentials during binary collisions has been established and recommendations have been made for potentials providing the most reliable data.

Keywords: Plasma, CVD, Diamond

\section{RESEARCH ON COMBUSTION-DRIVEN HVOF THERMAL SPRAYS $\$ 96,893$ DOE Contact: Robert E. Price, (301) 903-5822 \\ Pennsylvania State University Contact: G. Settles, (814) 863-1504}

The High-Velocity Oxy-Fuel (HVOF) thermal spray process combines the fields of materials, combustion, and gas dynamics. It relies on combustion to melt and propel solid particles at high speeds onto a surface to be coated. The goal of this research is to understand 
and improve the HVOF deposition of corrosion-resistant coatings, which are important in many energy-related industries. This involves both experimentation and modeling.

HVOF spraygun nozzle design and operating parameters have been found with which to vary the kinetic and thermal energies of the spray particles independently. Through metallographic analysis, the resulting coating properties are now being studied. The ability to do this is apparently unique, with results which are expected to be of direct use to HVOF users. For example, it should be possible to tailor coatings to produce clesirable properties such as low porosity, high density, and high corrosion resistance. An early result is that stainless steel particles already molten before impact tend to produce less desirable coatings than solid particles which fuse upon impact due to their kinetic energy.

Results of the research are presented annually at the National Thermal Spray Conference. One Ph.D. has been educated and a second graduate student is currently working on this project.

Keywords: Combustion, Oxy-Fuel

\section{EFFECT OF FORCED AND NATURAL CONVECTION ON SOLIDIFICATION OF BINARY MIXTURES \\ $\$ O$}

DOE Contact: Robert E. Price, (301) 903-5822

Purclue University Contact: F. Incropera, (317) 494-5688

This study deals with the influence of combined convection mechanisms on the solidification of binary systems. A major accomplishment of research performed to date has been the development and numerical solution of a continuum model, which uses a single set of equations to predict transport phenomena in the liquid, "mushy" (two-phase), and solid regions of the mixture. Calculations have been performed for aqueous salt solutions and/or lead/tin alloys involving forced convection, thermo/solutal natural convection, and/or thermo/diffusocapillary convection. The calculations have revealed a wide variety of rich and robust flow conditions, including important physical features of the solidification process which have been observed experimentally but have heretofore eluded prediction. These features include double-diffusive layering in the melt, development of an irregular liquidus front, remelting of solid, development of flow channels in the mushy region, and the establishment of characteristic macrosegregation patterns (regions of significantly different composition) in the final solid. Theoretical and experimental studies have also revealed means by which macrosegregation may be actively suppressed, as, for example, through the application of a magnetic field or intermittent rotation of the mold.

Keywords: Mixture, Convection

MATERIALS PROPERTIES, BEHAVIOR, CHARACTERIZATION OR TESTING

\section{CONTINUUM DAMAGE MECHANICS - CRITICAL STATES \\ $\$ 0$ \\ DOE Contact: Robert E. Price, (301) 903-5822 \\ Arizona State Contact: D. Krajcinovic, \\ (602) 965-8656}

Objective: Primary objective of the current research program is to examine a variety of critical states in mechanical response of brittle and quasi-brittle solids containing a large number of crack-like micro-defects. More specifically, the focus of the ongoing research is placed on the determination of circumstances (type of loading, confinement level, shape and size of the specimen, thermal and environmental conditions, etc.) leading to the onset of critical states defined as a threshold connectivity at which a solid ceases to support external loads.

Technical Approach: Current applied mechanics/ engineering practice in evaluating the mechanical failures of brittle and quasi-brittle solids emphasizes use of effective continuum theories coupled with the deterministic and highly idealized description of the defect geometry (such as doubly periodic arrays of penny-shaped cracks). In contrast, the approach selected in this research program accentuates the stochastic geometry of the microstructural disorder and its effect on the onset of macro-fracture and the type of the failure mode.

One of the important aspects of this research is to explore applicability of the novel methods of statistical physics (percolation theory, models of self-organized criticality, etc.) to micromechanical models. Some of the already obtained results provide connection between the mechanical parameters such as stiffness and damage variable and the percolation theory concepts such as the order parameter, excluded volume, etc. This provides a set of rational criteria for the selection of the universal dimensional invariants needed to describe the onset of a certain class of failures. Secondly, use of the statistical methods (such as fractal and multifractal formalism) provide a superior and size-independent (intrinsic) description of the fluctuations in the stress field (stress concentrations) in the vicinity of the critical states. This aspect alone should provide a definitive answer related to the dependence of the order-disorder 
transition on the microstructuraltexture and/or boundary conditions. In summary, the selected approach provides the best hope of description of the universal aspects of the stochastic nature of the damage and its evolution in the vicinity of the critical state.

Keywords: Continuum Mechanics, Fractals, Brittle Materials

\section{AN INVESTIGATION OF HISTORY-DEPENDENT DAMAGE IN TIME-DEPENDENT FRACTURE MECHANICS \\ $\$ 99,729$ \\ DOE Contact: Robert E. Price, (301) 903-5822 \\ Battelle Memorial Institute Contact: F. Brust, (614) 424-5034}

In order to meet the demand imposed by future technology, new plants with increased energy efficiency must operate at relatively high temperatures.

Additionally, the existing power generation equipment in the United States continues to age and is being used far beyond its intended life. Some recent failures have clearly demonstrated that the current methods for insuring safety and reliability of high temperature equipment is inadequate. Owing to these concerns, a thorough understanding of high temperature failure initiation and propagation in materials exposed to variable mechanical and thermal loading is very important.

In the past, the evolution of damage has been addressed through a macroscopic theoretical model (developed as part of this effort) which attempt to predict the crack growth and failure response of material components exposed to high temperature conditions. However, micro- mechanical processes such as diffusion of atomic flux into grain boundaries, elastic accommodation and creep deformation of the material and grain boundary sliding do contribute significantly to the nucleation and growth of voids leading to failure. Understanding gained by consideration of micromechanics of cavity growth is crucial for developing damage-based constitutive models as well as methodologies for life prediction of structural components. While the application of this understanding in estimating life of structural materials experiencing high temperature creep has met with some success, it is of limited use for structural components experiencing complex load histories under high temperature conditions.

A micro-mechanical model accounting for ratecontrolling microscopic processes has been developed as part of this effort. To date, both sustained and variable load histories have been investigated in two-dimensional geometries. The results illustrate the importance of accounting for nonlinear changes in geometry, grain-boundary diffusion processes, elastic accommodation of the surrounding material as well as more realistic constitutive laws for creep deformation. Current efforts involve investigating different load histories and three-dimensional effects. In addition, the ultimate goal of this effort is to establish a firm connection between the micro- and macro-mechanical models thereby leading to the development of appropriate methodology for life prediction of structural components exposed to high temperature conditions involving complex load histories.

\section{Keywords: Damage, Fracture Mechanics}

\section{INTELLIGENT CONTROL OF THERMAL PROCESSES \\ $\$ 517,000$ \\ DOE Contact: Robert E. Price, (301) 903-5822 \\ Idaho National Engineering Laboratory \\ Contact: J. R. Fincke, (208) 526-2031}

This project addresses intelligent control of thermal processes as applied to gas metal arc welding.

Intelligent control is defined as the combined application of process modeling, sensing, artificial intelligence, and control theory to process control. The intent of intelligent control is to produce a good product without relying on post-process inspection and statistical quality control procedures, by integrating knowledge of process engineering practice and process physics into sensing and control algorithms. The gas metal arc welding process is used as a model system; considerable fundamental information on the process has been developed at INEL and MIT during the past ten years. Research is being conducted on analytical modeling of nonlinear aspects of molten metal droplet formation and transfer, and integration of knowledge-based control methods (including artificial neural networks and fuzzy logic based connectionist systems) with iterative learning control methods. Results are being transferred to industrial partners through a related EE-OTT CRADA on Intelligent Diagnostics, Sensing, and Control of Thin Section Welding.

New work has been started on control methods for distributed thermal processes. The focus of this work is specifically on processes employing one or more point sources of heat and or mass with spatial rastering and temporal modulation of the source(s) to produce a distributed temperature field in a distributed mass. The prototypical process is plasma hearth melting of metals. The initial work is investigating iterative learning control to control the trajectory of a heat source through state 
space (including both the spatial terajectory of the heat source and the thermal parameter trajectory).

This project is part of a collaborative research program with the Massachusetts Institute of Technology.

Keywords: Fuzzy Logic, Neural Networks

\section{ELASTIC-PLASTIC FRACTURE ANALYSIS EMPHASIS ON SURFACE FLAWS $\$ 132,000$ \\ DOE Contact: Robert E. Price, (301) 903-5822 \\ Idaho National Engineering Laboratory Contacts: W. G. Reuter, J. Epstein, W. Lloyd, (205) 526-0111}

The objective is to improve design and analytical techniques for predicting the integrity of flawed structural components. The research is primarily experimental, with analytical evaluations guiding the direction of experimental testing. Tests are being conducted on materials ranging from linear elastic to fully plastic. The latter extends beyond the range of a $\mathrm{J}$-controlled field. Specimens containing surface cracks are used to simulate the fracture process (crack growth initiation, subcritical growth, and catastrophic failure) that may occur in structural components.

\begin{abstract}
Metallography and microtopography techniques have been developed to measure crack tip opening displacernent and crack tip opening angle for comparison with analytical models. Moiré interferometry techniques are used to evaluate and quantify the deformation in the crack region. These studies have resulted in the ability to predict crack growth initiation of specimens containing surface cracks using constraint and fracture toughness data obtained from standard fracture toughness specimens. Results are being transferred to industry in the form of an ASTM Test Standard on Surface Cracked Specimens (Structures) that is presently being developed. Future research will focus on predicting the stable crack growth process in base metal and in weldments.
\end{abstract}

Due to the complexity of studying the fracture process in weldments, diffusion bonded specimens were used initially to simulate a weldment. This provided an opportunity to study the fracture process in a model weldment (two dissimilar materials, e.g., base metal and weld metal) of either a butt weld or a single " $V$ " groove geometry that contained neither a heat affected zone nor residual stresses. This work has been completed and now the focus is on actual weldments of A710 steel. Two weldments have been fabricated with one having matched weld metal and the second an overmatched weld metal. Characterization of the microstructure and of local tensile properties is presently in progress. Testing of fracture toughness specimens, specimens containing surface cracks, and modified specimen geometries is planned for the future.

Keywords: Fracture Mechanics, Welding

\section{NONDESTRUCTIVE EVALUATION OF SUPERCONDUCTORS \\ $\$ 205,000$ \\ DOE Contact: Robert E. Price, (301) 903-5822 \\ Idaho National Engineering Laboratory \\ Contact: K. L. Telschow, (208) 526-1254}

This project is concerned with the development and application of new nondestructive evaluation (NDE) techniques and devices for the characterization of materials, particularly high-temperature superconducting materials in tape form. Microstructural and, particularly, superconducting properties, need to be measured noninvasively and spatially in order to aid the fabrication process.

Two approaches that are both noncontacting and potentially applicable to the industrial environment are being investigated separately and together. One approach uses noncontacting induced current for determination of critical currents on a local scale. This technique can be used alone or in conjunction with external applied fields and DC transport currents to determine spatial variations in critical current density. Its operation is based on inducing the critical state and determining full penetration through the tape with a small probe coil. A new integral equation approach has been found and solved iteratively that determines the flux front profile in geometries with azimuthal symmetry accounting for demagnetization effects. The capability of high temperature SQUID sensors for measurements in long length tapes is being investigated for increased sensitivity and full hysteresis behavior determination. The second approach uses lasers to generate and detect ultrasonic wave modes in tape geometries. Specific elastic wave modes are employed both analytically and experimentally to determine layer thickness, elastic constants and grain orientation. The stability of the critical state to elastic strain is being investigated using both approaches simultaneously in a coupled mode.

Keywords: Nondestructive Evaluation, Superconductors 


\section{ORIGINS OF ASYMMETRIC STRESS-STRAIN RESPONSE IN PHASE TRANSFORMATIONS $\$ 80,535$ \\ DOE Contact: Robert E. Price, (301) 903-5822 \\ University of Illnois Contact: H. Sehitoglu,} (217) $333-4112$

A number of uniaxial and stress state experiments on the NiTi alloys that are known to undergo thermo-elastic phase transformations were conducted. Unlike steels which exhibit virtually no recoverable transformation strains, the transformation strains in this class of materials are partially recovered upon unloading, depending on the applied strain levels. Using a servohydraulic intensifier, a servohydraulic test machine, and a novel pressurized test chamber; pressures of $750 \mathrm{MPa}$ and axial stresses of almost any magnitude are simultaneously generated and applied to the gage section of a solid, cylindrical NiTi specimens. The work utilizes a robust internal load cell that can measure axial forces without the effect of seal friction and demonstrate innovative ways of calibrating this load cell, and methods of axial and circumferential strain measurement in a pressure environment and verify accuracy of these results. Constitutive models proposed in the literature for thermo-elastic transformation were evaluated in light of these results. The current models predict that the volume fraction of martensite is solely dependent on the effective stress. Our experimental results indicate that there is a dependence of the transformations strain on the hydrostatic stress component with strong asymmetry in tension versus compression. In view of these experimental findings, new transformation models are being developed incorporating the low symmetry of the twinning planes. The stress-induced phase transformation of CuZnAl was also found to be stress state dependent but less so than $\mathrm{NiTi}$

Keywords: Alloys, Phase Transformations

\section{MODELING AND ANALYSIS OF SURFACE CRACKS \\ $\$ 192,000$ \\ DOE Contact: Robert E. Price, (301) 903-5822 \\ MIT Contacts: David M. Parks, (617) 253-0033 and F. A. McClintock, (617) 253-2219}

We are developing a mechanics basis for analyzing the fracture behavior of cracks located on or near the fusion zones of structural weldments. Such welds are often characterized by significant strength mismatch between base plate and weld metal, as well as by local strength gradients associated with metallurgical details of the heat-affected zones. Moreover, the local gradients in microstructure, and the accompanying gradients in material resistance to both ductile hole growth and cleavage fracture mechanisms provide additional complexity, compared to the corresponding fracture mechanics models of macroscopically homogeneous crack-tip microstructures and properties.

Under macroscopic mode I loading, strengthmismatched interface crack-tip stress and deformation fields show considerable differences from the corresponding fields in mechanically homogeneous media. In particular, both triaxial stress and plastic strain levels in the softer domain (e.g., an undermatched baseplate) are elevated. Families of mismatched fields have been characterized by finite element and slip-line solutions, and have been shown to apply from small-scale yielding through fully-plastic conditions.

The mismatched fields are being coupled with local models of cleavage and ductile fracture in the inhomogeneous crack-tip region, and the results compared with experiments on both model weldments created by diffusion-bonding and with actual welds in A710 steel.

Keywords: Fracture Mechanics, Welding

\section{DEVELOPMENT OF MEASUREMENT CAPA- BILITIES FOR THE THERMOPHYSICAL PROPERTIES OF ENERGY-RELATED FLUIDS $\$ 425,000$ \\ DOE Contact: Robert E. Price, (301) 903-5822 \\ National Institute of Standard and Technology Contacts: R. Kayser and W. Haynes, (301) $975-2583$}

The major objectives of this new three-year project are to develop state-of-the-art experimental apparatus for measuring the thermophysical properties of a wide range of fluids and fluid mixtures important to the energy, chemical, and energy-related industries. The specific measurement capabilities to be developed are the following: Small-Volume, Dual-Cell Dew-Bubble Point Apparatus; Heat-of-Vaporization Calorimeter and Effusion Cell for Vapor-Pressure Determinations; Solubility Measurements Using Magnetic Levitation; Thermal Diffusivity from Light Scattering; and PhaseEquilibria Apparatus for Azeotropic Aqueous-OrganicSalt Mixtures. These new apparatus will extend significantly the state of the art for properties measurements and make it possible to study a wide range of complex fluid systems (e.g., highly involatile, very insoluble, highly polar, electrically conducting, 
reacting) under conditions which have been previously inaccessible.

Keywords: Thermophysical Properties, Fluids

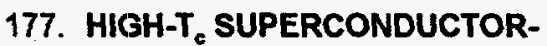
SEMICONDUCTOR INTEGRATION AND CONTACT TECHNOLOGY

$\$ 116,800$

DOE Contact: Robert E. Price, (301) 903-5822

National Institute of Standard and Technology

Contacts: J. Moreland, (303) 497-3641 and

J. W. Elkin, (303) 497-5448

The purpose of this project is to study materials problems faced in integrating high- $T_{c}$ superconductor (HTS) thin-film technology with conventional semiconducting technologies. The emphasis of the research is to investigate HTS-semiconductor contact systems and novel HTS-semiconductor devices. The ultimate goal is to develop HTS thin-film technology to its fullest potential for multi chip module interconnections, future ULSI source and drain connections, and microelectronic microwave filters. These potential applications provide the motivation for a thorough investigation of HTS thinfilm materials development of these hybrid systems. Determining the compatibility of HTS thin-film deposition and patterning processing with that of standard Si processing is crucial for expanding the applications of these hybrid technologies.

The nanostuctural properties of HTS materials have proven to have a principal influence on the electrical properties of HTS materials and devices. For this reason the use of scanned probe microscopies are being emphasized for evaluating HTS-semiconductor epitaxy as well as electrical conduction in interconnects and contacts to hybrid device structures. The further development of scanned probe microscopies, specifically for electronic device imaging will be invaluable not only for the HTS-semiconductor integration studies but for all developments in microelectronics in the foreseeable future. The current emphasis is on developing scanning potentiometry based on atomic force microscopy with resolution and sensitivity levels better than $50 \mathrm{~nm}$ and $1 \mathrm{mV}$, respectively. Also, investigations regarding adapting scanning potentiometry for high frequency applications up to $100 \mathrm{GHz}$ are under way.

Keywords: High $T_{c}$ Superconductors, Contacts
178. THIN FILM CHARACTERIZATION AND FLAW DETECTION

$\$ 0$

DOE Contact: Robert E. Price, (301) 903-5822

Northwestern University Contact:

J. D. Achenbach, (312) $491-5527$

This work is concerned with the determination of the elastic constants of thin films deposited on substrates, with the measurement of residual stresses in such films and with the detection and characterization of defects in thin film substrate configurations.

There are many present and potential applications of configurations consisting of a thin film deposited on a substrate. Thin films that are deposited to improve the hardness and/or the thermal properties of surfaces are of principal interest in this work. Thin film technology does, however, also include high Tc superconductor films, films for magnetic recording, superlattices and films for band-gap engineering and quantum devices. The studies carried out on this project also have relevance to those applications.

Both the film and the substrate are generally anisotropic. A line-focus acoustic microscope, is being used to measure the speed of wave modes in the thin film/substrate system. This microscope has unique advantages for measurements in anisotropic media. Analytical and numerical techniques are employed to extract the desired information on the thin film from the measured data. Recent results include: (1) use of multiple wave modes to determine thin film constants, (2) measurements of superlattice film constants, and (3) investigation of the effect of surface roughness.

$\begin{array}{ll}\text { Keywords: } & \text { Thin Films, Superlattices, Surface } \\ \text { Roughness }\end{array}$

179. TRANSPORT PROPERTIES OF DISORDERED POROUS MEDIA FROM THE MICROSTRUCTURE

$\$ 116,959$

DOE Contact: Robert E. Price, (301) 903-5822

Princeton University Contact: $S$. Torquato, (609) $258-4600$

This research program is concerned with the quantitative relationship between transport properties of a disordered heterogeneous medium that arise in various energy-related problems (e.g., thermal or electrical conductivity, trapping rate, and the fluid permeability) and its microstructure. In particular, we shall focus our attention on studying the effect of: porosity, spatial distribution of the phase elements, interfacial surface statistics, anisotropy, and size distribution of the phase elements, on the effective 
properties of models of both unconsolidated media (e.g., soils and packed beds of discrete particles) and consolidated media (e.g., sandstones and sintered materials).

Both theoretical, computer-simulation, and experimental techniques have been employed to quantitatively characterize the microstructure and compute the transport properties of disordered media. Statistical-mechanical theory has been used to obtain n-point distribution functions and to study percolation phenomena in continuum random-media models. For example, the pore-size distribution, lineal path function, and the chord-length distribution function have been investigated and computed. This has led to accurate predictions of transport properties of realistic models of isotropic as well as anisotropic heterogeneous media. Cross property relations have been derived. Rigorous relations which link the fluid permeability to length scales obtainable from Nuclear Magnetic Resonance experiments and the effective electrical conductivity have been derived. Moreover, the effective conductivity has been related to the effective elastic moduli. Recently, 3-D images of a sandstone have been obtained using $X$-ray tomographic techniques and statistical corrleation funcations have been extracted from them.

Keywords: Porous Media, Transport Properties

180. INELASTIC CONSTITUTIVE EQUATION: DEFORMATION INDUCED ANISTROPY AND THE BEHAVIOR AT HIGH HOMOLOGOUS TEMPERATURE $\$ 149,828$

DOE Contact: Robert E. Price, (301) 903-5822

Rensselaer Polytechnic Institute Contact: Erhard Krempl, (518) 266-6432

Using experimental results obtained with computercontrolled, servohydraulic testing machines, continuum mechanics and materials science as backgrounds, constitutive equations (mathematical models of material deformation behavior that are used in stress and life-time analyses) are being developed with emphasis on two aspects: Deformation induced anisotropy for large deformation on the one hand and high homologous temperature on the other. Both areas extend the modeling capability of the previously developed "unified," state variable viscoplasticity theory based on overstress (VBO).

A mathematical framework and a formulation for the representation of deformation induced anisotropy has been developed and this theory is now being applied to rolling of metals. In this case an isotropic metal can be deformed into metal with elastic and inelastic orthotropy. Simulation of this process is underway.

The small strain version of VBO has been extended to high homologous temperature and applied to Alloy 600 $\mathrm{H}$ at temperatures above 0.7 . The model can simulate the experimentally observed creep and tensile behavior. It is also shown that the transition from the solid to the fluid state can be accomplished easily with VBO. Applications to solder materials for which ambient temperature is a high homologous temperature and an effort to reduce the number of needed constants in the model are underway.

\section{Keywords: Deformation, Viscoplasticity}

\section{STRESS AND STABILITY ANALYSIS OF SURFACE MORPHOLOGY OF ELASTIC AND PIEZOELECTRIC MATERIALS $\$ 137,000$ DOE Contact: Robert E. Price, (301) 903-5822 Stanford University Contacts: H. Gao and D. Barnett, (415) 725-2560}

The objective of this research has been to study morphological stabilities and instabilities in elastic and piezoelectric solid. In morphologies are included surface shapes, cracks, and defect patterns. In this past year the conditions for stability or instability of surfaces and interfaces in piezoelectric materials (including arbitrary elastic and piezoelectric anisotropy) have been developed. ${ }^{1}$ This work has shown that piezoelectric coupling may tend to either stabilize or destabilize an initial flat boundary or interface. A destabilized surface evolves toward the formation of crack-like flaw. This study suggests that piezoelectric coupling could be utilized to control diffusive initiation of surface defects. A portion of future work will be directed toward corroborating theory with experiments and identifying whether more sophisticated theoretical models for defect generation need to be explored. Another direction which this research has taken is the study of fracture in piezoelectric solids. A strip saturation model and the concept of multiscale energy release rates have been

${ }^{1}$ N. Y. Chien, H. Gao, G. Herrmann, and D. M. Barnett, "Diffusive Surface Instabilities Induced by Electromechanical Loading," Proceedings of the Royal Society, London, A452, pp. 527-541 (1995). 
introduce $d^{1,2}$ to explain some existing experimental observations of the behavior of cracks in piezoelectric ceramics. Extensions of this work are underway.

Patterns of equilibrium 2-dimensional arrangements of large numbers of dislocations have been computed by using numerical methods to minimize the potential energy of the dislocation distributions. Efficiency of computation has been greatly enhanced by studying doubly periodic arrangements of dislocation cells for which some analytic reduction is possible. It has been found that many possible equilibrium patterns exist under zero applied stress, i.e., nearby equilibrium arrangements are always available. A study of the stabilty of these arrays under application of applied stresses is now underway.

Keywords: Surfaces, Interfaces, Stress Analysis, Piezoelectrics

182. OPTICAL TECHNIQUES FOR CHARACTERIZATION OF HIGH TEMPERATURE SUIPERCONDUCTORS

$\$ 231,000$

DOE Contact: Robert E. Price, (301) 903-5822

Stanford University: G. S. Kino,

(415) 497-0205

Photothermal techniques are used to measure the normal carrier density below the transition temperature $T_{c}$ in high-temperature superconductors, to study the nature of the phase transition, and to measure the homogeneity and quality of these materials. $A$ modulated focused laser beam incident on the sample varies its temperature periodically, and a second probe beam a few microns away measures the differential reflectivity associated with the thermal wave propagating along the sample. Changes in critical temperature in regions less than $100 \mu \mathrm{m}$ apart have been measured, and the difference in quality of different samples can clearly be seen. Measurement of thermal diffusivity in single-YBCO crystals yields good estimates of the variation of normal electron density with temperature. Observations of small changes in the phase variation yield the transition temperature of the material. Polarized light obsenvations of single-crystal

'H. Gao, T.-Y. Zhang, and P. Tong, "Local and Global Eriergy Release Rates for an Electrically Yielded Crack in Piezoelectric Ceramics," Journal of the Mechanics and Physics of Solids (in review).

${ }^{2} \mathrm{H}$. Gaio and D. M. Barnett, "An Invariance Property of Local Energy Release Rates in a Strip Saturation Model of Piezoelectric Fracture," International Journal of Fracture (in review).
YBCO near the transition point yield curves as a function of temperature with shapes that are very different, depending on the polarization of the probe beam relative to the $A$ and $B$ directions. Twinned samples do not show this anisotropy. The shape and sign of these curves also appears to provide a very sensitive measurement of the state of doping of the material. By measuring the modulated signals at the second harmonic of the input signal, the temperature modulation of the sample by the laser beam can be determined. During the last year the system has been rebuilt to give more accurate results, to work at lower temperatures so that we can make measurements of normal superconductors and compare with theory, and to make more rapid measurements of the quality of thin film superconductors.

Keywords: High $T_{c}$ Superconductors, Thin Films

\section{3-D EXPERIMENTAL FRACTURE ANALYSIS AT HIGH TEMPERATURES \\ $\$ 76,721$ \\ DOE Contact: Robert E. Price, (301) 903-5822}

University of Washington Contact:

Albert Kobayashi, (206) 543-5488

The objective of this three year project is to assess experimentally, the validity of $T^{\star}$ integral and its applicability to quasi-static and dynamic ductile fracture. Early in the second year, a protocol for extracting the $T^{*}$ integral values from the surface displacement fields obtained by moiré interferometry was established. The procedure consists of numerically evaluating the integral along a partial contour, a small distance, $\varepsilon$, in front of the crack tip, In order to assure a state of plane stress, $\epsilon$ is equated to one plate thickness and the resultant $T^{*}$ is designated $T^{*}{ }_{e}$. The procedure was verified through numerical experiments conducted at the Georgia Institute of Technology (GIT) under a parallel DOE grant.

The established procedure was used to determine $T^{*}{ }_{e}$ 's of A606 HSLA steel, single-edge notched (SEN) specimens with small stable crack growth, $\approx 2 \mathrm{~mm}$, and 2024-T3 aluminum, compact (CT) of large crack growth, $\approx 8 \mathrm{~mm}$. Parallel numerical analysis of these two sets of experiments were conducted at GIT where the experimentally and numerically determined $T^{*}{ }_{e}$ were found to be in excellent agreement. $T^{*}$, of the $A 606$ HSLA SEN specimen continued to increase with stable crack growth, possibly due to the lack of constraint in the SEN specimen. $T^{*}{ }_{c}$ of the 2024-T3 CT specimen reached a steady state value of $\approx 140 \mathrm{MPa}-\mathrm{mm}$. The CT specimen results suggest that $T^{*}{ }_{\mathrm{e}}$ could be a viable fracture parameter which controls stable crack growth. The crack tip opening angles (CTOA) for the two materials immediately reached steady state values with 
crack growth. However, results from a FAA funded study showed that CTOA is insensitive to the inherent decrease in ductility due to increased thickness and therefore may not be a proper fracture parameter.

Keywords: Fracture Mechanics, Crack Growth

\section{SIMULATION AND ANALYSIS OF DYNAMIC FAILURE OF DUCTILE MATERIALS $\$ 99,410$ \\ DOE Contact: Robert E. Price, (301) 903-5822 \\ Brown University Contact: B. Freund,} (401) 863-1157

A central goal in the mechanics of materials is the determination of parameters which characterize macroscopic failure of materials in terms quantifiable characteristics of their microstructure. The motivation is to establish which characteristics account for macroscopic failure, with a view toward improvement of failure resistance through material selection or microstructural design. in the present project, emphasis is on the behavior of ductile structural alloys under high rate loading conditions. Thus, the dominant mechanism of plastic deformation is crystallographic slip and material strength degrades through nucleation, growth and coalescence of micro-voids. Plastic strains in such processes can be large and strain localization is common. The approach is to adapt methodologies for analysis of elastic-viscoplastic systems to problems selected on the basis of their relevance to safety of pressure vessel and piping systems, to materials processing and metal forming technologies, and to structural reliability under dynamic loading. Initial emphasis has been on failure of an explosively loaded ring expanding under plane strain conditions, a configuration which has been studied experimentally. Calculations reveal that strain localization sites, or necks, are more pervasive under rapid loading, and the spacing of necks decreases with increase in loading rate. The influence of inertia on bifurcation of deformation states is also being investigated theoretically. The project is being carried out in collaboration with colleagues involved in experimental research on dynamic ductile failure at the California Institute of Technology.

Keywords: Dynamic Failure, Ductile Materials

\section{DEVICE OR COMPONENT FABRICATION, BEHAVIOR OR TESTING}

\section{AN ANALYTICAL-NUMERICAL ALTERNATING METHOD FOR 3-D INELASTIC FRACTURE AND INTEGRITY ANALYSIS OF PRESSURE- VESSELS AND PIPING AT ELEVATED TEMPERATURES \\ $\$ 85,000$ \\ DOE Contact: Robert E. Price, (301) 903-5822 \\ Georgia Institute of Technology Contact: S. Atluri, (404) 894-2758}

Current and future power generation plants require efficient operation so that energy savings may be realized. In addition, power generation equipment in the US continues to age, creating operational dangers for the working staff as well as greater potential for power outages. Current methods to ensure safe operation of these plant components which operate in the nonlinear material regime are simplistic, and hence, not very reliable. This program is developing advanced analytical tools which can be used to reliably assure safety of future plants as well as aging plants. The finite element alternating method is the state-of-the-art methodology for determining stress intensity factors for two and three dimensional crack growth problems. This method has permitted accurate and simple analyses of linear fracture problems to be made so that sophisticated reliability assessments of operating equipment may be made. This program has extended the finite element alternating method so that it may now be used in the nonlinear regime, i.e., the non-linear finite element alternating method. With this new methodology, sophisticated damage and fracture assessments can be made for components which experience failures in the elastic-plastic and high temperature creep regime. This is truly a revolutionary advance to the fracture assessment field.

Currently, sophisticated fracture assessments are being made using advanced fracture theories such as the T*integral which were previously unattainable. The methods are being verified by comparison of predictions to experimental results. It is anticipated that these advances will permit the designer to make sophisticated fracture assessments in the future with a minimum of effort.

Keywords: Fracture, Pressure Vessels, Piping 


\section{PULSE PROPAGATION IN INHOMOGENEOUS OPTICAL WAVEGUIDES $\$ 200,493$ \\ DOE Contact: Robert E. Price, (301) 903-5822 \\ University of Maryland Contact: C. Menyuk,} (301) 455-3501

We are presently working on two principal projects. First, we are studying randomly varying birefringence in optical fibers and its impact on both soliton and NRZ communications. We have derived a set of equations (modified Manakov equations) that allow us to simulate the propagation through a fiber with rapidly and randomly varying birefringence on the much longer length scale on which the signals varying due to chromatic dispersion, polarization mode dispersion, and nonlinearity. These equations also yield considerable physical insight into the behavior of these systems. We have benchmarked these codes carefully, and we have demonstrated that they yield the same results as computer codes that use far shorter step sizes and are far less efficient. In addition to Monte Carlo methods, we are now using analytical methods based on the theory of stochastic differential equations to completely characterize the probability distribution functions for the evolution of the signal's state of polarization and the corresponding terms in the modified Manakov equation that describes the complete evolution.

The second project is quasi-phase-matched waveguides. We are using a Green's function approach to determine the rate at which radiation leaks from the quasi-phase-matched guides. In the future we will look at oblique guides and guides with other unusual cross-sections that appear in the experiments to reduce unwanted Bragg reflections.

Keywords: Optical Waveguides, Monte Carlo

\section{FLUX FLOW, PINNING AND RESISTIVE BEIHAVIOR IN SUPERCONDUCTING NETWORKS}

$\$ 71,930$

DOE Contact: Robert E. Price, (301) 903-5822

University of Rochester Contact: $S$. Teitel, (716) 275-4039

The fluctuation of vortices and vortex lines has been shown to be a major source of electrical resistance for superconducting networks when placed in magnetic fields. Systems of particular interest include the new high temperature type II superconductors, and periodic arrays of Josephson junctions. Numerical simulations are being carried out to identify and characterize the nature of the various vortex structures present in such systems, as a function of temperature and applied magnetic field, and to understand the nature of the phase transitions between them.

Particular attention has recently been given to studying the equilibrium fluctuation of vortex lines in models of bulk high temperature superconductors.

Simulations have shown that there can be two distinct phase transitions describing the superconducting ordering parallel versus perpendicular to the applied magnetic field. The loss of order in the perpendicular direction has been associated with a melting of the ground state vortex line lattice. The loss of order in the parallel direction has been associated with the onset of a vortex line tangle percolating throughout the entire system. New simulations, relaxing earlier approximations, are being carried out to clarify this issue. The effect of applied currents and random vortex pinning sites will be added in future work. The dynamic behavior of vortices in two dimensional Josephson arrays has also recently been investigated using a detailed finite size analysis to verify proposed scaling equations.

This research will greatly enhance the fundamental understanding of behavior in strongly fluctuating superconducting materials. The results will have impact in understanding the magnetic properties of the new high temperature superconductors, and in the design of Josephson junction arrays for use as microwave detectors and generators.

Keywords: Superconductors, Flux Flow, Josephson Junctions

\section{GEOSCIENCES RESEARCH}

The BES Geosciences Research Program supports research that is fundamental in nature and of long-term relevance to one or more energy technologies, national security, energy conservation, or the safety objectives of the Department of Energy. It is also concerned with the extraction and utilization of such resources in an environmentally acceptable way. The purpose of this program is to develop geoscience or geosciencesrelated information in support of one or more of these Department of Energy objectives or to develop the broad, basic understanding of geologic materials and processes necessary for the attainment of long-term Department of Energy goals. In general, individual research efforts supported by this program involve elements relevant to several different energy objectives. The DOE contact for this Program is Paula M. Davidson, (301)903-5822. 
MATERIALS PREPARATION, SYNTHESIS, DEPOSITION, GROWTH OR FORMING

\section{AN INVESTIGATION OF ORGANIC ANION-MINERAL SURFACE INTERACTIONS DURING DIAGENESIS $\$ 200,000$ \\ DOE Contact: P.M. Davidson, (301) 903-5822 \\ SNL Contact: Patrick Brady, (505) 844-7216 and Randall Cygan}

The research is to investigate adsorption of anionic carboxylate and phenolate groups onto aluminosilicate surfaces in order to evaluate the role of organic acids as (1) catalysts for mineral dissolution and porosity evolution in deep basins, and (2) controlling agents of coupled dissolution and growth of during diagenesis. Combined experimental and theoretical approaches are used to investigate the mechanisms and reaction rates of organic anion adsorption. T-dependent adsorption of oxalate, acetate, salicylate and benzoate anions onto selected aluminosilicate surfaces are being measured, as are dissolution rates of alumina (as corundum), tremolite, albite, kaolinite and precipitation rates of kaolinite, in solutions containing various organic acids at temperatures of $30-90^{\circ} \mathrm{C}$. Theoretical investigations are testing mechanistic connections between metal-anion complexation, anion adsorption, and mineral growth with the new experimental data. The influence of surface-site chemistry and bonding are being investigated, in an attempt to establish general crystal-chemical rules for predicting the extent of organically-controlled reactions during diagenesis.

Keywords: Surface reactions, Aluminosilicate Minerals, Adsorption Mechanisms

\section{SOLUTION-REPRECIPITATION OF CALCITE AND PARTITIONING OF DIVALENT METALS $\$ 129,999$ \\ DOE Contact: P. M. Davidson, (301) 903-5822 \\ University of Chicago Contact: Frank M. Richter, (773) $702-8118$}

The proposed research is to investigate the exchange of metals (principally $\mathrm{Sr}$ and $\mathrm{Cd}$ ) between $\mathrm{CaCO}_{3}$ and fluids, at a fundamental level necessary for basing thermodynamic and kinetic treatments of dissolution/ reprecipitation. The proposed measurements of precipitation rates and exchange of $\mathrm{Sr}$ and $\mathrm{Cd}$ with calcite solid-solutions will serve as the basis for developing a more general treatment of governing mechanisms and kinetics of dispersion of tracers and contaminants uptake/release in calcites, the predominant constituents of limestones. Laboratory. measurements of exchange rates are to be complemented with analyses of the record of calcite- fluid exchange obtained from natural samples, in order to help determine a mechanistic understanding of the exchange rates over both short and longer time periods accessible in the sedimentary record.

Keywords: Carbonate Minerals, Dissolution and Precipitation Mechanisms

190. TRANSITION METAL CATALYSIS IN THE GENERATION OF PETROLEUM AND NATURAL GAS

$\$ 109,313$

DOE Contact: P. M. Davidson, (301) 903-5822

Rice University Contact: Frank D. Mango, (713) $527-4880$

Light hydrocarbons in petroleum, including natural gas $\left(C_{1}-C_{4}\right)$, are conventionally viewed as products of progressive thermal breakdown of kerogen and oil. Alternatively, transition metals, activated under the reducing conditions of diagenesis, can be proposed as catalysts in the generation of light hydrocarbons. Transition metal-rich kerogeneous sedimentary rocks were reacted under reducing conditions at temperatures for which the substrates alone, $\mathrm{N}$-octadecene + hydrogen, are stable indefinitely. Catalytic activity was measured to be on the order of $10^{-7} \mathrm{~g} \mathrm{CH}_{4} / \mathrm{d} / \mathrm{g}$ kerogen, suggesting robust catalytic activity over geologic time at moderate sedimentary temperatures.

Keywords: Transition Metals, Catalysis, Petroleum

191. MINERAL DISSOLUTION AND PRECIPITATION KINETICS: A COMBINED ATOMIC-SCALE AND MACRO-SCALE INVESTIGATION

$\$ 181,477$

DOE Contact: P. M. Davidson, (301) 903-5822

University of Wyoming Contact:

Carrick M. Eggleston, (307) 766-6769

Lawrence Livermore National Laboratory

Contact: Kevin G. Knauss, (510) 422-1372

The project combines atomic-scale and macroscale approaches for investigating mineral-fluid interactions, in order to provide improved understanding of mineral dissolution and precipitation processes. With the development of a high temperature flow-through atomic force microscope (AFM), atomic-scale kinetic experiments will be possible under geologically relevant conditions for important oxide and aluminosilicate minerals. Macroscopic measurements of dissolution/ precipitation rates, activation energies, and rates of step motion across surfaces, performed under identical conditions, will provide the basis for addressing open questions concerning the macroscopic rate laws and microscopic and interpretations, in terms of dissolution 
and precipitation mechanisms, and nature of the reactive interface.

Keywords: Atomic Force Microscopy, Silicate Minerals, Dissolution and Precipitation Mechanisms

\section{MATERIALS STRUCTURE AND COMPOSITION}

\section{REACTION MECHANISMS OF CLAY} MINERALS AND ORGANIC DIAGENESIS: AN HRTEM/AEM STUDY

$\$ 139,065$

DOE: Contact: P. M. Davidson, (301) 903-5822

Arizona State University Contact: P. R. Buseck (602) $965-3945$

The research is to investigate the structures of fine-scale diagenetic material using high-resolution transmission electron microscopylanalytical electron microprobe (HRTEMAEM) techniques which will facilitate in situ identification and evaluation of reaction mechanisms. As a basis for kinetic models this information is used to predict basinal diagenetic patterns for resource exploration. Structural analyses of intergrown product and reactant from three principal diagenetic reactions operative in the formation of hydrocarbon reservoirs are proposed: (1) berthierine to chamosite $(2)$ smectite to illite, and (3) maturation of kerogen to form oil and gas.

Keywords: Diagenetic Reactions, High-Resolution Transmission Electron Microscopy, Kerogen, Smectite, llite, Berthierine, Chamosite

\section{INFRARED SPECTROSCOPY AND HYDROGEN ISOTOPE GEOCHEMISTRY OF HYDROUS SILICATE GLASSES \\ $\$ 141,634$ \\ DOE Contact: P. M. Davidson, (301) 903-5822 \\ Caltech Contacts: S. Epstein, (818) 356-6100 \\ and E. Stolper, (818) 356-6504}

The focus of this project is the combined application of infrared (IR) spectroscopy and stable isotope geochemistry to the study of dissolved components in silicate melts and glasses. Different species of dissolved water and carbon dioxide (e.g., molecules of $\mathrm{H}_{2} \mathrm{O}$ and hydroxyl groups, molecules of $\mathrm{CO}_{2}$ and carbonate ion complexes) have been analysed to understand volatile transfer reactions in liquids and glasses. The partitioning of $\mathrm{H}$ isotopes between vapor and hydroxyl groups and molecisles of $\mathrm{H}_{2} \mathrm{O}$ dissolved in thyolitic melts was measured. Concentrations of $\mathrm{H}_{2} \mathrm{O}$ and $\mathrm{CO}_{2}$ in volcanic glasses and $\mathrm{CO}_{2}$ in rhyolitic liquid were measured at pressures up to 1500 bars. The fractionation of $O$ iso- topes between $\mathrm{CO}_{2}$ vapor and rhyolitic glass and melt was measured. The kinetics of $\mathrm{OH}$-forming reactions in silicate glasses were studied. Diffusion of water in basaltic melts and of water and $\mathrm{CO}_{2}$ in rhyolitic glasses and melts was studied. Results were used to understand oxygen "self-diffusion" in silicate minerals and glasses and enhanced oxygen diffusion under hydrothermal conditions.

Keywords: Infrared Spectroscopy, Silicate Minerals, Glasses, Silicate Liquids, Speciation

194. BIOMINERALIZATION: SYSTEMATICS OF ORGANIC-DIRECTED CONTROLS ON CARBONATE GROWTH MORPHOLOGIES AND KINETICS DETERMINED BY in situ ATOMIC FORCE MICROSCOPY $\$ 38,559$

DOE Contact: P. M. Davidson, (301) 903-5822

Georgia Inst. Of Technology Contact: P. Dove, (404) 894-6043

The research is to investigate biomineralization mechanisms of dissolution and precipitation reactions of the two common calcium carbonate polymorphs, calcite and (metastable) aragonite. Experiments have been undertaken to monitor surface reaction morphology and kinetics in the presence of isolated simple acidic and basic amino acids, that are candidates for directing growth in natural systems. In order to characterize dynamic nanoscale growth morphologies and mechanisms, atomic force microscopy (AFM) observations have been made under in aquo conditions. The combination of proposed mechanism and rate determinations are important for understanding and predicting controls by organic molecules on natural precipitation and dissolution of calcite and aragonite, and provide new constraints on models of bonding and reactivity at the nanoscale in organized structures.

Keywords: Biomineralization, Calcium Carbonate, Atomic Force Microscopy, Surface Reactions

\section{REACTIONS AND TRANSPORT OF TOXIC METALS IN ROCK-FORMING SILICATES AT $25^{\circ} \mathrm{C}$ \\ $\$ 200,000$ \\ DOE Contact: P. M. Davidson, (301) 903-5822 \\ Johns Hopkins University Contact: D. R. Veblen, (410) 516-8487 \\ Lehigh University Contact: E. IIton, (610) 758-5834}

Heterogeneous electron-cation transfer reactions between aqueous metals and silicates can be 
responsible for the retention or mobilization of multivalent cations in the near-surface environment. Reaction mechanisms are investigate as a basis for models of aqueous metal-mineral transport processes applicable to a wide range of problems, from toxic metal migration in aquifers to scavenging of heavy metals from solutions. Specific reactions to be investigated are aqueous $\mathrm{Cr}(\mathrm{III}), \mathrm{Cr}(\mathrm{VI}), \mathrm{Cd}(\mathrm{II}), \mathrm{Se}(\mathrm{VI}), \mathrm{Co}(\mathrm{II})$ solutions with specified surfaces of representative phyllosilicates biotite, and chain silicates pyroxene and amphiboles. As an outgrowth of this investigation, a widely applicable analytic tool is to be developed for measuring Fe(II)/Fe(III) concentrations of small areas (approximately $25 \times 50$ microns) of silicates in thin sections with X-ray photoelectron spectroscopy (XPS).

Keywords: Surface Reactions, High-Resolution Transmission Electron Microscopy, Phyllosilicates, Chain Silicates

196. THE CRYSTAL CHEMISTRY AND STRUCTURAL ANALYSIS OF URANIUM OXIDE HYDRATES

$\$ 0$

DOE Contact: P. M. Davidson, (301) 903-5822

University of New Mexico Contacts: D. Miller and R.C. Ewing, (505) 277-4163

Systematic crystal chemical relationships among uranium oxide hydroxide phases which are initial corrosion products of uraninite ore and spent nuclear fuel, are investigated to help constrain systematic models for crystal structure topologies. Current work involves the determination of crystal structures for identified key missing phases, such as ianthinite and schoepite, which contain oxidized $U^{6}+$ and are among corrosion products of $\mathrm{UO}_{2}$ in near-surface, oxidizing environments. Research objectives are to use the new data on structural topologies to interpret and predict speciation and thermodynamic stability relations among uranium oxide hydrates.

Keywords: Uranium Oxide Hydrates, Crystal Chemistry Structural Topology
MATERIALS PROPERTIES, BEHAVIOR, CHARACTERIZATION OR TESTING

\author{
197. OXYGEN AND CATION DIFFUSION IN OXIDE \\ MATERIALS \\ $\$ 180,000$ \\ DOE Contact: P. M. Davidson,(301) 903-5822 \\ LLNL Contact: F. J. Ryerson, (510) 422-6170 \\ University of California at Los Angeles \\ Contact: K. D. McKeegan
}

The objective of this work is to measure the diffusion parameters for various cations and oxygen in important rock-forming minerals to constrain both geochemical transport processes and diffusive mechanisms affecting physical properties such as creep and electrical conductivity. Oxygen self-diffusion coefficients have been measured for three natural clinopyroxenes, a natural anorthite, a synthetic magnesium aluminate spinel, and a synthetic akermanite over oxygen fugacities ranging from the $\mathrm{Ni}-\mathrm{NiO}$ to $\mathrm{Fe}-\mathrm{FeO}$ buffers. The oxygen self-diffusion coefficients of the three clinopyroxenes are indistinguishable. At a given temperature, oxygen diffuses about 100 times more slowly in diopside than indicated by previous bulkexchange experiments. New data for anorthite, spinel, and akermanite agree well with prior results obtained by gas-solid exchange and depth profiling methods at different oxygen fugacities, indicating that diffusion of oxygen in these nominally iron-free minerals is not greatly affected by $\mathrm{fO}_{2}$

Keywords: Diffusion, Minerals, Plastic Deformation

198. STRUCTURE AND REACTIVITY OF FERRIC OXIDE AND OXYHYDROXIDE SURFACES: QUANTUM CHEMISTRY AND MOLECULAR DYNAMICS

$\$ 200,000$

DOE Contact: P. M. Davidson, (301) 903-5822

PNL Contacts: Jim Rustad and Andrew Felmy, (509) 376-1134

The research is a theoretical investigation of the surface structure and reactivity of proton binding sites of ferric oxides and hydroxides. The surfaces of these common minerals are known to bind metals, oxy-anions, and organic chelates through mechanisms that are as yet poorly understood. The approach combines crystalline Hartree-Fock calculations for the ferric (hydr)oxides with a molecular dynamics (MD) model for water currently being developed by in collaboration with J. W. Halley of the University of Minnesota, in order to evaluate:

(1) structures and relative stabilities of various ferric (hydr)oxide surfaces; (2) the most reactive sites for proton adsorption, indicated by relative proton affinities 
in vacuo; (3) solvation corrections to relative surface energies and relative proton binding energies; (4) improvements in thermodynamic models of proton adsorption resulting from better predictions of surface structure, site types, and proton binding energies.

Keywords: Proton Adsorption, Surface Structure, Surface Reactivity, Ferric Oxides, Ferric Hydroxides

199. CATION DIFFUSION RATES IN SELECTED MINERALS

$\$ 150,000$

DOE Contact: P. M. Davidson, (301) 903-5822

Sanclia National Laboratory Contacts:

Riandall T. Cygan, H. R. Westrich and Diana Fisler, (505) 844-7216

Objectives of this research are to determine experimental cation diffusion coefficients for pyroxene and carbonate minerals at temperatures less than $1000^{\circ} \mathrm{C}$ for evaluating disequilibrium behavior in geological, nuclear waste, energy, and materials applications. A new thin-film technique for preparation of diffusion couples was used to measure the relative slow diffusion of $\mathrm{Mg}^{2+}, \mathrm{Mn}^{2+}$, and $\mathrm{Ca}^{2+}$ in pyroxenes and carbonates. Depth profiles of tracer isotopes are then evaluated using an ion microprobe. Comparison of the diffusion coefficients determined under various oxygen fugacities provides information about the diffusion mechanism and the defect structure of the mineral sample. The experimental work has been complemented by atomistic simulations of calcium self-diffusion in calcite. Lattice energy, defect formation energies, and activation energy for a cation vacancy migration have been calculated, providing the mechanism and favored direction of migration of cations in the calcite structure. Results suggest that relaxation of atomic sites in the vicinity of a cation vacancy is a significant contribution to the energy for the migration of cations.

Keywords: Cation Diffusion, Pyroxenes, Silicate Minerals, Carbonate Minerals, Diffusion Mechanism, Defect Structure

200. GRAIN BOUNDARY TRANSPORT AND RELATED PROCESSES IN NATURAL FINEGRAINED AGGREGATES

\$O

DOE Contact: P. M. Davidson, (301) 903-5822

Brown University Contacts: R.A. Yund, (401) 863-1931 and J.R. Farver

The objective of this study is the direct measure of diffusional transport rates in rocks and how the rates vary with mineralogy and microstructure, as well as temperature and pressure. The results provide much needed data on the nature of grain boundaries in rocks and the rate of transport of chemical components through rocks. Grain boundary diffusion of oxygen and cations in monominerallic aggregates of feldspar and of calcite, and aggregates of feldspar plus quartz were determined with the ion microprobe (SIMS). Calcium grain boundary diffusion rates in Ca-rich feldspar aggregates are several orders of magnitude slower than oxygen, and than potassium in K-rich feldspar. This suggests that differences in size and formal charge of chemical species may play an important role in their relative grain boundary diffusion rates. TEM analysis of microstructures suggests that the equilibrium distribution of water in feldspar aggregates is that of isolated pockets. Studies continue in order to evaluate the role of pressure and nonhydrostatic stresses on fluid-feldspar interfacial energies and microstructures.

Keywords: Diffusion, Rocks, Quartz, Feldspar,
Microstructures

\section{THERMODYNAMICS OF MINERALS STABLE NEAR THE EARTH'S SURFACE $\$ 150,000$ \\ DOE Contact: P. M. Davidson, (301) 903-5822 \\ UC Davis contact: A. Navrotsky, (916) 752-9307}

The objective of this research is to determine the enthalpies of formation of hydrous minerals and carbonates using high temperature solution calorimetry. Systematics in energetics of ionic substitutions are sought in order to predict the thermodynamics of complex multicomponent minerals. Mixing properties of mica, amphibole, clay, zeolite, and carbonate solid solutions are also analyzed. New calorimetric measurements confirm significant differences in enthalpy between the ordered and disordered carbonate solution series. Investigation of the energetics of ion exchange and hydration in zeolites is continuing, building on this group's recently published solution enthalpies of a suite of Ca-zeolites and their ion-exchanged forms. Using drop solution calorimetry; the study of energetics of polytypism of the kaolin minerals has been extended to several differently crystallized kaolinites and the minerals nacrite and halloysite. Enthalpies of formation in the illite/smectite system have been measured for the first time, providing good coverage of sedimentary sequences with different proportions of mixed layer compounds. Measurements on natural illite/smectite samples will be complemented with thermochemical measurements on selected synthetic compositional series to address the effects of various levels of 
impurities, and should provide constraints on the energetics of diagenetic processes.

Keywords: Thermochemistry, Solution Calorimetry, Zeolites, Carbonate Minerals, Clay Minerals

\section{NEW METHOD FOR DETERMINING THERMODYNAMIC PROPERTIES OF CARBONATE SOLID-SOLUTION MINERALS $\$ 133,661$ \\ DOE Contact: P.M. Davidson, (301) 803-5822 \\ UC Davis Contacts: P.A. Rock and W.E. Casey, (916) $752-0940$}

Incorporation of metals into calcium carbonate minerals is an important pathway for elimination of potentially toxic metals from natural waters. The thermodynamic properties of the resulting solution are, however, poorly known because of difficulties with the solubility measurements. This project uses a new method of measurement which avoids some of these difficulties. The new method is an electrochemical double cell including carbonates and no liquid junction. The cell is an advance over conventional techniques because: (1) reversibility can be directly established; (2) models of solute speciation are not required; $(3)$ the measurements do not perturb the chemistry significantly.

Keywords: Carbonate Minerals, Solubility, Electrochemical Cell

\section{THEORETICAL STUDIES OF METAL SPECIES IN SOLUTION AND ON MINERAL SURFACES $\$ 55,817$ \\ DOE Contact: P. M. Davidson,(301) 903-5822 \\ University of Maryland Contact: John Tossell,} (301) 314-1868

The project involves quantum mechanical (Hartree Fock) calculations of relative stabilities of species participating in dissolution and precipitation of gold on sulfide minerals. Although the solubility and surface adsorption of aqueous Au species on sulfide minerals are important agents of ore deposition, current understanding is limited by lack of information on surface complexation sites and speciation. This involves the evaluation of structures, stabilities and spectral properties of heavy metal sulfide species, such as $\mathrm{As}(\mathrm{SH})_{31} \mathrm{Sb}(\mathrm{SH})_{3}$ and $\mathrm{Au}(\mathrm{SH})_{2}^{-1}$, both in aqueous solution and adsorbed on mineral surfaces and the interaction of flotation collector molecules with sulfide mineral surfaces. Predicted properties of As hydroxides provide a check for systematic comparison with experimental data and with results for the corresponding sulfides. Calculations have been completed on possible +2 oxidation state sulfur oxides and on surface relaxation in $\mathrm{ZnS}$. Studies are in progress on the $\mathrm{Hg}$ sulfides and some methyl-Hg species. Analysis of aluminosilicate cage structures with single and double 4-ring geometries, is underway, with the goal of synthesizing new mineral-related compounds as candidate flotation collectors with improved efficiency.

Keywords: Surface Complexation, Gold Sulfides, Metal Transport

\section{MICROMECHANICS OF FAILURE IN BRITTLE GEOMATERIALS \\ $\$ 223,820$ \\ DOE Contact: N.B. Woodward, (301) 903-5822 \\ SUNY, Stony Brook Contact: Teng-Fong Wong. (516) 632-8240 \\ SNL Contact: Joanne Fredrich (505) 846-0965}

Differences in the onset of brittle failure in low-porosity and high-porosity rocks depend on the cementation, initial damage state and deformation history. However, efforts to predict failure are hindered by the inability to account for initial crack density and ductile intergranular phases. For example, although cementation increases brittle strength and reduces porosity, the toughening mechanism is not well understood. This project aims to resolve this question with a systematic study of microstructures induced in experimentally deformed samples (both pre-and post-failure) of (1) high-porosity carbonate rocks, in which plastic grain deformation and plastic pore collapse are thought to be important; (2) sandstones of higher porosity but varying degree of cementation; (3) low-porosity crystalline rocks (as a test of models on rocks with distinct mechanical properties).

Keywords: Brittle Failure, Plastic Deformation, Experimental Rock Deformation, Cementation

\section{THREE-DIMENSIONAL IMAGING OF DRILL CORE SAMPLES USING SYNCHROTRON- COMPUTED MICROTOMOGRAPHY $\$ 225,000$ \\ DOE Contact: P. M. Davidson, (301) 903-5822 \\ BNL Contact: Keith Jones, (516) 282-4588 \\ SUNY, Stony Brook Contact: W.B. Lindquist, (516) 632-8361}

Synchrotron radiation makes feasible the use of high resolution computed microtomography (CMT) for non-destructive measurements of the structure of different types of drill core samples. The goal of this work is to produce three-dimensional images of rock drill core samples with spatial resolution of 1 micron. 
CMT images are postprocessed (filtered) to provide specific grain/pore identification to each voxel in the image. The pore topology is analyzed statistically to yield information on disconnected pore volumes, throat areas, pore connectivity and tortuosity. Current effort is on development of software to analyze the 3-dimensional connectivity and shape of the pore space using the medial axis theorem from computational geometry.

Keywords: Synchrotron Radiation, Computed Microtomography, Pore Structure, Drill Cores

\section{SHEAR STRAIN LOCALIZATION AND FRACTURE EVOLUTION IN ROCKS $\$ 144,987$}

DOE Contact: N. B. Woodward, (301) 903-5822

Northwestern University Contact: J.W. Rudnicki, (708) $491-3411$

Prediction of the causative stresses, location, orientation, thickness, and spacing of fractures in fault zones is important to energy production, waste disposal, and mineral technologies. This study examines the relation of fractures to the macroscopic constitutive description and microscale mechanisms of deformation by testing a standard theory of localization that describes faulting as an instability of the constitutive description of homogeneous deformation. A new, more realistic nonlinear constitutive model, based on the growth and interaction of microcracks which produces increased bulk compliance, is being developed and calibrated with axisymmetric compression tests. Numerical studies (at SNL) will evaluate the complications of realistic geometries and boundary conditions. Preliminary results suggest that the response to an abrupt change in the pattern of deformation is completely nonlinear and cannot be approximated accurately by incrementally linear models, as is often done. This nonlinear response may therefore be critical to the evolution of typical fault zones.

Keywords: Shear Strain Localization, Fracture Evolution, Constitutive Description, Nonlinear Behavior

\section{DISSOLUTION RATES AND SURFACE CHEMISTRY OF FELDSPAR GLASS AND CRYSTAL $\$ 107,026$ \\ DOE Contact: P. M. Davidson, (301) 903-5822 \\ Penn State Contact: S. Brantley, (814) 863-1739}

Dissolution rates and mechanisms of the most common crustal mineral group, the feldspars, $(\mathrm{Na}, \mathrm{K}, \mathrm{Ca})$ $(\mathrm{Al}, \mathrm{Si}) \mathrm{AlSi}_{2} \mathrm{O}_{8}$, are key factors in environmental simulations of coupled fluid flow, effective water-rock surficial area, and fluid residence times. New dissolution experiments and characterization of these silicate mineral and glass surfaces and solutions are underway in order to help resolve discrepancies between existing laboratory measurements that are much faster than dissolution rates observed in the field for feldspars in soils, aquifers and small watersheds. Characterization of the laboratory-reacted solids and naturally weathered feldspars by IR and neutron methods for water content, and XPS and mass spectrometric methods for composition-depth profiling of leaching and surface adsorption complemented with surface analysis by fieldemission SEM and AFM methods, will be used to constrain rate-controlling mechanisms of dissolution. Mechanistic information provided with a variety of microanalytic methods that can encompass mechanisms of dissolution from glass to crystal and from laboratory to field environments will help to determine which of several competing dissolution models best describes the natural weathering process.

Keywords: Silicate Minerals, Dissolution Rates, Dissolution Mechanism, Surface Reactions, Surface Characterization

\section{TRANSPORT PHENOMENA IN FLUID-BEARING ROCKS $\$ 0$} DOE Contact: P. M. Davidson, (301) 903-5822

Renssalaer Polytechnic Institute Contact: E.B. Watson, (518) 276-6475

The research involves two parts: (1) determining the solubility and diffusivity of selected rock-forming minerals and mineral assemblages in deep $\mathrm{C}-\mathrm{O}-\mathrm{H}$ fluids, and (2) measuring the permeability of fluid-bearing synthetic rocks. A new procedure is being developed for measuring mineral solubilities and component diffusivities in fluids at pressures above $1 \mathrm{GPa}$, by measuring the total mass of transported component across a thermal gradient in dumbbellshaped capsules at constant $P(>1 \mathrm{GPa})$. Diffusivities are obtained from independent measurements of the component flux through different $T$ gradients. In the second portion of the investigation, rocks synthesized at high ( $P>1 \mathrm{GPa}$ ) pressures in the presence of differing 
fluid compositions and consequently porosity structure, will be analyzed at ambient conditions to determine permeability using dihedral angle measurements and bulk fluid (air) diffusion through the samples. Direct imaging of the pore structure will also be attempted with Scanning Electron Microscopy and synchrotron X-ray tomography.

Keywords: Diffusivity, Solubility, C-O-H Fluids, Porosity Structure, Rock Permeability

\section{CATION CHEMISORPTION AT OXIDE SURFACES AND OXIDE-WATER INTERFACES: $X$-RAY SPECTROSCOPIC STUDIES AND MODELING $\$ 246,861$ DOE Contact: P. M. Davidson, (301) 903-5822 Stanford University Contacts: G. E. Brown, and G. A. Parks, (415) 723-9168}

This project concerns reactions and reaction mechanisms between metal ions in aqueous solution and oxide surfaces representative of those found in the Earth's crust as an aid to developing both quantitative understanding of the geochemistry of mineral surfaces and the macroscopic models required to predict the fate of contaminants in earth surface environments. The objectives of this research are (1) to characterize sorption reactions by determining composition, molecular-scale structure, and bonding of the surface complexes produced using direct sorption measurements, synchrotron-based $X$-ray absorption fine structure (XAFS) spectroscopy, $X$-ray photoelectron spectroscopy (XPS), and UVNis/IR spectroscopy; (2) to investigate how these properties are affected by the solid surface, the composition of the aqueous solution, the presence or simple organic ligands containing functional groups common in more complex humic and fulvic substances, and time; and (3) to develop molecular-level and macroscopic models of sorption processes.

Keywords: Surface Complexation, Interace Reactions, Synchrotron $\mathrm{X}$-ray Absorption Spectroscopy

\section{OFFICE OF COMPUTATIONAL AND TECHNOLOGY RESEARCH}

\section{DIVISION OF ADVANCED ENERGY PROJECTS AND TECHNOLOGY RESEARCH}

\section{LABORATORY TECHNOLOGY RESEARCH (LTR) PROGRAM}

The LTR program supports research primarily at the five ER multi-program national laboratories: Argonne, Brookhaven, Lawrence Berkeley, Oak Ridge and Pacific Northwest.

The LTR program links advances in basic research at the DOE laboratories to applied technologies of interest to DOE mission areas through high-risk, multidisciplinary research collaborations with private industry. The program funds the laboratories while the industry partners support their own participation at a level equal to the LTR funding.

The LTR program builds upon the results of ER basic research and other DOE research programs in collaboration with industry partners to enhance missionoriented technologies at the laboratories while making technology available to industry for its use. The projects are selected in competitive peer reviews of solicited proposals submitted by the laboratories in conjunction with their partners.

The following multi-year projects are supported by LTR at the five multi-disciplinary ER laboratories.

\section{MATERIALS PREPARATION, SYNTHESIS, DEPOSITION, GROWTH OR FORMING}

\section{LUMELOID, A NEW SOLAR ENERGY CONVERSION MATERIAL (ANL94-42) $\$ 200,000$ \\ DOE Contact: Walter M. Polansky, (301) 903-5995 \\ ANL Contact: Michael Wasielewski, Chemistry, (630) 252-3538}

The Argonne National Laboratory (ANL) is carrying out a research project to develop photoactive polymer composite materials to directly convert solar energy into electricity. This collaboration utilizes ANL expertise in developing photoactive materials in combination with ARDI film technology to generate new material 
composites that could have a significant impact on cheap and efficient power generation from solar energy.

Keywords: Polymers, Composites, Solar Energy Conversion

211. COLD CATHODE ELECTRON EMISSION FROM DIAIMOND AND DIAMOND-LIKE CARBON THIN FILMS FOR FLAT PANEL COMPUTER DISPLAYS (ANL95-02)

$\$ 140,000$

DOE Contact: Walter M. Polansky, (301) 903-5995

ANL Contact: Alan Krauss, MSD/CHM, (630) 252-3520

Cold cathode electron emission has been observed from a number of diamond and diamond-like carbon thin films. It is expected that this phenomenon can be used for the development of high visibility displays for critical applications such as avionics, high reliability microelectronics applications for operation in harsh environments where maintenance is not feasible, and flat panel computer displays. The development of devices like flat panel computer displays which use cold cathode electron emission has been hampered by a lack of basic understanding of the emission process. A method has been developed at Argonne National Laboratory for the growth of diamond films in the nearabsence of atomic hydrogen, using $\mathrm{Ar}-\mathrm{C}_{60}$ or $\mathrm{Ar}-\mathrm{CH}_{4}$ plasmas. This method produces films which respond differently to variations in growth conditions compared with films grown in large quantities of hydrogen. The differences manifest themselves in the manner in which the nucleation density, grain size, grain boundary width, surface roughness, crystallographic orientation and the extent and localization of regions of $\mathrm{sp}^{2}$ and $\mathrm{sp}^{3}$ electronic bonding character vary with the hydrogen concentration in the plasma. We have been able to relate several of these properties to the effective work function, turn-on voltage and emission site density by comparing the electron emission behavior and physical properties of conventional micro-and nano-crystalline, and low-hydrogen nanocrystalline diamond films.

Keywords: Diamond, Diamond-like, Coatings, Thin Films, Computer Displays
212. GIANT MAGNETORESISTANCE WIRE SENSOR (ANL95-07)

$\$ 75,000$

DOE Contact: Walter M. Polansky, (301) 903-5995

ANL Contact: Samuel Bader, Materials Science, (630) 252-4960

Giant magnetoresistance (GMR) materials are composite metals whose resistance changes in the presence of magnetic fields. These materials are up to one hundred times more sensitive to magnetic fields than previously known systems. Currently the GMR materials are made by thin-film processing techniques thereby making their cost prohibitive for many applications. The goal of this project is to develop giant magnetoresistance sensors by inexpensive bulk processing techniques such as wire drawing, and to make prototype sensors that could be used in a variety of applications.

Keywords: Composites, Electrical, Magnetics, Sensors

\section{HIGH PERFORMANCE TAILORED MATERIALS FOR LEVITATION AND PERMANENT MAGNETIC TECHNOLOGIES (ANL97-02) $\$ 125,000$ \\ DOE Contact: Walter M. Polansky, (301) 903-5995 \\ ANL Contact: George W. Crabtree, Materials Science, (630) 252-5509}

The high temperature superconductor $\mathrm{Nd}_{1+x} \mathrm{Ba}_{2-x} \mathrm{Cu}_{3} \mathrm{O}_{7-y}$ has recently been recognized as a powerful new material in which strong magnetic flux pinning has been observed. This material can be used for the development of levitators and trapped-field permanent magnets. creating an opportunity to drive substantial advances in the performance and technical competitiveness of these technologies. The development of this material will shift the leading edge of materials research in this area from the two foreign laboratories (ISTEC, Japan and FZK, Germany) now dominating the field to the U.S. Although the strong pinning characteristics of this material have been recognized, the responsible pinning centers and efficient procedures for large scale fabrication of the material remain relatively obscure. ANL has identified a crucial new processing variable, the high temperature cooling rate during the growth process, which can be used to tailor the flux pinning properties of these materials. In addition, ANL has developed a low temperature oxygen anneal processing technique to control the magnetic field where maximum pinning occurs. An important objective of this project is to understand the origin of the superior flux trapping capabilities and to develop fabrication procedures using top-seeding techniques for making large samples for 
applications. Processing methodology will be developed based on property measurements using $X$-ray and neutron diffraction, magneto-optical imaging, magnetization measurements, and scanning tunneling microscopy on melt-textured material and single crystal samples. The best material will be tested in prototype levitating flywheels to assess its value and define problem areas in collaboration with our industrial partner, Superconductive Components, Inc. The development of high performance flux pinning materials will enable a new generation of levitation devices for frictionless bearings and flywheel energy storage, and of permanent trapped-field magnets. The materials performance advances achieved under this project can be applied to other developing technologies, such as coated conductors for high current carrying wires (IBAD and RABITS), and high power microwave filters for cellular communications. (1) The emission sites will be identified, and a determination of the site density will be made, using photo-electron emission microscopy (PEEM) for several varieties of electron emitting diamond and diamond-like carbon films. The project team has found that post-deposition treatment is critical in controlling emission properties, and the PEEM data will be studied in conjunction with oxygen and hydrogen plasma post-deposition processing. (2) Studies of the grain morphology of films produced both at SI Diamond and at ANL are being conducted using transmission electron microscopy. The ANL portion of these tasks will continue with funding from the Advanced Projects Research Agency as part of a program for improvement of diamond cathode materials for high resolution displays. Research in diamond structures and applications to electronics support DOE's long standing mission in materials sciences.

Keywords: Superconductors, Permanent Magnets, Processing Techniques, Materials Performance

\section{SYNTHESIS AND CRYSTAL CHEMISTRY OF TECHNOLOGICALLY IMPORTANT CERAMIC MEMBRANES (ANL97-06) \\ $\$ 125,000$ \\ DOE Contact: Walter M. Polansky, (301) 903-5995 \\ ANL Contact: James D. Jorgensen, Materials Science Division, (630) 252-5513}

Achieving the conversion of natural gas to synthesis gas (syngas) using oxygen-permeable ceramic membranes would bring vast resources of natural gas within our economic reach. This new technology depends on the development of suitable ceramic membrane materials whose performance is then demonstrated in prototype reactors. This project includes the development of suitable membrane materials at $\mathrm{ANL}$, and the construction of a prototype reactor to evaluate the materials performance and demonstrate the viability of the process at Amoco. A suitable ceramic membrane material, that demonstrates the potential for the desired performance, has been developed in previous work. However, the exact chemical composition and crystal structure of this material is not known. Neutron and $x$-ray diffraction techniques will be used to determine this information. This will allow the synthesis and processing of the membrane material to be optimized to produce the best performance. in situ neutron diffraction at elevated temperature in conditions that simulate the environment in a working syngas reactor will be used to study aspects of the materials related to achieving the longest possible working lifetime. Existing laboratory and pilot plant facilities will be upgraded and modified to facilitate testing of the ceramic membranes under increasingly rigorous conditions. This will provide a valid test of the suitability of the ceramic materials for use in large-scale reactors that convert natural gas into syngas and, at the same time, a useful test of the overall process.

Keywords: Natural Gas, Synthesis Gas (syngas), Ceramic Membranes, Testing of Membranes, Oxygen-Permeable Membranes

\section{COMPOSITE METAL-HYDROGEN ELECTRODES FOR METAL-HYDROGEN BATTERIES (BNL94-06) $\$ 115,000$ DOE Contact: Walter M. Polansky,} (301) 903-5995

BNL Contact: Myron Strongin, Physics Department, (516) 344-3763

The project focuses on the fabrication and characterization of nano-scale bimetallic multilayered films and a feasibility study of their use as hydrogen-containing negative electrodes (anodes) in nickel-metal hydride (NiMH) batteries. If the feasibility of using these new materials is established, it is anticipated that the project will contribute to the advancement of NiMH battery technology and provide batteries with more rapid charging characteristics, greater energy efficiency or larger energy storage capacity.

\section{Keywords: Composite Electrodes, Metal-Hydrogen Electrodes, Batteries}




\section{DIEVELOPMENT OF CdTe/CdZnTe MATERIALS FOR RADIATION DETECTORS \\ (BNL94-09) \\ $\$ 115,000$ \\ DOE Contact: Walter M. Polansky, (301) $903-5995$ \\ BNL Contact: Csaba Szeles, Physics, (516) $344-3710$}

The objective of this project is to broaden the potential use of Cadmium Zinc Telluride ( $\mathrm{CdZnTe}$ ) materials as room-temperature solid-state radiation detectors.

Achieving this goal requires improvement of the existing material-growth and processing techniques in order to enhance the production yield and energy resolution of CdZnTe crystals limited by the unpredictability of the as-grown material. This unpredictability is largely due to the uncontrolled incorporation of electrically active native and impurity-related defects in the bulk and at the surface of the crystals and defects at the semiconductor-metal interface. Production of better crystals demands improved understanding of the nature of lattice defects, their influence on the detector performance and their formation and compensation mechanism during the crystal growth and processing. The availability of inexpensive, high-efficiency, roomtemperature gamma-ray detectors is of great commercialization potential. It stimulates instrument and device manufacturers to develop new products and retrofit old applications using conventional $\mathrm{Nal}(\mathrm{TI})$ and HPGe detectors. The total addressable market for $\mathrm{CdZnTe}$ materiais and the new instruments and devices that integrate $\mathrm{CdZnTe}$ as a primary gamma-ray detector is in excess of $\mathbf{4 0}$ million dollars annually. DOE has extensive programs which use $X$-ray, gamma-ray and particle cletectors. Improved, low-cost, roomtemperature radiation detectors are important for a number of key DOE programs such as nuclear safety and safeguards, field assays, $X$-ray and gammadetectors for next generation light sources, solar cells, $X$-ray and gamma-ray satellite surveillance etc.

Keywords: CdZnTe, Radiation, X-ray, Gamma Detectors

\section{CORROSION RESISTANCE OF NEW ALLOYS FOR BIOMEDICAL APPLICATIONS (BNL94-20) $\$ 140,000$ \\ DOE Contact: Walter M. Polansky, (301) 903-5995 \\ BNL_Contact: Hugh Isaacs, Applied Science, (516) $344-4516$}

The development of new materials for prosthetic devices and other biomedical applications is currently underway. The objective of this project is to provide a detailed understanding of alloy corrosion in bio-systems and the role of the individual alloying additions. Ultimately an understanding of the interactions between alloy composition and the electrochemical response of alloys with optimum mechanical properties and biocompatibility will be developed. in situ XANES measurements in simulated bio-fluid (Ringer's solution) and under crevice conditions (concentrated chloride solution) will provide information on the chemical behavior of the alloys during corrosion. A detailed study of oxide formation will be carried out using XANES, surface analytical techniques and in situ AFM.

Keywords: Corrosion Resistance, Biomedical, Applications, Alloys

\section{CATALYTIC PRODUCTION OF ORGANIC CHEMICALS BASED ON NEW HOMOGENEOUSLY CATALYZED IONIC HYDROGENATION TECHNOLOGY (BNL97-05) \\ $\$ 118,000$ \\ DOE Contact: Walter M. Polansky, (301) 903-5995 \\ BNL Contact: Morris Bullock, Chemistry Division, (516) 344-4315}

This project will focus on the development of new technology for the production of organic chemicals of commercial interest, based on fundamental research at BNL exploring the reactivity of transition metal hydride complexes. The scientific objectives are to explore the feasibility, scope, and selectivity of catalytic ionic hydrogenation technology. In these reactions, $\mathrm{H}_{2}$ is added to an organic chemical sequentially, in the form of a proton $\left(\mathrm{H}^{+}\right)$followed by hydride $\left(\mathrm{H}^{-}\right)$. The project plans to discover transition metal complexes that can carry out these functions catalytically, with hydrogen $\left(\mathrm{H}_{2}\right)$ being the ultimate source of both the proton and hydride. Homogeneously catalyzed ionic hydrogenations offer the possibility of enabling efficient and selective hydrogenation processes for organic transformations that are difficult to achieve by conventional methods. Initial work will focus on attempts to develop prototype metal systems capabie of catalytic hydrogenation of ketones. Tungsten systems with weakly coordinating counterions will be investigated first, since preliminary results have indicated that such systems have the requisite ability to form cationic tungsten dihydride complexes upon reaction with $\mathrm{H}_{2} . A$ key issue to be addressed will be the relative binding strength of different ligands to the metal, and measurements of this type may require high pressure nuclear magnetic resonance experiments at DuPont. When a successfully functioning catalytic system is developed, optimization will be attempted by systematic variation of ligands and the metal. Further elaborations will later attempt to utilize these methods in asymmetric 
hydrogenations to produce commercially viable processes. This project supports the fundamental DOE mission in understanding the mechanisms for catalysis and the chemical conversion of materials from biomass.

Keywords: Catalytic Production, Ionic Hydrogenation, Hydrogen, Organic Transformations, Catalysis

\section{NOVEL BIOCOMPATIBLE "SMART" CONTACT LENS MATERIAL (LBL94-28) \\ $\$ 211,000$ \\ DOE Contact: Walter M. Polansky, (301) $903-5995$ \\ LBNL Contact: Carolyn Bertozzi, Materials \\ Sciences Division, (510) 643-1682}

Vision is by far the most important of the human senses and better ophthalmological care products are continuously being sought. For example, current synthetic contact lens materials have limited tolerance by the population. The project goal is to develop improved materials that will increase the quality of life not only for current wearers but also for those whose physiology cannot tolerate existing materials. In our design of new contact lens materials, we utilize the lessons we have learned in nature. Our approach is to modify materials with favorable lens properties so that they more closely resemble biological tissue, and are therefore tolerated well by the eye. The knowledge gained here is expected to further the understanding of how materials behave in a physiological environment and benefit biomedical implant devices development in general. The work represents a significant advance in the development of new biocompatible materials. The first phase in the development of new contact lens materials is the design of biocompatible monomers for incorporation into hydrogel polymers. In order to create lenses that best mimic biological tissue, we focused on carbohydrate molecules which comprise the coating of most living cells. Our strategy, therefore, is to synthesize polymerizable monomers possessing cell surface-like carbohydrates, and to incorporate them into lenses with better biocompatibility properties.

Keywords: Biocompatible, Smart Contact Lens, Materials, Monomers, Hydrogel Polymers

\author{
220. ALLOY DESIGN OF NEODYMIUM $\left(\mathrm{Nd}_{2} \mathrm{Fe}_{41} \mathrm{~B}\right)$ \\ PERMANENT MAGNETS (ORL94-15) \\ $\$ 155,000$ \\ DOE Contact: Walter M. Polansky, \\ (301) 903-5995 \\ ORNL Contact: Joseph Horton, Metals and \\ Ceramics, (423) 574-5575
}

The objective of this project is to improve the room temperature fracture toughness of the neodymium permanent magnet without decreasing its magnetic properties. This will improve machinability, allow closer tolerances, use as a structural element and more rapid and further market penetration for uses such as electric motors.

Keywords: Neodymium Magnets, Alloy Design, Fracture Toughness, Electric Motors

\section{DEVELOPMENT OF ALUMINUM BRIDGE DECK SYSTEM (ORL94-56) \\ $\$ 105,000$ \\ DOE Contact: Walter $M$. Polansky, (301) 903-5995 \\ ORNL Contact: H. Wayne Hayden, Metals \& Ceramics, (423) 574-6936}

The purpose of this project is to investigate refinement of the aluminum bridge deck panel system using aluminum multi-void extrusions joined together to make panel sections. The desired results could be of use for the upgrading of deficient bridges throughout the U.S. with the use of aluminum bridge decks, and to use aluminum decks on new bridges.

Keywords: Aluminum Bridge Decks, Cost Effective, Lightweight Systems, Consortium

222. MANUFACTURING OF Ni-BASE SUPERALLOYS WITH IMPROVED HIGHTEMPERATURE PERFORMANCE (ORL95-05) $\$ 137,000$

DOE Contact: Walter M. Polansky, (301) 903-5995

ORNL Contact: C. Liu, Metals and Ceramics Division, (423) 574-4459

The objective of this research project is to enhance the manufacturing of high-temperature nickel-base superalloys with improved performance through the control of vital minor elements in the parts-per-million range without significantly increasing production cost. It is anticipated that the control of these vital elements would extend the creep rupture life of superalloy structural members by more than an order of magnitude. Nickel-base superalloys are state-of-the-art 
materials for high-temperature structural applications in advanced engines, petrochemical, other energy conversion systems.

Keywords: Ni-base Superalloys, High-Temperatures, Manufacturing

\section{NIEW THERMOELECTRIC MATERIALS FOR SOLID STATE REFRIGERATION (ORL95-10) $\$ 150,000$ \\ DOE Contact: Walter M. Polansky, (301) 903-5995 \\ ORNL Contact: Brian Sales, Solid State Division, (423) 576-7646}

The goal of this project is to develop new materials that will significantly improve the performance of thermoelectric devices for solid state refrigeration and air conditioning. Thermoelectric refrigerators involve no moving parts, use no greenhouse gases, and are extremely reliable. ORNL will synthesize candidate thermoelectric materials along several paths including filled and unfilled materials with the skutterudite structure and unusual "kondo-like" alloys.

Keywords: Thermoelectric Devices, Refrigeration, Air Conditioning, Alloys

\section{POLYMER MULTILAYER (PML) FILM APPLICATIONS IN OPTICS, ELECTROLYTES, AND GLAZINGS (PNL94-06) \\ $\$ 200,000$ \\ DOE Contact: Walter M. Polansky, (301) 903-5995 \\ PNNL Contact: John Affinito, Materials and Chemical Sciences, (509) 375-6942}

The work undertaken in this research is in response to the requirement of a number of industries for a much higher rate, and much lower cost, process for vacuum deposition of dielectric and/or deposition techniques. The Polymer Multi-Layer (PML) deposition technology being developed at PNNL, can deposit fully cured polymer films, in a roll-to-roll web coating system, at line speeds in excess of 600 linear meters per minute. While the technology developed under this research can potentially be applied in many applications, in this project, four application areas are being explored. These are: (1) deposition, on flexible polyester substrate, of: enhanced and protected polymer/Ag/ polymer and polymer/Al/ polymer reflectors; (2) all polymer (polymer1/ polymer2)", Quarter Wave Optical Ihickness (QWOT) multilayer reflection filters; (3) polymer/ silver/polymer "Heat Mirror" structures; and
(4) thin film battery structures utilizing polymer-only electrolyte layers.

Keywords: Polymer Multilayer Films, Optics, Electrolytes and Glazings, Film Deposition

\section{DEVELOPMENT OF MIXED METAL OXIDES (PNL94-28) \\ $\$ 25,000$ \\ DOE Contact: Walter M. Polansky, (301) 903-5995 \\ PNNL Contact: Larry Pederson, Materials and Chemical Sciences, (509) 375-2731}

This research is directed towards the development of unique lithiated metal oxides for use in secondary batteries. The oxides will be produced using PNNL's glycine nitrate process and will involve varying the compositions of the materials to optimize their desired properties. Lithiated manganese oxides are expected to be used in future lithium ion systems and a lithium polymer system (which is becoming commercially available with a vanadium oxide cathode). The lithium polymer system is expected to be used as a power source for electric vehicles later in this decade.

Keywords: Mixed Metal Oxides, Lithiated Metal Oxides, Lithiated Mn Oxides, Secondary Batteries, Polymer Systems

\section{DEVELOPMENT OF TAPE CALENDARING TECHNOLOGY FOR SEPARATION MEMBRANES (PNL95-04) $\$ 257,000$ \\ DOE Contact: Walter M. Polansky, (301) 903-5995 \\ PNNL Contact: Timothy Armstrong, Materials \& Chernical Sciences, (509) 375-3938}

The purpose of this research is to develop tape calendering technology to produce mixed conducting and oxygen ionically conducting oxide membranes for use as air separation and oxygen production devices. Tape calendering technology shows exceptional promise as a means to manufacture complex ceramic structures on a large scale and at low cost. This project could provide key technology that would help to produce large quantities of oxygen at a significantly lower cost than current cryogenic methods. Tape calendering combines oxide powders, binder, and plasticizer in a high-intensity mixer. The binder-plasticizer system can be softened by externally heating the mixing chamber, using only internal heating resulting from frictional forces generated within the mixing chamber, or combinations of the two. The softened binder system mixes with the ceramic powder to form a plastic-like mass. The mass is calendered into a thin, flat tape 
using a two-roll mill with counter rotating rolls. Tape thickness is controlled by the spacing of the two rolls.

Keywords: Tape Calendering of Oxide Membranes, Separation Membranes, Air Separation, Oxygen Production, Complex Ceramic Structures

227. INNOVATIVE MULTILAYER THERMAL BARRIER COATINGS FOR GAS TURBINE ENGINES (PNL95-07)

$\$ 245,000$

DOE Contact: Walter M. Polansky, (301) 903-5995

PNNL Contact: Edward Courtright, Materials \& Chemical Sciences, (509) 375-6926

The objective of this project is to determine the feasibility of producing innovative multilayer thermal barrier coatings. The fundamental issues associated with maximizing infrared reflectivity and phonon scattering, and the thermodynamic stability issues which affect durability, reliability, and life-cycle performance are being investigated. In the first phase of the program, the feasibility of producing higher performance thermal barrier coatings with multilayered systems will be demonstrated. In the second phase of the program, actual components will be coated and tested under simulated engine conditions, e.g., burner rigs or in actual land-based gas turbine engines

Keywords: Thermal Barrier Coatings, Multilayer Coatings, Gas Turbine Engines, Thermal Barriers

\section{INTERFACIAL INTERACTIONS OF BIOLOGICAL POLYMERS WITH MODEL SURFACES (PNL97-21) \\ $\$ 124,000$ \\ DOE Contact: Walter M. Polansky (301) 903-5995 \\ PNNL Contact: Allison Campbell, Materials and Chemical Sciences Division, (509) 375-2180}

The adsorption of biological polymers onto surfaces affects many different industrial processes. However, the controlling mechanisms and the interfacial structure are not well understood for most systems. This project will develop and apply state of the art methods to design, synthesize, and characterize systems for adsorption experiments. Specifically, molecular beam epitaxy, chemical vapor deposition, and self-assembling monolayers will be used to construct surfaces with controlled properties such as chemistry, topography, and heterogeneity. For the first time, chemical vapor deposition methods for producing controlled surfaces of the biologically relevant calcium oxalate, carbonate, and phosphate systems will be developed. Biological polymers of human serum albumin, Protein $G$, and fibrinogen will be used in the adsorption experiments. These provide excellent models since they exhibit a range of structures, sizes, and chemistries. State of the art techniques of neutron scattering and reflectometry, quartz crystal microbalance, liquid chromatographyl mass spectroscopy, and atomic force microscopy will be employed to study adsorption in situ. Information on adsorption kinetics, isotherms, and protein conformation will be obtained in real time. Finally, solid state nuclear magnetic resonance experiments will be conducted to identify the specific protein residues that are interacting with the surface. This investigation will provide molecular level information on specific interactions that has not yet been obtained. The project will contribute to achieving DOE's mission in fundamental science, while also providing knowledge and technology to potentially enable the development of improved materials for use in health care.

Keywords: Interfacial Interactions, Biological Polymers, Model Surfaces, Design Synthesis and Characterization, Vapor Deposition

\section{HIGHLY DISPERSED SOLID ACID CATALYSTS ON MESOPOROUS SILICA (PNL97-28) $\$ 125,000$ \\ DOE Contact: Walter M. Polansky, (301) 903-5995 \\ PNNL Contact: Yong Wang, (509) 376-5117}

This project will develop new materials optimized for use as solid acid catalysts by coupling the advanced characteristics of mesoporous silica with the superacidic properties of tungstophosphoric acid and sulfated zirconia. The surface of mesoporous silica will be functionalized to accommodate the dispersion of tungstophosphoric acid and sulfated zirconia. This approach should produce a new class of highly active, shape selective, and robust solid superacid materials. The novel catalysts will be tested with the alkylation and isomerization reactions in the bench and pilot scale testing unit. The goal is to exceed the performance characteristics of existing solid superacid catalysts, thereby enabling the chemical and petrochemical industries to replace homogeneous acid catalysts. This will contribute to DOE's mission to reduce environmental impacts in the energy sector. Homogeneous acid catalysts such as sulfuric acid and aluminum chloride are currently used to catalyze many of industrially important reactions. Although these homogeneous acid catalysts are efficient, they are not environmentally benign and create many operational 
problems. These problems can be mitigated with solid acid catalysts. Tungstophosphoric acid and sulfated zirconia are two solid acid catalysts with super acidity. Low catalytic efficiency is the common problem with these two catalysts. In addition, it is difficult to disperse tungstophorsphoric acid on supports due to its large cluster size and sulfated zirconia generally suffers rapid deactivation. These problems can be minimized with the superior characteristics of mesoporous silica. This work will enhance understanding of how the mesoporous support properties and acid grafting strategy influence reactivity, yields, selectivity, thermal stability, coking, and regeneration of the solid acid catalysts. Research under this project was initiated in August 1997. To date, efforts have been conducted to define the specific catalyst properties of interest. Initial synthesis and functionalization of the mesoporous silica supports has also been initiated.

Keywords: Solid Acid Catalyst, Mesoporous Silica, Tungstophosphoric Acid, Sulfated Zirconia

DEVICE OR COMPONENT FABRICATION, BEHAVIOR OR TESTING

\section{APPLICATION OF HIGH PERFORMANCE COIMPUTING OF AUTOMOTIVE DESIGN AND MANUFACTURING (ANL94-54) \\ $\$ 175,000$ \\ DOE Contact: Walter M. Polansky (301) 903-5995 \\ ANL. Contact: David Weber, Reactor}

Engineering Division, (630) 252-8175

This research focuses on the application of highperformance computing to automotive design and manufacturing. The major thrust of the work is to develop easy-to-use computer codes for new high performance computing (HPC) platforms. Argonne National Laboratory is focusing on two areas: computational fluid dynamics and composite material modeling. The Computational Fluid Dynamics (CFD) task will develop "next generation" computational tools for the analysis of CFD phenomena. These tools, including improved physical models and taking advantage of advanced parallel computing architectures, will allow manufacturers to design improved systems and shorten the design time. The Composite Materials Modeling Task will develop predictive numerical analysis tools. This research will: (1) permit the reliable incorporation of lightweight fiberglass reinforced composites into the design of more fuel efficient passenger automobiles without compromising passenger safety, (2) decrease design and manufacturing times and cost, and (3) result in a decrease in domestic fuel consumption. DOE will benefit by adding advanced numerical methods for composite materials to its current suite of state-of-the-art computational tools. This new capability can then be used for other DOE projects that require modeling of composite materials.

Keywords: Composites, Modeling, Analyses

\section{DEVELOPMENT OF RAPID PROTOTYPING TECHNOLOGY FOR BIOCERAMIC APPLICATIONS, (ANL 95-08) $\$ 276,000$ \\ DOE Contact: Waiter M. Polansky, (301) 903-5995 \\ ANL Contact: William A. Ellingson, Energy Technology Division, (630) 252-5068}

This project addresses the need to reduce medical costs associated with orthopaedic implant design, fabrication, and implantation, including medical costs for injury recovery time, as many situations require special implant configurations and designs. The approach is to reduce the cost of producing these complex implants using FDA approved bio-ceramic materials through two activities: (1) development of a new fabrication technology called "Rapid Prototyping" (also called Solid Freeform Fabrication) through use of FDA approved bioceramic materials, and (2) development of reverse engineering technology using 3-Dimensional X-ray Computed Tomographic Imaging (often called CAT scans in the press) and necessary advanced digital imaging methods. Tasks in the project include development of: (1) appropriate bioceramic feed stock for the rapid prototyping machine, (2) binder burn out and sintering schedules for the bioceramic materials, (3) machine parameters for proper fabrication of these materials, (4) digital image methods to allow digital files to be extracted from the "CAT" scan images to allow use by the rapid prototyping machine, (5) algorithms to allow digital image files as input to CAD software packages for design modifications, and (6) surgical implant procedures for these new implants. To date, selected bones (chosen by the industrial partners as being of importance), hand and forearm, have been used for high resolution $X$-ray imaging, and digital images have been obtained. The files have been extracted and modified to allow input to the rapid prototyping machine. (Feedstock materials for the rapid prototyping machine, using aluminum oxide, have been developed including binder burn out and sintering schedules.) The first hand bone and forearm bone have been fabricated using the feedstock material and the rapid prototyping machine. New bioceramic materials including hydroxyapetite/tricalciumphosphate are now under development. Machine parameters, including thickness of layer, filament temperature, and cross-head speed, have been established for using the new feedstock material. The reverse engineering research is currently under study by the industrial 
partner for application. This project supports the DOE mission in materials research and medical applications.

Keywords: Rapid Prototyping, Bioceramics, Applications, Reverse Engineering, CAT Scans, Bones, CAD

\section{SMOOTH DIAMOND FILMS FOR FRICTION AND WEAR APPLICATIONS AND CHEMICALLY PROTECTIVE COATINGS (ANL97-05) \\ $\$ 150,000$ \\ DOE Contact: Walter M. Polansky, (301) 903-5995 \\ ANL Contact: Alan R. Krauss, D. M. Gruen, Materials Science and Chemistry Division, (630) 252-3520}

Diamond has a number of properties which, in principle, make it an exceptional material for a large number of applications. In particular, the extreme hardness (harder than any other known material), chemical inertness (it resists attack by almost all known acids and bases), and low coefficient of friction (comparable with that of Teflon ${ }^{\mathrm{M}}$ ) make it an ideal candidate for a wide range of applications involving sliding or rolling contact between moving surfaces. However, conventional diamond chemical vapor deposition (CVD) methods produce coatings with extremely rough surfaces. This roughness has limited the development of diamond film technology for tribological applications, and penetration of diamond film technology into these markets has been disappointingly slow. This project concerns the use of a process developed at Argonne National Laboratory for the production of ultra-smooth diamond coatings on rotating and sliding mechanical parts in order to reduce energy consumption, improve product reliability, and reduce toxic emissions into the environment. Films produced by this process have been shown to possess tribological properties which eliminate the problems which have so far limited the use of diamond coatings for applications involving moving parts. The work to be performed addresses adaptation of the process for the production of diamond coatings that are 10-100 times smoother than those produced by existing processes. End face mechanical seals, used to prevent the leakage of gases and liquids in equipment with rotating shafts, have been chosen as the area of application. The benefits obtained in terms of energy savings, increased productivity, reduced maintenance, and reduced release of environmentally hazardous materials for this single application will be substantial, but the technology which will be developed will also be directly applicable to a large number of application areas in manufacturing and transportation, in most cases with similar benefits. This project supports DOE mission in the application of basic research developments in material sciences to improved processing technologies.

Keywords: Diamonds, Films, Coatings, Applications

233. MICROFABRICATION OF A MULTI-AXIS MICRO-ACCELEROMETER USING HIGH ASPECT RATIO MICROFABRICATION (HARM) AND SILICON MICROMACHINING (BNL94-02) $\$ 100,000$

DOE Contact: Walter M. Polansky, (301) 903-5995

BNL Contact: John Warren, Instrumentation, (516) $344-4203$

The primary goal of this project is to use high aspect ratio microfabrication to bulk fabricate all of the components of a multi-axis accelerometer. The inherent accuracy of the microfabrication process (based on lithography) should also lead to improvements in performance. The completed micro-accelerometer will have many applications in aviation, auto navigation, active automotive suspension system control, drill bit navigation, and airbag deployment. The high aspect ratio microfabrication process has many scientific applications and is currently being used in the Instrumentation Division at BNL to construct prototype position-sensitive $X$-ray detector arrays that have many applications in high energy physics. Knowledge gained from microfabrication methods is directly applicable to these on-going efforts.

Keywords: Microfabrication, Accelerometer, X-ray Detector

\section{NONDESTRUCTIVE X-RAY SCATTERING CHARACTERIZATION OF HIGH TEMPERATURE SUPERCONDUCTING WIRES (BNL95-10) $\$ 160,000$ DOE Contact: Walter M. Polansky, (301) 903-5995 \\ BNL Contact: Thomas Thurston, Physics, (516) 344-5534}

Prototypes of generators, transformers, transmission cables, and current limiters which utilize wires made of high-temperature superconducting materials are just beginning to be built. Although the ultimate purposes of these electric power devices vary, all of them offer the potential for substantial energy savings, since there is no loss of energy in the form of heat generated by electrical resistance. DOE has programs to develop technologies for electric power applications of high temperature superconductors. All of the electric power applications of high-temperature superconductors 
described above require long lengths (at least $\sim 100$ meters) of wire with large current carrying capacities. Unfortunately, there are a variety of effects that can limit the current carrying capacity of the wires, with the consequence that today's wires have capacities which are at least 10 times smaller than the maximum theoretical capacity. The purpose of this research is to characterize the structure of the superconducting material within wires in order to understand the causes of poor current carrying capacity, and to suggest alternative processing procedures which can minimize or eliminate the effects which cause poor wire performance. The methods which Brookhaven is using to characterize the wires utilize intense beams of $X$-rays generated at Brookhaven's National Synchrotron Light Source. Work performed earlier showed that the current carrying capacity is affected by the presence of certain impurity phases, and by poor texturing of the superconducting material within the wires. Both of these deleterious effects can be readily measured only with the intense $X$-ray beams available at facilities like the National Synchrotron Light Source. Work currently in progress involves direct $X$-ray monitoring of superconducting wire processing in a "mini-factory" which has been set up at Brookhaven. This work has already suggested modifications increase the current carrying capacity of wires. BNL has started to apply the techniques developed to characterize these wires on other problems of interest to the DOE, such as characterizing the properties of battery electrode materials and permanent magnets.

Keywords: Superconducting Wires, Prototypes, Characterization, High-Temperature

\section{THIN FILM LITHIUM BATTERIES, (BNL95-11) $\$ 80,000$ \\ DOE: Contact: Walter M. Polansky, (301) $903-5995$ \\ BNL Contact: James McBreen, Applied Science, (516) 344-4513}

This research is focused on the development and testing of polymer electrolytes for primary thin film lithium batteries. A cell design, based on thin electrodes, with the cell enclosed in a thin heat sealed foil-laminate pouch like that used in the food industry (e.g., coffee) has been developed by an industry source. While this design is attractive for thin film batteries, and is adequate for prevention of ingress of water vapor or air, it presents many technical challenges. The foil laminate gives no mechanical support to ensure intimate contact between the electrodes and the electrolyte. Bulging of the pouch and its contents can result in large increases in the resistance losses in the cell. These problems were solved by the development of a new low cost. polymer electrolyte, with good conductivity, and excellent adhesion to the electrodes.

Keywords: Thin Films, Lithium, Batteries

236. NEW CATALYSTS FOR DIRECT METHANOL OXIDATION FUEL CELLS (BNL95-14)

$\$ 80,000$

DOE Contact: Walter M. Polansky, (301) 903-5995

BNL Contact: Radoslav Adzic, Applied

Science, (516) 344-4522

A search for an active metal oxide-metal electrocatalysts for methanol oxidation has been performed with platinum electrocatalyst supported on several types of metal oxides. Synthesis and the electrochemical and/or spectroscopic characterizations were carried out. A very active electrocatalyst was obtained with Pt supported on Ru oxide. Reaction intermediates and products for some systems were characterized by in situ Transform Infrared Spectroscopy (FTIR).

Keywords: Electrocatalysts, Methanol Oxidation, Fuels Cells

\section{DEVELOPMENT OF MULTI-CHANNEL ASIC\& FOR CdZnTe GAMMA DETECTOR ARRAYS (BNL97-06) \\ $\$ 82,000$ \\ DOE Contact: Walter M. Polansky, (301) 903-5995 \\ BNL Contact: Paul O'Connor, Instrumentation Division, (516) 344-7577}

The objective of this project is to develop an X-ray imaging module consisting of a multi-element Cadmium Zinc Telluride (CZT) detector and a CMOS applicationspecific integrated circuit (ASIC). The module will detect $x$ and gamma rays in the energy range from $20-150$ $\mathrm{keV}$ in the photon counting mode. The electronics must be compatible with the CZT detector characteristics and at a minimum preamplify and shape the pulse signals from the detector elements. There is currently a large need for solid state gamma and $X$-ray imaging capability for both medical and industrial applications. In industry, a need exists for imaging food products for foreign matter, non-contact, high speed weighing of consumer products to ensure minimum weight compliance and multi-energy high speed imaging of manufactured products to detect subtle defects. Solid state CZT arrays offer the possibility of reducing the weight and bulkiness of existing nuclear medicine cameras based on Nal scintillators and photomultiplier angular camera technology. Small hand held imaging devices show promise for locating cancer tissue during surgery through the use of monocional antibodies 
tagged with radioactive tracers. For security screening, CZT arrays when used with multi-energy $X$-rays can detect explosives and other contraband. The technical approach consists of the evaluation of the performance of various existing BNL circuits with CZT arrays, adapting the existing design so that the front end and shaping parameters are ideally matched to the CZT detectors, producing a prototype array of a certain size by tiling arrays and ASIC circuits, developing a 64 or greater channel ASIC for larger substrates (or finer pitch), and configuring existing building blocks to build a multiplexing and image processing ASIC. The development of these solid-state detectors will benefit DOE mission areas in time-resolved $X$-ray crystallography, nuclear medicine, and extended X-ray absorption.

Keywords: ASICs, CdZnTe Detector Arrays, Application, Solid State Detectors

\section{MICROCIRCUITS AND SENSORS FOR PORTABLE, LOW-POWER DATA COLLECTION AND TRANSMISSION (BNL-97-07) $\$ 125,000$ \\ DOE Contact: Walter M. Polansky, (301) 903-5995 \\ BNL Contact: Paul O'Connor, Instrumentation Division, (516) 344-7577}

The objective of this project is to design, fabricate and test two novel devices for data collection and transmission: an optical photosensor array and a $2.4 \mathrm{GHz}$, single-chip, frequency-agile radio transceiver. Both devices can be processed in a standard CMOS integrated circuit process. CMOS technology has advanced to the point where many conventional electronics systems can be fully integrated on a single chip. Up to now the vast majority of these chips perform purely electronic functions. In this project we propose to investigate two integrated circuits with sensors which can process information in the form of radio-frequency waves and optical images. Our project goal is to develop an inexpensive single-chip frequency agile RF transceiver operating at the $2.4 \mathrm{GHz}$ range - a universally accepted unlicensed band - with data rates up to $250 \mathrm{Kbps}$ and an approximate range of 50 feet. We have previously demonstrated successful circuit blocks and will be seeking to use a higher performance CMOS 0.35 micron process to achieve lower power consumption and higher integration density. For the optoelectronic imaging portion of this project, we will investigate the "active pixel" architecture. This architecture uses photodiode sensors which can be made in a native CMOS process. The imaging array requirements (pixel size and count, spectral responsivity, speed, signal-to-noise ratio, dynamic range, linearity, crosstalk, and power consumption) will first be specified based on a knowledge of the 2D bar code reader system. We plan to model alternative photodetectors using the semiconductor device simulation codes currently used at BNL for silicon radiation detector development. This project supports the DOE mission in advanced semiconductor research for development of crosscutting sensor technologies.

Keywords: Data Collection and Transmissions, CMOS Process, Integrated Circuits, Microcircuits, Sensors, Imaging Arrays

\section{RECHARGEABLE ZINCIAIR BATTERIES FOR CONSUMER APPLICATIONS (LBL94-43) $\$ 62,000$ \\ DOE Contact: Walter M. Polansky, (301) 903-5995 \\ LBNL Contact: Elton Cairns, Energy \& Environment Division, (510) 486-5028}

The $\mathrm{Zn} / \mathrm{air}$ battery is an especially appealing technology for use in consumer batteries because of its high specific energy, low cost and environmentally benign components. The zinc-air technology is greatly underutilized because of the generally low power available from the cell. The power limitations stem primarily from the air electrode as a result of the slow kinetics of the electrochemical reduction of oxygen from air. Complete utilization of the zinc loading can also be a problem at high power drains. The focus of this project has been to address these two limitations in order to extend the possible markets for the zinc/air primary battery technology. The first year of this project has been concerned with the application of novel electrocatalysts to the air electrode structure to improve the high-power performance of this electrode. The second year will focus on the study and modification of the zinc electrode formulation in order to optimize zinc utilization at high power. Four electrocatalyst systems are under study at LBNL. The electrocatalysts are added to a state-of-the-art air electrode and performance is evaluated in the three-electrode configuration in the absence of zinc. Two candidates appear promising and will be incorporated into full zinc-air cells for testing.

Keywords: Zn/Air Batteries, Electrochemistry, Electrocatalysts, Electrodes 
240. MICROMAGNETIC STRUCTURES (LBL95-12) $\$ 378,000$

DOE Contact: Walter M. Polansky, (301) 903-5995

LBINL Contact: Neville Smith, Accelerator and Fusion, (510) 486-5423

This goal of this project is to produce a powerful and unique tool for microscopic imaging of magnetic materials (a tool which will take full advantage of the capabilities of the ALS), and to use this tool to develop new magnetic materials for high density information storage. The microscope is based on a full field photoelectron emission technique, and magnetic information is extracted using a synchrotron radiation spectroscopy known as X-ray Magnetic Circular Dichroism. The microscope will have elemental and chemical selectivity, combined with surface sensitivity, and the ability to measure surface magnetic moments. This combination of features is unique in the array of tools currently used to study magnetic materials. The project uses LBNL's expertise in design and operation of synchrotron instrumentation, beamlines, and experimental end stations in the production of artificially engineered magnetic microstructures.

Keywords: Micromagnetics, Information Storage, Magnetic Imaging, Photoelectron Emissions

\section{DEVELOPMENT OF ZINC/NICKEL OXIDE BATTERIES FOR ELECTRIC VEHICLE APPLICATIONS (LBL95-27) \\ $\$ 42,000$ \\ DOE Contact: Walter M. Polansky, (301) 903-5995 \\ LBNL Contact: Frank McLarnon, Energy Conversion and Storage, (510) 486-4636}

The goal of this project is to develop a light-weight, rechargeable battery for electric vehicles. This battery uses an alkaline electrolyte, a zinc negative electrode and a nickel oxide positive electrode. It has two major advantages over competing types such as cadmium/ nickel oxide (nickel-cadmium) and metal-hydride/nickel oxide (nickel-metal hydride): it delivers more energy per unit battery mass and costs less to produce. LBNL has developed a novel electrolyte for the zinc/nickel oxide battery that extends its useful life to several hundred charge-discharge cycles. Additional improvements to lower the battery mass and to increase the ability of the electrolyte to wet the electrodes are being investigated. If these efforts are successful, full-size electric vehicle batteries will be built for testing. A superior zinc/nickel oxide battery could be the key to inexpensive and durable electric vehicles which will reduce air pollution and petroleum imports while creating a new growth industry.

Keywords: Zn/Ni Batteries, Electric Vehicles, Alkaline Electrolytes, Zn and Ni Electrodes

\section{CATALYTIC CONVERSION OF CHLORO- FLUOROCARBONS OVER PALLADIUM- CARBON CATALYSTS (LBL95-45) $\$ 275,000$ \\ DOE Contact: Walter M. Polansky, (301) 903-5995 \\ LBNL Contact: Gabor Somorjai, Materials Sciences, (510) 486-4831}

Chlorofluorocarbons must be substituted as refrigerants and chemicals because of their adverse health effects (ozone depletion and other effects). The hydrodechlorination ( $\mathrm{HDCl}$ ) of $\mathrm{C}_{2} \mathrm{~F}_{4} \mathrm{C}_{12}$ is a technology that uses palladium catalyst supported on carbon. This research investigates the structure and bonding of reactants and products on palladium crystal surfaces that are also used as model catalysts. The elementary steps of the reaction and its mechanism are explored this way. The causes of catalyst deactivation is being studied, along with the use of promoters to inhibit it. The roles of the carbon support and the palladium-carbon interface are also of interest as they influence the catalytic reaction rate and selectivity.

Keywords: Chlorofluorocarbons, Pd Catalysts, Hydrodechlorination, Reaction Mechanisms

\section{IONICALLY CONDUCTIVE MEMBRANES FOR OXYGEN SEPARATION (LBL97-03) $\$ 125,000$ \\ DOE Contact: Walter M. Polansky, (301) 903-5995 \\ LBNL Contact: Steven J. Visco, Materials Sciences Division, (510) 486-5821}

The global market for industrial oxygen is estimated at $\$ 20$ billion annually. The dominant technology for the production of commercial oxygen is cryogenic distillation. The high capital equipment costs for cryogenic $\mathrm{O}_{2}$ separation limits this technology to large installations. Accordingly, industrial suppliers of oxygen are highly motivated to develop technologies that can satisfy increasing demand for oxygen through smaller scale plants. One approach under development elsewhere is the use of mixed ionic-electronic ceramics; when such ceramic electrolytes are exposed to compressed air on one side and ambient pressure on the other, oxygen diffuses through the mixed conductor from the compressed side to the low pressure side due to the chemical potential gradient of oxygen across the membrane. The drawback to this technology is the need 
for a compressor which raises issues of noise and reliability. Another problem is that permeation delivers ambient pressure oxygen. In contrast, we propose the efficient electrolytic extraction of oxygen from air using novel thin-film structures consisting of high strength ionic membranes supported on porous, catalytic electrodes. Using this technology, high purity $\mathrm{O}_{2}$ can be electrochemically pressurized as an integral part of the separation process. The simplicity of operation of an electrolytic $\mathrm{O}_{2}$ generator promises high reliability as well as low cost. Still, to survive as a commercial process, this approach must be cost-competitive to cryogenic production of $\mathrm{O}_{2}$. Key to success is highly efficient operation (low power consumption) of the device along with low fabrication costs. Power losses in the electrolytic oxygen cell will be related to ohmic losses across the electrolyte membrane, charge transfer polarization at the electrode/electrolyte interfaces, and mass transfer polarization across the electrodes. The LBNL approach addresses the above issues in such a way that both scientific and technical success are likely. The LBNL team has initiated preparation of porous substrates suitable for colloidal deposition. High temperature furnaces are being installed for sintering of bilayer structures suitable for high oxygen flux in an electrolytic oxygen generator. The LBNL investigator recently met with the principal investigator for the industrial partner to discuss the timeline for the development plan. A tentative date of October 1997 has be agreed upon for the LBNL team to travel to industrial partner's laboratory in order to discuss the development plan in detail, and to ensure maximum productivity of the collaborative effort. This research supports the DOE mission in materials research and applications.

Keywords: Oxygen, Membranes, Separation, Ceramic Electrolytes, Catalytic Electrodes, Oxygen Generators

\section{LIGHT EMISSION PROCESSES AND DOPANTS IN SOLID STATE LIGHT SOURCES (LBL97-13) $\$ 125,000$ \\ DOE Contact: Walter M. Polansky, (301) 903-5995 \\ LBNL Contact: Eugene E. Haller, Materials Sciences Division, (510) 486-5294}

Light emitting diodes (LEDs) functioning in the red and infrared have been manufactured in large quantities since the 1960 s. However, until very recently, only very inefficient and dim LEDs were available in the green and, especially, in the blue. Although there are a handful of semiconducting materials with sufficiently wide bandgaps to function in principle in the blue region of the spectrum, fundamental material properties and limitations have prevented bright and efficient diodes from being made. Recently, breakthroughs in the heteroepitaxial growth of gallium nitride ( $\mathrm{GaN}$ ) and its alloys with indium and aluminum have changed the blue and green LED technology outlook. Formerly, it was believed that III-V nitride layers had too high a defect density to function as LEDs. Nevertheless, a Japanese company (Nichia) has developed a family of blue and green LEDs based on GaN that are bright and efficient. For the last two years, Japanese companies have been manufacturing and selling blue GaN LEDs in bulk quantities. This project is a collaboration with HewlettPackard Company (HP), the leading producer of LEDs, to investigate the fundamental light-emitting mechanism. Epitaxial thin film growth, including specialized structures and doping series and basic parametric characterization, will be performed in the industrial research laboratories of HP. Highly homogenous, reliably reproducible, and stable metal organic vapor phase epitaxial growth processes have been established at HP laboratories. Highly specific spectroscopic characterization and analysis aimed at revealing the basic principles underlying doping and recombination will be performed by LBNL's Materials Sciences Division, supporting key DOE missions in materials research.

Keywords: LEDs, Semiconducting Materials, Gallium Nitride, Light Emitting Mechanisms, Heteroepitaxial Growth, Blue Emitting Diodes, Red Emitting Diodes, Green Emitting Diodes

\section{COMBINATORIAL DISCOVERY AND OPTIMIZATION OF NOVEL MATERIALS FOR ADVANCED ELECTRO-OPTICAL DEVICES (LBL97-18) $\$ 125,000$ \\ DOE Contact: Walter M. Polansky, (301) 903-5995 \\ LBNL Contact: Xiao-Dong Xiang, Materials Sciences Division, (510) 486-4864}

Advanced materials are the building blocks of the emerging photonic technologies which are the foundation for a new industrial base. Complex oxide ceramics (ternaries and higher order compounds) exhibit a wide range of technologically significant properties such as the electro-optic effect. The rapid expansion in the types of phenomena exhibited by modern advanced ceramics has revived interest in the use of complex oxides for advanced optical device applications. This project directly supports DOE's interests in materials research for advanced ceramic applications. However, due to the complexity of multicomponent oxides, searching for new materials or optimization of existing materials has become a 
forbidding task for the materials community. This project will: (1) use the method of combinatorial synthesis and screening, recently developed at LBNL, to evaluate a wide range of oxide materials and compounds and optimize the advanced oxide materials for electro-optical devices; and (2) use heteroepitaxial thin film growth methods, developed at NZAT, to fabricate advanced oxide electro-optical devices based on search and optimization results. The goal of this project is to produce commercially viable advanced electro-optical devices. If successful, this project will play an important role in forming a strong foundation for the emerging large scale integrated optics device industry.

Keywords: Photonic Technologies, Oxide Ceramics, Mutli-Component Oxides, Electro-Optical Devices, Synthesis, Thin Films

\section{DEVELOPMENT OF A THIN-FILM BATTERY POWERED HAZARD CARD AND OTHER MICROELECTRONIC DEVICES (ORL94-39) $\$ 74,000$ DOE Contact: Walter M. Polansky, (301) 903-5995 \\ ORNL Contact: John Bates, Solid State (423) 574-6280}

The goals of this research project are to investigate the feasibility of powering integrated circuit chips and compact microelectronic-based devices with thin-film, rechargeable batteries that can withstand temperatures of up to $200^{\circ} \mathrm{C}$, and to determine and eliminate obstacles to their manufacturability. Since they have high energies per unit of volume and mass and because they are rechargeable, thin film lithium batteries have potentially many applications as small power supplies in consumer and medical microelectronic products. This research into battery technology will enable the reduction in size and improvement in performance of existing microelectronic devices.

Keywords: Thin-Film Batteries, Microelectronics, Electronic Devices

\section{ION IMPLANTATION PROCESSING TECHNOLOGIES (ORL94-72) \\ $\$ 136,000$ \\ DOE: Contact: Walter M. Polansky, (301) 903-5995}

ORNL Contact: Tony Haynes, Solid State, (423) 574-2858

The objective of this project is to cooperate in ion implantation research and related processing of semiconductors to accelerate the development cycle for three critical technologies required for the manufacturing of the next generation of microelectronic integrated circuits (ICs). These include: (1) gettering of impurities, where the goal is to identify and evaluate implantation-based schemes for generating stable gettering sites for deleterious impurities within silicon wafers; (2) dielectrics, where the aim is to develop and test thin dielectric films for compatibility with shallow junction formation; and (3) metallization, where the challenge is to eliminate stress-induced metal failures. In this research, the feasibility of using ionimplantation-based approaches for solving these problems during manufacturing will be evaluated.

Keywords: Ion Implantation, Integrated Circuits, Semiconductor Manufacturing

\section{RAPID PROTOTYPING OF CERAMICS (ORL94-95) $\$ 153,000$ \\ DOE Contact: Waiter M. Polansky, (301) 903-5995 \\ ORNL Contact: Robert Lauf, Engineering Technology Division, (423) 241-2102}

The goal of this project is to develop fundamental knowledge and apply that knowledge to the technology of rapid product realization for structural ceramic components. A major part of the effort is directed to modifying solid freeform fabrication techniques to produce sinterable ceramic green bodies rather than plastic models. The program also recognizes the crucial role of advanced computational techniques for creating and manipulating the large data files needed to adequately represent complex three-dimensional components with the necessary resolution.

Keywords: Freeform Fabrication, Rapid Manufacturing, Ceramics

\section{DEVELOPMENT OF A THIN FILM BATTERY POWERED TRANSDERMAL MEDICAL DEVICE (ORL95-11) \\ $\$ 187,000$ \\ DOE Contact: Walter M. Polansky, (301) 903-5995 \\ ORNL Contact: John B. Bates, Solid State Division, (423) 574-6280}

Heart and brain activity are monitored by measuring microvolt signals developed on the surface of the skin using transdermal electrodes. The first objective of this project was to develop a thin-film battery powered preamplifier that would attach directly to these electrodes so that the small electrocardiogram (EKG) and electroencephalogram (ECG) signals could be amplified before transmission to the recording unit. These "active" electrodes will eliminate the effect of 
interference from ac pickup in the long cables from the recording unit and improve the reliability in diagnosing heart or brain malfunctions. By incorporating batteries into the circuit to power the amplifiers, no change to existing EKG or ECG recording equipment is required. A thin-film lithium battery was developed that exceeds the requirements of Teledyne's transdermal-electrode application. The battery, which is based on a $\mathrm{LiCOO}_{2}$ cathode, was fabricated directly onto the backside of the multi-chip modules developed by Teledyne as a prototype electrode preamplifier. This was the first demonstration of integration of thin-film batteries into electronic devices. When developed, the active electrodes will significantly improve the reliability of EKG and ECG diagnostic measurements and thereby help to improve the quality of patient care at a lower cost. The second objective of this project is to demonstrate manufacturing of thin-film batteries in a pilot scale facility at Teledyne. The cathode and electrolyte films deposited at Teledyne are being shipped to ORNL for a comparison of their properties with those grown at ORNL. To date, Teledyne has fabricated excellent $\mathrm{LiCOO}_{2}$ cathode films over areas nearly 40 times larger than possible at ORNL. Batteries fabricated at Teledyne will be evaluated at ORNL. If they meet the rigid requirements of the medical device, full-scale manufacturing will follow. Teledyne has licensed ORNL's thin-film battery technology for application in medical devices. The work performed in this project supports DOE's Basic Energy Sciences programs in advanced battery technology and advanced ceramics.

Keywords: Thin-Film Batteries, Transdermal Medical Devices, Lithium, Multi-Chip Modules

\section{RAPID PROTOTYPING OF BIOCERAMICS FOR IMPLANTS (ORL95-12) \\ $\$ 64,000$ \\ DOE Contact: Walter M. Polansky, (301) 903-5995 \\ ORNL Contact: Ogbemi Omatete, Metals and Ceramics Division, (423) 576-7199}

The goal of this research is to combine the ORNL gelcasting process and an injection stereolithography process to make a rapid manufacturing system suitable for the fabrication of limited-production ceramic components for implants and prostheses. This project will complement a related effort led by Argonne National Laboratory in the conversion of CAT/MRI data sets into a format suitable for rapid freeform fabrication processes.

Keywords: Ceramics, Gelcasting Process, Rapid Manufacturing, Freeform Fabrication
251. DEVELOPMENT OF HIGH-TEMPERATURE SUPERCONDUCTING WIRE USING RABITS COATED CONDUCTOR TECHNOLOGIES

(ORL97-02)

$\$ 100,000$

DOE Contact: Walter M. Polansky, (301) 903-5995

ORNL Contact: David K. Christen, Solid State

Division Donald M. Kroeger, Metals and

Ceramics Division, (423) 574-6269

This project is developing a recent breakthrough at Oak Ridge National Laboratory that offers a potential new route to the fabrication of high-temperature superconducting (HTS) wires for power applications. The new process produces high-Tc coatings that have high critical-current densities at liquid nitrogen temperatures, and enable operation in substantial magnetic fields. The present approach exploits the growth of crystalline biaxially-aligned coatings on oriented metal tapes produced by simple thermomechanical processing. The tapes start with inexpensive polycrystalline metals or alloys that are biaxially aligned by deformation rolling and thermal annealing treatment, followed by the epitaxial deposition of thin, passivating buffer layers. The project team is investigating the scientific and technical feasibility of making long-length coated conductors that can provide operating characteristics that are currently unattainable by any electrical conductor, including present prototype HTS tapes that utilize the "powder-in-silver-tube" fabrication approach. The research focuses on both the simplification and optimization of oxide buffer layers on reactive metals, and specifically will evaluate (co)evaporation techniques for both the buffer layer(s) and the superconductor coatings. $3 \mathrm{M}$ has an established experience base in high-rate deposition of other materials using this manufacturing technology. Southwire is the leading U.S. manufacturer of utility wire and cable, and is a retailer of underground transmission cables (a prime first candidate for HTS insertion). A cost-effective route to high-temperature superconducting wires would provide substantial national energy benefits in the technology of electric power production, storage, and distribution. Superconducting transmission lines alone would enable 2-3 times the power transfer into urban areas without the need for additional rights-of-way and without significant losses to resistance. Other applications, such as power transformers, motors, current limiters, and magnetic energy storage, are projected to produce markets of tens of billions of dollars per year. This project will help DOE's Office of Utility Technologies, 
Energy Efficiency and Renewable Energy program to develop high-temperature superconductors.

Keywords: Superconducting Wires, Coatings, Metalworking, Coated Conductors, Electrical Equipment, Distribution and Transmission, High Temperature

\section{INSTRUIMENTATION AND FACILITIES}

\section{MICRO-SPECTROSCOPY FACILITY FOR NEW INFRARED IMAGING MATERIALS (BNL94-60) $\$ 91,000$ \\ DOE Contact: Walter M. Polansky, (301) 903-5995 \\ BNL Contact: Gwyn Williams, NSLS \\ (516) 344-7529}

Brookhaven National Laboratory is developing a custom synchrotron beamline facility for characterizing infrared sensor technology materials. New materials for high performance and/or low cost infrared imaging systems will be developed and tested. The testing involves infrared microspectroscopy using infrared synchrotron radiation as the source for the microscope. Synchrotron radiation is 1000 times brighter than conventional thermal infrared sources, making this a unique facility.

Keywords: Micro-spectroscopy, Infrared, Imaging Materials, Synchrotron Beamline

\section{DEVELOPMENT OF ENVIRONMENTALLY CONSCIOUS MACHINING FLUIDS (ORL94-91) \\ $\$ 204,000$ \\ DOE Contact: Walter M. Polansky, (301) 903-5995 \\ ORNL Contact: Thomas Morris, Metals and Ceramics, (423) 241-2796}

The objective of this project is to develop required cutting fluids for ceramic and other advanced materials that are more environmentally benign and will reduce or eliminate the environmental problems associated with management and disposal of these cutting fluids. The specific goal of the project is to develop a method to degrade synthetic cutting fluids and reduce their total organic carbon (TOC) content and chemical oxygen demand (COD) to allow for final disposal in municipal sewage treatment facilities. Water-based industrial fluids can have excessively high TOC (ca. $>15,000$ PPM), thus making their treatment especially challenging.

Keywords: Cutting Fluids, Ceramics, Machining, Environmental

\section{NOVEL METHODS FOR FABRICATION COST REDUCTION OF PRESSURE INFILTRATION CAST METAL MATRIX COMPOSITE COMPONENTS (ORL95-01) $\$ 192,000$ \\ DOE Contact: Walter M. Polansky, (301) 903-5995 \\ ORNL Contact: James Hansen, Engineering Technology Division, (423) 241-2102}

The goal of this project is to develop pressure infiltration casting as a method to manufacture high quality metal matrix composite castings at high production rates. The manufacturing demonstration component of the project is a lightweight ( 60 percent reduction or 20 pound weight savings versus cast iron calipers), high modulus, particulate reinforced aluminum brake caliper.

Keywords: Pressure Infiltration Casting, Manufacture,
Metal Matrix Composites

\section{ULTRA-PRECISION AUTOMATED MEASUREMENT FOR MANUFACTURING (ORL95-08) \\ $\$ 75,000$ \\ DOE Contact: Walter M. Polansky, (301) 903-5995 \\ ORNL Contact: C. Thomas, Fusion Energy Division, (423) 574-1155}

Project goal is to demonstrate a new level of automated process control, noncontact measurement technology for the United States manufacturing sector. The immediate goal is proof of concept for intelligent automated electronic interferometry inspection of digital microchips with a resolution better than the lithographic mask resolution (e.g., a transverse resolution of 200 nanometers and a longitudinal resolution of 20 nanometers). This will allow automated 3-dimensional inspection of the chips between processing steps to insure success of the processing at each step; immediately identify process failures; save time, money, and energy; improve quality and yield by eliminating defective chips early in the processing; and immediately identify process failures. The intention is to provide a totally automated, rapid, on-line inspection capability to automatically detect and sort defective chips or call for human intervention. This technology can be extended to inspection and process control for all kinds of precision components, particularly for the automotive, electronics, and defense industries. Some examples of additional uses include: automated inspection of precision machined parts; automated inspection of heads and platters for hard disk drives (where some tolerances are starting to approach the sub-micron level); and automated noncontact inspection 
of aircraft wing sections and automotive body panels on a more macroscopic level.

Keywords: Ultra-Precision Measurements, Automated Process Control, Manufacturing, Inspection

\section{NEURAL NETWORK MODEL (ORL95-90)}

$\$ 248,000$

DOE Contact: Walter M. Polansky,

$$
\text { (301) 903-5995 }
$$

ORNL Contact: Gerald Ludtka, (423) 574-5098

The goal of this project is to significantly reduce the required number of iterations in the sheet metal forming die design process, a process typically involving extensive and costly physical prototyping. The project employs a collection of emerging computational technologies such as digital simulations of deformation processes, neural networks, high-performance computing, and 3-dimensional optical metrology in order to achieve accurate and timely computations during the design process as well as during the control of the stamping process so as to eliminate a large fraction of the presently required design iterations.

Keywords: Neural Networks, Die Design, Sheet Metal Forming, Optical Metrology, Stamping Process

\section{MICROFABRICATED INSTRUMENTATION FOR CHEMICAL SENSING IN INDUSTRIAL PROCESS CONTROL (ORL97-08) $\$ 99,000$ DOE Contact: Walter M. Polansky, (301) 903-5995 \\ ORNL Contact: J. Michael Ramsey, Chemical and Analytical Sciences Division, (423) $574-5662$}

The monitoring of chemical constituents in manufacturing processes is of economic importance to most industries. The monitoring and control of chemical constituents may also be of importance for product quality control or, in the case of process effluents, of environmental concern. The most common approach now employed for chemical process control is to collect samples which are returned to a conventional chemical analysis laboratory. The objective of this project is to demonstrate the use of microfabricated structures, referred to as "lab-on-a-chip" devices, that accomplish chemical measurement tasks that emulate those performed in the conventional laboratory. The devices envisioned could be used as hand portable chemicalanalysis instruments where samples are analyzed in the field or as emplaced sensors for continuous "real-time" monitoring. This project will focus on the development of filtration elements and solid phase extraction elements that can be monolithically integrated onto electrophoresis and chromatographic structures pioneered at ORNL. Successful demonstration of these additional functional elements on integrated microfabricated devices will allow lab-on-a-chip technologies to address real world samples that would be encountered in process-control environments. The resultant technology will have broad application to industrial environmental monitoring problems such as monitoring municipal water supplies, waste-water effluent from industrial facilities, or monitoring of run-off from agricultural activities. The technology will also be adaptable to manufacturing process control scenarios. This project supports DOE missions in environmental quality and energy efficiency.

Keywords: Microfabricated Instrumentation, Chemical Sensing, Industrial Process Control, "Labon-a-Chip Devices," Chemical Analysis, Environmental Monitoring, Manufacturing Processes

\section{MODELING AND SIMULATION OF ADVANCED SHEET METAL FORMING (PNL94-38) $\$ 170,000$ DOE Contact: Walter M. Polansky, (301) 903-5995 \\ PNNL Contact: Mark Smith, Materiais \& Chemical Sciences, (509) 376-2847}

This project will enhance numerical modeling and simulation of advanced sheet metal forming processes, allowing rapid elevated temperature processing of lightweight aluminum alloy sheet. In this project, improved material deformation models and predictive codes for advanced forming processes will be developed. Development of the new capabilities will allow the manufacturing industries to optimize the component and tooling designs and improve the forming processes without costly trial and error development of the advanced forming technology. Implementation of this modeling and forming technology will enhance the competitiveness of U.S. industry.

Keywords: Advanced Sheet Metal Forming, Modeling and Simulation, Lightweight Al Alloy Sheets, Manufacturing, Competitiveness of U.S. Industry 
MATERIALS PROPERTIES, BEHAVIOR, CHARACTERIZATION OR TESTING

\section{NEXT GENERATION CORROSION INHIBITORS FOR STEEL IN CONCRETE (BNL95-12) $\$ 50,000$ \\ DOE Contact: Walter M. Polansky, (301) 903-5995 \\ BNL Contact: Hugh Isaacs, Applied Science (516) 344-4516}

Steel-reinforced concrete is the most widely used construction material in the world. This is almost an ideal composite, with the steel providing tensile strength and the alkaline concrete imparting passivity to the steel. However, passivity can be compromised by the ingress of chlorides from a marine environment or from de-icing salts. To address this problem, corrosion inhibitors are added to the concrete mixture, usually as simple inorganic anions (e.g. nitrite). Both the mechanism of corrosion in a concrete environment and the action of inhibition are not well understood. The goal of this project is to elucidate the action of corrosion and the behavior of inhibitors. The objective of the study will ultimately be to develop more effective inhibition, possibly by the use of mixed anodic/cathodic inhibitors or altering the form in which the inhibitors are added. Corrosion measurements are being made of the anodic and cathodic kinetics taking place in concrete, which describe the processes occurring with and without inhibitors. Nitrite inhibitors have been found to display different clegrees of effectiveness at various stages during the development of corrosion. In sufficient quantities, the inhibitors maintain passivity. However, they apparently have little action on the very early stages of passivity breakdown. At a later stage, when corrosion is well developed, corrosion is again influenced by nitrite additions. Very small quantities distinctly reduce the corrosion rates, whereas large additions again act to produce passivity and no corrosion. Efforts are now underway to define more closely the critical factors determining the differences in behavior. X-ray absorption near edge measurements will also be performed to examine the effect (if any) of inhibitors on the structure and chemistry of the passive oxide. Research in this area supports the DOE mission in materials characterization and processing.

Keywords: Steel-Reinforced Concrete, Corrosion, Corrosion Inhibitors, Passivation
260. PREVENTIONIELIMINATION OF METALWATER EXPLOSIONS IN ALUMINUM CASTING PITS (ORL92-05)

$\$ 174,000$

DOE Contact: Walter M. Polansky, (301) 903-5995

ORNL Contact: Rusi P. Taleyarkhan, Engineering Technology Division, (423) 576-4735

Metal-water or steam explosions in aluminum industry casting pits have caused numerous injuries and fatalities, and significant damage and destruction of infrastructure over the past fifty years. Traditionally, industry has attempted to prevent explosions by using an empirical-based approach involving the coating of sensitive surfaces with materials like Tarset Standard (TS). However, due to environmental concerns and other reasons, TS is being discontinued from production, leaving industry with the task of evaluating and finding alternate materials. As part of this project with the Aluminum Association (AA), ORNL is investigating how steam explosions initiate over specific surfaces, and what other coatings and novel methods may be appropriate as alternatives to TS. Work completed has resulted in the development and validation of a unique apparatus that, at significant cost reduction, accurately and rapidly simulates in a laboratory environment the interaction of molten aluminum contacting various submerged surfaces without attendant safety problems associated with field experiments involving molten aluminum pours in waterfilled containers. While further testing and theoretical model development still need to be done, unprecedented insights have been obtained on key phenomenological issues. This has enabled the development of a novel approach for conclusive explosion prevention. A patent has been filed and granted for this novel, environmentally-friendly, costeffective approach based on knowledge of fundamentals of the physics of explosion initiation. Field demonstrations are planned. This project supports DOE's energy-related mission to develop a more energy-efficient metal-casting operation. Additionally, this work is expected to provide a better physical understanding of entrapment-boiling heat transfer that could be applied to safety improvements in DOE and commercial nuclear reactors.

Keywords: Aluminum Production, Aluminum Casting Explosion, Molten Aluminum, Heat Transfer, Injuries and Fatalities 


\section{IN-LINE ALUMINUM SENSORS (ORL95-04) $\$ 113,000$ \\ DOE Contact: Walter M. Polansky, (301) 903-5995 \\ ORNL Contact: Jack Young, Chemical \& Analytical Sciences, (423) 574-5241}

The objective of this project is to develop in-line sensors for commercial aluminum electrolysis cell operation. The sensors to be developed will be of a Raman spectral type. The research goal is to develop technology which will allow measurement of soluble alumina, bath ratio and bath temperature. These in-line measurements will be inputs to new process control algorithms that can then be developed to improve the efficiency of aluminum electrolysis operations thereby reducing energy consumption. Such energy saving is in line with the goals of DOE. The improved control algorithm will also lead to a reduction in the anode effect which results in wasted energy and fluorocarbon emission. Reduction of potentially hazardous environmental gases is also a goal of DOE. Along with the development of these sensors, the basic chemistry of the melts will be studied to gain knowledge of speciation and effect of impurities on the process efficiency. A critical parallel study will be carried out to develop sheath materials that will have a useful lifetime (6 months) in cryolite melts. With such sheath materials, the long-term measurement of temperature by standard techniques can also be accomplished.

Keywords: Aluminum Electrolysis Cell, in-Line Sensors, Manufacture

\section{THE ROLE OF YTTRIUM IN IMPROVING THE OXIDATION RESISTANCE IN ADVANCED SINGLE CRYSTAL NICKEL-BASED SUPERALLOYS FOR TURBINE APPLICATIONS (ORL-95-07) \\ $\$ 149,000$ \\ DOE Contact: Walter M. Polansky, (301) 903-5995 \\ ORNL Contact: Kathleen Alexander, Metals and Ceramics Division, (423) 574-0631}

The focus of this project is to examine the role of yttrium and other alloying elements on the microstructure and oxidation performance of improved single crystal nickelbased superalloys for advanced turbine applications. Anticipated improvements from these new alloys include enhanced durability and performance at the high temperatures required to improve energy efficiency. Specific technical goals include: (1) identifying the partitioning behavior of the elemental additions in these superalloys before and after burner rig and engine tests and the effect on the misfit energy between the phases in the alloys; (2) examining the oxidation performance of these newly-developed alloys; and, (3) relating the microstructural observations to the observed performance.

Keywords: Turbines, Ni-Based Superalloys, Oxidation, Yttrium Alloying, Microstructure

\section{ATOMIC SCALE STRUCTURE OF ULTRATHIN MAGNETIC MULTILAYERS AND CORRELATION WITH RESISTANCE, GIANT MAGNETORESISTANCE, AND SPIN- DEPENDENT TUNNELING (ORL97-03) $\$ 100,000$ DOE Contact: Walter M. Polansky, (301) 903-5995 \\ ORNL Contact: William H. Butler, Metals and Ceramics Division, (423) 574-4845}

Giant Magnetoresistance (GMR) and Spin-Dependent Tunneling (SDT) are two recently discovered phenomena that are providing important new insights into how spin affects the transport of electrons in materials. These phenomena have the potential to spark revolutionary advances in several important technologies and both require the controlled deposition of ultrathin films. In order to realize the scientific and technological potential of these phenomena, it is necessary to relate the spin-dependent transport properties to the spin-dependent electronic structure of the deposited structures. Since spin dependent transport is very sensitive to structure at that scale, an understanding of the deposited structures at the atomic scale is required to accomplish that goal. Recent advances in electronic structure theory allow the calculation of spin-dependent transport. The missing key, however, is atomic-scale characterization of the deposited films. Through a close collaboration between theory and experiment, the objective of this project is to determine the physical, chemical, and magnetic structure of GMR and SDT films and to relate their structure to their magnetic and transport properties. This will be achieved by combining a uniquely powertul set of characterization tools, (X-ray Reflection and Diffraction, Atom- Probe Microscopy, Z-Contrast Electron Microscopy with Electron Energy Loss Spectroscopy, and Electron Holography) with firstprinciples computer codes that are capable of calculating the spin-dependent conductivity for realistic systems. The industrial partners (Honeywell Solid State Electronics Center and Nonvolatile Electronics Inc.) are uniquely qualified to optimize their deposition processes and to relate the structures they deposit to the observed spin-dependent transport. Success in this project should lead to better read sensors for magnetic disk drives, a new type of non-volatile radiation resistant magnetic 
random access memory device, and better position and motion sensors for numerous industrial, transportation, and consumer product applications. Additionally, this work enhances DOE's basic materials sciences programs in magnetic structures and advanced characterization methods.

Keywords: Giant Magnetoresistance, Spin-Dependent Tunneling Electron Transport, Magnetic Multilayers, Atomic Scale Structures, Applications

\section{PROCESSINGIPROPERTY RELATIONSHIPS IN CENTRIFUGALLY CAST AL-METAL MATRIX COMPOSITES (MMC) (PNL94-02) $\$ 245,000$ \\ DOE Contact: Walter M. Polansky, (301) 903-5995 \\ PNNL Contact: Ed Courtright, Material Sciences, (509) 375-6926}

The goal of this project is to develop cost-effective selectively reinforced metal matrix processing technology. Light alloy metal matrix composites reinforced with silicon carbide or alumina particulates can replace steel in many automobile applications, and the corresponding reduction in vehicle weight translates to a proportional increase in gas mileage. This project concentrates on understanding the microstructure of centrifugally cast MMC's because the process offers the unique capability to distribute the particle phase in regions or zones where the reinforcements will have the greatest benefit. Emphasis will be placed on understanding processing/property relationships and in determining how these can be controlled to optimize selectively reinforced composite structures.

Keywords: Metal Matrix Processing, Centrifugal Casting, Al-Metal Composites

\section{BIOACTIVE AND POROUS METAL COATINGS FOR IMPROVED TISSUE REGENERATION (PNL95-23) \\ $\$ 191,000$ \\ DOE Contact: Walter M. Polansky, (301) 903-5995 \\ PNINL Contact: Allison Campbell, Materials \& Chemical Sciences, (509) 375-2180}

The goal of this project is to combine complementary technologies and conduct a testing program which would provide information necessary to develop novel health-related technology devices. If the laboratory research demonstrates that metals or alloys can be reproducibly and uniformly coated using PNNL's unique technology and the biologically suitable metallic or alloy devices coated with the technology are shown to have improved performance in selected animal studies and clinical trials, then the potential products will target a growing market currently estimated to be between $\$ 1.2$ to $\$ 1.5$ billion annually.

Keywords: Biologically Suitable Metallic Devices, Tissue Regeneration, Health-Related Technology Devices

\section{ADVANCED ENERGY PROJECTS PROGRAM}

The Division of Advanced Energy Projects (AEP) provides support to explore the feasibility of novel, energy-related concepts that evolve from advances in basic research. These concepts are typically at an early stage of scientific development and, therefore, are premature for consideration by applied research or technology development programs. The AEP also supports high-risk, exploratory concepts that do not readily fit into a program area but could lead to applications that may span several disciplines or technical areas.

The Division provides a mechanism for exploring the conversion of basic research results into applications that could impact the Nation's energy economy. AEP does not support ongoing, evolutionary research or large scale demonstration projects. Technical topics include physical, chemical, materials, engineering, and biotechnologies. Projects can involve interdisciplinary approaches to solve energy-related problems. The DOE Contact for this program is Walter M. Polansky, 301/903-5995.

\section{DEVICE OR COMPONENT FABRICATION BEHAVIOR OR TESTING}

\section{COMPOSITE MAGNETOSTRICTIVE MATERIALS FOR ADVANCED AUTOMOTIVE MAGNETOMECHANICAL SENSORS $\$ 449,000$ \\ DOE Contact: Walter M. Polansky, 301/903-5995 \\ Ames Laboratory Contact: David C. Jiles, $515 / 294-9685$}

There is a well established need for torque sensors for a variety of applications in automobiles. Such sensors can be used for electronic control of the vehicle by monitoring steering and drive train torques. In this project, new highly magnetostrictive materials are being investigated for use in advanced steering systems. Such sensors will eliminate the need for maintaining a pressurized hydraulic power steering system and will improve fuel efficiency by $5 \%$. These sensors will need to meet stringent specifications such as the ability to operate over a range of temperatures between minus $40^{\circ} \mathrm{C}$ and plus $85^{\circ} \mathrm{C}$, be able to survive unexpected mechanical shocks of up to $500 \mathrm{~N}$ and operate under continual vibrational forces of $150 \mathrm{~N}$. In addition, the sensors must be able to sustain overload torques of 135 N.m without malfunctioning or significantly changing 
sensitivity over the normal operating range of $+/-10$ N.m. Analysis of the relationship between the magnetomechanical effect (the change in magnetization with stress) and the magnetostriction (particularly the rate of change of strain with magnetic field) has shown that highly magnetostrictive materials with low anisotropy, and hence high permeability, form the most promising class of materials from which to develop such high performance sensors. This project is therefore investigating the fabrication of composite materials consisting of the highly magnetostrictive material Terfenol-D in a high-strength matrix material, in order to meet the performance specifications for these torque sensors.

Keywords: Magnetostrictive Materials, Torque Sensors, Terfenol-D

\section{ENERGY RELATED APPLICATIONS OF SELECTIVE LINE EMITTERS $\$ 266,000$ DOE Contact: Walter M. Polansky, 301/903-5995 Auburn University Contact: M. Frank Rose, 334/844-5894}

Infrared heat sources are used extensively for many processes in industry. From initial work, it appears feasible to develop intense infrared sources based upon electronic transitions in compounds of the rare earths, which tend to radiate efficiently at discrete wavelengths rather than a continuum. This project is aimed at conducting the basic and exploratory research that will allow the development of high intensity, discrete frequency infrared sources that are custom tailored to specific industrial processes. This will be accomplished by investigating and characterizing the emissive properties of the rare earths in inert forms such as oxides, borides, carbides, or nitrides. The Center for the Rare Earth Elements at the DOE Ames Research Laboratory will be used as the source of information for selection of suitable rare earth elements and compounds. Fibrous inert compounds of the rare earths will be formed as necessary. Oxide fibers can be formed by soaking activated carbon fibers in a suitable liquid compound of the rare earth, such as a nitrate of the material. Since activated carbon fibers can be greater than $70 \%$ porous, a substantial fraction of the liquid can be absorbed for suitable processing. The composite materials are formed into a paper with minor additions of cellulose using standard paper-making technology. Subsequent heating in a reducing atmosphere removes the cellulose and carbon, and forms essentially a pure metallic shell, mimicking the size of the activated carbon precursor. The final dimensions of the rare earth oxide fiber are determined by the initial dimensions of the precursor material. Successful samples will be characterized for strength, flexibility, and lifetime at temperature. Large area radiators for specific frequencies will be constructed and evaluated with the cooperation of an industrial affiliate.

Keywords: Solar Cells, Photovoltaic, MOMBE, Metalorganic Molecular Beam Epitaxy

\section{INVESTIGATION OF HIGH EFFICIENCY MULTI BAND GAP MULTIPLE QUANTUM WELL SOLAR CELLS \\ $\$ 225,000$ \\ DOE Contact: Walter M. Polansky, 301/903-5995 \\ City College of City University of New York Contact: Robert Alfano, 212/650-5532}

This project will investigate and develop multiple quantum well (MQW) solar cells which are expected to reach much higher efficiency than that obtained from conventional bulk solar cells by reducing radiative and nonradiative relaxation processes through resonant tunneling. The maximum energy conversion efficiency of a conventional bulk solar cell is limited to less than $-33 \%$ because of its single band gap. Using a novel MQW-based solar cell with multi band gaps, one expects to enhance the maximum energy efficiency to $-72 \%$. These high efficiency MQW solar cells have the potential of being widely used in compact computers, space power supplies, micro-scale motors, consumer products, home electronic devices, guide signs, and other renewable energy applications. In preliminary studies, we have measured carrier dynamics and band gap structures for GaAs, InP and their alloys, and calculated the resonant tunneling time and the barrier potential design criteria for achieving maximum energy conversion efficiency in MQW structures. Based on these measurements and calculations, we have designed several GaAs- and InP-based MQW solar cell structures which have been fabricated using the MBE facility at CCNY. The current-voltage (I-V) characteristics of the fabricated GaAs/AlGaAs MQW solar cells have been measured, and an enhancement of energy efficiency for the MQW solar cells over that of the conventional bulk solar cells has been observed. This project will enhance these studies and develop high efficiency multiband gap MQW solar cells. We will investigate resonant tunneling times for GaAs/AIGaAs and In GaAs/InP MQW structures to make sure that the resonant tunneling process dominates photocarrier collection. We will measure the I-V characteristics and investigate the energy efficiencies for GaAs/AlGaAs and InGaAs/InP MQW solar cells with different well and barrier configurations to select the best one. We will study multi-unit GaAs-and InP-based MQW solar cells to further increase the range of the band gaps and the energy efficiency. The target for the energy efficiency improvement is at least $150 \%$ for MQW solar cells over the conventional bulk solar cells. Industrial evaluations will be made by two companies (Applied Solar Energy in California and Plasma Physics in New York) during 
this project to determine the scientific and commercial potential of the MQW solar cells.

Keywords: Solar Cells, Photovoltaic, Quantum Well, GaAs/AlGaAs, InGaAs/InP

\section{A NOVEL TANDEM HOMOJUNCTION SOLAR CELL: AN ADVANCED TECHNOLOGY FOR HIGH EFFICIENCY PHOTOVOLTAICS $\$ 2: 55,000$ \\ DCE Contact: Walter M. Polansky, 301/903-5995 \\ Colorado State University Contact: \\ Bruce Parkinson, 970/491-0504}

A material for the construction of a solar cell must meet a number of criteria to be suitable for large scale photovoltaic applications. It must be made up of abundant elements, which are environmentally benign, and when combined into a crystal have suitable electronic properties. The required electronic properties include a bandgap in the $1.1-1.8 \mathrm{eV}$ range, high absorption coefficients to minimize the amount of material required, and high mobilities of photo generated carriers to facilitate the collection of these carriers. The semiconductor, $\mathrm{ZnSnP}$, meets all of the above requirements. It is isoelectronic with the III-V alloy InGaP $\mathrm{G}_{2}$, but has the advantage, for photovoltaic applications, of not containing expensive and rare group III elements. In addition, this material does not contain toxic heavy metals such as are found in CdTe and CulnSe, $/$ CdS thin film solar cells. The absorption coefficient for this material is also very high. The bandgap of $\mathrm{ZnSnP}_{2}$ has the additional interesting and useful property of ranging from 1.24 to $1.66 \mathrm{eV}$, depending on the preparation conditions. Bulk crystal growth techniques have not yielded high mobility $\mathrm{ZnSnP}$ but there is no a priori reason that the electronic properties of these materials cannot be as good as III-V materials, since very high mobilities were only achieved in III-V's after the development of modern epitaxial growth techniques. State-of-the-art metal-organic molecular beam epitaxy (MOMBE) will be used to grow epitaxial layers of $\mathrm{ZnSnP}$ on lattice matched $\mathrm{GaAs}$ substrates. Studies of the order-disorder transition in the metal sublattice, using both optical and electrical techniques and especially solid state NMR to examine atomic scale local environments, will be conducted in order to find the conditions for preparing materials with various bandgap energies and to understand the basic chemistry and physics associated with this interesting order/disorder phase transition. When the conditions are established for preparing a material of a given bandgap, a "tandem homojunction" solar cell will be fabricated by variation of growth conditions in the MOMBE chamber in the appropriate way. This device should show significant efficiency advantages over a single material device or tandem heterojunction devices where lattice mismatch produces recombinationpromoting interface states.

Keywords: Solar Cells, Photovoltaics, MOMBE, Metalorganic Molecular Beam Epitaxy

\section{MAGNETICALLY ENHANCED THERMOELECTRIC COOLING $\$ 250,000$ \\ DOE Contact: Walter M. Polansky, 301/903-5995 \\ Los Alamos National Laboratory Contact: Albert Migliori, 505/667-2515}

Cryogenic solid-state refrigerators based on the Ettinghausen effect can provide vastly superior performance to Peltier devices, opening up new markets in electronics and in superconductor-, and medical applications. Surprisingly, this most effective of solidstate cryogenic refrigeration processes is not being studied at present. Yet it is much less restrictive in the possible materials that can be used, is simpler to construct (even noting that a small permanent magnet must produce a field at the device), and has already achieved lower temperatures than Peltier coolers, the only devices presently under investigation. Recent discoveries of new hybridization-gap semi-conductors and semi-metals, and the commercial availability of high-strength $\mathrm{Nd}_{2} \mathrm{Fe}_{14} \mathrm{~B}$ permanent magnets, open the way for development of new ultra-high-performance, all solid-state Ettinghausen refrigerators. We will initiate studies of such coolers using modern materials to engineer the world's best solid-state cryocooler.

Keywords: Thermoelectric Cooling, Peltier Devices, Solid-State Refrigeration, Ettinhausen Effect

\section{PHOTOCHEMICAL SOLAR CELLS $\$ 150,000$} DOE Contact: Walter M. Polansky, 301/903-5995 National Renewable Energy Laboratory Contact: Arthur J. Nozik, 303/384-6603

Very high power conversion efficiencies (8-12\%) for photochemical solar cells were reported in 1991. These solar cells consist of highly porous nanocrystalline films of $\mathrm{TiO}_{2}$ (band gap=3.0 eV) that are sensitized to the visible region of the solar spectrum through adsorption of Ru-containing metal-organic dye complexes on the $\mathrm{TiO}_{2}$ particle surface. This represents more than two orders of magnitude improvement in the power conversion efficiency of dye-sensitized semiconductor electrodes in a photochemical cell. A dye-sensitized photochemical solar cell system based on $\mathrm{TiO}_{2}$ powders is very attractive from the point of view of potential low cost and high semiconductor photo stability. This project is an integrated program of basic and applied development research that is funded jointly by three U.S. Department of Energy program offices: the 
Division of Chemical Sciences in the Office of Basic Energy Sciences, the Photovoltaic program in the Office of Utility Technology and Advanced Energy Projects. In addition to the molecular dye-sensitized $\mathrm{TiO}_{2}$ system, research is also occurring to study other organic heterojunctions with wide bandgap semiconductors for photovoltaic applications. The AEP portion of the project is to develop a configuration where the system is able to efficiently split water into hydrogen and oxygen, rather than to produce electricity. An inexpensive source of solar-produced hydrogen would be greatly beneficial to the energy economy of the world, and would result in the use of hydrogen as a non-polluting substitute for many of the fuels currently in use.

Keywords: Photochemical Solar Cells, Hydrogen Production, Dye-Sensitive Semiconductors

\section{EFFICIENT ENERGY UP-CONVERSION OF INFRARED TO VISIBLE LIGHT AT SEMICONDUCTOR HETEROJUNCTIONS $\$ 268,000$ \\ DOE Contact: Walter M. Polansky, 301/903-5995 \\ National Renewable Energy Laboratory Contact: Hyeonsik M. Cheong, 303/384-6484}

A recently-discovered energy up-conversion phenomenon in semiconductor heterostructures will be studied. This phenomenon could be used to make light emitting devices that emit a wide range of colors and even multiple colors or white light. Possible applications for such devices are energy-efficient multi-color displays or a white light source to replace incandescent lamps in some areas. The principal advantage of such devices would be that multiple elements of these up-conversion structures with different emission colors, as well as the excitation source for the up-conversion, can be grown monolithically on a single wafer. When GaAs/AIGaln $\mathrm{P}_{2}$ heterostructures are excited with a near-infrared laser at $1.52 \mathrm{eV}(815 \mathrm{~nm})$, electrons and holes are created in the lower-band-gap material (GaAs). Some of these electrons and holes are excited to the higher-band-gap material ( $\mathrm{AlGa} \mid n \mathrm{P}_{2}$ ), and then radiatively recombine at the band gap of AlGaln $P_{2}$, giving up-converted luminescence in red, orange, or green depending on the aluminum concentration in the AlGalnP ${ }_{2}$ alloy. The objective of the study is to demonstrate the feasibility of the devices utilizing this novel phenomenon of upconversion. In order to achieve this, we will examine various semiconductor heterostructures to find the optimal semiconductor heterostructure system that give the highest up-conversion efficiency. This will require sophisticated band-structure engineering using a number of different semiconductors including GaAs, AlGaAs, GalnP ${ }_{2}$, and AlGalnP ${ }_{2}$. We will also perform a systematic study of the mechanism for this upconversion using both $\mathrm{Cw}$ and ultrafast optical spectroscopies. The final phase of this project will be devoted to realization of a prototype device in which either vertical-cavity surface-emitting laser structure or a pn junction is used to excite up-conversion luminescence.

Keywords: Light Emitting Diodes, GaAs, AlGaAs, GaInP $_{2}$, AlGalnP $P_{2}$, Energy Up Conversion, LED

\section{ELECTRICALLY ACTIVE LIQUID MATRIX COMPOSITES \\ $\$ 300,000$ \\ DOE Contact: Walter M. Polansky, 301/903-5995 \\ Oak Ridge National Laboratory Contact: \\ Robert J. Lauf, 423/574-5176}

Varistors are nonlinear electrical resistors used to protect electrical equipment from the damaging effects of power surges. $\mathrm{ZnO}$ varistors are made by standard ceramic processes and are generally formed into cylinders or disks electroded on the end faces. Failure modes include catastrophic fracture, thermal runaway, and slow degradation of electrical properties. "Moldable" surge protective materials, comprising metal and semiconductor particles dispersed in a silicone rubber matrix, are not as nonlinear as $\mathrm{ZnO}$ but can be formed into a number of devices by injection molding. The material fails when an arc punches through at one point, leaving a carbonized, conductive path to ground. We have recently discovered that a slurry of metal, insulating, and semiconducting particles in dielectric oil can exhibit the same nonlinearity as the moldable rubber compositions, but with the added features that it is self-healing, thixotropic, and its I-V characteristics can serve as an excellent model system with which to study the poorly-understood electrical phenomena that occur in moldable varistors. In this project, we will: (1) determine the compositional limits for optimal electrical properties and relate these findings to theoretical percolation models; (2) determine the rheological properties of the experimental materials and identify promising avenues for improving them; and (3) determine the dielectric constants and the temperature dependence of key electrical properties.

Keywords: Liquid Matrix Composites, Surge Protectors, Varistors, $\mathrm{ZnO}$

\section{SEMICONDUCTOR BROADBAND LIGHT EMITTERS \\ $\$ 390,000$ \\ DOE Contact: Walter M. Polansky, 301/903-5995 \\ Sandia National Laboratory Contact: Paul Gourley, 505/844-5806}

Semiconductors are compact, lightweight, operate in air, and are rugged. However, conventional semiconductor diodes emit light only in a narrow range of 
wavelengths. To obtain broadband emission, new structures are needed that utilize a wide range of alloy compositions available from modern semiconductor growth techniques. Fractal lattice and chirped quantum wells form a new class of materials which can provide broadband light emitters. The goal of this project is to develop such multi-alloy structures grown by metal organic vapor phase epitaxy and molecular beam epitaxy for efficient, broadband light emission. To develop broadband emitters, we will focus our efforts on this class of fractal and chirped quantum-well structures utilizing inAlGaP alloys grown by metal-organic vapor phase epitaxy on GaAs substrates. The work will concentrate on three areas: materials design and growth, characterization and modeling, and device design and fabrication. The interplay of these three parallel efforts will lead to optimized device structures that emit broadband light with at least $300 \mathrm{meV}$ bandwidth in the green to red regions and a few percent external quantum efficiency. Materials and design parameters will be understood through a wide variety of experimental and theoretical tools. To implement this new class of broadband emitters, we will design, grow and fabricate light-emitting diode structures, and measure electro luminescence spectra, current-voltage, and light-current characteristics.

Keywords: Broadband Light Emitters, IndiumAluminum-Gallium-Phosphide, Fractal Lattice and Chirped Quantum Wells

\section{MATERIALS PREPARATION, SYNTHESIS, DEPOSITION, GROWTH OR FORMING}

\section{NEXT GENERATION HIGH-TEMPERATURE STRUCTURAL MATERIALS FOR HEAT EXCHANGERS AND HEATING ELEMENTS $\$ 294,000$ \\ DOE Contact: Walter M. Polansky, 301/903-5995 \\ Ames Laboratory Contact: Mufit Akinc, 515/294-0744}

The project is centered on the development of a new generation of electrical furnace heating elements and heat exchangers. Existing materials for heat exchangers and heating elements are limited by their mechanical and/or oxidative stability at high temperatures. $\mathrm{MoSi}_{2}$ is limited by its low creep strength above $1000^{\circ} \mathrm{C}$ whereas other metallic or intermetallic materials are limited to about $1000^{\circ} \mathrm{C}$. Increasing the temperature capability of existing heat exchangers and heating elements by several hundred degrees and/or providing alternative furnace designs will provide significant energy efficiencies as well as ecological benefits. Recent work in our laboratory shows that boron doped $\mathrm{MO}_{5} \mathrm{Si}_{3}$ exhibits outstanding oxidative stability in addition to its excellent high temperature creep strength and high melting point. However, a number of scientific and technical issues remain to be elucidated. An integrated multi-disciplinary approach to synthesis and processing, microstructural, thermomechanical and electrical investigation of select compositions around $\mathrm{Mo}_{5} \mathrm{Si}_{3} \mathrm{~B}$ is being pursued. The investigation will focus on establishing the fundamental relationship between composition, microstructure, and physical properties of B-doped $\mathrm{Mo}_{5} \mathrm{Si}_{3}$. In particular, select compositions will be synthesized and sintered to produce dense parts. A number of compositions will be studied for their stability in air and in corrosive atmospheres up to $1500^{\circ} \mathrm{C}$. Thermomechanical properties of successful conpositions will be investigated as a function of temperature and will be related to their microstructure. Thermoelectric properties such as thermal and electrical conductivity will be determined at temperatures up to $1500^{\circ} \mathrm{C}$ and above. Optimum compositions will be determined and process scale-up will be considered for heating element and heat exchanger applications.

Keywords: Heating Elements, Resistance Heaters, High Temperature Materials, $\mathrm{MoSi}_{2}$, $\mathrm{Mo}_{5} \mathrm{Si}_{3} \mathrm{~B}$

\section{PHOTOREFRACTIVE LIQUID CRYSTALS: NEW MATERIALS FOR ENERGY-EFFICIENT IMAGING TECHNOLOGY $\$ 289,000$ \\ DOE Contact: Walter M. Polansky, 301/903-5995 \\ Argonne National Laboratory Contact: \\ Gary P. Wiederrecht, 630/252-6963}

This project will develop a new class of materials that will be used to produce energy-efficient image processing micro-devices. These materials will exploit the photorefractive effect, a light-induced change in the refractive index of a nonlinear optical material that results from photo generation of a space charge field caused by directional charge transport over macroscopic distances within a solid. Both frequency and phase information contained in light that has passed through a distorting medium can be recovered noisefree using photorefractive materials. The only high quality photorefractive materials commercially available today are expensive single crystals of inorganic materials such as barium titanate. This project will develop a completely new approach that combines cheap, easily processed organic materials with a built-in method of achieving the solid state order necessary to achieve photo refractivity comparable to that seen in inorganic crystals. The new approach uses organic molecules that undergo a phase transition above ambient temperatures to a liquid crystalline phase. Selfordering in the liquid crystalline phase, followed by cooling to an ordered molecular solid, will impart both good optical nonlinearity and directional photoconductivity to thin solid films of these materials. These solid films have the potential to possess greater photorefractive sensitivity and faster response times than any material developed to date. The liquid crystals 
will be based on easily oxidized, disc-shaped organic molecules that are known to have liquid crystalline phases. The specific materials will be derivatives of triphenylenes, coronenes, porphyrins, and phthalocyanines. These molecules can be used to achieve the macroscopic order and good photoinduced charge generation characteristics that are required of high quality photorefractive materials for application throughout the visible and near-infrared spectral regions. Intrinsically asymmetric, nonlinear optical molecules, e.g., a chiral p-nitroaniline derivative, will be attached to the disc-shaped molecules and oriented in the liquid crystalline phase so as to maximize the nonlinear susceptibility of the material. Optical studies on the resulting solids will be utilized to verify the existence of photo refractivity and to accurately characterize the materials. Several device applications will be demonstrated.

Keywords: Photorefractive Liquid Crystals, Image Processing, Nonlinear Optical Materials

\section{TRITIATED POROUS SILICON: A STAND- ALONE POWER SOURCE \\ $\$ 250,000$ \\ DOE Contact: Walter M. Polansky, 301/903-5995 \\ Argonne National Laboratory Contact: \\ Carl E. Johnson, 630/252-7533}

Tritiated porous silicon could form the basis for a new class of stand-alone power sources that are rugged and portable and have high reliability over a very long period (>10 yr.). The tritium is covalently bonded to the silicon and, thus, cannot escape as a gas into the environment. This material would be able to provide the relatively lowlevel power requirement of many types of highly integrated devices in optoelectronics and sensor technology. The proposed research involves three tasks: (1) demonstrate the synthesis of tritiated porous silicon; (2) model the synthesis process; and (3) assess the optical activity of this novel material. The objective of this project is to attain proof-of-concept and lay the foundation for development of a commercial device. The data base resulting from the proposed work would provide a firm foundation for future engineering design efforts aimed at device development for specific applications.

Keywords: Porous Silicon, Power Supplies, Tritium

\section{SUPPORTED MOLTEN METAL CATALYSTS: DEVELOPMENT OF A NEW CLASS OF CATALYSTS $\$ 322,000$ \\ DOE Contact: Walter M. Polansky, 301/903-5995 \\ University of lowa Contact: Ravindra Datta, 319/335-1395}

This project is concerned with the design and development of an entirely novel class of active and selective catalysts called supported molten-metal catalysts (SMMC), with a view to eventually replace some of the existing precious metal heterogeneous catalysts used in the production of fuels and chemicals. SMMC is based on supporting ultra-thin films of the relatively low-melting, inexpensive, and abundant metals and semimetals, from groups la, IIb, IIlb, IVb, $\mathrm{Vb}$, and $\mathrm{Vlb}$ elements, on porous refractory supports, much like supported microcrystallites of traditional solid catalysts. This technique could conceivably provide orders of magnitude higher surface area than that obtainable in conventional reactors containing molten metals in pool form while avoiding corrosion. These have so far been the chief stumbling blocks in the use of molten metal catalysts despite their higher selectivity and lower susceptibility to deactivation. While the SMMC technique can be applied to a large variety of reactions, we will initially concentrate on dehydrogenation and reforming reactions due to their commercial significance. Thus, dehydrogenation of methylcyclohexane and decalin and reforming of methylcyclopentane will be studied. These represent reactions of increasing complexity in catalytic reforming. The initial choice is tellurium-based catalysts including alloys, due to the very promising results obtained in preliminary screening experiments. Other catalytic formulations will also be tested. The activity, selectivity, and stability of the selected catalysts will be compared with the traditional Pt catalyst in differential packed-bed reactors. The commercial potential of the developed catalysts will be explored.

Keywords: Molten Metal Catalysts, SMMC, Dehydrogenation, Reforming

\section{COMBINATORIAL SYNTHESIS OF HIGH $T_{c}$ SUPERCONDUCTORS $\$ 250,000$ \\ DOE Contact: Walter M. Polansky, 301/903-5995 Lawrence Berkeley National Laboratory:

$$
X \text {. D. Xiang, 510/486-6640 }
$$

Currently, there is a tremendous interest in materials such as high temperature superconductors, organic conductors, permanent magnets, nonlinear optical materials and zeolites. However, even though the properties of such materials have been extensively investigated, few general principles have emerged that 
allow one to predict the structures of new materials with enhanced properties. Consequently, the discovery of such materials remains a time consuming and rather unpredictable trial and error process made even more difficult by the increasing complexity of modern materials. The question arises whether there is a more efficient and systematic approach to search through the largely unexplored universe of ternary, quaternary, and higher order solid state compounds, in order to discover materials with novel electronic, optical, magnetic or mechanical properties. We will develop a new approach to materials discovery that will significantly increase the rate at which novel materials are discovered as well as increase our ability to correlate physical properties with structure. Specifically, we will develop the ability to rapidly synthesize and analyze large libraries, or collections, of solid state materials for specific electronic, magnetic, optical and structural properties. The aim of this project is twofold: (1) to develop the technology to the point where it can be used effectively for materials discovery; and (2) to apply the technology to the discovery of new superconducting materials.

Keywords: Combinatorial Synthesis, High Temperature Superconductors, High Tc Superconductors, Superconducting Materials

\section{FABRICATION AND CHARACTERIZATION OF MIC:RON SCALE FERROMAGNETIC FEATURES $\$ 106,000$ \\ DOE Contact: Walter M. Polansky, 301/903-5995 University of Nebraska Contact:}

Peter A. Dowben, 402/472-9838

This is a project to study micro scale features of ferromagnetic nickel, cobalt, cobalt-palladium alloys and cobalt-palladium heterostructures fabricated by "direct writing," i.e., by selective area deposition from organometallic compounds. There are two goals for this research program. First, by making magnetic features smaller and smaller, in a variety of different shapes, the project will elucidate the influence of defects on magnetization reversal and coercivity. Second, the project will determine if there is any coupling between small ferromagnetic features (approx. 1 micron), possibly substrate mediated, on the length scale of 1000 angstroms smaller. This research project is based upon conventional methods for imaging magnetic domains. Polarized light microscopy permits not only imaging micron scale features but also determination of the magnetic orientation and coercivity with some spacial resolution. A microscope will be used to make polar Kerr rotation measurements and obtain spatiallyselective magnetic information. A unique capability for probing the electronic structure of our magnetic features at resonance: spin polarized inverse photoemission with both longitudinal and transverse spin polarization will also be used. Essential to this project is a new technique for fabricating micro-scale ferromagnetic features. Organometallic chemical vapor deposition techniques sufficient to deposit pure metal features with excellent spacial resolution have been developed at this laboratory. These techniques allow selective deposition of large uniform arrays of nickel, cobalt, cobaltpalladium alloys and cobalt-palladium heterostructures in features as small as 0.2 microns, and as thin as a few monolayers or as thick as 10 microns. Multi layers can be made by the successive deposition of different metals or alloys by the sequential photolysis of different organometallic source compounds. While unconventional in many respects, this project utilizes a technology that is compatible with the fabrication of metal features 100 angstroms across in one ScanningTunneling microscopy run. The approach is superior to techniques employing ion beams or conventional lithography and is inexpensive and compatible with the fabrication of the next generation of optical and magnetic recording media.

\section{Keywords: Ferromagnetic Features, Micron-Scale Magnets, Organometallic CVD}

\section{MICRO-HOLLOW CATHODE DISCHARGE ARRAYS: HIGH PRESSURE, NONTHERMAL PLASMA SOURCES \\ $\$ 259,000$ \\ DOE Contact: Walter M. Polansky, 301/903-5995 \\ Old Dominion University Contact: \\ Karl H. Schoenbach, 757/683-4625}

Hollow cathode discharges are known as nonthermal plasma sources: the electron energy distribution in the two stages of the discharge (predischarge and main discharge) contains a large percentage of high energy $(>10 \mathrm{eV})$ electrons. By reducing the size of the cathode holes from $\mathrm{cm}$ to ten's of microns, we were able to extend their range of operation from subtorr range to almost atmospheric pressure. The presence of highenergy electrons and the measured characteristics of micro-hollow cathode discharges, such as: (1) positive current voltage characteristics, which allow the construction of discharge arrays without ballast, (2) stable operation for dc, ac, and pulsed voltages,

(3) low applied voltage (several hundred volts), and

(4) strong radiative emission in the UV, allow the utilization of micro-hollow cathode discharge arrays (MHCDAs) for flat panel displays, surface processing, gaseous emission treatment, and as broad area electron and ion sources. The MHCDAs consist either of sets of metal meshes, spaced a distance on the order of the hole diameter apart, or of metal-plated, perforated dielectric foils. The simplicity, low cost, and the low required voltage for hollow electrode arrays makes MHCDAs strong competitors to other electrotechnologies which rely on nonthermal plasmas (such as barrier discharges, and pulsed corona discharges). 
This project is studying the physics of micro-hollow cathode discharge operation in a positive differential conductivity mode. Particularly, the conditions for discharge array operation at atmospheric pressure are being explored, concentrating on the electron energy distribution and the spectral emission of micro-hollow cathode discharges. This project is focusing on two applications: (1) UV light sources (excimer lamps) for food and water sterilization and for surface treatment; and (2) gas reactors for treatment of hazardous gases, such as perfluoro compounds, used in the semiconductor industry, and volatile organic compounds (VOC's).

\section{Keywords: Plasma Sources, Hollow-Cathode Discharge}

\section{RAPID MELT AND RESOLIDIFICATION OF SURFACE LAYERS USING INTENSE, PULSED ION BEAMS \\ $\$ 300,000$ \\ DOE Contact: Walter M. Polansky, 301/903-5995 \\ Sandia National Laboratories Contact: Bob Turman, 505/845-7119}

In the past, the introduction of new material surface treatments like galvanizing, sputtering, and plasma spraying have enabled new products and opened new markets. The capability to rapidly melt and resolidify surface layers using intense, pulsed ion beams can enable another such advance. This project will develop a next-generation surface processing technology based on new, repetitively-pulsed ion beams. Rapid solidification is known to greatly improve metal surface properties such as corrosion, wear, and fatigue resistance, but the lack of an economic and effective way to apply this technique to surfaces has prevented its use except in high value applications. Intense, pulsed, high energy ion beams treat surfaces through surface melting followed by rapid thermal quenching by thermal diffusion into the underlying, untreated bulk material. This process produces non-equilibrium microstructures, nanocrystalline phases, and extended solid solutions leading to improved corrosion and friction properties of metals, as well as surface smoothing and defect healing, grain refinement, and modification of surface layer hardness. The low cost and in-depth deposition of high energy pulsed ion beams gives pulsed ion beam technology important advantages over laser treatment. The project will determine the capabilities and limitations of rapid melt and resolidification using pulsed ion beams. It will document the non-equilibrium micro-structures produced in treated layers and their effect on metal surface properties and will do the initial process development needed to show how this technique can be applied to commonly used metals. If successful, this will enable new ways to modify surfaces for enhanced properties and lifetimes with greatly improved energy efficiency and costeffectiveness and will enable a significant reduction in the use of heavy metal and solvent-based surface treatment coating processes.

Keywords: Ion Beam Processing, Rapid Solidification, Surface Modification, Pulsed Ion Beams

\section{EXPERIMENTAL AND THEORETICAL INVESTIGATION OF DUAL-LASER ABLATION FOR STOICHIOMETRIC LARGE-AREA MULTICOMPONENT FILM GROWTH $\$ 108,000$ \\ DOE Contact: Walter M. Polansky, 301/903-5995 \\ University of South Florida Contact: \\ Sarath Witanachchi, 813/974-2789}

We have recently discovered a novel dual-laser ablation process that dramatically alters the dynamics of the conventional single-laser ablation process. Initial experiments, using this process, allowed the production of high quality, defect-free films of $\mathrm{Y}_{2} \mathrm{O}_{3}$ that were not possible with single excimer laser ablation. This provided the motivation for investigating the physical mechanisms operative in this novel process. Two major problems associated with single laser ablation have hindered the development of this method as a manufacturing process. They are: (1) deposition of micron and submicron particulates; and (2) relatively narrow expansion profiles that limit the area of uniform film growth. Dual-laser ablation can potentially overcome both these major drawbacks while retaining the main advantages of the single laser ablation technique. A systematic study will be used to ascertain expansion characteristics of individual elements, with different volatility, in a multi-component material system, under the dual-laser ablation process that would determine the required conditions for large-area defect-free stoichiometric film growth. A speciessensitive hydrodynamic model will be used. This will provide a clear understanding of the basic mechanisms operative in this process, and thus aid the process optimization for any material system. The dual-laser ablation system comprises a tandem combination of excimer and $\mathrm{CO}_{2}$ laser pulses with an adjustable interpulse delay, that is spatially overlapped on the target. The primary objective of the research is to study experimentally the effect of the process parameters on the species velocity distribution and expansion profile for individual components, and to develop a speciessensitive theoretical model that is consistent with the experimental observations. The project will investigate a Cu target to establish the process characteristics for a single-element plume. It will also study the expansion characteristics of CuinSe $e_{2}$ and Culn ${ }_{1-x} \mathrm{Ga}_{x} \mathrm{Se}_{2}$ plumes to explore the behavior of individual elements in multicomponent plumes. Investigation of spatial stoichiometric control of $\mathrm{Ga}$ in the Culn $\mathrm{n}_{1-x} \mathrm{Ga}_{x} \mathrm{Se}_{2}$ will aid 
semiconductor doping studies. The new understanding of the dual-laser ablation process will facilitate the extension of this method to other material systems. The method offers ease of control, simplicity and highquality film growth, that could yield a method of choice for both epitaxial and highly oriented polycrystalline multi-cornponent film growth.

Keywords: Laser Ablation, Stoichiometric Evaporation, Dual Laser Ablation

\section{MATERIALS PROPERTIES, BEHAVIOR, CHARACTERIZATION OR TESTING}

\section{SHAPE MEMORY ALLOY REINFORCEMENT OF METALS \\ $\$ 405,000$ \\ DOE Contact: Walter M. Polansky, 301/903-5995 \\ Oak Ridge National Laboratory Contact: Terry N. Tiegs, 423/574-5173}

A dispersed phase of shape memory alloy (SMA) has been employed to increase the hardness of a metal system. The hardness is well known to be directly related to the yield strength of the material and therefore a corresponding increase in the yield strength of the metal system is implied. The SMA works by generating an internal stress state in the matrix metal thereby increasing the stress required for yielding of the metal. The initial effort for the proof of principle used aluminum as the matrix material and NiTi for the shape memory alloy. The basic concept utilizes a dispersion of shape memory alloy particles in a metal matrix to induce internal stresses that increase the hardness and yield strength of the metal. The shape memory effect is a well known phenomenon observed in several material systems. Its characteristic are that when a SMA is mechanically deformed while below a specific transition temperature, it will return to its original shape, when the temperature is raised above the specific temperature. The shape memory alloy reinforcement of metals (SMART) works by: (1) taking a powder metallurgyproduced two-phase composite consisting of SMA particles dispersed in a metal matrix; (2) deforming the composite below the transition temperature; and (3) raising the temperature above the transition temperature to trigger the shape memory effect and induce internal stresses within the composite. Increasing the yield strength and hardness of materials is of considerable importance. Possible applications for SMART include high strength and lightweight structures for vehicles and industrial parts. Also these materials may be used for sensors and actuators where the reversibility of the shape memory effect could be utilized. To progress past the initial development stage for SMART, additional research and development is required. Such R\&D would include development of optimum processing techniques, examination of the reinforcement-matrix interface, determination of the mechanical property envelope (including actual yield and ultimate tensile strength measurements) and survey the corrosion resistance of this class of composites.

Keywords: Shape Memory Alloy, Composite Materials, Metal Matrix Composite

\section{EXPLOITATION OF ROOM TEMPERATURE MOLECULE/ POLYMER MAGNETS FOR MAGNETIC AND ELECTROMAGNETIC INTERFERENCE SHIELDING AND ELECTROMAGNETIC INDUCTION APPLICATIONS \\ $\$ 212,000$}

DOE Contact: Walter M. Polansky, 301/903-5995

Ohio State University: Arthur J. Epstein, $614 / 292-1133$

There are increasing needs in today's society for lightweight, electromagnetic radiation shielding materials for operation at low frequencies ( $<\mathrm{MHz}$ range). This is partially driven by the growth of electric power distribution, telecommunications, and electromechanical power devices; concerns about electromagnetic interference; and an increasing need for lightweight inductive materials for efficient and portable motors and transformers. We reported the first polymer(tetracyanoethylene)-based magnet that remained strongly magnetic up to $350 \mathrm{~K}\left(170^{\circ} \mathrm{F}\right)$. We also demonstrated that more-than doubling of the room temperature magnetization can be achieved using a new route. Molecule/polymer-based magnetic materials are technologically attractive due to anticipated room temperature synthesis, processing, and device manufacture. Though these materials are relatively new, we already demonstrated that unoptimized versions of the materials shield magnetic fields independent of frequency between 10 and $10^{4} \mathrm{~Hz}$ - a range difficult to shield using electrical conductors alone - with initial room-temperature real permeabilities of 13 , which is close to iron. In late 1994, a preliminary report from a French group disclosed that a second class of molecule-based magnets (based on mixed-metal Prussian Blue type materials) has magnetic transitions near room temperature. The report suggests that additional molecule-based magnetic materials may be suitable for magnetic shielding. We have now synthesized similar (but not identical) Prussian Blue type materials with vanadium replacing iron. Our preliminary results on these modified Prussian Bluetype materials revealed an even higher saturation magnetization, though a lower transition temperature than reported by the French group, indicating opportunity for chemical tuning of the magnetic properties including initial permeabilities and transition temperatures. This project involves an integrated synthesis/processing/characterization/modeling component to ascertain the feasibility of using molecule-based magnetic materials, with emphasis on 
the study of the high Tc Prussian Blue-type magnetic materials, for shielding and induction applications from dc/low frequency to communications frequencies. The objective of this project is to establish the ultimately achievable intrinsic real and imaginary magnetic permeabilities and corresponding electric permittivities and their control through synthesis and processing.

Keywords: Polymer Magnets, Molecule-Based Magnets, Electromagnetic Shielding

\section{MOLECULAR SURFACE MODIFICATION AS A} MEANS OF CORROSION CONTROL $\$ 292,000$

DOE Contact: Walter M. Polansky, 301/903-5995

Princeton University Contact:

Andrew B. Bocarsly, 609/258-3888

Corrosion is a major materials problem in many industries. In the petrochemical industry which provides a major market for iron based materials, corrosion challenges exist from the production of hydrocarbons to their refining and conversion to chemical products. Corrosion of concern to the petrochemical industry occurs in a variety of environments ranging from highly acidic to alkaline, and temperatures ranging from room temperature up to $-1100^{\circ} \mathrm{C}$. The goal of this research is to investigate the chemistry of novel organic films (corrosion inhibitors) of 5 angstroms to 20 angstroms dimension that may provide a corrosion resistant barrier on the surface of metallic materials. Joint studies at Princeton University and Exxon Research and Engineering Company suggest that developments in the fields of surface science and materials chemistry are now at a point where an utilitarian molecular view of corrosion processes is possible. This capability is expected to allow for the "molecular design" of next generation inhibitors having the requisite properties to provide for corrosion protection under extreme chemical and thermal conditions. In this project which is a collaborative effort involving members of the Princeton Materials Institute and scientists from Exxon's Research and Engineering Laboratory, state-of-the-art surface characterization tools will be brought together to generate a molecular level understanding of model organic films appropriate for corrosion control. The mechanisms of film protection and film breakdown will be investigated thoroughly. The order and packing density of the films will be studied as a function of temperature, using Grazing Incidence $X$-ray Diffraction involving synchrotron $X$-radiation as a main characterization tool. The interface stability of the molecule, its bonding mechanism and dissociation pathways will be studied by using a combination of spectroscopies such as Temperature Programmed Desorption, High Resolution Electron Energy Loss Spectroscopy and Auger Electron Spectroscopy on model substrate surfaces. Additionally, low energy electron diffraction will be used to characterize the material surface after molecular debonding. The mechanistic understanding derived from these different techniques will be used to construct molecular frameworks that may provide corrosion resistance. The performance of these molecular architectures in real environments will be investigated using electrochemical reactors available at Exxon's Corporate Research Laboratories.

Keywords: Surface Modification, Corrosion Control, Corrosion Inhibitors

\section{SMALL BUSINESS INNOVATION RESEARCH PROGRAM}

\section{MATERIALS, PREPARATION, SYNTHESIS, DEPOSITION, GROWTH OR FORMING}

\section{PHASE I}

Controlled Permeability Chemically Activated Fly Ash (CAFA) for Reactive Contaminant Barrier - DOE Contact Tom Hicks, (803) 725-2027; By-products Development Co. Contact Mr. Thomas Silverstrim, (610) 461-2961

Advanced Multilayer Braze foil for $\mathrm{Si}_{3} \mathrm{~N}$, Joining - DOE Contact Yok Chen, (301) 903-3428; Eltron Research, Inc. Contact Ms. Eileen E. Sammells, (303) 440-8008

A Novel Reactive Joining Compound for High Temperature Applications - DOE Contact Yok Chen, (301) 903-3428; Sienna Technologies, Inc. Contact Dr. Ender Savrun, (425) 485-7272

Fabrication of Active Braze Allovs for High Temperature Service - DOE Contact Yok Chen, (301) 903-3428; Surmet Corporation Contact Dr. Suri A. Sastri, (617) $272-3250$

Diamond-Like Nanocomposites: Hard. Wear Resistant. Low Friction Coatings for Tribological Applications DOE Contact Yok Chen, (301) 903-3428; Advanced Refractory Technologies, Inc. Contact Mr. Keith A. Blakely, (716) 875-4091

High Growth Rate Cubic Boron Nitride Deposition DOE Contact Yok Chen, (301) 903-3428; Applied Science And Technology, Inc. Contact Mr. John M. Tarrh, (617) 937-5135

Development of Novel Boron-Based Multilayer Thin-Film - DOE Contact Yok Chen, (301) 903-3428; Front Edge Technology, Inc. Contact Mr. Stephen Denlinger, (818) 856-8979 
Nano-Layered Diboride Materials with Enhanced Hardness, Strength, and Toughness for Wear Applications - DOE Contact Yok Chen, (301) 903-3428; Hyper-therm High-temperature Composites, Inc. Contact Mr. Wayne S. Steffier, (714) 375-4085

Advanced Plasma Surface Modification System - DOE Contact Yok Chen, (301) 903-3428; Ism Technologies, Inc. Contact Mr. Robert J. Stinner, (619) 530-2332

High-Flux, Low Energy, lon Source for High Rate Ion-Assisted Deposition of Hard Coatings - DOE Contact Yok Chen, (301) 903-3428; Plasmaquest, Inc. Contact Dr. John E. Spencer, (972) 680-1811

An lon Source Design Useful for the Production of Tribiological Thin Films - DOE Contact Yok Chen, (301) 903-3428; Stirling Technologies Inc. Contact Mrs. Bobbie C. Stirling, (423) 483-0142

Semi-Solid Thermal Transformation to Produce Semi-Solid Formable Alloys - DOE Contact Yok Chen, (301) 903-3428; Hot Metal Molding, Inc. Contact Mr. B. Willcox, (541) 298-0814

A Simple Process to Manufacture Grain Aligned Permanent Magnets- DOE Contact Yok Chen, (301) 903-3428; Advanced Materials Corporation Contact Mr. Vijay K. Chandhok, (412)268-5121

A Novel Technique for the Enhancement of Coercivity in High Energy Permanent Magnets- DOE Contact Yok Chen, (301) 903-3428; Advanced Materials Corporation Contact Dr. S.G. Sankar, (412) 268-5649

Controlled Atmosphere Plasma Spraying of NdFeB Magnet Materials - DOE Contact Yok Chen, (301) 903-3428; Aps Material, Inc. Contact Mr. Joseph T. Cheng, (937) 278-6547

Stabilization of Nitride Magnet Material Via Sol-Gel Route - DDE Contact Yok Chen, (301) 903-3428; Chemat Technology, Inc. Contact Ms. Jenny Sajoto, (818) $727-9786$

A Novel Process to Produce Nanostructured Permanent Magnetic Materials - DOE Contact Yok Chen, (301) 903-3428; Nanomaterials Research Corporation Contact Dr. Tapesh Yadav, (520) 294-7115

Coke Resistant Catalyst for the Partial Oxidation Reforming of Hydrocarbon Fuels - DOE Contact JoAnn Milliken, (202) 586-2480; Aspen Systems, Inc. Contact Mr. Hamed Borhanian, (508) 481-5058

CO Tolerant Doped-Metal Oxide Catalysts - DOE Contact JoAnn Milliken, (202) 586-2480; Giner, Inc. Contact Dr. Anthony B. LaConti, (617) 899-7270
Advanced Electrocatalysts for Direct Methanol Oxidation - DOE Contact JoAnn Milliken, (202) 586-2480; Giner, Inc. Contact Dr. Anthony B. LaConti, (617) 899-7270

A Combinatorial Approach to the Synthesis and Characterization of Novel Anode Materials for Direct Methanol Fuel Cells - DOE Contact JoAnn Milliken, (202) 586-2480; Symyx Technologies Contact Mr. Isy Goldwasser, (408) 328-3100

Novel Multifunctional Direct Methanol Fuel Cell Catalysts - DOE Contact JoAnn Milliken, (202) 586-2480; T/j Technologies, Inc. Contact Mr. Leslie Alexander, (313) 213-1637

Low Cost Deposition of Buffer Lavers for Manufacturable YBCO HTS Conductors - DOE Contact James Daley, (202) 586-1165; American Superconductor Corporation Contact Mr. Ramesh Ratan, (508) $836-4200$

Stoichiometric YBCO Epitaxial Coatings on RABITS Using Low Cost CCVD Processing - DOE Contact James Daley, (202) 586-1165; Ccvd, Inc., Dba Microcoating Technologies Contact Dr. Andrew T. Hunt, (770) 457-7767

Buffer Layers on Textured Nickel Using Commercially Viable CCVD Processing - DOE Contact James Daley, (202) 586-1165; Cevd, Inc., Dba Microcoating Technologies Contact Mr. Jeffrey C. Moore, (770) 457-7767

Micromachined SiC Sensors For Harsh Environment Applications - DOE Contact Rolf Butters, (202) 586-0984; Advanced Technology Materials, Inc. Contact Dr. Duncan W. Brown, (203) 794-1100

Silicon Carbide Sensors for Harsh Environments - DOE Contact Rolf Butters, (202) 586-0984; Busek Company, Inc. Contact Mrs. J. Budny, (508) 655-5565

Development of Efficient and Practical Passive Solar Building Systems with High Recycled Content Using the Preplaced Aggregate Concrete Technology - DOE Contact Mary Margaret Jenior, (202) 586-2998; Dpd, Inc. Contact Ms. Faragnis Jamzadeh, (517) 349-5653

Heterogeneous Hydroformylation of Alkanes with Syngas - DOE Contact Donald Krastman, (412) 892-4720; Tda Research, Inc. Contact Mr. Michael E. Karpuk, (303) 940-2301

Advanced NZP-Ceramic Based Thermal Barrier Coatings with Enhanced Oxidation and Thermal Shock Resistance - DOE Contact Udaya Rao, (412) 892-4743; Lotec, Inc. Contact Mr. Santosh Y. Limaye, (801) 483-3100 
Tubular SOFC with Deposited Nano-Scale YSZ Electrolyte - DOE Contact Udaya Rao, (412) 892-4743; Nextech Materials, Ltd. Contact Mr. William J. Dawson, (614) 766-4895

Integrated Bandpass Filter Contacts for TPV Cells DOE Contact Bill Barnett, (301) 903-3097; Edtek, Inc.

Contact Mr. William E. Horne, (206) 395-8084

In-Situ Ultrahigh-Pressure Wateriet Peening of Nuclear Reactor Internals for the Prevention of Stress Corrosion Cracking - DOE Contact John Warren, (301) 903-6491; Waterjet Technology, Inc. Contact Ms. Diana Suzuki, (206) 872-1925

Thallium-Containing III-V Quaternary Compound Semiconductor for Use in Infrared Detection - DOE Contact Karl Veith, (202) 586-6002; Astropower, Inc. Contact Mr. Thomas J. Stiner, (302) 366-0400

High Speed Long Wavelength Infrared Detector Array/Preamplifier Development - DOE Contact Carl Friesen, (208) 526-1765; Fermionics Corporation Contact Dr. Peter C.C. Wang, (805) 582-0155

Development of Cadmium Germanium Arsenide Crystals - DOE Contact Carl Friesen, (208) 526-1765; Inrad, Inc. Contact Mr. James L. Greco, 201-767-1910

AllnGaN Light Emitting Diodes for Spectroscopic Applications - DOE Contact Carl Friesen, (208) 526-1765; Svt Associates, Inc. Contact Dr. Peter Chow, (612) 934-2100

\section{An Easily Dispersed Reactive Coating for Surface} Decontamination - DOE Contact Carl Friesen, (208) 526-1765; Lynntech, Inc. Contact Dr. Oliver J. Murphy, (409) 693-0017

High Quantum Efficiency Spin-polarized Photocathodes - DOE Contact Jerry Peters, (301) 903-5228; Spire Corporation Contact Mr. Richard S. Gregorio, (617) $275-6,000$

Rapid Quench $\mathrm{Nb}_{3} \mathrm{Al}$ for High Field Accelerator Applications - DOE Contact Jerry Peters, (301) 903-5228; Plastronic, Inc. Contact Mr. Michael Tomsic, (937) 335-0656

Ultra-Lightweight Carbon-Carbon Cooling Structure For Pixel and Silicon Strip Detectors - DOE Contact Richard Plano, (301) 903-4801; Hytec, Inc. Contact Mr. William O. Miller, (505) 662-0080
Epitaxial Growth of SiC on Silicon for Radiation Hard Particle Detectors - DOE Contact Richard Plano, (301) 903-4801; Lawrence Semiconductor Research Laboratory, Inc. Contact Lamonte H. Lawrence, (602) $438-2300$

Development of Scintillators and Waveshifters for Detection of lonizing Radiation - DOE Contact Richard Plano, (301) 903-4801; Ludlum Measurements, Inc. Contact Mr. Donald G. Ludlum, (915) 235-5494

Low Viscosity Organic Insulation Systems For Improved Processing and Reduced Radiation Induced Gas Evolution - DOE Contact $H$. Stanley Staten, (301) 903-4950; Eltron Research, Inc. Contact Ms. Eileen E. Sammells, (303) 440-8008

Radiation Resistant Joining Methods for Structural Applications in Fusion Energy Systems - DOE Contact F. W. Wiffen, (301) 903-4963; Starfire Systems, Inc. Contact Dr. Walter Sherwood, (518) 276-2112

\section{PHASE \| (FIRST YEAR)}

An Attrition-Resistant Zinc Titante Sorbent for a Iransport Reactor - DOE Contact Daniel C. Cicero, (304) 285-4826; Intercat Development, Inc. Contact Ms. Wendy L. Hansen, (908) 223-4644

A Light Scattering Based Sensor for On-Line Monitoring of Fiber Diameter Distribution During Fiberglass Manufacturing - DOE Contact Rolf Butters, (202) 586-0984; Mission Research Corporation Contact Mr. Scot R. Fries, (805) 963-8761

Novel Use of Gas Jet Plasma to Prepare Amorphous Silicon Alloy - DOE Contact Alec Bulawka, (202) 586-5633; Energy Conversion Devices, Inc. Contact Ms. Nancy M. Bacon, (810) 280-1900

High Rate Deposition of Transparent Conducting Zinc Oxide Using Activated Oxygen for Photovoltaic Manufacturing Cost Reduction - DOE Contact Alec Bulawka, (202) 586-5633; Energy Photovoltaics, Inc. Contact Mr. David A. Jackson, (609) 587-3,000

Development of Optimal $\mathrm{SnO}_{2}$ Contacts for CdTe Photovoltaic Applications - DOE Contact Yok Chen, (301) 903-3428; Green Development, LLC Contact Dr. Jianping $X_{i},(303)$ 278-4571

Large Area, Low Cost Processing for CIS Photovoltaics - DOE Contact Yok Chen, (301) 903-3428; International Solar Electric Technology, Inc. Contact Dr. Bulent Basol, (310) 216-4427

Improved Processes for Forming CIS Films - DOE Contact Yok Chen, (301) 903-3428; Unisun Contact Dr. Chris Eberspacher, (805) 499-7840 
Ultrafast Polysilylene Scintillators - DOE Contact Tim Fitzsimmons, (301) 903-9830; Adherent Technologies, Inc. Contact Ms. Susan K. Switzer, (505) 822-9186

\section{PHASE III (SECOND YEAR)}

Low Cost. Contamination-Tolerant Electrocatalysts for Low-Temperature Fuel Cells - DOE Contact David Koegel, (301) 903-5997; Aspen Systems, Inc. Contact Dr. Kang P. Lee, (508) 481-5058

A Low Cost. High Temperature Superconductor Wire Manufacturing Technology - DOE Contact James Daley, (202) 586-1165; American Superconductor Corporation Contact Mr. Ramesh Ratan, (508) 836-4200

A Low Cost Receiver Plate Manufacturing Process for Hiah Concentration Photovoltaic Systems - DOE Contact Alec Bulawka, (202) 586-5633; Amonix, Inc. Contact Mr. Vahan Garboushian, (310) 325-8091

An Intumescent Mat Material for Joining of Ceramics to Metals at High Temperatures - DOE Contact William J. Gwilliam, (304) 285-4401; CeraMem Corporation Contact Dr. Robert L. Goldsmith, (617) 899-0467

Development of Modulator Quality Rubidium Titanyl Arsenate Crystals for Remote Sensing Laser Systems DOE Contact Michael O'Connell, (202) 586-9311; Crystal Associates, Inc. Contact Mr. G. M. Loiacono, (201) 612-0060

A Novel Method to Recycle Thin Film Semiconductor Materials - DOE Contact Alec Bulawka, (202) 586-5633; Drinkard Metalox, inc. Contact Mr. Fred Gallagher, (704) $332-8173$

An Improved Material and Low-Cost Fabrication Options for Candle Filters- DOE Contact William J. Gwilliam, (304) 285-4401; FluiDyne Engineering Corporation Contact Dr. Gary J. Hanus, (612) 544-2721

An Integrated Catalyst/Collector Structure for Regenerative Proton-Exchange Membrane Fuel Cells DOE Contact David Koegel, (301) 903-5997; Giner, Inc. Contact Dr. Anthony B. LaConti, (617) 899-7270

Nanostructured interstitial Alloys as Catalysts for Direct Energy Applications - DOE Contact David Koegel, (301) 903-5997; Nanomaterials Research Corporation Contact Dir. Angelo Yializis, (602) 575-1354

Environmentally Responsible Recycling of Thin-Film Cadmium Telluride Modules - DOE Contact Alec Bulawka, (202) 586-5633; Solar Cells, Inc. Contact Mr. Frederick L. Yocum, (419) 534-3377
Low-Cost. Large-Area, High-Resistivity Substrates for Gas Microstrip Detectors - DOE Contact Richard Meyer, (301) 903-3613; Spire Corporation Contact Mr. Richard S. Gregorio, (617) $275-6000$

An Economic Sorbent for the Removal of Mercury. Chlorine, and Hydrogen Chloride from Coal Combustion Flue Gases - DOE Contact Sean Plasynski, (412) 892-4867; TDA Research, Inc. Contact Michael E. Karpuk, (303) 940-2301

\section{MATERIALS PROPERTIES, BEHAVIOR, CHARACTERIZATION OR TESTING}

\section{PHASE I}

Nondestructive Measurements of Key Mechanical Properties of Alloy 718 Welded Structures Using Novel Stress-Strain Microprobe Technology - DOE Contact Yok Chen, (301) 903-3428; Advanced Technology Corporation Contact Mr. Fahmy M. Haggag, (423) $483-5756$

Processing For Surface Hardness: Novel Characterization Techniques for Dynamic Tribological Properties of Thin Films - DOE Contact Yok Chen, (301) 903-3428; Nano Instruments, Inc. Contact Dr. Warren C. Oliver, (423) 481-8454

A Novel Mass Spectrometer for Characterization of Electrochemical Processes - DOE Contact Al Landgrebe, (202) 586-1483; Southwest Sciences, Inc. Contact Mr. Alan C. Stanton, (505) 984-1322

New Insulation Techniques for High Voltage. High Frequency Motors - DOE Contact Jim Merritt, (202) 586-0903; Satcon Technology Corporation Contact Mr. David B. Eisenhaure, (617) 661-0540

Development of Carbon Products from the Waste Stream of the Super Critical Deashing Process in Coal Liquefaction - DOE Contact Thomas Brown,

(412) 892-4691; Fiber Materials, Inc. Contact Mr. David R. Audie, (207) 282-5911

Sol-Gel Coatings as Corrosion Barriers for Carbonate Fuel Cell Components - DOE Contact Udaya Rao, (412) 892-4743; Energy Research Corporation Contact Mr. Hans C. Maru, (203) 825-6006

Enhanced Flaw Detection by Time-Reversal Auto-Focusing of an Ulitrasonic Array - DOE Contact John Warren, (301) 903-6491; Foster-Miller, Inc. Contact Mr. Adi R. Guzdar, (617) 684-4239

High Resolution Cryogenic Calorimeter for Beta and Gamma Ray Detection - DOE Contact Dick Meyer, (301) 903-3613; Concept Technology Contact Dr. Alan Singsaas, (619) 695-0402 
High Current Density High Repetition Rate Ferroelectric Cathode - DOE Contact Jerry Peters, (301) 903-5228 Fm Technologies, Inc. Contact Dr. Frederick M. Mako, (703) 425-5111

High Current Capacity High Temperature Superconducting Film Based Tape for High Field Magnets - DOE Contact Jerry Peters, (301) 903-5228; Midwest Superconductivity, Inc. Contact Dr. Jonathan W. Wilson, (913) 749-3613

A Polycrystalline Pixel Diamond Film Particle Detector DOE Contact Richard Plano, (301) 903-4801; Applied Science And Technology, Inc. Contact Mr. John M. Tarrh, (617) 937-5135

Resistance Welding Vanadium Alloys - DOE Contact F. W. Wiffen, (301) 903-4963; Hitech Metallurgical Co. Contact Mr. Kenneth H. Holko, (619) 586-7272

Low Cost Technique for Testing Ceramic Insulator Coatings - DOE Contact F. W. Wiffen, (301) 903-4963; Reb Research And Consulting Contact Dr. Robert E. Buxbaum, (810) 547-7942

\section{PHASE || (FIRST YEAR)}

Carbon Monoxide Tolerant Anodes for Proton Exchange Membrane (PEM) Fuel Cells - DOE Contact Ronald J. Fiskum, (202) 586-9154; EIC Laboratories, Inc. Contact Dr. A. C. Makrides, (617) 769-9450

Low Cost Advanced Bipolar Plates for Proton Exchange Membrane Fuel Cells - DOE Contact Ronald J. Fiskum, (202) 586-9154; Materials And Electrochemical Research (MER) Contact Dr. J. C. Withers, (520) 574-1980

Improved Bi-2223 Flux Pinning Through Chemical Doping - DOE Contact James Daley, (202) 586-1165; American Superconductor Corporation Contact Mr. Ramesh Ratan, (508) 836-4200

Low Cost Multifilament Composite Process - DOE Contact James Daley, (202) 586-1165; American Superconductor Corporation Contact Mr. Ramesh Ratan, (508) 836-4200

Template-Mediated Synthesis of Periodic Membranes for Improved Liquid-Phase Separations - DOE Contact Kristine Bilenki, (301) 903-1687; American Research Corporation Of Virginia Contact Mrs. Anne Churchill, (540) 731-0655

Novel Fiber-Based Adsorbent Technology - DOE Contact Kristine Bilenki, (301) 903-1687; Chemica Technologies, Inc. Contact Mr. Daniel J. Brose, (541) 385-0355
Metal-Binding Silica Materials for Wastewater Cleanup DOE Contact Kristine Bilenki, (301) 903-1687; Tpl, Inc. Contact Ms. Jacqueline Taylor, (505) 343-8890

Superhard Nanophase Cutter Materials for Rock Drilling Applications - DOE Contact Paul Grabowski, (202) 586-0478; Diamond Materials, Inc. Contact Dr. Bernard H. Kear, (908) 445-2245

Evaluation and Constitutive Modeling of Unidirectional SiC/SiC Composites with Engineered SiC Fiber Coatings Subjected to Neutron Irradiation - DOE Contact F. W. Wiffen, (301) 903-4963; Hyper-therm High-temperature Composites, Inc. Contact Mr. Wayne S Steffier, (714) 375-4085

Innovative Fabrication of SiC/SiC Composites with High Through-the-Thickness Thermal Conductivity - DOE Contact F. W. Wiffen, (301) 903-4963; Materials And Electrochemical Research (MER) Contact Dr. R. O. Loutfy, (520) 574-1980

High Numerical Aperture Scintillating Fibers - DOE Contact Robert Woods, (301) 903-3367; Biogeneral, Inc. Contact Ms. Andrea Gray, (619) 453-4451

\section{PHASE II (SECOND YEAR)}

Rotating, In-Plane Magnetization and Magneto-Optic Imaging of Cracks Under Coatings on Ferromagnetic Metals - DOE Contact Dennis Harrison, (301) 903-2884; Physical Research, Inc. Contact Dr. William C. L. Shih, (310) 378-0056

Development of Laser Materials and Rugged Coatings as Components for Tunable Ultraviolet Laser Systems DOE Contact Michael O'Connell, (202) 586-9311; Lightning Optical Corporation Contact Mr. Wayne Ignatuk, (813) 938-0092

Application of Raman Spectroscopy to Identification and Sorting of Post-Consumer Plastics for Recycling - DOE Contact Simon Friedrich, (202) 586-6759; National Recovery Technologies, inc. Contact Dr. Charles E. Roos, (615) 734-6400

A Sensor for Automated Plastics Sorting - DOE Contact Simon Friedrich,(202) 586-6759; Radiation Monitoring Devices, Inc. Contact Dr. Gerald Entine, (617) 926-1167 


\section{DEVICE OR COMPONENT FABRICATION, BEHAVIOR OR TESTING}

\section{PHASE I}

Hydrocarbon Gas Sensors Based on Wide Band-Gap Semiconductors - DOE Contact Wanda Ferrell, (301) 903-0043; Svt Associates, Inc. Contact Dr. Peter Chow, (612) 934-2100

Shaft Weld Replacement with a Ceramic Locking Assembly Joint - DOE Contact Yok Chen, (301) 903-3428; Goss Engineers, Inc. Contact Ms. Gabrielle M. Goss, (303) 721-8783

A Novel Technology for $\mathrm{Si}_{3} \mathrm{~N}_{4}$-To Superalloy Joints With High Use Temperature Capability - DOE Contact Yok Chen, (301) 903-3428; Materials And Electrochemical Research (MER) Contact Dr. Raouf Loutfy, (520) 574-1980

Development of Economical Procedures for Producing and Processing Fine Grained SSM Feedstock via Mechanical Stirring - DOE Contact Yok Chen, (301) 903-3428; Formcast, Inc. Contact Mr. Charles Carlberg, (303) 778-6566

A New Semi-Solid Forming Process For Fabrication of High Volume Fraction ( $>15$ vol\%) Metal/Metal Carbide Nanocomposites - DOE Contact Yok Chen, (301) 903-3428; Nanopowder Enterprises, Inc. Contact Dr. Gary S. Tompa, (908) 885-5909

Alternative Metal Forming Using Laser Engineered Net Shaping - DOE Contact Yok Chen, (301) 903-3428; Optomec Design Company Contact Mr. Thomas A. Swann, (505) 343-9139

Production of High Performance BSCCO-2223 Tapes Using Hydrostatic Pressure - DOE Contact James Daley, (202) 586-1165; American Superconductor Corporation Contact Mr. Ramesh Ratan,

(508) 836-4200

Development of Long-length Fabrication Technology for High $T_{c}$ Superconductors Operation in High Magnetic Fields at $77 \mathrm{~K}$ - DOE Contact James Daley, (202) 586-1165; Ues, Inc. Contact Mr. Francis F. Williams, Jr., (937) 426-6900

Non-Linear Inductor for Power Electronics Protection DOE Contact Jim Merritt, (202) 586-0903; Energen, Inc. Contact Dr. Chad H. Joshi, (617) 271-9876

Novel Fabrication of Low Cost Performance Bipolar Plates - DOE Contact Jim Merritt, (202) 586-0903; Materials And Electrochemical Research (MER) Contact Dr. J. C. Withers, (520) 574-1980
Corrosion Resistant Bipolar Plates for PEM Fuel Cells DOE Contact Jim Merritt, (202) 586-0903; Physical Sciences Inc. Contact Mr. George E. Caledonia, (508) 689-0003

Reduced Part Count Motor Fabrication - DOE Contact Jim Merritt, (202) 586-0903; Unique Mobility, Inc. Contact Mr. Donald A. French, (303) 278-2002

Removal of Particulate and $\mathrm{SO}, \mathrm{NO}_{\mathrm{x}}$ Precursors in Integrated Gasification Combined Cycle Systems - DOE Contact Mildred Perry, (412) 892-6015; Industrial Filter And Pump Manufacturing Company Contact Mr. Jeffrey D. Burgeson, (708) 656-7800

Use of Novel, Low-Cost Additives to Improve Sorbent Efficiency for Control of Mercury Emissions in Coal-Fired Power Plant Flue Gases - DOE Contact Thomas Brown, (412) 892-4691; Physical Sciences Inc. Contact Mr. George E. Caledonia, (508) 689-0003

Mixed Phase Positive Electrodes for Long Life AMTEC Modules - DOE Contact Bill Barnett, (301) 903-3097; Tda Research, Inc. Contact Mr. Michael E. Karpuk, (303) $940-2301$

High Brightness LEDs Based on the (Al, Ga, In)N Materials System - DOE Contact Karl Veith, (202) 586-6002; Advanced Technology Materials, Inc. Contact Dr. Duncan W. Brown, (203) 794-1100

Development of High Power RF Windows and Waveguide Components For the Next Linear Collider DOE Contact Jerry Peters, (301) 903-5228; Calabazas Creek Research Contact Dr. R. Lawrence Ives, (408) $741-8680$

Cost Reduction for Production of Superconducting Niobium Cavities - DOE Contact Jerry Peters, (301) 903-5228; Meyer Tool \& Mfg., Inc. Contact Mr. Edward C. Bonnema, (708) 425-9080

Electrical Discharge Machining Application to the Development of mm-wave Accelerating Structures DOE Contact Jerry Peters, (301) 903-5228; Ron Witherspoon, Inc. Contact Dr. Steven Schwartzkopf, (408) $370-6620$

Direct Adhesive Technology for Arbitrary Conductors DOE Contact Jerry Peters, (301) 903-5228; Advanced Magnet Laboratory, Inc. Contact Mr. Mark W. Senti, (407) $728-7543$

Controlled Processing for High-Performance Fine Filament Bi-2223 Conductors - DOE Contact Jerry Peters, (301) 903-5228; American Superconductor Corporation Contact Mr. Ramesh Ratan, (508) $836-4200$ 
Development of a High Field NbTi Superconductor Using an Approach Combining Artificial Flux Pinning With Conventional Thermomechanical Processing DOE Contact Jerry Peters, (301) 903-5228; Supercon, Inc. Contact Ms. Elaine Drew, (508) 842-0174

Conventionally Processed NbTi Superconductors with Artificial Ferromagnetic Pinning Centers for High Magnetic Field ( $>8$ T) Application - DOE Contact Jerry Peters, (301) 903-5228; Supercon, Inc. Contact Ms. Elaine Drew, (508) 842-0174

Liquid Core Optical Scintillating Fibers - DOE Contact Richard Plano, (301) 903-4801; Nano Systems, Inc. Contact Mr. Robert W. Boerstler, (203) 881-2827

High Performance Heat Pipe Cooling of Electron Cyclotron Heating Mirrors P12-2426 - DOE Contact T. V. George, (301) 903-4957; Thermacore, Inc. Contact Mr. Donald M. Ernst, (717) 569-6551

Reaction Bonding of Silicon Carbide Composites for Fusion Applications - DOE Contact F. W. Wiffen, (301) 903-4963; Busek Company, Inc. Contact Mrs. J. Budny, (508) 655-5565

Net Shape Gradient W-Cu Plasma Facing Components by Pressure Infiltration - DOE Contact Sam E. Berk, (301) 903-4171; Foster-miller, Inc. Contact Mr. Adi R. Guzdar, (617) 684-4239

Joining of Silicon Carbide for Fusion Applications - DOE Contact F. W. Wiffen, (301) 903-4963; Lanxide Corporation Contact Mr. Marc S. Newkirk, (302) 456-6217

A Novel Divertor Design Based on a Tungsten Wire Brush Tile - DOE Contact Sam E. Berk, (301) 903-4171; Materials And Electrochemical Research (MER) Contact Dr. Raouf O. Loutfy, (520) 574-1980

Beryllium and Tungsten Brush Armor for Plasma Facing Components - DOE Contact Sam E. Berk, (301) 903-4171; Plasma Processes, Inc. Contact Ms. Cheri McKechnie, (205) 851-7653

Fabrication for Reliable Tungsten Brush Structures for Fusion Reactor Applications - DOE Contact Sam E. Berk, (301) 903-4171; Surmet Corporation Contact Dr. Suri A. Sastri, (617) 272-3250

\section{PHASE II (FIRST YEAR)}

Catalytic Membrane for High Temperature Hydrogen Separations - DOE Contact Otis Mills, (412) 892-5890; Ceramem Corporation Contact Dr. Robert L. Goldsmith, (617) 899-0467
Advanced Coal Based Power System Components Using Reaction Bonded Silicon Carbide - DOE Contact Otis Mills, (412) 892-5890; Busek Company, Inc. Contact Mrs. J. Budny, (508) 655-5565

A New Separation and Treatment Method for Soil and Groundwater Restoration - DOE Contact Kristine Bilenki, (301) 903-1687; Lynntech, Inc. Contact Dr. Olive J. Murphy, (409) 693-0017

Continuous Analyzer for Monitoring Hydrogen Chloride and Chlorine During Site Cleanup Activity - DOE Contact Michael Torbert, (301) 903-7109; Ada Technologies, Inc. Contact Dr. Judith Armstrong, (303) $792-5615$

Long-Life Electrical Neutron Generator - DOE Contact Michael O'Connell, (202) 586-9311; First Point Scientific, Inc. Contact Dr. John R. Bayless, (818) $707-1131$

Passive Electronic Components from Nanostructured Materials - DOE Contact David Koegel, (301) 903-3159; Nanomaterials Research Corporation Contact Mr. Thomas Venable, (520) 294-7115

A Multicore Optical Fiber Sensor for Mass Transport and Particulates - DOE Contact Wanda Ferrell, (301) 903-0043; Owen Research, Inc. Contact Mr. Brian L. Sperry, (303) 427-1312

Infrared Hollow Waveguide Organic Solvent Analyzer DOE Contact Wanda Ferrell, (301) 903-0043; Polestar Technologies, Inc. Contact Ms. Karen K. Carpenter, (617) $449-2284$

Stratospheric Water Vapor Microsensor - DOE Contact Wanda Ferrell, (301) 903-0043; Deacon Research Contact Dr. Olive Lee, (415) 493-6100

Compact, Airborne Laser Multigas Sensor - DOE Contact Wanda Ferrell, (301) 903-0043; Physical Sciences, Inc. Contact Mr. George E. Caledonia, (508) 689-0003

Microwave Radiometer for Passively and Remotely Measuring Atmospheric Water Vapor - DOE Contact Wanda Ferrell, (301) 903-0043; Radiometrics Corporation Contact Dr. Randolph Ware, (303) 497-8005

Advanced Water Sensor for Unmanned Aerial Vehicles DOE Contact Wanda Ferrell, (301) 903-0043;

Southwest Sciences, Inc. Contact Dr. Alan C. Stanton, (505) 984-1322

High-Gain Monocapillary Optics - DOE Contact Tim Fitzsimmons, (301) 903-9830; Aracor Contact Mr. Ed LeBaker, (408) 733-7780 
High Performance X-Ray and Neutron Microfocusing Optics - DOE Contact Tim Fitzsimmons, (301) 903-9830; Hirsch Scientific Contact Mr. Gregory Hirsch, (415) 359-3920

Very Low Friction Small Radius Domed Cutters for Percussion Drill Bits - DOE Contact Paul Grabowski, (202) 586-0478; Novatek Contact Mr. David R. Hall, (801) $37.4-6000$

Developrnent and Testing of a Jet Assisted Polvcrystalline Diamond Drilling Bit - DOE Contact Paul Grabowski, (202) 586-0478; Novatek Contact Mr. David R. Hall, (801) 374-6000

Advanced Low-Stress Bonding of Thermally Stable Polycrystalline Diamond Cutters to Tungsten Carbide Substrates - DOE Contact Paul Grabowski, (202) 586-0478; Science Research Laboratory, Inc. Contact Dr. Jonah Jacob, (617) 547-1122

Nanocrystalline Superhard, Ductile Ceramic Coatings for Roller Cone Bit Bearings - DOE Contact Paul Grabowski, (202) 586-0478; Spire Corporation Contact Mr. Richard S Gregorio, (617) 275-6000

Solid-State Ultracapacitors for Electric Vehicles and Consumer Electronics - DOE Contact Al Landgrebe, (202) 586-1483; Cape Cod Research, Inc. Contact Ms. Katherine D. Finnegan, (508) 540-4400

Hiah Surface Area Non-Oxide Ceramic Electrodes for Ultracapacitors - DOE Contact Al Landgrebe, (202) 586-1483; T/J Technologies, Inc. Contact Mr. Leslie Alexander, (313) 213-1637

Wrappable Inorganic Electrical Insulators for Superconducting Magnets - DOE Contact T. V. George, (301) 903-4957; Composite Technology Development, Inc. Contact Dr. Naseem A. Munshi, (303) 447-2226

Joining of Tungsten Armor Using Functional Gradients DOE Contact T. V. George, (301) 903-4957; Plasma Processes, Inc. Contact Ms. Cheri McKechnie, (205) $851-7653$

Carbon Thermostructure for Silicon-Based Particle Detectors - DOE Contact Richard Plano, (301) 903-4801; Energy Science Laboratories, Inc. Contact Dr. Timothy R. Knowles, (619) 552-2034

High Performance Optical Detectors for Calorimetry DOE Contact Robert Woods, (301) 903-3367; Radiation Monitoring Devices, Inc. Contact Dr. Gerald Entine, (617) 926-1167
Coplanar CdZnTe 0-I-n, Gamma-Ray Detectors for Nuclear Spectroscopy - DOE Contact Richard Rinkenberger, (301) 903-3613; Spire Corporation Contact Mr. Richard S. Gregorio, (617) 275-6000

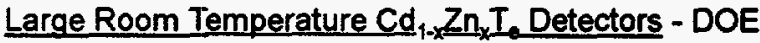
Contact Richard Rinkenberger, (301) 903-3613; W. Peter Trower, Inc. Contact Dr. W. Peter Trower, (540) 953-2249

In-Situ Nondestructive Measurements of Key Mechanical Properties of Reactor Pressure Vessels Using Innovative SSM Technology - DOE Contact John Warren, (301) 903-6491; Advanced Technology Corporation Contact Mr. Fahmy M. Haggag, (423) 483-5756

Oxidation Induction Time Technology for Electric Cable Condition Monitoring and Life-Assessment - DOE Contact Duli Agarwal, (301) 903-3919; Pacific-sierra Research Corporation Contact Mr. Norman L. Duncan, (703) 516-6372

\section{PHASE II (SECOND YEAR)}

Advanced High Power Silicon Carbide Internally Cooled X-Ray - DOE Contact Bill Oosterhuis, (301) 903-3426; SSG, Inc. Contact Mr. Dexter Wang, (617) 890-0204.

Chemical Microsensor Arrays as Intearated Chip Compatible Devices for Chemical Weapons Nonproliferation Inspection - DOE Contact Robert Marianelli, (301) 903-5808; Microsensor Systems, Inc. Contact Dr. Hank Wohitjen, (502) 745-0099

A High Resolution Multi-hit Time to Digital Converter Integrated Circuit - DOE Contact Robert Woods, (301) 903-3367; Lecroy Corporation Contact Mr. Joseph Migliozzi, (914) 578-6006

A Helium-Cooled Faraday Shield Using Porous Metal Cooling - DOE Contact T. V. George, (301) 903-4957; Thermacore, Inc. Contact Mr. Donald M. Ernst, (717) 569-6551

Low Cost Fabrication of Large Silicon Carbide/Silicon Carbide Composite Structures - DOE Contact F. W. Wiffen, (301) 903-4963; Lanxide Corporation Contact Dr. Christopher Kennedy, (302) 456-6320

Bandgap-Engineered Thermophotovoltaic Devices for High Efficiency Radioisotope Power - DOE Contact Bill Barnett, (301) 903-3097; Edtek, Inc. Contact Mr. W. E. Horne, (206) 395-8084

Rugged, Tunable Infrared Laser Sources - DOE Contact Michael O'Connell, (202) 586-9311; Deacon Research Contact Dr. Olive Lee, (415) 493-6100 
An Innovative Membrane and Process for Removal and Recovery of Natural Gas Liquids - DOE Contact William J. Gwilliam, (304) 285-4401; Membrane Technology And Research, Inc. Contact

Ms. E. G. Weiss, (415) 328-2228

A Lower Cost Molten Carbonate Matrix - DOE Contact William J. Gwilliam, (304) 285-4401; M-C Power Corporation Contact Mr. Patrick F. McSweeney, (708) $986-8040$

\section{SMALL BUSINESS TECHNOLOGY TRANSFER PROGRAM}

\section{MATERIALS PREPARATION, SYNTHESIS, DEPOSITION, GROWTH OR FORMING}

\section{PHASE I}

Improved Beta-Alumina Fabrication Using Rapid Plasma Sintering - DOE Contact David Koegel, (301) 903-3159; Advanced Modular Power Systems, Inc. Contact Dr. Thomas Hunt, (313) 677-4260

New High-Performance GaSb-Based Thermophotovoltaic (TPV) Devices - DOE Contact David Koegel, (301) 903-3159; Astro Power, Inc. Contact Dr. Allen Barnett (302) 366-0400

High Efficiency Magnetic Refrigerators as Alternate Environmentally Safe Commercial Refrigeration Devices - DOE Contact David Koegel, (301) 903-3159; Materials and Electrochemical Research Corp. Contact Dr. R. O. Loutty, (520) 574-1980

\section{PHASE II (FIRST YEAR)}

Cabled Monofilament Subelements for Improved Multifilament Niobium Tin Performance and Reduced Cost - DOE Contact Jerry Peters, (301) 903-5228; Supercon, Inc. Contact Ms. Elaine Drew, (508) 842-0174

\section{PHASE \| (SECOND YEAR)}

Laser Processing of Thermal Sprayed Beryllium Plasma Facing Components - DOE Contact T. V. George, (301) 903-4957; Plasma Processes, Inc. Contact Mr. Tim McKechnie, (205) 851-7653

Amorphous Silicon/Crystalline Silicon Heterojunctions for Nuclear Radiation Detector Applications - DOE Contact Richard Rinkenberger, (301) 903-3613; Quantrad Sensor, inc. Contact Dr. Nicholas J. Szluk, (408) $727-7827$
Low Loss Sapphire Windows for High Power Microwave Transmission - DOE Contact T. V. George, (301) 903-4957; Thoughtventions Unlimited Contact Dr. Stephen C. Bates, (203) 657-9014

\section{DEVICE OR COMPONENT FABRICATION, BEHAVIOR OR TESTING}

\section{PHASE 1}

Novel Thin Film Scintillator for Intermediate Energy Photons Detection and Imaging - DOE Contact Dick Meyer, (301) 903-4398; NZ Applied Technologies, Inc. Contact Mr. Peter Norris, (617) 935-0300

Silicon Carbide Heat Exchanger for Advanced CoalBased Power Systems - DOE Contact Udaya Rao, (412) 892-4743; Busek Company, Inc. Contact Dr. Vlad Hruby, (508) 655-5565

Advanced Ceramic Hot Gas Filters - DOE Contact Theodore McMahon, (304) 285-4865; LoTec, Inc. Contact Mr Santosh Y. Limaye, (801) 483-3100

\section{PHASE II (FIRST YEAR)}

High Speed Motor Alternators for Hybrid Electric Vehicle Energy Storage - DOE Contact Jim Merritt, (202) 586-0903, SatCon Technology Corporation Contract Mr. Michael Turmelle, (617) 349-0861

A Flywheel Motor Alternator for Hybrid Electric Vehicles - DOE Contact Jim Merritt, (202) 586-0903; Visual Computing Systems Corporation Contact Mr. Robert J. Westerkamp, (812) 923-7474

\section{PHASE II (SECOND YEAR)}

Environmentally Benign Manufacturing of Compact Disk Stampers - DOE Contact Helen Kerch, (301) 903-2346; Prism Company Contact Mr. Peter Ciriello, (508) 785-2511

\section{OFFICE OF FUSION ENERGY SCIENCES}

The mission of the Office of Fusion Energy Sciences (OFES) is to advance plasma science, fusion science and fusion technology-the knowledge base needed for an economically and environmentally attractive fusion energy source. The policy goals that support this mission are: (1) advance plasma science in pursuit of national science and technology goals; (2) develop fusion science, technology and plasma confinement innovations as the central theme of the domestic program; and (3) pursue fusion energy science and technology as a partner in the international effort. 
A significant component of the fusion energy program is the development and validation of the materials required for the fusion systems. Materials must be developed that will meet the unique requirements of fusion, as well as the standard requirements of a high efficiency, high reliability power generating system. The unique requirements of fusion are the result of the intense neutron environment, dominated by the $14 \mathrm{MeV}$ neutrons characteristic of the deuterium-tritium fusion reaction. For performance, the materials must have slow and predictable degradation of properties in this neutron environment. For safety and environmental considerations, materials must be selected with activation products that neither decay too rapidly (affecting such safety factors as system decay heat) nor too slowly (affecting the waste management concerns for end-of-life system components). Materials that meet these requirements are referred to as "Low Activation Materialsi." Programs to develop the materials for plasma-facing components, for diagnostic and control systems, for structures in the high neutron flux regions, for the production of tritium in the blanket, and for the superconducting magnets required for confinement are sponsored by OFES.

The fusion materials program in the United States is conducted with a high degree of international cooperation. Bilateral agreements with Japan and the Russian Federation enhance the ability of each party to mount fission reactor irradiation experiments. The Fusion Materials Agreement under the International Energy Agency (IEA) serves as a usefull venue for the exchange of information and the coordination of programs of research on Fusion Materials. Of particular importance is the International Thermonuclear Experimental Reactor (ITER) engineering design activity, conducted in partnership with the European Union, Japan, and the Russian Federation. More than one-half of the materials work sponsored by OFES is in support of the ITER collaboration.

\section{MATERIALS PROPERTIES, BEHAVIOR, CHARACTERIZATION OR TESTING}

\section{STRUCTURAL MATERIALS DEVELOPMENT $\$ 670,000$ \\ DOE Contact: F. W. Wiffen (301) 903-4963 \\ ANL Contact: D. L. Smith (630) 252-4837}

This program is directed at the development of advanced, low activation structural materials for application in fusion power system first wall and blankets. Emphasis at ANL is on the development of vanadium-base alloys and on chemical corrosion/ compatibility of the structural materials with other system materials. The vanadium alloy development is focused on the V-Cr-Ti system, with the goals of identifying promising candidate compositions, determining the properties of candidate alloys, and evaluating the response to irradiation conditions that simulate anticipated fusion system operation. The compatibility studies include vanadium and other candidate structural materials, and focus on the effects of exposure to projected coolants, including liquid lithium and helium.

Keywords: Vanadium, Compatibility, Lithium, Irradiation Effects, Alloy Development

\author{
288. MODELING IRRADIATION EFFECTS IN \\ SOLIDS \\ $\$ 50,000$ \\ DOE Contact: F. W. Wiffen, (301) 903-4963 \\ LLNL Contact: T. Diaz de la Rubia, \\ (510) $422-6714$
}

Large scale computer simulation and experimental data on irradiation effects are combined to extend the understanding of the primary damage processes in solids. Special attention is given to the energy range appropriate for the $14 \mathrm{MeV}$ neutrons produced in D-T fusion, and to the materials of interest for fusion systems.

Keywords: Modeling, Irradiation Effects

\section{FUSION SYSTEMS MATERIALS $\$ 3,270,000$ \\ DOE Contact: F. W. Wiffen, (301) 903-4963 \\ ORNL Contacts: E. E. Bloom, (423) 574-5053 and A. F. Rowcliffe, (423) 574-5057}

This program is directed at the development and qualification of structural materials and insulating ceramics for use in components of fusion power systems exposed to the intense neutron flux. Candidate low activation structural material systems include ferritic/martensitic steels, vanadium alloys and SiC/SiC composites. Investigations focus on the most critical questions or limiting properties in each of these systems: ferritic/ martensitic steels-DBTT transition shifts and fracture toughness; vanadium alloyswelding processes, effects of irradiation on fracture toughness, and compatibility in proposed coolant systems; SiC/SiC composites-definition of the effects of irradiation on properties and structure and evaluation of advanced composite fibers and coatings. The insulating ceramic activity is initially developing an understanding of irradiation effects in alumina, spinel and other materials. The greatest concern is to establish the permanent and transient changes in electrical properties, requiring measurement while the specimen is under irradiation. Work on these material classes involves irradiation in fission reactors, including HFIR, 
HFBR, and other test reactors, as partial simulation of the fusion environment.

Keywords: Ceramics, Steels, Vanadium, Silicon Carbide, Composites, Irradiation Effects, Electrical Properties

\section{STRUCTURAL MATERIALS FOR FUSION SYSTEMS $\$ 960,000$} DOE Contact: F. W. Wiffen, (301) 903-4963 PNNL Contacts: R. H. Jones, (509) 376-4276 and R. Kurtz, (509) 373-7515

The goal of this program is to develop an understanding of radiation effects that provides a basis for development of irradiation-insensitive materials. The objective is low activation materials for use as structures in divertor, first wall, and blanket components of fusion systems. Irradiation in fission reactors is used to simulate fusion conditions, with measurement of physical and mechanical properties used to track irradiation effects. A modeling activity complements the experimental measurements. The ultimate goal is optimized ferritic steels, vanadium alloys, and $\mathrm{SiC} / \mathrm{SiC}$ composite materials for fusion power plant use.

Keywords: Steels, Vanadium, Silicon Carbide, Composites, Irradiation Effects, Modeling

\section{DEVELOPMENT OF RADIATION-HARDENED CERAMIC COMPOSITES FOR FUSION APPLICATIONS

This research is directed at furthering the understanding of the effects of irradiation on the $\mathrm{SiC} / \mathrm{SiC}$ composite system, as the basis for developing superior composite materials for fusion structural applications. The focus of the work is on the evaluation of improved fibers and alternative interface layer materials.

Keywords: Silicon Carbide, Composites

\section{DAMAGE ANALYSIS AND FUNDAMENTAL STUDIES FOR FUSION REACTOR MATERIALS DEVELOPMENT \\ $\$ 150,000$ \\ DOE Contact: F. W. Wiffen, (301) 903-4963 \\ UCSB Contacts: G. R. Odette, (805) 893-3525 and G. E. Lucas, (805) 893-4069}

This research is directed at developing a fundamental understanding of both the basic damage process and microstructural evolution that take place in a material during neutron irradiation. This understanding is used with empirical data to develop physically-based models of irradiation effects. The focus is on the fracture properties of vanadium alloys and ferritic stainless steels, including helium effects, to: (a) develop an integrated approach to integrity assessment, (b) develop advanced methods of measuring fracture properties, and (c) analyze the degradation of the mechanical properties of steels. The program also contributes to the assessment of the feasibility of using these alloys in ITER and other fusion systems.

Keywords: Vanadium, Steels, Irradiation Effects Fracture

\section{DEVELOPMENT OF LITHIUM-BEARING CERAMIC MATERIALS FOR TRITIUM BREEDING IN FUSION REACTORS $\$ 100,000$ DOE Contact: S. Berk, (301) 903-4171 \\ ANL Contact: C. Johnson, (630) 252-7533}

Research activities are focused on critical issues of ceramic breeder blankets for fusion reactors, including ceramic breeder material tritium retention and release, ceramic breeder and beryllium irradiation response, chemical compatibility of ceramic breeder materials and beryllium with blanket coolant and structural materials, and heat transfer and temperature control in ceramic breeder materials. Computer models are tested against data on irradiation of lithium-oxide and lithium-zirconate materials in a fast-spectrum fission reactor. There is good agreement between model predictions and experimental data in the area of transient tritium release.

Keywords: Ceramics, Compatibility, Tritium Release, Modeling, Lithium Ceramics

\section{POST-IRRADIATION EXAMINATION OF LITHIUM-BEARING CERAMIC MATERIALS FOR TRITIUM BREEDING IN FUSION REACTORS \\ $\$ 20,000$ \\ DOE Contact: S. Berk, (301) 903-4171 \\ PNNL Contact: G. Hollenberg, (509) 376-5515}

Research activities are for post-irradiation examinations (PIE) of the ceramic breeder materials irradiated in the Fast Flux Test Facility. The PIE was conducted as part of the BEATRIX-II program under an International Energy Agency agreement between the US, Japan and Canada. PIE involved capsule disassembly, neutron radiography, plenum gas analysis, photography, mensuration characterization, tritium inventory measurements, microstructural characterization and thermal conductivity measurements. PIE for specimens from the BEATRIX-II Phase 1 irradiation (lithium-oxide irradiated to 5 percent lithium atom burnup) and the 
Phase 2 irradition (lithium-oxide and lithium-zirconate irradiated to 5 percent lithium atom burnup) was completed in FY 1995.

Keywords: Ceramics, Lithium Ceramics, Tritium Release

295. INTERNATIONAL THERMONUCLEAR EXPERIMENTAL REACTOR (ITER) MATERIALS DEVELOPMENT FOR PLASMA FACING COMPONENTS

$\$ 5,000,000$

DOE Contact: S. Berk, (301) 903-4171

SNL Contact: M. Ulrickson, (505) 845-3020

Research activities include: improved techniques for joining beryllium or tungsten to copper alloys, determination of the tritium retention of beryllium, improvement of the thermal conductivity of plasma sprayed beryllium, development of radiation damage resistant carbon-fiber composites, determination of erosion rates of beryllium, tungsten and carbon under normal and disruption conditions and thermal fatigue testing of beryllium, tungsten and carbon-fiber composites. The joining techniques being investigated include diffusion bonding, induction brazing, electroplating and inertial welding. Tritium retention and permeation measurements have been conducted on the Tritium Plasma Experiment. The improvements in the plasma spray technique are centered on improving the beryllium powder and selection of the proper powder sizes. Highly oriented pitch based carbon fibers have been used to produce carbon-fiber composite for neutron irradiation. The erosion rates are measured on both plasma simulators and tokamaks. The thermal fatigue testing is carried out on electron beam test systems.

Keywords: Plasma-Facing Components, Beryllium, Tungsten, Carbon-Fiber Composite, Joining, Erosion, Thermal Fatigue

\section{ITER MATERIALS EVALUATION} $\$ 330,000$

DOE Contact: F. W. Wiffen, (301) 903-4963

ORNL Contacts: E. E. Bloom, (423) 574-5053 and A. F. Rowcliffe, (423) 574-5057

ITER requires structural materials and insulating ceramics for use in a range of system components exposed to the neutrons produced by the fusion reaction. ORNL's part of the ITER materials program is directed at the selection of promising compositions of copper alloys, evaluating bonded copper alloy-stainless steel structures and assisting in the development of the database needed for the use of these materials. Irradiation effects and mechanical properties of these materials are under study. The insulating ceramics work is focused on the electrical properties under irradiation, and the in situ measurement techniques to determine this response are being developed. The work at ORNL emphasizes the use of the HFIR and of fission test reactors in Russia to perform the irradiations in support of the ITER materials development and evaluation.

Keywords: Steels, Copper, Vanadium, Ceramics, Irradiation Effects, Electrical Properties

\section{ITER STRUCTURAL MATERIALS EVALUATION $\$ 200,000$ \\ DOE Contact: F. W. Wiffen, (301) 903-4963 \\ PNNL Contact: R. H. Jones, (509) 376-4276}

Materials systems of interest to ITER for use as structural materials in the divertor, first wall and blankets are under evaluation to select the most attractive candidates in each system, and to develop the property database on these. The PNNL program is evaluating copper alloys and stainless steels for the ITER program. The emphasis is on irradiation effects, especially on fracture properties, for the bonded structures.

Keywords: Steels, Copper, Irradiation Effects

298. DEVELOPMENT OF $\mathrm{Nb}_{3} \mathrm{Sn}$ SUPERCONDUCTING WIRE FOR THE ITER MAGNET PROGRAM $\$ 200,000$ DOE Contact: T. V. George, (301) 903-4957 MIT Contact: J. Minervini, (617) 253-5503

A major development and industrial procurement activity of a high critical current density $\mathrm{Nb}_{3} \mathrm{Sn}$ superconducting wire for use in the ITER Model Coil program was completed recently. Intermagnetics General Corporation/Advanced Superconductors Inc. (IGC/ASI) delivered over 5 metric tons of superconducting wire to the ITER HP1 strand specification. The strand was subsequently cabled by BIW, Inc. into 4 cables of greater than 1000 strands, each over $200 \mathrm{~m}$ long, for use in the US Inner Coil Module of the ITER CS Model Coil. The strand procurement program was supported by characterization and acceptance measurements of strand critical superconducting properties and ac losses by several university and national laboratories. Further work is continuing to enhance the wire performance while reducing production costs.

Keywords: Superconductors, Magnet Materials, $\mathrm{Nb}_{3} \mathrm{Sn}$

\section{STRUCTURAL MATERIALS DEVELOPMENT FOR THE CONDUIT OF ITER CABLE-IN-CONDUIT-CONDUCTORS $\$ 200,000$ \\ DOE Contact: T. V. George, (301) 903-4957 MIT Contact: J. Minervini, (617) 253-5503}

The conduit material selected for the ITER cable-in-conduit-conductors is the high strength superalloy Incoloy Alloy 908 , developed via collaboration between INCO Alloys International (IAI) 
and MIT. IAI has recently delivered over 60 metric tons of this material in the shape of square extrusions with a circular hole, in unit lengths up to $10 \mathrm{~m}$, for the ITER CS Model Coil Program. A significant database has been developed by materials properties characterization as well as industrial processing experience and coil winding experience. Work is continuing on alloy development to reduce the sensitivity of the material to Stress Accelerated Grain Boundary Oxidation (SAGBO).

Keywords: Conduit, Incoloy, Magnet Materials 
The Influence of Radiation and Multivalent Cation Additions on Phase Separation and Crystallization of Glass

241,000

Chemical and Ceramic Methods Toward Safe Storage of Actinides Using Monazite

Atmospheric-Pressure Plasma Cleaning of Contaminated Surfaces

404,000

Chemical Decomposition of High-level Nuclear Waste Storage/Disposal Glasses Under Irradiation

Analysis of Surface Leaching Processes in Vitrified High-Level Nuclear Wastes Using in situ Raman Imaging and Atomistic Modeling

Investigation of Microscopic Radiation Damage in Waste Forms Using ODNMR and AEM Techniques

in situ Spectro-Electrochemical Studies of Radionuclide Contaminated Surface Films on Metals and the Mechanism of their Formation and Dissolution

Determination of Transmutation Effects in Crystalline Waste Forms

Radiation Effects on Materials in the Near-Field of Nuclear Waste Repository

An Alternative Host Matrix Based on Iron Phosphate Glasses for the Vitrification of Specialized Nuclear Waste Forms

Microstructural Properties of High Level Waste Concentrates and Gels with Raman and Infrared Spectroscopies

Fundamental Thermodynamics of Actinide-Bearing Mineral Waste Forms

Photooxidation of Organic Wastes Using Semiconductor Nanoclusters

Optimization of Thermochemical, Kinetic, and Electrochemical Factors Governing Partitioning of Radionuclides During Melt Decontamination of Radioactively Contaminated Stainless Steel

Mechanism of Pitting Corrosion Prevention by Nitrite in Carbon Steel Exposed To Dilute Salt Solution

Stability of High-Level Waste Forms

Radiation Effects in Nuclear Waste Materials

New Silicotitanate Waste Forms: Development and Characterization

lon-Exchange Processes and Mechanisms in Glasses

Distribution \& Solubility of Radionuclides \& Neutron Absorbers in Waste Forms for Disposition of Plutonium Ash \& Scraps, Excess Plutonium, and Miscellaneous Spent Nuclear Fuels

Modeling of Diffusion of Plutonium in Other Metals and of Gaseous Species in Plutonium-Based Systems 
Office of Environmental Management

\section{OFFICE OF ENVIRONMENTAL MANAGEMENT}

The Office of Environmental Management (EM) was established to effectively coordinate and manage the Department's activities to remediate the DOE Defense Complex and to properly manage waste generated by current operations. EM conducts materials research within two offices:

Office of Waste Management - The Office of Waste Management uses current technologies to minimize production of DOE-generated waste, alter current processes to reduce waste generation, and work with the Office of Science and Technology to develop innovative technologies for the treatment and disposal of present and future waste streams. The mission of the Office is to minimize, treat, store, and dispose of DOE waste to protect human health, safety, and the environment.

Office of Science and Technology - The Office of Science and Technology (OST) is responsible for managing and directing targeted basic research and focused, solution-oriented technology development programs to support the DOE Office of Environmental Management (EM). Programs involve research, development, demonstration, and deployment activities that are designed to produce innovative technologies and technology systems to meet national needs for regulatory compliance, lower life-cycle costs, and reduced risks to both people and the environment. Certain areas of the OST program focus on materials research in order to provide better, safer and less expensive approaches to identify, characterize and remediate DOE's waste problem.

Four Focus Areas have been formed to focus the EM-wide technology development activities on DOE's most pressing environmental management problems and are co-led by all EM offices:

Subsurface Contaminants. Hazardous and radioactive contaminants in soil and groundwater exist throughout the DOE complex, including radionuclides, heavy metals, and dense, nonaqueous phase liquids. Groundwater plumes have contaminated over 600 billion gallons of water and 50 million cubic meters of soil. In addition, the Subsurface Contaminants Focus Area is responsible for supplying technologies for the remediation of numerous landfills at DOE facilities. Technology developed within this speciality area provides effective methods to contain contaminant plumes and new or alternative technologies for remediating contaminated soils and groundwater.

Radioactive Tank Waste Remediation. Across the DOE Complex, hundreds of large storage tanks contain hundreds of thousands of cubic meters of high-level mixed waste. Primary areas of concern are deteriorating tank structures and consequent leakage of their contents. Research and technology development activities must focus on the development of safe, reliable, cost-effective methods of characterization, retrieval, treatment, and final disposal of the wastes.

Mixed Waste Characterization, Treatment, and Disposal. DOE faces major technical challenges in the management of low-level radioactive mixed waste. Several conflicting regulations together with a lack of definitive mixed waste treatment standards hamper mixed waste treatment and disposal. Disposal capacity for mixed waste is also expensive and severely limited. DOE now spends millions of dollars annually to store mixed waste because of the lack of accepted treatment technology and disposal capacity. In addition, currently available waste management practices require extensive, and hence costly waste characterization before disposal. Therefore, DOE must pursue technology that leads to better and less expensive characterization, retrieval, handling, treatment, and disposal of mixed waste.

Decontamination and Decommissioning. The aging of DOE's weapons facilities, along with the reduction in nuclear weapons production, has resulted in a need to transition, decommission, deactivate, and dispose of numerous facilities contaminated with radionuclides and hazardous materials. While building and scrap materials at the sites are a potential resource, with a significant economic value, current regulations lack clear release standards. This indirectly discourages the recovery, recycling, and/or reuse of these resources. The development of enhanced technologies for the decontamination of these materials, and effective communication of the low relative risks involved, will facilitate the recovery, recycle, and/or reuse of these resources. Improved materials removal, handling, and processing technologies will enhance worker safety and reduce cost.

The projects listed in this report are managed under the Environmental Management Research Program (EMSP), a joint program of EM and the Office of Energy Research (ER). Basic research under the EMSP contributes to environmental management activities that decrease risk to the public and workers, provide opportunities for major cost reductions, reduce time required to achieve EM's mission goals, and, in general, address problems that are considered intractable without new knowledge. This program is designed to inspire "breakthroughs" in areas critical to the EM mission through basic research and is managed in partnership with ER. ER's well-established procedures are used for merit review of applications to the EMSP. Subsequent to the formal scientific merit review, applications that are judged scientifically meritorious are evaluated by DOE for relevance to the objectives of the EMSP. The current EMSP portfolio consists of 202 awards amounting to a total of $\$ 160$ million in three-year funding. Twenty-one of those awards were in scientific disciplines related to materials issues that have potential to solve Environmental Management challenges. The 1997 
component of materials research amounts to $\$ 6,870,939$. This figure is smaller than that reported for FY96 because of a redefinition of the materials research component. The entire EMSP portfolio can be viewed on the World Wide Web at http://WWIN.em.doe.gov/science.

MATERIALS PROPERTIES, BEHAVIOR, CHARACTERIZATION OR TESTING

\section{THE INFLUENCE OF RADIATION AND MULTIVALENT CATION ADDITIONS ON PHASE SEPARATION AND CRYSTALLIZATION OF GLASS \\ $\$ 241,000$ \\ DOE Contact: Chet Miller, (202) 586-3952 \\ University of Arizona Contact: \\ Michael C. Weinberg, (520) 621-6909}

Recent reviews which have dealt with critical issues regarding the suitability of glasses for nuclear waste disposal have identified liquid-liquid immiscibility and crystallization processes as having the potential to alter significantly storage behavior, especially chemical corrosion characteristics. These phase transformation processes can be abetted (or deterred) by radiation or the inclusion of small quantities of other components such as transition metals, rare earths, actinides, etc. Consequently, in order to minimize the chances for the occurrence of deleterious phase separation or crystallization, it is essential to examine the influence of these factors on phase transformation kinetics.

The major goal of this program is to study the influence of irradiation and multivalent cations and redox conditions upon the thermodynamics and kinetics of phase separation and crystallization in selected glass compositions. Any observed changes in transformation behavior will be related to structural modifications caused by radiation. Finally, guidelines will be developed to mitigate the deleterious effects of phase separation and crystallization by composition adjustments, based on the development of a database from ongoing and existing measurements and the development of appropriate models.

The characteristics of phase separation are being analyzed, experimentally, using SEM, EDS, HSEM, TEM, and SAXS. Crystallization is being studied using XRD, SEM, TEM, and optical microscopy. Structural changes are being examined using IR and Raman Spectroscopies and solid state NMR measurements.

Keywords: Radiation, Phase Separation, Crystallization, Glasses

\section{CHEMICAL AND CERAMIC METHODS TOWARD SAFE STORAGE OF ACTINIDES USING MONAZITE $\$ 429,000$ DOE Contact: Chet Miller, (202) 586-3952 Rockwell International Corporation Contact: P.E.D. Morgan, (805) 373-4273 \\ ORNL Contact: Lynn A. Boatner, (423) $574-5492$}

The program is investigating monazite ceramics for safe, secure, geologically tested, very long term, containment for actinides. The main outstanding fundamental research issues facing the use of monazite as a waste form necessitate the development of fundamental understanding of: sintering mechanisms involved in forming high density monazite ceramics; physical and chemical properties of grain boundaries in these ceramics; interactions with impurities and additives used to promote densification; physical properties of polycrystalline monazite ceramics; and the precipitation of monazite phases in an efficient, simple and economical manner. This program is addressing these issues to serve as a knowledge base for using monazite as a nuclear waste form.

Keywords: Monazite, Waste Form, Sintering, Densification

\section{ATMOSPHERIC-PRESSURE PLASMA CLEANING OF CONTAMINATED SURFACES $\$ 404,000$ \\ DOE Contact: Chet Miller, (202) 586-3952 \\ University of California at Los Angeles Contact: Robert F. Hicks, (310) 206-6865 \\ LANL Contact: Gary Selwyn,} (505) 667-7824

Decommissioning of transuranic waste (TRU) into low-level radioactive waste (LLW) represents the largest cleanup cost associated with the nuclear weapons complex. This project is developing a low-cost technology for converting TRU into LLW based on the selective plasma etching of plutonium and other actinides from contaminated structures. Plasma etching has already been used to remove $\mathrm{Pu}$ films from materials. However, this process is operated under vacuum, making it both expensive and difficult to apply to many nuclear wastes. A major breakthrough in this field was the demonstration of the operation of a g-mode, resonant-cavity, atmospheric-pressure plasma jet (APPJ). This jet etches kapton at between 10 and $15 \mu \mathrm{m} /$ hour, and tantalum at between 1 and $2 \mu \mathrm{m} / \mathrm{hour}$. Etching occurs below $373 \mathrm{~K}$, so that delicate materials will not be destroyed by this process. The plasma jet may be used to selectively remove plutonium and other actinide elements by converting them into volatile compounds that are trapped by adsorption and filtration. 
Since the jet operates outside a chamber, many nuclear wastes may be treated, including machinery, duct-work, concrete and other building materials. At LANL, the source physics is being studied using Stark-broadening, microwave interferometry, and laser-induced fluorescence (LIF). The metastables, neutrals and radical species produced with mixtures of $\mathrm{NF}_{3}, \mathrm{CF}_{4}$, $\mathrm{C}_{2} \mathrm{~F}_{6}, \mathrm{O}_{2}, \mathrm{He}$ and $\mathrm{Ar}$ are being identifieci by LIF, optical emission spectroscopy (OES), laser Raman spectroscopy (LRS), coherent anti-Stokes Raman spectroscopy (CARS), and mass spectroscopy (MS). At UCLA, the elementary surface reactions of these species with tantalum and tungsten (surrogate metais for $\mathrm{Pu}$ ) are being studied in ultrahigh vacuum using a supersonic molecular-beam coupled to the plasma jet. The surfaces are being characterized by $X$-ray photoemission (XPS), infrared spectroscopy (IR), low-energy electron diffraction (LEED), and scanning-tunneling microscopy (STM). In addition, plutonium etching experiments are being carried out at the Los Alamos Plutonium Facility.

Keywords: Plasma Etching, Plutonium

\section{CHEMICAL DECOMPOSITION OF HIGH-LEVEL NUCLEAR WASTE STORAGE/DISPOSAL GLASSES UNDER IRRADIATION $\$ 163,000$ \\ DOE Contact: Chet Miller, (202) 586-3952 \\ Naval Research Laboratory Contact:}

David L. Griscom, (202) 404-7087

This project is addressing potential hazards of radiation-induced gas phase formation in borosilicate glasses intended for vitrification of high-level nuclear waste. The present research effort is designed to: (1) demonstrate unambiguously the nature(s) of any radiation-induced gas phases which may be dissolved in high-level-nuclear-waste-glass forms and lead to bubble formation; (2) provide fundamental knowledge necessary to assess the vulnerability of these forms to chemical explosion, particularly if dissolved oxygen is verified; and (3) develop an efficient method of surveying wide ranges of potential waste glass compositions to determine the dependence of radiolytic oxygen evolution on glass composition and hence determine compositions with superior resistance to decomposition.

Keywords: Borosilicate Glass, Gas Phases, High Level Waste

\section{ANALYSIS OF SURFACE LEACHING PROCESSES IN VITRIFIED HIGH-LEVEL NUCLEAR WASTES USING IN-SITU RAMAN IMAGING AND ATOMISTIC MODELING $\$ 186,333$ \\ DOE Contact: Chet Miller, (202) 586-3952 \\ University of Florida Contact: Joseph H. Simmons, (352) 392-6679}

This research combines a novel investigative technique with novel modeling studies to analyze leaching processes in glasses. Its utility is that it will provide both a means of conducting fundamental studies of the corrosion behavior of high valence and multivalent ions in the waste glass as well as a proven in-situ method for monitoring the chemical corrosion behavior of radioactive waste glasses, remotely and in burial sites. The research has three major thrusts: (1) the development of in-situ Raman Imaging Spectroscopy for a detailed examination of leaching processes and associated structural changes and mineral precipitates on the surface of borosilicate glasses loaded with simulated high-level nuclear wastes, (2) the application of this method to the analysis of transition states and their energetics during surface leaching by novel modeling studies, and by comparison with existing methods of IR, Auger XPS and SIMS spectroscopy, SEM, TEM and STM/AFM microscopy and BET surface analysis; and (3) the extension of in-situ Raman Imaging Spectroscopy for conducting remote tests on radioactive loaded samples, and for the examination of variations over the surface of large ingots. The research comprises fundamental studies of (1) the relationship between leaching processes and Raman spectroscopy, using both tests on simple liquids and quantum mechanical modeling; and (2) the examination of transition states in hydration processes involving the higher valence and multivalent ions and their use in predicting, with high accuracy, their solubility in aqueous solutions using both experimental and quantum mechanical modeling methods. The combination of these two studies has the potential to offer a novel method which has both in-situ and remote capabilities for the analysis of leaching processes on high-level radioactive waste glasses. This method makes possible tests on radioactive materials with greatly reduced personnel exposure, and makes possible the examination of leaching processes in real-time in burial sites. Finally, this method can be applied to the continuous monitoring of the conditions of glass boules during actual disposal conditions.

Keywords: High Level Waste, Leaching, Glass 


\section{INVESTIGATION OF MICROSCOPIC RADIATION DAMAGE IN WASTE FORMS USING ODNMR AND AEM TECHNIQUES $\$ 232,667$ \\ DOE Contact: Chet Miller, (202) 586-3952 \\ Argonne National Laboratory Contact: Guokui Liu, (630) 252-4630}

This project investigates the microscopic effects of radiation damage in crystalline and glass high level waste forms (HLW). Information about the nature of electronic interaction and the chemical bonding properties of radionuclides in damaged phases is being developed. Connections between the consequences of alpha and beta-decay processes and radionuclide release and chemical decomposition in waste forms are being established. Detailed studies focus on the microscopic effects of alpha-decay of the transuranic isotopes ${ }^{238,239} \mathrm{Pu},{ }^{241,243} \mathrm{Am}$, and ${ }^{243,244} \mathrm{Cm}$ and the betaand alpha-decay of ${ }^{249} \mathrm{BK}\left({ }^{249} \mathrm{Cf}\right)$ doped into crystalline materials 10 to 30 years ago and currently prepared borosilicate glasses. Electronic and chemical binding properties and local structural changes of parent radionuclide species and their decay daughters in the radiation damaged regions of the waste forms are being probed using nonlinear laser spectroscopic techniques, such as optically detected nuclear magnetic resonance (ODNMR), in concert with analytical electron microscopy (AEM) imaging and analysis and $X$-ray diffraction methods. Experimental information obtained using various techniques for the same materials is being compared and systematic measurements are being made after the samples undergo a series of annealing tests. Theoretical models based on electronic and nuclear interactions of the actinides and their surrounding ligands are being developed to interpret the experimental results and correlate the microscopic effects of radiation damage to the macroscopic mechanical and chemical properties of the HLW materials.

Keywords: High Level Waste, Radiation Damage

306. IN-SITU SPECTRO-ELECTROCHEMICAL STUDIES OF RADIONUCLIDE CONTAMINATED SURFACE FILMS ON METALS AND THE MECHANISM OF THEIR FORMATION AND DISSOLUTION

$\$ 335,000$

DOE. Contact: Chet Miller, (202) 586-3952

Argonne National Laboratory Contact:

Carlos A. Melendres, (630) 252-4346, Northern Illinois University Contact:

S. M. Mini, (815) 753-6484

The aim of this research is to gain a fundamental understanding of the structure, composition, and mechanism of formation of radionuclide-containing surface films on metals that are relevant to the problem of decontamination of piping systems and waste storage tanks at DOE nuclear facilities. This project seeks to expand our knowledge, while obtaining useful practical information, through the conduct of a systematic research activity that utilizes the unique facilities at Argonne National Laboratory, e.g., the Advanced Photon Source (APS) for X-ray absorption spectroscopy (XAS), as well as specialized laboratory facilities and instrumentation for carrying out experiments with radioactive materials. Formal collaboration with a university assures that a strong basic approach is taken in the analyses and methodologies used to achieve the desired goals.

The research consists of electrochemical studies of the corrosion and passivation behavior of iron, nickel, chromium, and stainless steel over a wide $\mathrm{pH}$ range and as a function of temperature from 25 to $95^{\circ} \mathrm{C}$. The energetics and dynamics of film formation and dissolution and the effect of incorporation of heavy metal ions and radioactive elements are being investigated. Synchrotron X-ray absorption and vibrational (infrared and Raman) spectroscopic techniques are being used to define in-situ the structure and composition of the various oxide phases that are formed as a function of temperature.

Keywords: $\begin{aligned} & \text { Surface Films, Metals, Piping, Waste } \\ & \text { Tanks }\end{aligned}$

307. DETERMINATION OF TRANSMUTATION EFFECTS IN CRYSTALLINE WASTE FORMS $\$ 304,328$ DOE Contact: Chet Miller, (202) 586-3952

Argonne National Laboratory Contact:

Denis M. Strachan, (630) 252-4479

PNNL Contact: Nancy J. Hess, (509) 375-2142

The objective of this study is to characterize the effects of transmutation in a candidate waste form for ${ }^{137} \mathrm{Cs}$ by investigating samples of a cesium aluminosilicate mineral, pollucite, that have undergone "natural" decay of the Cs under ambient temperature while isolated from interfering chemical effects. There currently is no information on $\beta$-decay transmutation effects in waste forms in which transmutation has occurred over the natural decay time of the decaying isotope. This causes large uncertainty as to the effect of the transmutation on the physical and chemical properties of the waste form. As a result, uncertainties arise about the viability of the waste form as a long-term storage media for nuclear waste. Information on the effects of transmutation from $\alpha$-decay will give support to the selection of alternate waste forms for separated ${ }^{137} \mathrm{Cs}$ and give information on the long-term behavior of candidate waste forms.

The approach is to nondestructively examine small stainless steel capsules containing pure pollucite. The contents of these capsules will be examined with $X A N E S, X A F S$, and small angle anomalous $X$-rays. The synchrotron facilities at Stanford and ANL will be 
utilized. The scientific team is comprised of members from PNNL, ANL, and LANL.

Keywords: Transmutation, Crystalline Waste Forms, Synchrotron Radiation Facilities

\section{RADIATION EFFECTS ON MATERIALS IN THE NEAR-FIELD OF NUCLEAR WASTE REPOSITORY \\ $\$ 136,000$ \\ DOE Contact: Chet Miller, (202) 586-3952 \\ University of Michigan Contacts: \\ Lu-Min Wang, (313) 647-8530 and \\ Rodney C. Ewing, (313) 647-8529}

Successful, demonstrated containment of radionuclides in the near-field can greatly reduce the complexity of the performance assessment analysis of a geologic repository. The chemical durability of the waste form, the corrosion rate of the canister, and the physical and chemical integrity of the back-fill provide important barriers to the release of radionuclides. However, near-field containment of radionuclides depends critically on the behavior of these materials in a radiation field.

A systematic study is being performed of elastic and inelastic damage effects in materials in the near-field. These include: (1) waste forms (glass and crystalline ceramics); (2) alteration products of waste forms (clays and zeolites); (3) back-fill materials (clays and zeolites). The work draws on over twenty years of experience in studying radiation effects in minerals and complex ceramics and utilizes an unusual combination of studies of natural phases of great age with ion beam and electron irradiations of synthetic phases under carefully controlled conditions.

$\begin{array}{ll}\text { Keywords: } & \text { Radiation Effects, Near-field, Geologic } \\ \text { Repository }\end{array}$

309. AN ALTERNATIVE HOST MATRIX BASED ON IRON PHOSPHATE GLASSES FOR THE VITRIFICATION OF SPECIALIZED NUCLEAR WASTE FORMS

$\$ 208,278$

DOE Contact: Chet Miller, (202) 586-3952

University of Missouri-Rolla Contact:

Delbert E. Day, (573) 341-4354

Borosilicate glass is the only material currently approved and being used to vitrify high level nuclear waste. Unfortunately, many high level nuclear waste feeds in the U.S. contain components which are chemically incompatible with borosilicate glasses. Current plans call for vitrifying even these problematic waste feeds in borosilicate glasses after the original waste feed has been pre-processed and/or diluted to compensate for the incompatibility. However, these pre-treatment processes, as well as the larger waste volumes resulting from dilution. will add billions of dollars to the DOE's cost of cleaning up the former nuclear weapons production facilities. Such additional costs may be avoided by developing a small number of alternative waste glasses which are suitable for vitrifying those specific waste feeds that are incompatible with borosilicate glasses.

An alternative waste form based on a new family of iron-phosphate glasses which appear to be well suited for many waste feeds, especially those which are incompatible with borosilicate glasses, has recently been developed.

More information on the atomic structure, valence states, nature of bonding, structure-property relationships, crystallization kinetics, and optimized melt processing conditions is needed for iron phosphate glasses and their waste forms. This research is using techniques such as EXAFS, XANES, XPS, X-ray and neutron diffraction, IR, SEM, Móssbauer spectroscopy and DTAVDSC to obtain the information needed to demonstrate that iron phosphate waste forms can meet the stringent requirements for nuclear waste disposal.

Keywords: Iron Phosphate Glasses, Vitrification, Nuclear Waste

\section{MICROSTRUCTURAL PROPERTIES OF HIGH LEVEL WASTE CONCENTRATES AND GELS WITH RAMAN AND INFRARED SPECTROSCOPIES \\ $\$ 155,000$ \\ DOE Contact: Chet Miller, (202) 586-3952 \\ Los Alamos National Laboratory Contact: Stephen F. Agnew, (505) 665-1764}

Nearly half of the high level radioactive waste stored at Hanford is composed of highly alkaline concentrates referred to as either salt cakes or Double-Shell Slurry (DSS), depending on their compositions and processing histories. The major components of these concentrates are water, sodium hydroxide, and sodium salts of nitrate, nitrite, aluminate, carbonate, phosphate, and sulfate. In addition, there are varying amounts of assorted organic salts such as EDTA, glycolate, and citrate. Although measurements of the bulk properties of these wastes, such as viscosity, gel point, density, etc., have been exhaustively reported in the past, little is known about how those macroscopic characteristics are related to the microscopic physical and chemical properties of the waste. Such characteristics as viscosity, solids volume percent, and gas retention can change dramatically with relatively small changes in composition and temperature and these same properties are important for the determination of safe storage conditions as well as in planning retrieval, pretreatment, and disposal of the wastes.

The aim of this work is to use FTIR, Raman, and NMR spectroscopies, along with thermophysical heats of gelation, to relate the microstructural, physical and chemical properties of these concentrates to their macroscopic characteristics. With this better 
understanding of macroscopic characteristics, the DOE will be in a better position to safely store these wastes as well as to be able to better plan for their retrieval, pretreatment, and final disposal. These microscopic properties are being related to the macroscopic characteristics by using:

- Water vapor pressure measurements for concentrates to unambiguously determine water activity as a function of composition and temperature.

- FTIR, Raman, and AI NMR spectroscopies to determine the form and solubility of aluminate in caustic slurries.

- Micro-Raman spectroscopy to identify and quantify phases of each species for a variety of concentrates.

- Measurements of the heat of gelation and its dependence on water activity, presence of organic, and other properties.

Keywords: High Level Waste, Raman Spectroscopy, Infrared Spectroscopy

\section{FUINDAMENTAL THERMODYNAMICS OF ACTINIDE-BEARING MINERAL WASTE FORMS $\$ 3813,333$ \\ DOE Contact: Chet Miller, (202) 586-3952 \\ Los Alamos National Laboratory Contact: Mark A. Williamson, (505) 667-4045 \\ LLNL. Contact: Bartley B. Ebbinghaus, (510) 422-8792 \\ UC Davis Contact: Alexandra Navrotsky, (916) $752-3292$}

The end of the Cold War raised the need for the technical community to be concerned with the disposition of excess nuclear weapon material. The plutonium will either be converted into mixed-oxide fuel for use in nuclear reactors or immobilized in glass or ceramic waste forms and placed in a repository. The stability and behavior of plutonium in the ceramic materials as well as the phase behavior and stability of the ceramic material in the environment is not well established. In order to provide technically sound solutions to these issues, thermodynamic data are essential in developing an understanding of the chemistry and phase equilibria of the actinide-bearing mineral waste form materials proposed as immobilization matrices. Mineral materials of interest include zircon, zirconolite, and pyrochlore. High temperature solution calorimetry is one of the most powerful techniques, sometimes the only technique, for providing the fundamental thermodynamic data needed to establish optimum material fabrication parameters, and, more importantly, to understand and predict the behavior of the mineral materials in the environment The purpose of this project is to experimentally determine the enthalpy of formation of actinide orthosilicates, the enthalpies of formation of actinide substituted zirconolite and pyrochlore, and develop an understanding of the bonding characteristics and stabilities of these materials.

Keywords: High Temperature Solution Calorimetry, Actinides

\section{PHOTOOXIDATION OF ORGANIC WASTES USING SEMICONDUCTOR NANOCLUSTERS $\$ 417,000$ \\ DOE Contact: Chet Miller, (202) 586-3952 \\ SNL Contact: J. P. Wilcoxon, (505) 844-3939 \\ Colorado State University Contact: D. F. Kelley, (970) $491-6381$}

Solar detoxification is a process wherein sunlight is captured by a semiconductor particle in suspension to create electrons and holes that then diffuse to the particulate surface to effect the oxidation and reduction of toxic pollutants. Using solar energy to oxidize organic chemicals to carbon dioxide and dilute mineral acids is very energy efficient compared to other methods such as incineration. Finding an efficient particulate has thus been a focus of research, which has had only limited success, the fundamental problem being that materials that efficiently absorb in the visible portion of the solar spectrum also photocorrode.

Past solar detoxification efforts have relied almost exclusively on titanium dioxide, and although it is photostable, it is a white material with a UV bandgap that absorbs less than $7 \%$ of the solar spectrum. It also suffers from electron-hole recombination in commercially available forms. Recent research has made possible the synthesis of photostable semiconductor nanoclusters with visible band gaps that can be tuned by adjusting the cluster size. Thus bulk materials with near IR absorbence edges can be made into visible band-edge materials with stronger redox potentials.

The rate of electron-hole recombination is small in nanoclusters, so they have the potential to act as highly efficient solar detoxification agents. In effect, they act more like molecular organic photoredox catalysts, but with significant advantages in chemical stability because they are inorganic. This project is investigating the use of these materials in practical detoxification applications.

Keywords: Photooxidation, Nanoclusters 
313. OPTIMIZATION OF THERMOCHEMICAL, KINETIC, AND ELECTROCHEMICAL FACTORS GOVERNING PARTITIONING OF RADIONUCLIDES DURING MELT DECONTAMINATION OF RADIOACTIVELY CONTAMINATED STAINLESS STEEL $\$ 400,000$

DOE Contact: Chet Miller, (202) 586-3952

SNL Contact: James A. Van den Avyle, (505) 845-3105

Melt Decontamination represents an effective scrap metal recycling route for the estimated $1,200,000$ tons of contaminated stainless steel and nickel currently within the DOE complex. At present, this material must be considered a substantial disposal liability. However, with appropriate recycling, this material may be regarded as an asset worth an estimated $\$ 5$ billion. The goal of this project is to optimize a melt decontamination process through a basic understanding of the factors which govern the partitioning of various radionuclides between the metal, slag, and gas phases. Radionuclides which are captured by a slag phase may be stabilized by promoting the formation of synthetic minerals within a leach-resistant matrix. This research describes an integrated program of simulation and experimentation designed to investigate and optimize liquid metal techniques for the decontamination and recycling of radioactive scrap metal.

Keywords: Melt Decontamination, Radioactive Scrap Metal

\section{MECHANISM OF PITTING CORROSION} PREVENTION BY NITRITE IN CARBON STEEL EXPOSED TO DILUTE SALT SOLUTIONS $\$ 216,667$

DOE Contact: Chet Miller, (202) 586-3952

Savannah River Technology Center

Contact: Philip E. Zapp, (803) 725-2567

University of South Carolina Contact: John Van Zee, (803) 777-2285

The overall goal of this project is to develop a fundamental understanding of the role of nitrite in preventing the breakdown of protective oxide coating on steel and the onset of pitting. A fundamental understanding of the materials science and electrochemistry of the nitrite role is expected to lead to superior and more cost-effective corrosion prevention methods for storing and processing complex, industrially important salt solutions. One important application of this new information in the DOE complex involves the high-level radioactive waste solutions contained in carbon steel tanks.

There is an extensive base of engineering knowledge of corrosion prevention by nitrite in alkaline salt solutions containing various organic and inorganic aggressive species. This knowledge is empirical; effective nitrite concentrations have been related to solution composition and temperature through numerous laboratory tests. The role of nitrite has not been explained electrochemically in a general manner that permits the prediction of nitrite effectiveness in solutions of widely varied composition.

A model is being developed of the nitrite concentration required to prevent pitting corrosion in terms of the electrochemical and surface oxide properties of the carbon steel solution system for a wide range of solution compositions. Typical industrial salt solutions contain numerous ionic species and suspended insoluble compounds, as well as dissolved organic species.

Keywords: Pitting Corrosion, Nitrite, Carbon Steel

\section{STABILITY OF HIGH-LEVEL WASTE FORMS $\$ 254,000$ \\ DOE Contact: Chet Miller, (202) 586-3952 \\ Oak Ridge National Laboratory Contact: Theodore M. Besmann, (423) 574-6852}

The assessment of release of radionuclides from waste repositories depends substantially on the leaching behavior of the spent fuel or waste form. Assumed rates based on dissolution of specific phases (assumption of unit activity) will lead to potentially grossly overestimated values as well as possibly underestimated values, and are therefore difficult to defend. Current, experimentally-determined values are less than desirable since they depend on measurement of the leach rate under non-realistic conditions designed to accelerate processes that are geologic in time scale. With the possible consideration of a hot repository for the disposal of spent fuel and high-level waste forms, the materials will experience elevated temperatures (> $100^{\circ} \mathrm{C}$ ) for hundreds of years or longer, driving chemical and phase changes. The objective of the effort is to develop a basic understanding of the phase equilibria and solid solution behavior of the constituents of high-level waste forms and to model that behavior. The results of this effort will provide reaction path information for leaching/transport codes such as ESP, as well as basic insights into complex ceramic solution behavior, bonding in glasses, and crystal chemistry of the fluorite-structure uranium dioxide-fission product system.

Keywords: Spent Fuel, High Level Waste, Leaching, Transport 


\section{RADIATION EFFECTS IN NUCLEAR WASTE MATERIALS \\ $\$ 960,000$ \\ DOE Contact: Chet Miller, (202) 586-3952 \\ PNIVL Contact: William J. Weber, (509) 375-2299 \\ Argonne National Laboratory Contact: \\ R. B. Bircher, (630) 252-4996 \\ LANL Contact: Michael A. Nastasi, (505) 667-7007 \\ University of Michigan Contact: \\ Rodney C. Ewing, (313) 647-8529}

The objective of this multidisciplinary, multi-institutional research effort is to develop a fundamental understanding at the atomic, microscopic, and macroscopic levels of radiation effects in glass and ceramics that provides the underpinning science and models for evaluation and performance assessments of glass and ceramic waste forms for the immobilization and disposal of high-level tank waste, plutonium residues and scrap, surplus weapons plutonium, and other actinides. Studies focus on the effects of ionization and elastic-collision interactions on defect production, defect interactions, structural rearrangements, diffusion, solid-state phase transformations, and gas accumulation using actinide containing materials, gamma irradiation, ion-beam irradiation and electron-beam irradiation to simulate the effects of alpha decay and beta decay on nuclear waste glasses and ceramics. This program exploits a variety of structural, optical, and spectroscopic probes to characterize the nature and behavior of the defects, defect aggregates, and phase transformations. Computer simulation techniques are used to determine defect production from ballistic and ionization interactions, calculate defect stability, energies of formation and migration, damage processes within an alpha-recoil cascade, and defect/gas diffusion and interaction.

Keywords: Glass, Ceramics, Radiation Effects

\section{NEW SILICOTITANATE WASTE FORMS: DEVELOPMENT AND CHARACTERIZATION $\$ 400,000$ \\ DOE Contact: Chet Miller, (202) 586-3952 \\ PNL Contact: Mari Lou Balmer, (509) 372-4693 \\ SNL Contact: Tina Nenoff, (505) 844-0340 \\ UC Davis Contact: Alexandra Navrotsky, (916) $752-3292$}

This program outlines a new strategy for disposing of crystalline silicotitanate (CST) ion exchangers by in situ heat treatment to produce an alternate waste form. New waste forms and disposal strategies specific to CST secondary waste that are developed in this work will offer an alternative to current disposal plans which call for recombining the separated Cs, Sr-loaded CST into the high activity waste streams then dissolving it in borosilicate glass. This research is predicated by work at Pacific Northwest National Laboratory that shows that thermally treated CSTs have durabilities better than borosilicate glass. The goal of the program is to reduce the costs associated with CST waste disposal, to minimize the risk of contamination to the environment during CST processing, and to provide DOE with technical alternatives for CST disposal. Because there is uncertainty in repository availability and in waste acceptance criteria, it is likely that Cs and Sr loaded ion exchangers will require short term storage at Hanford or that new scenarios for long term storage or disposal of nuclides with relatively short half lives (such as ${ }^{137} \mathrm{Cs}$ and ${ }^{50} \mathrm{Sr}$ ) will arise.

This research synthetically explores both low and high temperature stable and metastable phases involving the key component elements. This allows for characterization of all potential by-products from thermal treatment of CSTs. The technical objective of the work is to (1) fully characterize the phase relationships, structures and thermodynamic and kinetic stabilities of crystalline silocotitanate waste forms, and (2) to establish a sound technical basis for understanding key waste form properties, such as melting temperatures and aqueous durability, based on an in-depth understanding of waste form structures and thermochemistry.

Keywords: Silicotitanate, Waste Form

\section{ION-EXCHANGE PROCESSES AND MECHANISMS IN GLASSES $\$ 300,333$ \\ DOE Contact: Chet Miller, (202) 586-3952 \\ PNL Contact: B. Peter McGrail, (509) 376-9193 \\ LBNL Contact: David K. Shuh, (510) 486-6937}

Recent performance assessment calculations of a disposal system at Hanford, Washington for low activity waste glass show that a $\mathrm{Na}$ ion-exchange reaction can effectively increase the radionuclide release rate by over a factor of 1000 and so is a major factor that currently limits waste loading. However, low temperature ion exchange has not been thought to be important in recent analyses of waste glass durability. The objective of this work is to develop an understanding of the processes and mechanisms controlling alkali ion exchange and to correlate the kinetics of the ion-exchange reaction with glass structural properties.

lon-exchange reaction mechanisms are being studied by using nuclear reaction analysis techniques to probe the distribution of isotopically-labeled elements in the hydrated layers on glass surfaces. Differences in the uptake and distribution of these isotopes provide a signature characteristic of specific ion-exchange reactions. X-ray absorption spectroscopy is used to identify and correlate key structural properties, such as the number of nonbridging oxygens, bonding of alkali to other elements in the glass, and alkali coordination, with differences in measured rates of alkali exchange. The 
fundamental understancling of the ion-exchange process developed under this study will provide a sound scientific basis for formulating low exchange rate glasses with higher waste loading, resulting in substantial production and disposal cost savings.

Keywords: Ion-exchange, Glasses

319. DISTRIBUTION \& SOLUBILITY OF RADIONUCLIDES \& NEUTRON ABSORBERS IN WASTE FORMS FOR DISPOSITION OF PLUTONIUM ASH \& SCRAPS, EXCESS PLUTONIUM, AND MISCELLANEOUS SPENT NUCLEAR FUELS

$\$ 600,000$

DOE Contact: Chet Miller, (202) 586-3952

PNNL Contact: Xiangdong Feng, (509) 373-7284

Australian Nuclear Science \& Technology Organisation Contact: Eric R. Vance LBNL Contact: David K. Shuh, (510) 486-6937

University of Michigan Contact: Rodney C. Ewing, (313) 647-8529

The objective of this multi-institutional, multi-national research effort is to understand the distributions, solubilities, and releases of radionuclides and neutron absorbers in waste forms. The results will provide the underpinning knowledge for developing, evaluating, selecting, and matching waste forms for the safe disposal of various wastes associated with $\mathrm{Pu}$, miscellaneous spent nuclear fuels (SNF), and other transuranic (TRU) wastes and for developing deterministic model for the long-term performance assessment of radionuclide containment.

The scope of this project includes: (1) systematically investigate the solubility and partition behavior of selected waste forms as a function of composition, temperature, and processing conditions with the goal of enhancing our understanding of the physics and chemistry of radionuclides and neutron absorbers in simplified waste forms; (2) determine the local structure of radionuclides and neutron absorbers waste forms in various phases: (a) develop a microscale characterization to determine what phases are presented and how key elements are partitioned among those phases using optical, scanning, and transmission microscopies and $X R D$; (b) develop a molecular level characterization to understand local coordination using EXAFS and NMR; (c) an atomic level characterization to determine oxidation state using XANES; (3) selectively study waste form properties with the emphasis on the release behaviors of neutron absorbers and radionuclides.

Keywords: Radionuclides, Neutron Absorbers, Solubility, Waste Form
320. MODELING OF DIFFUSION OF PLUTONIUM IN OTHER METALS AND OF GASEOUS SPECIES IN PLUTONIUM-BASED SYSTEMS $\$ 145,000$

DOE Contact: Chet Miller, (202) 586-3952

West Virginia University Contact:

Bernard R. Cooper, (304) 293-3423

University of Connecticut Contact:

Gayanath Fernando, (860) 486-0442

The research is aimed at developing and utilizing computational-modeling-based methodology to treat two major problems. The first of these is to be able to predict the diffusion of plutonium from the surface into the interior of another metal such as uranium or stainless steel (fcc iron). The second is the more complicated situation of treating the diffusion of a gaseous species into plutonium-containing oxidized material, specifically the solid-state diffusion of $\mathrm{O}_{2}$-driven by an oxygen gradient. The first class of problem, diffusion of plutonium into host metals, is pertinent to characterizing contamination and consequent clean-up procedures in situations where plutonium has been in contact with other metals for extended periods of time. The second situation is pertinent to complicated hydrogen generation mechanisms creating possibly catastrophic pressure in situations, such as storage barrels, where oxidized plutonium-containing material has been stored for long periods of time.

The investigation of thermally-activated diffusion makes use of transition state theory with dynamic corrections. In transition state theory the number of crossings of a specified counting surface that separates initial and final states is equated to the number of such crossings that occur in an equilibrium system. The use of ab-initiobased atomistic potentials allows efficient mapping of the pertinent energy barriers. Molecular dynamics can be used to treat realistically the nature of the hoppings as well as to correct for dynamical effects such as recrossings. Grain boundaries are simulated and incorporated into dynamic simulations to study the relative importance of grain boundary diffusion in allowing plutonium atoms to penetrate into the interior of the host metals.

The two main components of the modeling study are: (1) the treatment of diffusion and of the pertinent grain boundary modeling and (2) the development of physically accurate plutonium atomistic potentials. The physical quality of these potentials is the controlling quantity in determining the ability to be accurately predictive for the questions of interest.

Keywords: Diffusion, Plutonium, Modeling and Simulations 
Office of Nuclear Energy. Science and Technology - Grand Total

Office of Engineering and Technology Development

$\$ 2,080,000$

Space and National Security Programs

$\$ 2,080,000$

Materials Preparation. Synthesis, Deposition. Growth or Forming

$\$ 1,815,000$

Development of an Improved Process for the Manufacture of DOP-26 Iridium

Alloy Blanks, Product Characterization and Exploratory Alloy Improvement Studies Carbon-Bonded Carbon Fiber Insulation Production Maintenance, Manufacturing

Process Development and Product Characterization

$1,425,000$

390,000

Materials Properties, Behavior. Characterization or Testing

$\$ 265,000$

Development of Materials for Advanced Radioisotope Power Systems 265,000

Office of Naval Reactors

$\$ 63,000,000^{1}$

${ }^{1}$ This excludes $\$ 47$ million for the cost of irradiation testing in the Advanced Test Reactor (ATR). 


\section{OFFICE OF NUCLEAR ENERGY, SCIENCE AND TECHNOLOGY}

\section{OFFICE OF ENGINEERING AND TECHNOLOGY DEVELOPMENT}

\section{SPACE AND NATIONAL SECURITY PROGRAMS}

Space and National Security Programs include the development and production of radioisotope power systems for both space and terrestrial applications and the technical direction, planning, demonstration and delivery of space nuclear reactor power and propulsion systems. During FY 1997, space nuclear reactor power and propulsion activities remained dormant. Essentially all materials programs were aimed at: (1) support of the production of General Purpose Heat SourceRadioisotope Thermoelectric Generators for the NASA Cassini Mission, (2) maintenance of iridium alloy and carbon bonded carbon fiber insulation heat source components manufacturing capability, (3) continued improvement in heat source materials and their production processes and product characterization, and (4) materials (non-thermoelectric) support for future high efficiency advanced radioisotope power systems.

MATERIALS PREPARATION, SYNTHESIS, DEPOSITION, GROWTH OR FORMING

\section{DEVELOPMENT OF AN IMPROVED PROCESS FOR THE MANUFACTURE OF DOP-26 IRIDIUM ALLOY BLANKS, PRODUCT CHARACTERIZA- TION AND EXPLORATORY ALLOY IMPROVEMENT STUDIES $\$ 1,425,000$ \\ DOE Contact: W. Barnett, (301) 903-3097 \\ ORNL Contacts: E. P. George, \\ (615) 574-5085 and E. K. Ohriner, (615), 574-8519}

An iridium alloy, DOP-26 (i.e., Ir-0.3 wt.\% W with Th and $\mathrm{Al}$ dopant additions), serves as the fuel clad or capsule material for isotope heat sources employed in recent and contemporary space power systems for NASA deep space missions. This program is aimed at the optimization of the new improved process route previously selected for the production of DOP-26 iridium alloy sheet, namely a consumable vacuum arc cast' extrusion/"warm" rolling route. The effectiveness of this production process was further demonstrated in the production of DOP-26 alloy blanks, foil and clad vent sets for the Cassini Mission. Production yields have continued to exceed our goals.

During FY 1997, production of DOP-26 iridium alloy blanks, foil and clad vent set hardware for the Cassini mission was completed. Transfer of the clad vent set manufacturing operation from the $Y-12$ plant to the Oak Ridge National Laboratory was initiated. Iridium alloy manufacturing capabilities are being maintained in a production maintenance mode.
Iridium process improvement activities were continued. Bare rolling is ready for introduction into the sheet production process. Bare cup forming development was continued. Scale-up and evaluation of a new DOP-40 low thorium alloy (Ir-0.3 wt. \% tungsten with dopant additions of $40 \mathrm{ppm}$ cerium and $15 \mathrm{ppm}$ thorium) was continued.

Keywords: Consumable Arc Melt, Extrusion, Noble Metal, Rolling, Forming

322. CARBON-BONDED CARBON FIBER INSULATION PRODUCTION MAINTENANCE, MANUFACTURING PROCESS DEVELOPMENT AND PRODUCT CHARACTERIZATION $\$ 390,000$

DOE Contact: W. Barnett, (301) 903-3097

ORNL Contacts: R. Dinwiddie, (615) 574-9978 and D. J. McGuire, (423) 574-4835

Carbon-bonded carbon fiber (CBCF) type thermal insulation material is employed in Isotopic General Purpose Heat Source (GPHS) Module assemblies for use in current GPHS-RTG (radioisotope thermoelectric generator). This material was originally employed in GPHS-R7Gs for the Galileo/NASA (1989 launch) and Ulysses/NASA-ESA (1990 launch) Missions. Material produced for the Cassini Mission (1997 launch) was made with a replacement carbon fiber (new vendor, former source not available) utilizing an optimized process and process controls. The FY 1997 program encompassed (1) continued maintenance of capability for both tube and plate billet production, (2) continued characterization of Cassini CBCF insulation high temperature thermal conductivity, and (3) study of the role of inert additives on high temperature thermal conductivity.

Keywords: Insulators/Thermal, High Temperature Service, Fibers

MATERIALS PROPERTIES, BEHAVIOR, CHARACTERIZATION OR TESTING

\section{DEVELOPMENT OF MATERIALS FOR ADVANCED RADIOISOTOPE POWER SYSTEMS $\$ 265,000$ DOE Contact: W. Barnett, (301) 903-3097 Oak Ridge National Laboratory Contact: J. King, (423) 574-4807}

Materials support was provided for two advanced radioisotope power systems, namely a heat source for a small Stirling Engine and an Alkali metal Thermal to Electric Converter (AMTEC) Cell. 
Long-term intermediate temperature creep properties of T-111 tantalum alloy were continued. Evaluation of the high temperature reflectivity of rhodium plated Haynes-25 alloy was initiated.

Keywords: Tantalum Alloy, Creep, Rhodium Plate, Reflectivity

\section{OFFICE OF NAVAL REACTORS}

The materials program supports the development and operation of improved and longer life reactors and pressurized water reactor plants for naval nuclear propulsion.

The objective of the materials program is to develop and apply, in operating service, materials capable of use under the high power density and long life conditions required of naval ship propulsion systems. This work includes irradiation testing of reactor fuel, poison, and cladding materials in the Advanced Test Reactor at the Idaho National Engineering Laboratory. This testing and associated examination and design analysis demonstrates the performance characteristics of existing materials as well as defining the operating limits for new materials.

Corrosion, mechanical property, and wear testing is also conducted on reactor plant structural materials under both primary reactor and secondary steam plant conditions to confirm the acceptability of these materials for the ship life. This testing is conducted primarily at two Government laboratories-Bettis Atomic Power Laboratory in Pittsburgh and Knolls Atomic Power Laboratory in Schenectady, New York.

One result of the work on reactor plant structural material is the issuance of specifications defining the processing and final product requirements for materials used in naval propulsion plants. These specifications also cover the areas of welding and nondestructive testing.

Funding for this materials program is incorporated in naval projects jointly funded by the Department of Defense and the Department of Energy. This funding amounts to approximately $\$ 110$ million in FY1997 including approximately $\$ 47$ million as the cost for irradiation testing in the Advanced Test Reactor. The Naval Reactors contact is David I. Curtis,

(703) 603-5565. 
OFFICE OF CIVILIAN RADIOACTIVE WASTE MANAGEMENT

Office of Civilian Radioactive Waste Management - Grand Total

FY 1997

Materials Properties, Behavior, Characterization or Testing

$\$ 15,400,000$

Waste Packages

$\$ 15,400,000$

$\$ 15,400,000$ 


\section{OFFICE OF CIVILIAN RADIOACTIVE WASTE MANAGEMENT}

Materials research is ongoing in the Office of Civilian Radioactive Waste Management in the development of waste packages for eventual geologic disposal.

\section{MATERIALS PROPERTIES, BEHAVIOR, CHARACTERIZATION OF TESTING}

\author{
324. WASTE PACKAGES \\ $\$ 15,400,00$ \\ DOE Contact: David Haught, (702) 794-5474 \\ M\&O Contacts: Hugh Benton. \\ (702) 295-4389 and David Stahl, \\ (702) $295-4383$
}

The development of the nation's high-level waste repository has been delegated to DOE's Yucca

Mountain Site Charactization Project Office. Framatome Cogema Fuels (formerly B\&W Fuel Company), as part of the Civilian Radioactive Waste Management System Management \& Operating (M\&O) Contractor, is responsible for designing the waste package and related portions of the engineered barrier system. The advanced conceptual design was completed in 1996. Progress on the waste package and the supporting materials studies has been documented in various reports.

The waste package design effort includes the development of waste packages to accommodate uncanistered commercial spent nuclear fuel (SNF), canistered SNF, canistered defense high-level waste, Navy fuel, and other DOE owned spent nuclear fuel. The analytical process that is underway to support these designs included thermal, structural, and neutronic analyses. Also included are materials selection and engineering development. The waste package materials effort includes the testing and modeling of materials being considered for inclusion in the waste package and the engineered barrier system. The testing includes general aqueous and atmospheric testing, localized attack such as pitting and service corrosion, microbiologically-influenced corrosion, galvanic corrosion, and stress corrosion cracking. The corrosion test facility started the long-term (at least fiveyear) test program in FY 1996 with corrosion-allowance materials. Corrosion-resistant materials were added in FY 1997. Waste form materials are also being evaluated for alteration and leaching under repositoryrelevant conditions. Chemical simulations have been performed to evaluate the performance of engineered barrier materials. These latter efforts support both design and performance assessment.

Keywords: Yucca Mountain Repository, Waste Package, Engineered Barrier System 


\section{OFFICE OF DEFENSE PROGRAMS}

FY 1997

Ofice of Defense Programs - Grand Total

$\$ 96,633,600$

The Weapons Research, Development and Test Program

$\$ 96,633,600$

Sandia National Laboratories

$\$ 23,183,600$

Materials Preparation, Synthesis, Deposition, Growth or Forming

$\$ 6,231,000$

Materials Processing

Sol-Gel Preservation of Mankind's Cultural

Synthesis and Modeling of Field-Structured Anisotropic Composites

Molecular Imprinting in Aerogels for Remote Sensing of Chemical Weapons and Pesticides

Smart Interface Bonding Alloys (SIBA): Tailoring Thin Film Mechanical Properties

Atomically-Engineered Nanostructures: An Interdisciplinary Approach Properties

Enabling Science \& Technology for Cold Spray Direct Fabrication Properties

Atomic-Level Studies of Surfactant-Directed Materials Growth

Freeforming of Ceramics and Composites from Colloidal Slurries

Laser Assisted Arc Welding for Aluminum Alloys

System Studies in Electrochemical Processing Properties

$2,999,000$

137,000

370,000

390,000

455,000

400,000

330,000

400,000

450,000

200,000

100,000

Materials Properties, Behavior, Characterization or Testing

$\$ 11,227,000$

Aging and Reliability

Nanoscale Structures and Phenomena

Applications-Driven Interdisciplinary Research

Materials Stability and Thin Coatings

Catalytic Membrane Sensors

Photonic Band Gap Structures as a Gateway to Nano-Photonics

Model Determination and Validation for Reactive Wetting Processes

Ultra-hard Multilayer Coatings Properties

Molecular-Scale Lubricants for Micromachine Applications

Understanding and Control of Energy Transfer Mechanisms in Optical Ceramics Properties

Integrated Thin Film Structures for IR Imaging Properties

The Initiation and Propagation of Nano-Scale Cracks at an Adhesive/Solid Interface Properties

Monolithic Structures for Nanoseparation Properties

Fundamental Aspects of Micromachine Reliability

Intelligent Polymers for Nanodevice Performance Control

Quantum Dot Arrays

$1,997,000$

$1,070,000$

885,000

$2,483,000$

361,600

375,000

351,000

472,000

475,000

400,000

430,000

400,000

339,000

350,000

439,000

400,000

Device or Components Fabrication. Behavior or Testing

$\$ 1,522,600$

Wide-Bandgap Compound Semiconductors to Enable Novel Semiconductor Devices Project

290,000

Scanning Probe-Based Processes for Nanometer-Scale Device Fabrication

442,600

Surface Micromachined Flexural Plate Wave Device Integrated on Silicon

525,000

Modeling Electrodeposition for Metal Microdevice Fabrication Properties

265,000

Instrumentation and Facilities

$\$ 4,203,000$

Advanced Analytical Techniques

998,000

Nanostructures, Advanced Materials and Ion Beam Sciences

$2,792,000$

Physico-Chemical Stability of Solid Surfaces

413,000 
OFFICE OF DEFENSE PROGRAMS (continued)

FY 1997

The Weapons Research, Development and Test Program (continued)

Lawrence Livermore National Laboratory

$\$ 20,250,000$

Materials Preparation, Synthesis, Deposition, Growth or Forming

$\$ 7,775,000$

Engineered Nanostructure Laminates

$2,000,000$

Sol Gel Coatings

KDP and DKDP Crystal Development and Production

Energetic Materials Strategic Chemistry

CHEETAH Thermochemical Code

Explosives Development

335,000

$4,000,000$

$350,000^{\circ}$

$190,000^{1}$

$900,000^{1}$

Materials Properties, Behavior, Characterization or Testing

$\$ 2,250,000$

Interfaces, Adhesion, and Bonding

Laser Damage: Modeling and Characterization

250,000

$1,000,000$

KDP Characterization

$1,000,000$

Instrumentation and Facilities

$\$ 10,225,000$

Scanning Tunneling Microscopy (STM) and Atomic Force Microscopy (AFM)

250,000

500,000

Fatigue of Metal Matrix Composites

50,000

Materials Produced with Dynamic High Pressure

Properties of Hydrogen at High Shock Pressures and Temperatures

400,000

Atomic Level Explosive Calculations

Metastable Solid-Phase High Energy Density Materials

400,000

AFM Investigations of Crystal Growth

535,000

290,000

Uranium Casting Program

$1,000,000$

Uranium Spin Forming

$1,500,000$

Plutonium Near Net Shape Casting

Electron Beam Cold Hearth Melting of Uranium

$2,500,000$

900,000

NIF Capsule Mandrel R\&D

Polyimide Coating Technology for ICF Targets

800,000

500,000

Beryllium Ablator Coatings for NIF Targets

600,000

Los Alamos National Laboratory

$\$ 53,200,000$

Materials Preparation, Synthesis, Deposition, Growth or Forming

$\$ 2,500,000$

Rapid Solidification Processing

500,000

Structural Alloy Development

$2,000,000$

Materials Structure or Composition

$\$ 3,300,000$

National High Magnetic Field Laboratory

$1,800,000$

Neutron Diffraction

$1,500,000$

'This activity is jointly funded $(50: 50)$ by DOE DP and the DoD. 
OFFICE OF DEFENSE PROGRAMS (continued)

FY 1997

The Weapons Research, Development and Test Program (continued)

Los Alamos National Laboratory (continued)

Materials Properties, Behavior. Characterization or Testing

$\$ 18,300,000$

Dynamic Mechanical Properties of Weapons Materials

Deformation Characterization and Modeling

Materials Aging

Powder Characterization

$2,000,000$

$5,000,000$

$11,000,000$

300,000

Device or Component Fabrication, Behavior or Testing

$\$ 29,100,000$

Manufacturing Process Development

Advanced Engineering Methods Development

Component Fabrication

Laser Target Fabrication

Pulsed Power Target Fabrication

Advanced Strategic Computing Initiative Materials Modeling

$8,000,000$

$1,100,000$

$10,000,000$

$5,000,000$

$3,000,000$

$2,000,000$ 


\section{THE WEAPONS RESEARCH, DEVELOPMENT AND TEST PRIOGRAM}

\section{SANDIA NATLONAL WABORATORIES}

\section{MATERIALS PREPARATION, SYNTHESIS, DEPOSITION, GROWTH OR FORMING}

\section{MATERIALS PROCESSING \\ $\$ 2,999,000$ \\ DOE Contact: Robin Staffin, (202) 586-7590 \\ SNL Contact: John A. Sayre, (505) 845-9757}

The Materials Processes Program focuses on the research required to create laboratory scale materials processes for re-manufacturing weapons components by more rapid, predictable, and affordable methods than those used in the past. Projects emphasize the predictability of microstructure and composition from the processing conditions, and the incorporation of this predictability into scientific models and simulations for use by weapons designers and manufacturing engineers. A new feature of this thrust is a focus on processes which enable fabrication with fewer steps from design to product, with the ultimate goal of onestep fabrication of complex shape parts composed of multiple materials directly from a CAD file.

Keywords: Processing, Fabrication

\section{SOLLGEL PRESERVATION OF MANKIND'S CULTURAL \\ $\$ 137,000$ \\ DOE Contact: Maurice J. Katz, (202) 586-6385 \\ SNL Contact: William Hammetter,} (505) 272-7603

Our cultural heritage, as reflected in artifacts and works of art, is being lost at an astonishing rate due to the ravages of nature and especially mankind. Since the industrial revolution, chemical by-products of man's technological advances have caused the deterioration of our most precious cultural treasures. Most vulnerable are stone objects that are subjected to outdoor environments in industrialized or urban settings. This research comprises three basic elements: (1) molecular modeling of the weathering mechanisms and resultant surface structure of model limestones, (2) mineralspecific passivation of the weathered surface to prevent further hydrolytic attack, and (3) in situ polymerization (within the weathered surface) to form a UV stable network that imparts strength and hydrophobicity. This research has been conducted in collaboration with The Metropolitan Museum of Art (MMA) and The Getty Conservation Institute (GCI), who have provided samples and ensured relevance to the conservation communities. In addition to solving the urgent need to preserve our cultural treasures, the methodology developed here can be applied to other mineralcorrosion problems such as the degradation of concrete infrastructure, environmental contamination by leached mine tailings, protection of ship hulls, and scale formation in petroleum wells.

Keywords: Conservation, Sol-Gel

\section{SYNTHESIS AND MODELING OF FIELD- STRUCTURED ANISOTROPIC COMPOSITES $\$ 370,000$ \\ DOE Contact: Maurice J. Katz, (202) 586-6385 \\ SNL Contact: James Martin, (505) 844-9125}

The modeling, synthesis and processing capability is being developed to create novel anisotropic polymer/ ceramic and polymer/metal composite materials by applying external electric or magnetic fields to systems consisting of a polymerizable continuous phase into which particles having an electric permittivity or magnetic permeability mismatch are suspended. A linear field will create one-dimensional particle chains, a well known effect. This project used the recent discovery that rotating fields create two-dimensional particle sheets in the plane of the field. These unique structures can be captured by polymerizing the continuous phase during a field anneal. A key aspect of this program is modeling and controlling the evolution of structure in these materials.

Keywords: Polymer, Ceramic, Metal, Composite

328. MOLECULAR IMPRINTING IN AEROGELS FOR REMOTE SENSING OF CHEMICAL WEAPONS AND PESTICIDES

$\$ 390,000$

DOE Contact: Maurice J. Katz, (202) 586-6385

SNL Contact: Roger Lee Clough (505) 844-3492

Recent events in Japan, Iraq, and elsewhere have underlined the need for reliable, inexpensive sensors for chemical warfare agents. Warfare agents, such as sarin, belong to a general class of phosphate and phosphonate esters that have a very broad range of activities including materials for nuclear weapons production, pesticides, genetic material, and biological cellular signals. Current methods to detect these agents are limited to laboratory analysis. An in-field, real-time sensor-based approach with remote sensing capability is highly desired.

Under this project, highly sensitive and specific optical sensors for phosphate and phosphonate esters are being designed and developed using molecular recognition sites in high surface area aerogels. Molecular recognition sites are engineered using computer aided molecular design and generated via the powerful "template imprinting" technique in aerogels. The material is designed with active fluorophores at the receptor site reporting on target molecule recognition via fluorescence signal through complexation with the phosphonate guest. From these materials are developed various toxic gas sensor motifs, such as visual detectors that monitor color changes, or 
extremely low level sensing applications that follow fluorescence lifetimes. Granular bulk aerogels will also be developed for our "smart pebbles" concept.

Application of this inconspicuous material to an area of interest will provide a remote sensing system for covert chemical warfare agent production facilities, battlefield alert for chemical weapons release, and agricultural pesticide application and runoff.

Keywords: Aerogel, Remote Sensing

\section{SMART INTERFACE BONDING ALLOYS (SIBA): TAILORING THIN FILM MECHANICAL PROPERTIES \\ $\$ 455,000$ \\ DOE Contact: Maurice J. Katz, (202) 586-6385 \\ SNL Contact: Stephen Foiles, (925) 294-2898}

The use of the newly discovered strain-stabilized 2-D interfacial alloys as smart interface bonding alloys (SIBA) is being explored. These materials are being used as templates for the heteroepitaxial growth of metallic thin films. SIBA are formed by two metallic components which mix at an interface to relieve strain and prevent dislocations from forming in subsequent thin film growth. The composition of the SIBA is determined locally by the amount of strain, and therefore can react "smartly" to areas of the highest strain to relieve dislocations. In this way, SIBA can be used to tailor the dislocation structure of thin films.

This project includes growth, characterization and modeling of films grown using SIBA templates. Characterization includes atomic imaging of the dislocations structure, measurement of the mechanical properties of the film using interface force microscopy (IFM) and the nanoindenter, and measurement of the electronic structure of the SIBA with synchrotron photoemission. Resistance of films to sulfidation and oxidation is also being examined. The Paragon parallel processing computer is being used to calculate the structure of the SIBA and thin films in order to develop ability to predict and tailor SIBA and thin film behavior.

This work will lead to the development of a new class of thin film materials with properties tailored by varying the composition of the SIBA, serving as a buffer layer to relieve the strain between the substrate and the thin film. Such films will have improved mechanical and corrosion resistance allowing application as protective barriers for weapons applications. They will also exhibit enhanced electrical conductivity and reduced electromigration making them particularly suitable for application as interconnects and other electronic needs.

Keywords: Joining, Smart Materials
330. ATOMICALLY-ENGINEERED NANOSTRUCTURES: AN INTERDISCIPLINARY APPROACH PROPERTIES $\$ 400,000$

DOE Contact: Maurice J. Katz, (202) 586-6385

SNL Contact: Gordon Osbourn, (505) 844-8850

Scanning Tunneling Microscopy (STM) is a powerful tool for both characterizing and manipulating the atomic topographies of surfaces. For chemically-uniform model systems, e.g. clean Si surfaces, STM can provide considerable scientific insights. However, STM has typically been unable to provide unambiguous chemical recognition of atomic sites in many technologically relevant, but chemically heterogeneoous systems. This limitation is due to several problems: (1) There are no direct means for verifying proposed STM atomic identifications, and no theoretical guidance on what multivariate STM features would best characterize the atoms; (2) It is difficult to directly observe chemical information by inspecting individual STM images, and this chemical information is "buried" among the multiple-bias images; (3) STM tip structures have important yet poorly understood effects on STM data, and these tips often change due to tip-surface interactions during imaging. This project is developing theoretical and experimental underpinnings to address the three issues above with the goal of enabling unambiquous, computer-based identification of atomic sites in multivariate STM imagery, focusing on heterogeneous III-V semiconductor materials and atomically-engineered nanostructures. The project has several subtasks: (1) develop the first "database" of multivariate STM spectral features (i.e., the analogue of satellite "ground truth" spectra); (2) study the effects of different tip states on the STM spectral features and attempt to establish procedures for computationally removing or minimizing variable-tip effects; (3) use pattern recognition of STM spectral imagery, based on the results of $A$ and $B$ tasks, to map out the atomic scale chemical structure of selected cleaved (110) III-V surfaces. The alloy ordering and interfacial structure of III-V structures of current programmatic interest for IR device applications is being studied.

Keywords: Nanostructures, STM

\section{ENABLING SCIENCE \& TECHNOLOGY FOR COLD SPRAY DIRECT FABRICATION PROPERTIES \\ $\$ 330,000$ \\ DOE Contact: Maurice J. Katz, (202) 586-6385 \\ SNL Contact: Mark Smith, (505) 845-3256}

Direct Fabrication is envisioned as a rapid, agile, economical process technology that additively builds up a net or near-net shaped component made of one or more materials directly from a computer model; such technology would be of enormous benefit to SNL's core National Security Mission and U.S. industry. Cold Spray Processing (CSP) is a recently discovered, poorly understood, Russian technology that can rapidly deposit 
( $\mathrm{mm} / \mathrm{sec})$ metals, polymers, and composites at temperatures $<200^{\circ} \mathrm{C}$ by accelerating powder particles up to $600-1000 \mathrm{~m} / \mathrm{s}$ in a supersonic compressed air or gas jet. The Russians have used CSP for high-rate coating deposition, but no one has attempted direct fabrication via CSP. One can envision a radical new fabrication technology in which a highly focused CSP particle "beam" is combined with a multi-axis robotic motion system in order to spray-fabricate a single- or multi-material component directly from a computer model. CSP build rates should be substantially higher than present layer-wise direct fabrication techniques and, since CSP particles are never fully melted, superior surface finishes, microstructures, and properties might be achieved (finer grain size, no brittle phases, minimal oxidation, less residual stress, etc.). With CSP, one might alsi deposit functionally graded or layered materials at low temperatures, thus eliminating joining operations, simplifying design/fabrication, reducing part counts, and decreasing stress cracking. (For example, aluminum has been CSP-deposited directly onto smooth, unprepared glass with excellent adhesion.) CSP may also be an environmentally friendly alternative to problem technologies, such as copper electroplating and soldering or painting of aircraft, weapons, etc.

This project explores the use of cold spray processing for direct fabrication of simple proof-of-concept shapes.

Keywords: Cold Spray Processing, Direct Fabrication

\section{ATOMIC-LEVEL STUDIES OF SURFACTANT- DIRECTED MATERIALS GROWTH $\$ 400,000$ \\ DOE Contact: Maurice J. Katz, (202) 586-6385 \\ SNL. Contact: Terry Michalske, (505) 844-5829}

This project is investigating converting surface impurities from a nuisance to a systematically applicable nano-fabrication tool. Combining Sandia's special facilities, including the "atom-tracker" Scanning Tunneling Microscope (AT-STM), Low Energy Electron Microscopy (LEEM), and Massively Parallel Computation (MPC), the objective is to learn how common adsorbed atoms ("surfactants") can be used to manipulate and direct thin-film growth, and to develop a "surfactant toolkit" that enables production of either atomically' fiat or 3-dimensionally nano-structured surfaces. The approach is to start with model systems, studying surfactant-modified diffusion on and near metal and semiconductor surfaces, and integrating realtime experimental and advanced computational modeling capabilities. The AT-STM is being used to study $\mathrm{H}$-assisted Si adatom diffusion on Si(001), and the LEEM to investigate both $\mathrm{H}$-assisted step fluctuations on the same surface and $\mathrm{O}$-assisted island growth on Pt(111). Ge segregation versus adsorbate overlayer coverage is being investigated in Si-Ge alloys via novel surface stress measurements. Theoretical efforts are closely coupled to experiments-MPC is indispensable in developing reliable, atomic-scale, mechanistic models.

Keywords: AT-STM, LEEM, MPC

\section{FREEFORMING OF CERAMICS AND COMPOSITES FROM COLLOIDAL SLURRIES $\$ 450,000$ \\ DOE Contact: Maurice J. Katz, (202) 586-6385 \\ SNL Contact: Michael Cieslak, (505) 845-9144}

This project is developing a model-based direct freeform fabrication technique for ceramic, metal, or graded composite components. These components are fabricated without molds or tooling by building twodimensional layers into three-dimensional shapes by dispensing colloidal suspensions through an orifice. Any conceivable two-dimensional pattern may be "written" layer by layer into a three-dimensional shape. Initial experiments have demonstrated technique feasibility for simple aluminum oxide shapes. The goal is to develop model-based processing rules that will aid in the development of slurries with the appropriate rheology, density, and drying kinetics to insure process success for a variety of ceramics and composites. Software and equipment development is also essential for precise control of layer thickness and feature resolution.

Development of this technique into a manufacturing process requires: computer simulations of the relevant physical phenomena; materials expertise for tailoring colloidal slurry properties and processing dissimilar materials; software and equipment expertise for CAD model conversion; and, robotics expertise for process optimization and incorporation of knowledge-based processing capabilities with closed loop sensor-based control.

This work directly impacts the production of neutron tubes (MC4277, MC4300 and RP2) and ceramic fixtures for switch tubes (MC3859).

Keywords: Ceramics, Composites, Freeforming

\section{LASER ASSISTED ARC WELDING FOR ALUMINUM ALLOYS $\$ 200,000$ \\ DOE Contact: Maurice J. Katz, (202) 586-6385 \\ SNL Contact: Brian Damkroger (505) 845-3592}

At this time, there exists a strong need in the defense programs, automotive, aerospace and transportation industries for a rapid, robust, high quality process for welding aluminum alloys, especially for relatively thin gauge product. While laser beam welding is widely applied in these industries it has not proved valuable for aluminum because of problems with reflectivity and weld joint variability. Gas metal arc welding (GMAW) is widely used for thick section aluminum welding because the process can compensate for part fit-up and metallurgical deficiencies. Under this project a new welding process is being developed by combining 
together a fiber optic delivered pulsed Nd:YAG laser with a miniaturized GMAW system. The new laser assisted arc welding (LAAW) process couples the process advantages of these two unique heat sources and will also enable process capabilities never before envisioned in arc welding. These two heat sources are being combined in a compact (likely patentable) device that can be manipulated on the end of a robotic arm. The focused pulsed Nd:YAG laser beam assures deep weld penetration and ablative removal of the tenacious aluminum oxide. The arc is focused and located by the metal vapor and gas ions generated by the high intensity laser beam. Increased arc stability is anticipated since the gas metal arc is known to be stabilized by thermal ionization of the shielding gas. The project is a System of Laboratories (SOL) collaboration among ORNL, INEEL and SNL. These three laboratories have distinguished themselves for their contributions to the science and technology of materials joining. The team established through this SOL interaction should allow the U.S. to successfully compete with international entities, such as Germany's Fraunhofer Institute, in developing (and hence owning) advanced joining technologies for commercially critical markets.

Keywords: Laser-Assisted Arc Welding

\section{SYSTEM STUDIES IN ELECTROCHEMICAL PROCESSING PROPERTIES $\$ 100,000$ \\ DOE Contact: Maurice J. Katz, (202) 586-6385 \\ SNL Contact: Martin Carr, (505) 844-6070}

The objective of this project is to develop physical models and associated analytical tools that will allow a number of electrochemical processes of interest to be more effectively characterized. In addition to the availability of new models and tools, the important contribution of this activity is the determination of the conceptual feasibility of using this type of approach to solve engineering-level electrochemical problems. Because of the limited scope of the project, two very specific processes have been selected for detailed study. Four primary tasks are included: (1) detailed analysis of relevant literature information, (2) planning and execution of required experiments, (3) formulation of analytical models, and (4) laboratory demonstration/ validation of the models using untested configuration.

Keywords: Electrochemical Processing, Modeling
MATERIALS PROPERTIES, BEHAVIOR, CHARACTERIZATION OR TESTING

\author{
336. AGING AND RELIABILITY \\ $\$ 1,997,000$ \\ DOE Contact: Robin Staffin, (202) 586-7590 \\ SNL Contact: Richard J. Salzbrenner, \\ (505) 844-9408
}

The Materials Aging and Reliability and Aging Project advances the understanding of the microstructural mechanisms which control the aging, reliability, and performance of materials. The selection of subprojects is based on the risk (likelihood vs. consequence) of the failure of a specific material to weapon performance or surety. All subprojects seek to develop fundamentallybased prediction capability to determine the effects of aging on the performance and reliability of non-nuclear materials used in nuclear weapons. This project supports materials science work that is collaborative with other research programs to develop predictive capability that can be applied to the enduring stockpile.

Keywords: Aging, Reliability

\section{NANOSCALE STRUCTURES AND PHENOMENA $\$ 1,070,000$ DOE Contact: Robin Staffin, (202) 586-7590 SNL Contact: Michael I. Baskes, (925) 294-3226}

The Nanoscale Structures and Phenomena Project encompasses research on all classes of materials whose properties depend on phenomena unique to small (<1 micron) size. Properties are studied in order of decreasing interest and include mechanical, electrical, magnetic, and optical. Synthesis of both materials and structures, materials characterization, and performance are linked using appropriate theory and modeling of model systems. Emphasis is placed on obtaining an understanding of controlling mechanisms in these model systems and extending this understanding to predictions of complex materials and devices.

Keywords: Nanoscale Structures, Nanoscale Phenomena

\section{APPLICATIONS-DRIVEN INTERDISCIPLINARY RESEARCH $\$ 885,000$ \\ DOE Contact: Robin Staffin, (202) 586-7590 \\ SNL Contact: Samuel T. Picraux, (505) 844-5829}

The Applications-Driven Interdisciplinary Research works with the National Security sector [including Micromechanical (IMEMS) reliability and high-reliability neutron tube fabrication and mid-IR based chemical sensors] and focuses on collaboration. Research 
specifically focuses on National Security and building on emerging technology core capabilities.

Keywords: Sensors, Micromechanical, Infrared

\section{MATERIALS STABILITY AND THIN COATINGS} $\$ 2,483,000$

DOE Contact: Robin Staffin, (202) 586-7590

SNL Contact: Terry A. Michalske, (505) 844-5829

The Materials Stability Thin Coatings research seeks to develop and apply atomic- and molecular-level microscopies, spectroscopies, and theoretical models to examine fundamental materials processes that control phenomena, including: interfacial adhesion, lubrication, wear thermal stability, thin-film and surface kinetics, radiation effects, corrosion, hydrogen effects, curing, fracture, and chemical and physical vapor deposition processes. Also, this research seeks to develop a scientific basis for design, manufacture, and application of small, smart products; new models to predict useful lifetimes for currently used materials and structures; and transfers of technology regarding degradation of resistant/stable materials to U.S.

Keywords: Coatings, Stability

340. CATALYTIC MEMBRANE SENSORS $\$ 361,600$

DOE Contact: Maurice J. Katz, (202) 586-6385

SNL Contact: William Hammetter. (505) 272-7603

The goal of this project is to develop a fundamentally new catalytic membrane-based sensor (CMS) with enhanced sensitivity and specificity through modification of an SNL-developed Pd/Ni-based hydrogen sensor. This will be accomplished through overlays of size selective gas separation membrane and ion exchangeable titanate catalyst. The goal is to process these CMS elements into an array that utilizes different catalysts and membranes. This will enable significant improvement of both the selectivity and specificity via pattern recognition methodologies. In FY 1997, the project met the following milestones toward the synthesis and processing of these CMSs:

(1) synthesis and characterization of double alkoxides,

(2) membrane modified sensor ( $\mathrm{H} 2$ sensor),

(3) catalytically active HTO or HTO-like layer on a membrane, (4) catalytic adjustability by ion exchange, and (5) catalyst layer on the sensor.

Keywords: Catalysis, Membranes, Sensors

\section{PHOTONIC BAND GAP STRUCTURES AS A GATEWAY TO NANO-PHOTONICS $\$ 375,000$}

DOE Contact: Maurice J. Katz, (202) 586-6385

SNL. Contact: Adelbert Owyoung, (505) 844-5481

The goal of this project is to explore the fundamental physics of a new class of photonic materials, photonic bandgap structures (PBG), and to exploit its unique properties for the design and implementation of photonic devices on a nano-meter length scale for the control and confinement of light. The low loss, highly reflective and quantum interference nature of a PBG material makes it one of the most promising candidates for realizing an extremely high-Q resonant cavity, $>100,000$, for optoelectronic applications and for the exploration of novel photonic physics, such as photonic localization, tunneling and modification of spontaneous emission rate. Moreover, the photonic bandgap concept affords a new opportunity to design and tailor photonic properties in very much the same way one manipulates, or bandgap engineers, electronic properties through modern epitaxy.

Keywords: Photonics, Bandgap, Epitaxy

\section{MODEL DETERMINATION AND VALIDATION} FOR REACTIVE WETTING PROCESSES $\$ 351,000$

DOE Contact: Maurice J. Katz, (202) 586-6385

SNL Contact: Frederick Yost, (505) 844-5278

This work was undertaken to develop a computational model of reactive wetting processes. Although wetting and spreading have been studied in great detail, most of this work pertains only to inert or nonreactive wetting. Inert wetting is driven by an imbalance of surface tension forces with no other interaction between the wetting liquid and the substrate. In reactive wetting other processes such as diffusion, intermetallic reactions, and environmental reactions may drive or hinder the continuous advance of the wetting front. Additional aspects of reactive wetting are being investigated to determine the driving and dissipation forces that are thought to control the spreading behavior in reactive wetting systems. With this understanding wetting problems of technological significance can be controlled and processes can be improved.

Keywords: Wetting, Computation

\section{ULTRA-HARD MULTILAYER COATINGS PROPERTIES \\ $\$ 472,000$ \\ DOE Contact: Maurice J. Katz, (202) 586-6385 \\ SNL Contact: Ellen Stechel, (505) 844-2436}

This project is exploring the production of ceramic multilayer structures that are potentially harder than any natural or artificial material. Diamond and cubic boron nitride (CBN) are the two hardest substances known to man. Numerous proven technologies rely on the superior mechanical properties of these materials. The question arises: Is it possible to manufacture a material that is harder than diamond? In theory, the answer is yes. Experiment indicates that properly grown multilayer coatings of two materials are harder than either of the materials making up the individual layers. The increase in hardness is mainly due to the resistance of dislocation flow across the interfaces between phases of 
different elasticity. This experimental fact leads to the possibility that a new class of ultra-hard materialsharder than diamond-can be made by growing the appropriate multilayer film.

This project uses a combination of growth, analysis and theoretical modeling capabilities at Sandia that could possibly lead to a revolutionary jump in both materials understanding and performance-a material harder than diamond.

Keywords: Multilayer, Ultrahard

\section{MOLECULAR-SCALE LUBRICANTS FOR MICROMACHINE APPLICATIONS $\$ 475,000$ \\ DOE Contact: Maurice J. Katz, (202) 586-6385 \\ SNL Contact: Terry Michalske, (505) 844-5829}

The nature of this work is to develop the physics and chemistry base for designing molecular-scale lubricants for the reduction of friction- and stiction-induced failure in silicon micromachines. The approach is tailoring the molecular properties of lubricants, applying local probes that can directly monitor the response of lubricants in contact conditions, and evaluating the performance of model lubricants on micromachine test structures specifically designed for friction and stiction studies.

Model lubricants under investigation are the silane coupling agents that form self-assembling monolayer (SAM) films on native oxide silicon surfaces. With atomic force microscopy (AFM) and interfacial force microscopy (IFM), the role of chain length, chemical end group, and chain structures on the frictional and adhesive properties of the SAM films is being examined.

Using a recently-completed scanning near-field optical microscope (SNOM), the goal is to provide the first-ever simultaneous correlation between SAM film structure and dynamic mechanical response. Emission from dilute concentrations of "guest" chromophores, whose orientation(s) are sensitive to lateral- and normal-forceinduced changes in the lubricating film structure will be monitored. These AFM, IFM, and SNOM measurements will form a very important link for molecular dynamics simulations, that, in turn, should be able to predict micromachine performance under all conditions.

Keywords: Lubricants, Micromachines

\section{UNDERSTANDING AND CONTROL OF ENERGY TRANSFER MECHANISMS IN OPTICAL CERAMICS PROPERTIES $\$ 400,000$ DOE Contact: Maurice J. Katz, (202) 586-6385 \\ SNL Contact: Clifford Renschler, (505) 844-0324}

A radically new material strategy for rare-earth (RE) hosts was developed. In this approach, the optical performance of the dopant is modified through atomic- level engineering of its local structural environment in a nanocomposite, optical ceramic host material. This program examines the influence of nanoscale heterogeneities on ion-ion and ion-lattice energy transfer dynamics through atomic-level engineering of the RE ion local environment. Both direct optical evaluation of the dopant behavior and theoretical structural modeling and simulation were employed evaluate these novel host materials. The local atomic structure in the vicinity of RE dopants was successfully modeled using a powerful Sandia-developed (QUEST) computational approach based on local density functional theory. In $\mathrm{Al}_{2} \mathrm{O}_{3}$, this technique is being extended to model the difference in tetrahedral versus octahedral site symmetry on the density of electronic and vibrational states, to allow the investigation of a variety of dopant site types characteristic of multiphase hosts (e.g., interfaces and clusters). This work will result in a new, computer-based, predictive materials modeling capability in both single and multiphase candidate hosts, before fabrication, and will yield an improved class of materials at the junction between fundamental solid-state physics and nanophase science to enable RE optics in photonic integrated circuits.

\section{Keywords: Energy Transfer, Optics, Ceramics}

\section{INTEGRATED THIN FILM STRUCTURES FOR IR IMAGING PROPERTIES $\$ 430,000$ DOE Contact: Maurice J. Katz, (202) 586-6385 SNL Contact: Alan Hurd, (505) 272-7642}

Uncooled pyroelectric IR imaging systems, such as night vision goggles, offer important strategic advantages in battlefield scenarios and reconnaissance surveys. Unfortunately, the current technology for fabricating these devices is limited by low throughput and high cost which ultimately limit the availability of these sensor devices.

This project is developing an alternative design for pyroelectric IR imaging sensors that utilizes a multilayer thin film deposition scheme to create a fully integrated thin film element on an active silicon substrate for the first time. The approach combines a thin film pyroelectric imaging element with a thermally insulating $\mathrm{SiO}_{2}$ aerogel thin film to produce a new type of uncooled IR sensor that offers significantly higher thermal, spatial, and temporal resolutions at a substantially lower cost per unit.

\section{Keywords: Thin Films, IR Imaging}




\section{THE INITIATION AND PROPAGATION OF NANO-SCALE CRACKS AT AN ADHESIVE/SOLID INTERFACE PROPERTIES $\$ 400,000$ \\ DOE Contact: Maurice J. Katz, (202) 586-6385 \\ SNL Contact: Wendy Cieslak, (505) 844-8633}

This project is investigating submicron debonding processes at polymer/solid interfaces with a combination of continuum stress analysis, molecular dynamics (MD) simulations, and a new experimental approach. Each component of this program is designed to provide complementary information with the goal of bridging the gap between molecular and continuum descriptions. The objective is a validated, molecular-tocontinuum fracture theory. Despite significant progress made in recent years in the fields of fracture mechanics and adhesion science, it is still not possible to predict the lifetime of a polymer/solid interface from first principles. On the continuum level, considerable headway has been made in an interfacial fracture mechanics approach for preexisting macroscopic cracks between linear elastic materials. Little is known, however, about modeling cracks on a micron or submicron level, how microcracks develop into macroscopic cracks, or about length scale limitations on the use of a continuum analysis. Furthermore, there is an interphase region with property gradients between the two bulk materials. The effect of interface structure and molecular properties on fracture mechanics parameters is unknown. On the molecular scale, much is known about polymer dynamics, the origin of viscoelastic behavior and relaxation phenomena, and the behavior of polymers near surfaces. Yet it is not clear how stress concentrations develop on a molecular scale in an imperfect thermoset polymer, or how nanoscale inhomogeneities grow into microcracks under stress. An understanding of the link between the molecular and the continuum levels is required before the goal of a truly comprehensive model of fracture can be approached. Such a theory would allow the prediction of lifetimes given the detailed interface structure, material properties, and the thermal history, and would aid greatly in the design of interfaces that are more resistant to aging.

Keywords: Nanoscale, Interface, Adhesive

\section{MONOLITHIC STRUCTURES FOR NANOSEPARATION PROPERTIES $\$ 339,000$ DOE Contact: Maurice J. Katz, (202) 586-6385 SNL Contact: James Wang, (925) 294-2786}

Miniaturization in detection and separation technologies requires easily built, rugged devices based on materiais that have well understood interactions with analytes at the molecular level. The goal of this project is to design such materials for state-of-the-art separation science, understand their structure/function relationships, and fabricate them into useful devices. Sandia expertise in the synthesis of micro- and nanoporous materials is being utilized to develop contiguous, high surface area polymers as nanoporous supports for ultra-efficient separations. These materials are being evaluated using capillary electrochromatography (CEC) as a test bed. The interaction of functionalized surfaces of these supports with analytes, propelled by the electroosmotic flow (EOF), is being quantified in terms of separation efficiency and selectivity. Dramatic gains enabling miniaturization are anticipated with increased efficiency and selectivity of CEC. The goal is to engineer an open and interconnected network where every nanopore functions as a CEC column. These enhancements are not possible in conventional chromatographic methods. These new solid supports, which are cast as fluid solutions and cured to monolithic polymer structures, are being integrated into micro-machined grooves as pre-prototype devices for ultra-efficient separations. Unfilled microgrooves are also being evaluated for their inherent separation efficiencies.

\section{Keywords: Nanoseparation, Polymers}

\section{FUNDAMENTAL ASPECTS OF MICROMACHINE RELIABILITY $\$ 350,000$ \\ DOE Contact: Maurice J. Katz, (202) 586-6385 \\ SNL Contact: Terry Michalske, (505) 844-5829}

A fundamental basis for designing micromechanical devices with high yield, reliable performance and long life is lacking. Mechanical design tools for macro-scale machines relate reliability to inertial forces. However, the performance of micron-scale structures of high aspect ratio is dominated by surface forces. The technical goal of this project is to use experimental reliability results obtained directly from micromachined test structures to develop and verify mechanics models containing interaction terms appropriate to the micronscale (e.g. capillarity, van der Waals forces, electrostatics, etc.). Issues to be addressed include autoadhesion (stiction), friction and wear. Microbridge structures with varying geometry and surface properties (roughness, chemical coatings etc.) Are being designed and built. Deformations are being monitored by interferometry in an environmental chamber. Finite element models incorporating new surface elements are being developed, verified and refined by comparing against experimental results. An additional objective is to investigate friction and wear using smart micromachined structures that enable self-diagnosis by electrical monitoring of capacitance and $Q$ factor changes. Optical detection technique is being explored. Dynamical response models incorporating internal friction terms as well as damping are being verified and refined using experimental results. Friction due to energy loss at rubbing surfaces can then be extracted.

This project is developing a new tool set based on an experimental and theoretical foundation. The tool set 
can be used to calculate and characterize reliability of micromachines for integrated microsystem applications.

Keywords: Micromachine, Reliability

\section{INTELLIGENT POLYMERS FOR NANODEVICE PERFORMANCE CONTROL $\$ 439,000$ \\ DOE Contact: Maurice J. Katz, (202) 586-6385}

SNL Contact: Clifford Renschler (505) 844-0324

This project is developing a revolutionary enabling technology for the accurate, predictable manipulation of the fundamental optical, electrical and rheological properties of a new class of intelligent polymers. Their potential for write-once memories and nanoscale "device on command" capability could find application in reduced size parts (WPP) and intelligent manufacturing technologies, and compartmentalized activities at Sandia and in other government agencies (use control, tamper detection). The autonomous response polymers will remain passive prior to stimulation from specific light or heat sources, when they will undergo changes in morphology, conductivity or refractive index in response to the stimuli. Existing materials are limited to laboratory-scale manipulation of polymer conductivity with ill-defined thermally- or photochemically-initiated changes to the polymer's chemical structure. The approach of this project provides enhanced, welldefined control of polymer properties through molecular scale design of polymer structure. Materials are synthesized to covalently incorporate energetic chemical functionalities within the polymers' molecular structures. Appropriate energetic groups are then selected as monomers from molecular modeling of the energetic group's kinetic and thermodynamic response to heat and light, and the compatibility of the groups to co-monomers bearing latent reactivity. The energetic groups are incorporated as terminal groups or as blocks of repeat units within the polymer backbone by employing living polymerization techniques including Ring Opening Metathesis Polymerization (ROMP). Energetic group decomposition, stimulated from a specific source, indirectly activates the reactive repeat units, resulting in dramatic changes in macroscopic properties including refractive index, electrical conductivity or material bulk morphology.

\section{Keywords: Polymers, Nanodevices}

\section{QUANTUM DOT ARRAYS $\$ 400,000$ \\ DOE Contact: Maurice J. Katz, (202) 586-6385 SNL Contact: George Samara}

This project integrates two areas of Sandia research to fabricate new molecularly engineered, cluster-based, nanocomposite materials. First, Sandia has patented the inverse micellar synthesis of highly monodisperse metal and semiconductor nanoclusters, or "quantum dots." These 10-100 A nanoclusters have many interesting properties, including large catalytic activity, room temperature luminescence, size dependent bandgaps, etc., and are sufficiently monodisperse that size-dependent cluster properties can be easily resolved. However, these clusters are currently stable only in the reaction bath. Second, Sandia has developed an expertise in synthesizing bulk periodic mesoporous materials by templating silica around liquid crystalline surfactant assemblies. These surfactanttemplated porous materials (STPMs) are similar to zeolites, but the unit cell size is $40 \AA$ versus the $4-8 \AA$ typical for zeolites. These are the first periodic materials whose uniform pore size is commensurate with the typical dimensions of quantum dots. These new materials should be an ideal matrix for quantum dots; moreover, the quantum dots should form a highly periodic array, which may give rise to a host of new coherent phenomena. The goal of this project is to synthesize a new class of materials, "Quantum Dot Arrays" (QDAs), that consists of metal or semiconductor clusters periodically arrayed in an isolating silica matrix. Such cluster-based materials will have unique optical, catalytic, and dielectric properties: gold clusters in silica would give a high dielectric material for supercapacitors; low work function clusters could make a good field emitter; luminescent silicon clusters could make optical arrays; supported nanocluster catalysts could be made as thin films.

Keywords: Quantum Dot, Nanocluster

\section{DEVICE OR COMPONENT FABRICATION, BEHAVIOR OR TESTING}

\section{WIDE-BANDGAP COMPOUND SEMICONDUCTORS TO ENABLE NOVEL SEMICONDUCTOR DEVICES PROJECT $\$ 290,000$ DOE Contact: Maurice J. Katz, (202) 586-6385 SNL Contact: Jeffrey Nelson, (505) 844-4395}

This project is an interdisciplinary investigation into the growth and physical properties of wide-bandgap compound semiconductors for the purpose of enabling both optoelectronic and microelectronic device development. The AlGalnN material system is widely considered to be essential to the development of a wide array of UV and blue optical devices as well as hightemperature microelectronics. A critical limiting factor in the demonstration of advanced III- $\mathrm{N}$ based devices is the lack of an in-depth understanding of the physics and chemistry that govern the unique properties of these materials. This work focuses on two important areas in the development of these materials. A portion of the effort concentrates on understanding the growth of III-N materials by gas-source molecular beam epitaxy (GSMBE), specifically the effects of substrate preparation, substrate temperature, V/III ratio, and growth rate on the nucleation and growth of AlGalnN on $6 \mathrm{H}-\mathrm{SiC}(0001)$ surfaces using in situ reflection highenergy electron diffraction (RHEED), reflection mass 
spectroscopy (REMS), and scanning tunneling microscopy (STM). In combination with efforts to study crystal growth processes in these materials, the physical properties of the AIGaInN material system are being investigated. Analytical investigations include calculations to determine bandstructure and development of a model for optical gain and lasing which will include an exact treatment of Coulomb effects. Steady state and time-resolved luminescence is used to evaluate the nature of defect states in these materials as well as to study the excitonic properties which are expected to be enhanced for wide-bandgap semiconductors. Magnetoluminescence experiments determine energy dispersion and effective masses and these results are directly compared with bandstructure calculations. Another aspect of the work is an evaluation of how various processing techniques which are relevant for device fabrication, such as post-growth annealing, reactive ion etching and implantation, affect the optical and electronic properties of the III-N materials.

Keywords: MBE, HEED, REMS, STM

\section{SCANNING PROBE-BASED PROCESSES FOR NANOMETER-SCALE DEVICE FABRICATION $\$ 442,600$ \\ DOE Contact: Maurice J. Katz, (202) 586-6385 SNL Contact: Terry Michalske, (505) 844-5829}

Nanometer-scale electronic device technology requires a novel physics base that includes fabrication processes, characterization techniques and materials properties allowing reliable performance of devices at this very small length scale. This program integrates and expands Sandia's expertise in scanning-probe based fabrication and characterization of nanostructures with capabilities in microelectronic fabrication to produce fully accessible nanostructures for electronic evaluation. The objective is an order of magnitude decrease in feature size compared to conventional fabrication technology. Approaches to nanostructure fabrication using scanning probe-based (STM, AFM) processes in combination with extensive device fabrication are being explored. For prototype device structures critical nanoscale components are being integrated with conventional test structures to allow full electrical accessibility. Two approaches to nanostructure fabrication are being explored: investigation of molecular layer resists based on simple adsorbed atoms and molecules which can be patterned by electron induced desorption or reaction, and development of a more general AFM-based nanolithographic capability, based on anodic oxidation under an AFM tip. In parallel with these fabrication approaches, low temperature electrical measurements are being performed, and selected nanoelectronic devices are being fabricated and characterized.
354. SURFACE MICROMACHINED FLEXURAL PLATE WAVE DEVICE INTEGRATED ON SILICON

$\$ 525,000$

DOE Contact: Maurice J. Katz, (202) 586-6385

SNL Contact: Stephen Martin, (505) 844-9723

Small, reliable chemical sensors are needed for a wide range of applications, such as, weapons state-of-health monitoring, nonproliferation activities and manufacturing emission monitoring. Advantages of a flexural plate wave (FPW) architecture for these sensors include improved sensitivity, reduction in operating frequency to be compatible with standard digital microelectronics and sensing in liquid media. This project investigates fabrication of these miniaturized, high reliability devices, which requires successful execution and integration of three technologies: acoustic sensor design; Si surface micromachining; and high quality piezoelectric thin film deposition.

Keywords: Micromachines, Silicon

\section{MODELING ELECTRODEPOSITION FOR METAL MICRODEVICE FABRICATION PROPERTIES $\$ 265,000$ \\ DOE Contact: Maurice J. Katz, (202) 586-6385 \\ SNL Contact: Jill Hruby, (925) 294-2596}

LIGA, an acronym from the German words for lithography, electroforming, and molding, is a promising new process for producing metal microdevices having micron to millimeter features. Currently under worldwide development, this process offers a means to manufacture high resolution, high aspect-ratio devices including microscale valves, motors, solenoid actuators, and gear trains. Most research in LIGA has focused on the lithography process used to produce LIGA molds. Filling these molds by electrodeposition has received much less attention, despite several serious problems. Device-scale voids in the deposited metal occur frequently and often without apparent cause. These problems are likely due to the depletion of metal ions and the accumulation of hydrogen in the stagnant layer between the top and bottom of the mold. The presence of this diffusion layer distinguishes LIGA electrodeposition from traditional electroplating and electroforming processes.

To help understand and optimize the electroforming portion of the LIGA process, this project is developing a one-dimensional numerical model describing the electrodeposition of metal into high aspect-ratio molds having lateral dimensions on the micron scale. To guide model development, and later to validate this model, a series of one and two-dimensional laboratory experiments are being coordinated.

Keywords: Micromachines, Electrodeposition 


\section{INSTRUMENTATION AND FACILITIES}

\section{ADVANCED ANALYTICAL TECHNIQUES $\$ 998,000$}

DOE Contact: Robin Staffin, (202) 586-7590

SNL Contact: Julia M. Phillips, (505) 844-1071

The Advanced Analytical Techniques Project supports the development of advanced methods of characterizing materials structure and providing chemical analysis. Each of the relatively independent subprojects is directed towards advancing the state-of-the-art in materials characterization by developing new capabilities for extracting information about materials through the development of new hardware or data analysis techniques. Each project must offer at least one of the following: (1) improvement in Sandia's ability to monitor the nuclear stockpile or nuclear weapon production or maintenance processes, or (2) the capability to perform failure analysis on weapons components, materials, or subsystems.

Keywords: Chemical Analysis, Characterization

\section{NANOSTRUCTURES, ADVANCED MATERIALS, AND ION BEAM SCIENCES $\$ 2,792,000$}

DOE Contact: Robin Staffin, (202) 586-7590

SNL Contact: George A. Samara, (505) 844-6653

This research keeps Sandia at the forefront of experimental and theoretical materials science relevant to National Security needs and includes experiment and theory of new materials (e.g., nanoclusters, nanostructures, polymeric ferro electrics, amorphous diamond films, and shock wave-induced phenomena) of proven or potential application in current or future weapon systems. The program also develops new ionbeam based tools required to fully characterize or modify these new materials systems (e.g., radiation effects microscopy) and new computational tools for improved structural/electronic/photonic property simulations.

Keywords: Nanostructures, lon Beam

\section{PHYSICO-CHEMICAL STABILITY OF SOLID SURFACES \\ $\$ 413,000$ \\ DOE Contact: Maurice J. Katz, (202) 586-6385 \\ SNL Contact: Terry Michalske, (505) 844-5829}

The application of physico-chemical phenomena to either increase machinability of hard materials, improve the wear resistance of cutting surfaces, or enhance sintering of particle compacts can have large economic impact on technologies ranging from materials forming processes to oil well drilling. Unfortunately, the broad application of these physico-chemical principles is limited by the ability to predict the optimum conditions for a wide variety of materials surfaces. Predictive models must be built upon understanding of the elementary events involved in surface damage and mobility. The project is developing a new approach to examine the fundamental mechanisms controlling physico-chemical surface stability that combines: (1) atomic-scale control of surface contact forces and displacements under well controlled adsorbate conditions using the Interfacial Force Microscope; (2) atomic-level imaging of surface and near-surface structure and defects using Field lon Microscopy and Transmission Electron Microscopy; and (3) firstprinciples modeling of the effect surface stress on adsorbate bonding interactions and the subsequent generation of surface damage.

Keywords: Stability, Surface, Wear

\section{WAWRENCE UUVRMORE NATIONAI} LABORATORY

\section{MATERIALS PREPARATION, SYNTHESIS,} DEPOSITION, GROWTH OR FORMING

\section{ENGINEERED NANOSTRUCTURE LAMINATES $\$ 2,000,000$ \\ DOE Contact: G. J. D'Alessio, (301) 903-6688 \\ LLNL Contact: Troy W. Barbee, Jr., (925) 423-7796}

Multilayers are man-made materials in which composition and structure are varied in a controlled manner in one dimension during synthesis. Individual layers are formed using atom by atom processes (physical vapor deposition) and may have thicknesses of from one monolayer $(0.2 \mathrm{~nm})$ to hundreds of monolayers $(>100 \mathrm{~nm})$. At this time more than 75 of the 92 naturally occurring elements have been incorporated in multilayers in elemental form or as components of alloys or compounds. In this work deposits containing up to 225,000 layers of each of two materials to form up to $500 \mu$ thick samples have been synthesized for mechanical property studies of multilayer structures.

These unique man-made materials have demonstrated extremely high mechanical performance as a result of the inherent ability to control both composition and structure at the near atomic level. Also, mechanically active flaws that often limit mechanical performance are controllable so that the full potential of the structural control available with multilayer materials is accessible. Systematic studies of a few multilayer structures have resulted in free-standing foils with strengths approaching those of whiskers, approximately 70 percent of theory. Also, new mechanisms for mechanically strengthening materials are accessible with nanostructure laminates.

Applications now under development include: coatings for aircraft gas turbine engines; EUV, soft X-ray and X- 
ray optics spectroscopy and imaging; high performance capacitors for energy storage; capacitor structures for industrial applications; high performance tribological coatings; strength materials; integrated circuit interconnects; machine tool coatings; projection X-ray lithography optics.

Keywords: Thin Films, Multilayer Technology

\section{SOL GEL COATINGS}

$\$ 335,000$

DOE Contact: G. J. D'Alessio, (301) 903-6688

LLNL Contact: I. M. Thomas, (925) 423-4430 and J. Britten, (925) 423-7653

This project investigates the preparation of multilayer sol-gel high reflection (HR) coatings using colloidal $\mathrm{SiO}_{2}$ with either $\mathrm{HfO}_{2}$ or $\mathrm{ZrO}_{2}$. The incorporation of an organic polymer binder such as polyvinyl alcohol or polyvinyl pyrolidinone into the high index component has resulted in an increase in the damage threshold and a decrease in the number of layer pairs required for high reflection. A laboratory size meniscus coater was evaluated and found to produce mirrors of high optical performance and adequate damage threshold. This is now the preferred method of application, and a large machine capable of producing Beamlet and NIF size mirrors is in place.

Keywords: Sol Gel Coatings, Meniscus Coater, HR Coatings

\section{KDP AND DKDP CRYSTAL DEVELOPMENT AND PRODUCTION \\ $\$ 4,000,000$ \\ DOE Contact: G. J. D'Alessio, (301) 903-6688 \\ LLNL Contact: J. J. DeYoreo, (925) 423-4240}

Potassium dihydrogen phosphate (KDP) and its deuterated analog (DKDP) are important nonlinear crystals which will be used both for frequency conversion as well as for a large Pockels cell on the National Ignition Facility (NIF). These crystals are very expensive, due in part to the very long times required to grow large boules (2-3 years) and the cost of $D_{2} O$ for growing DKDP. This project has developed an alternative growth technique that dramatically increases the growth rate of these crystals.

Using this method both KDP and DKDP are being grown at 10 times the rates achieved with conventional methods. High quality crystals up to almost $57 \mathrm{~cm}$ on a side have been grown by this method. Crystals at the $10-15 \mathrm{~cm}$ scale are being grown in order to determine optimum hydrodynamic and regeneration conditions, and to understand the effects of impurities and stresses on the stability of the growing crystal face and the performance of the crystals.

Keywords: KDP, Nonlinear Crystals, Crystallization
362. ENERGETIC MATERIALS STRATEGIC CHEMISTRY $\$ 350,000^{1}$ DOE Contact: Bharat Agraval, (301) 903-6688 LLNL Contact: R. L. Simpson, (925) 423-0379

Vicarious nucleophilic substitution chemistry is being used to synthesize energetic materials. New explosive molecules are being synthesized. Alternate routes to existing molecules, such as TATB, have been developed.

Keywords: Examination, Explosive, Energetic, TATB

\section{CHEETAH THERMOCHEMICAL CODE $\$ 190,000^{1}$ DOE Contact: Bharat Agraval, (301) 903-6688 LLNL Contact: R. L. Simpson, (925) 423-0379}

A thermochemical code for the prediction of detonation performance is being developed. In addition to detonation performance, thermochemical calculations of impetus and specific impulse for propellant applications may also be made.

Keywords: Examination, Explosive, Energetic, TATB

\section{EXPLOSIVES DEVELOPMENT} $\$ 900,000^{1}$

DOE Contact: Bharat Agraval, (301) 903-6688

LLNL Contact: R. L. Simpson, (925) 423-0379

New explosives are being developed for hard target penetrators. The goals include insensitivity to shock loading and significantly higher energy density than that of currently available materials.

Keywords: Explosive

MATERIALS PROPERTIES, BEHAVIOR, CHARACTERIZATION OR TESTING

\section{INTERFACES, ADHESION, AND BONDING $\$ 250,000$ \\ DOE Contact: Iran L. Thomas, (301) 903-6688 \\ LLNL Contact: Wayne E. King, (925) 423-6547}

The experimental effort is producing results that are directly comparable with theoretical calculations. Planar metal/metal interfaces and metal/ceramic interfaces (in anticipation of improvements in the theory) of well defined misorientations are being investigated. In order to span the entire range of length scales described above, macroscopic bicrystals a few millimeters thick, with interfacial areas on the order of a square centimeter, are required. In order to obtain such bicrystals, diffusion bonding is used. An ultra-high-

'General energetic materials-related input. This activity is jointly funded $\{50: 50)$ by DOE DP and the DoD. 
vacuum diffusion bonding machine has been developed in parallel with this research project.

Keywords: Interfaces, Bonding, Electronic Structure

\section{LASER DAMAGE: MODELING AND CHARACTERIZATION $\$ 1,000,000$ DOE Contact: G. J. D'Alessio, (301) 903-6688 LLNL Contact: M. R. Kozlowski, (925) 424-5637}

The objective of this project is to understand the mechanisms for laser-induced damage in optical materials used in high-peak-power laser systems such as the National Ignition Facility (NIF). Materials of primary concern are optical coatings and polished fused silica surfaces. The primary characterization tools used in the studies include Atomic Force Microscopy (AFM), Total internal Reflection Microscopy (TIRM), Near-field Scanning Optical Microscopy (NSOM), Secondary Ion Mass Spectroscopy (SIMS) and Photothermal Microscopy (PTM). Efforts are focused on the development of characterization tools that have improved resolution and detection limits and that can differentiate between damaging and non-damaging defects.

An understanding is also needed of the growth of damage resulting from illumination pulses after the initial onset of damage. The damage growth rate determines the functional lifetime of the optic in the laser system. The dependence of the damage growth rate on laser wavelength, pulse length, and pulse repetition rate are being determined. Also of interest is the influence of optic environment (air vs. Vacuum) on the damage processes.

Keywords: Coatings, Atomic Force Microscopy, Laser Damage

\section{KDP CHARACTERIZATION}

$\$ 1,000,000$

DOE Contact: G. J. D'Alessio, (301) 903-6688

LLNL Contact: J. J. DeYoreo, (925) 423-4240

Very large, high quality crystals of potassium dihydrogen phosphate (KDP) and its deuterated analogue (DKDP) are required for present and advanced high power lasers in the ICF Program. The performance of these crystals is limited by impurities and strain which induces anomalous birefringence and wavefront distortion and by defects which result in laserinduced damage at low laser fluence. The level of impurities, internal strain and the laser damage threshold are the most important factors in determining the yield of useable plates from an "as-grown" boule. The goal of this project is to identify the defects which are the source of strain and damage in KDP and DKDP, understand how these defects are generated, and how to avoid them during the growth process.
Techniques used include optical scatterometry, spectroscopy, X-ray typography, crystal growth and chemical analysis to determine the distribution of defects in crystals and their relationship to the growth process. Strain and damage have been related to specific defects using these methods and the process of laser damage as well as laser and thermal annealing is now under investigation in situ.

Keywords: KDP, Strain, Crystal

\section{INSTRUMENTATION AND FACILITIES}

\section{SCANNING TUNNELING MICROSCOPY (STM) AND ATOMIC FORCE MICROSCOPY (AFM) $\$ 250,00$ DOE Contact: G. J. D'Alessio, (301) 903-6688 \\ LLNL Contact: W. Siekhaus, (925) 422-6884}

A large stage scanning probe microscope that can perform scanning tunneling as well as contact and noncontact atomic force microscopy on the surface of objects as large as $6^{\prime \prime}$ in diameter, a small stage modified so that it can perform non-contact AFM and STM as well as nano-indentation, and an ultra-high vacuum instrument that can perform non-contact AFM and STM measurements and STM spectroscopy (STS) are being used for the following studies:

Uranium Hydriding - Understanding the early stages of uranium hydriding and the effect of surface impurities is of paramount importance in science based stockpile stewardship. The UHV STM/AFM is used to determine the effect of local impurities on uranium hydriding.

Electronic Properties of Nano-scale Particles - Nm-scale clusters various materials, deposited by laser ablation and by evaporation in a noble gas atmosphere onto the basal plane of graphite are analyzed by STM to determine their size distribution and by optical spectroscopy and electron spectroscopy to determine their size-dependent optical properties and electronic structure.

- Dissolution Rate of Uranium Oxide - The dissolution of uranium oxide by ground is being determined by AFM on single crystal uranium oxide by monitoring the rate of recession of the U02 surface with reference to a gold marker.

- Combined Scanning Probe Microscopy/NanoIndentation - Used to identify the local mechanical properties of composite materials such as fiber reinforced plastics, bone-, tooth- and arterialtissue from healthy and diseased arteries.

Keywords: NDE, Chemical Reaction, Uranium Hydriding, Stockpile Stewardship, Uranium Oxide Dissolution, Nuclear Waste Disposal, Etching, Cluster, Nano-indentation, Mechanical Properties, Biomaterials, Tooth, Artery, Bone 


\section{FATIGUE OF METAL MATRIX COMPOSITES $\$ 500,000$ \\ DOE Contact: Warren C'ernock, (202) 586-7590 \\ LLINL Contact: Donald Lesuer, (925) 422-9633}

This project involves Lawrence Livermore National Laboratory and General Motors. The project is studying the mechanisms of high cycle fatigue in squeeze cast metal matrix composites. The life limiting microstructural features are being determined and the processing-structure-property correlations are being established. Models that can predict lifetimes will be developed.

Keywords: Materials Properties, Behavior, Characterization or Testing

\section{MATERIALS PRODUCED WITH DYNAMIC HIGH PRESSURE \\ $\$ 50,000$ \\ DOE Contact: G. J. D'Alessio, (301) 903-6688 \\ LLNL Contact: William Nellis, (925) 422-7200}

This project produces novel materials (crystal structures, microstructures, and properties) using high shock pressures. The terms dynamic and shock are used synonymously in this context. Tuneable shock pressure pulses are produced by the impact of a projectile launched from a small two-stage light-gas gun. Shock pressures range from 0.01-1 Mbar, temperatures range from 50 up to a few $1000^{\circ} \mathrm{C}$, strain rates on loading range above $10^{8} / \mathrm{s}$ and quench rates on release of pressure are $10^{12} \mathrm{bar} / \mathrm{s}$ and $10^{\circ} \mathrm{K} / \mathrm{s}$ in specimens which are recovered intact for investigation. A gas gun is used to achieve these high shock pressures. Specimens range from 1 micron to $3 \mathrm{~mm}$ thick and from 3 to $23 \mathrm{~mm}$ in diameter. The observed material structures are correlated with computational simulations to enhance understanding of the effects produced. For example, a computational model of the dynamic compaction of nanocrystalline Al particles was shown to be in good agreement with the structure of compacts produced experimentally. A wide variety of materials characterization measurements are made both before and after apolication of high dynamic pressures, including $X$-ray uiiliciction, TEM, SEM, magnetization, NMR, ana neutron scattering. Over the past few years nanocrystalline $A \mathrm{l}$, ceramic, and magnetic powders have been dynamically compacted, unusual glass has been produced in bulk and nanocrystalline $S i$ in grain boundaries by shock compressing quartz single crystals, and impacts in nature have been investigated by studying structural effects in shocked minerals. A new gas breach to achieve shock pressures of $<50 \mathrm{Kbar}$ to induce high densities of defects and compact powders was built in FY 1997.

Keywords: Shock Pressures, Gas Gun, Materials Characterization, Ceramics, Magnets. Nanocrystalline Si, Glass

\section{PROPERTIES OF HYDROGEN AT HIGH SHOCK PRESSURES AND TEMPERATURES}

$\$ 400,000$

DOE Contact: G. J. D'Alessio, (301) 903-6688

LLNL Contacts: William Nellis,

(925) 422-7200 and Neil Holmes,

(925) 422-7213

The properties of hydrogen at high pressures and temperatures are a "Holy Grail" issue for laser fusion, condensed matter physics, and planetary physics. Hydrogen in the form of deuterium-tritium is the fuel in laser fusion targets; the metallization of hydrogen by electronic bandgap closure has been a key goal of condensed matter physics since the early part of this century: and Jupiter with its 300 Earth masses is 90 percent hydrogen at high pressures and temperatures. This project measures temperatures and electrical conductivities of cryogenic liquid hydrogen and deuterium shock-compressed to pressures up to $2 \mathrm{Mbar}\left(2 \times 10^{6} \mathrm{bar}\right)$ and temperatures up to $5000 \mathrm{~K}$ with a two-stage light-gas gun. These conditions are achieved by impact of projectiles accelerated to velocities up to $8 \mathrm{~km} / \mathrm{s}$. Shock temperatures up to $5000 \mathrm{~K}$ at $1 \mathrm{Mbar}$ were measured by a fast optical spectrometer and show that hydrogen undergoes a continuous dissociative phase transition above $200 \mathrm{kbar}$. This continuous dissociation absorbs energy, which causes lower temperatures and higher densities in the Mbar shock pressure range than was thought previously.

Electrical conductivities were measured using metal electrodes at pressures in the range 1 to $2 \mathrm{Mbar}$ at calculated temperatures of 2000 to $4000 \mathrm{~K}$. A novel technique was used to produce just enough shock heating to excite just enough electronic carriers to be able to measure the electrical conductivity of hydrogen at Mbar pressures in the short time duration of the experiment. These are the only electrical conductivity measurements on condensed hydrogen at any pressure. This project, for the first time, metallized hydrogen at $1.4 \mathrm{Mbar}$ and $3000 \mathrm{~K}$ in the fluid and determined the density dependence of the electronic bandgap in the molecular fluid phase. The observed metallization pressure in the fluid is about one-half what was predicted for the solid at $0 \mathrm{~K}$.

Keywords: Shock Pressures, Shock Temperatures, Electrical Conductivities, Gas Gun, Hydrogen, Cryogenics, Equation of State, Dissociation, Metallization

\section{ATOMIC LEVEL EXPLOSIVE CALCULATIONS $\$ 400,000$ \\ DOE Contact: Maurice Katz, (202) 586-5799 \\ LLNL Contacts: Larry Fried, (925) 422-7796}

A package of atomic-level calculations has been assembled that will allow design of new explosive molecules. The package includes calculations of solid density, heat of formation, chemical stability and 
sensitivity. This package is being tried on various new postulated compositions in concert with feedback from three organic and inorganic synthesis chemists. The intent is to couple Molecular Design with actual synthesis routes at the start so that the final selected design will be something with a good chance of being made in the lab. The target is to provide 10 to 15 percent more detonation energy than $\mathrm{CL}-20$ with no decrease in sensitivity.

Keywords: Energetic Materials, High Explosives, Molecular Design, Detonation

\section{METASTABLE SOLID-PHASE HIGH ENERGY DENSITY MATERIALS \\ $\$ 535,000$ \\ DOE Contact: Maurice Katz, (202) 586-5799 \\ LLNL Contacts: H. Lorenzana, (925) $422-8982$ and $M$. Finger, (925) $422-6370$}

Conventional energetic materials such as propellants, explosives and fuel cells store energy within internal bonds of molecules. This work is exploring the predicted existence of novel materials that are calculated to store two to four times the energy content per volume of existing explosives, a dramatic improvement in performance. Though the atomic components are similar to standard energetic materials, these new materials differ from conventional molecular systems in that they form infinite, three-dimensional networks of covalent bonds, otherwise known as "extended" solids. Every bond in these new systems is energetic; the result is a correspondingly larger storage of energy per volume. Specifically, pure nitrogen is calculated to be recoverable at ambient conditions as an energetic solid with three times the energy content of $H M X$, a very high performance explosive. Since these materials are predicted to exist at high pressures and high temperatures, experimental capabilities have been developed for synthesizing and characterizing such compounds at megabar pressures.

The existence of a new extended solid (polymeric) phase of $\mathrm{CO}$ has been verified at about $50 \mathrm{kbar}$. This new material is recoverable at ambient conditions, and is believed to be energetic. The equation-of-state of various candidate structures for $\mathrm{CO}$ have been calculated, but further experimental constraints are needed in the structure and bond nature. Accordingly, Raman measurements of absorption in the visible and infrared have been performed. This information has provided important insights as to the character of the bonds present in this material. During FY 1997 techniques for generating "large" samples of the extended-solid phase of $\mathrm{CO}$ at high pressures have been developed, in order to measure stoichiometry and energy content.

Keywords: Energetic Materials, High Energy Density Materials

\section{AFM INVESTIGATIONS OF CRYSTAL GROWTH $\$ 290,000$ \\ DOE Contact: G. J. D'Alessio, (301) 903-6688 \\ LLNL Contact: J. J. DeYoreo, (925) 423-4240}

The nanometer-scale morphology of crystalline surfaces exerts a strong control on materials properties and performance. While many researchers have studied vapor deposited metal and semiconductor surfaces grown far from equilibrium, few studies have given attention to the morphology of crystal surfaces grown from melts or solutions near equilibrium despite the fact that most bulk crystals are grown in this regime. Understanding the mechanisms of growth and the origin of defects in such crystals can impact materials performance in a number of fields including optics, electronics, molecular biology, and structural biology. We are using atomic force microscopy (AFM) to investigate the growth of single crystal surfaces from solution in order to determine the mechanism of growth, the kinetics of step advancement, the effect of impurities, and the origin of defects.

This method has been applied to inorganic, organic and macromolecular crystals each of which serve as important model systems. These include $\mathrm{KH}_{2} \mathrm{PO}_{4}$, $\mathrm{CaCO}_{3}$ doped with amino acids, molecular tapes of diketopipeizine derivatives, the protein canavalin and the satellite tobacco mosaic virus. The results of these investigations are providing an understanding of the fundamental physical controls during solvent mediated crystallization.

Keywords: Morphology, Crystal Surfaces, Atomic Force
Microscopy

375. URANIUM CASTING PROGRAM $\$ 1,000,000$

DOE Contact: Marshall Sluyter, (301) 903-5491

LLNL Contact: Jeff Kass, (925) 422-4831

The uranium casting program is addressing the use of permanent molds for near net shape castings, controlled cooling for segregation and microstructure control and the effect of alloy additions and subsequent heat treatment on microstructure. Process modeling has played a key role in producing high quality castings in uranium and uranium alloys.

Keywords: Uranium Casting

\section{URANIUM SPIN FORMING}

$\$ 1,500,000$

DOE Contact: Marshall Sluyter, (301) 903-5491

LLNL Contact: Jeff Kass, (925) 422-4831

Spin forming is being explored as a method to produce near net shape wrought uranium components. Process 
modeling has been useful in predicting stress/ strain distribution and spring back. Near net shape components have been produced.

Keywords: Spin Forming

377. PLUTONIUM NEAR NET SHAPE CASTING $\$ 2,500,000$

DCE Contact: Marshall Sluyter, (301) 903-5491

LLINL Contact: Jeff Kass, (925) 422-4831

Near net shape casting is being explored using permanent molds. High quality castings have been produced. Process modeling has played a significant role in defining conditions needed for solidification control.

\section{Keywords: Shape Casting}

\section{ELIECTRON BEAM COLD HEARTH MELTING OF URANIUM $\$ 900,000$ \\ DOE Contact: Marshall Sluyter, (301) 903-5491 \\ LLNL Contact: Jeff Kass, (925) 422-4831}

An existing electron beam evaporation chamber has been modified to produce controlled solidification uranium alloy ingots. Scrap feeders of various types are being evaluated. High quality ingots which meet the applicable uranium alloy specification have been produced.

Keywords: Electron Beam Melting, Uranium

\section{NIF CAPSULE MANDREL R\&D $\$ 800,000$ DOE Contact: G. J. D'Alessio, (301) 903-6688 LLNL Contact: R. Cook, (925) $422-3117$}

This program has as its objective the development of $2 \mathrm{~mm}$ thin-walled plastic shells that will serve as the mandrel for the production of capsule targets for the National Ignition Facility (NIF). The mandrels must be extremely spherical ( $<1 \mu \mathrm{m}$ out of round), have wall thickness uniformity better than $1 \mu \mathrm{m}$, and have a surface finish of less than $10 \mathrm{~nm}$ ( $\mathrm{rms}$ over modes $>9$ ). Several routes are being explored.

Keywords: Polymers, Laser Fusion Targets, Microencapsulation, Microshells

\section{POLYIMIDE COATING TECHNOLOGY FOR ICF TARGETS $\$ 500,000$ \\ DOE Contact: G. J. D'Alessio, (301) 903-6688 \\ LLNL Contacts: R. Cook, (925) 422-3117 and Steve Letts, (925) $422-4373$}

This program has as its objective the development of a vapor based, high strength polyimide coating technology that will allow us to produce a smooth, 150 to
$200 \mu \mathrm{m}$ polyimide ablator coating on a $2 \mathrm{~mm}$ diameter capsule target for the National Ignition Facility (NIF). Such targets should be strong enough to hold the full DT fuel load (about $300 \mathrm{~atm}$ ) at room temperature, allowing us important flexibility in fielding these capsules for ignition experiments.

Keywords: Polymers, Laser Fusion Targets, Polyimide, Ablator

\section{BERYLLIUM ABLATOR COATINGS FOR NIF TARGETS \\ $\$ 600,000$ \\ DOE Contact: G. J. D'Alessio, (301) 903-6688 \\ LLNL Contacts: R. McEachern, (925) 423-4734, R. Cook, (925) 422-3117, R. Wallace, (925) 423-7864 and A. Jankowski, (925) 423-2519}

This program has as its objective the development of sputter deposition techniques that will allow us to deposit 150 to $200 \mu \mathrm{m}$ of a strong, smooth, Cu-doped Be ablator on a spherical plastic mandrel shell. These Be coated capsule targets have been shown by calculation to offer some important advantages as ignition targets for the National Ignition Facility (NIF).

Keywords: Beryllium, Laser Fusion Targets, Ablator, Sputter Deposition

\section{LOS ALAMOS NATIONAL SABORATORY}

\section{MATERIALS PREPARATION, SYNTHESIS,} DEPOSITION, GROWTH OR FORMING

\section{RAPID SOLIDIFICATION PROCESSING $\$ 500,000$ DOE Contact: R. Jones, (301) 903-6688} LANL Contact: D.J. Thoma, (505) 665-3645

The project incorporates process development and product comparisons resulting from rapid solidification processing techniques including melt spinning and gas atomization. Alloy homogeneity, phase stability, mechanical and physical properties are used for comparison.

Keywords: Rapid Solidification, Melt Spinning, Atomization, Phase Stability, Alloy Homogeneity

\section{STRUCTURAL ALLOY DEVELOPMENT} $\$ 2,000,000$

DOE Contact: Yok Chen, (301) 903-4174

LANL Contact: D.M. Parkin, (505) 667-8455

Alloy development for high temperature applications has focused on laves phase and silicide-based materials. Synthesis incorporates rapid solidification, plasma arc melting, vacuum arc melting, and powder 
synthesis techniques. Characterization is performed to detail phase stability and transformation

thermodynamics, microstructure evolution, mechanical properties and high-temperature oxidation.

Keywords: Laves Phase, Silicide, Rapid Solidification, Plasma Arc Melting, Vacuum Arc Melting, Powder Synthesis

\section{MATERIALS STRUCTURE OR COMPOSITION}

\section{NATIONAL HIGH MAGNETIC FIELD LABORATORY \\ $\$ 1,800,000$ \\ DOE Contact: J.J. Smith, (301) 903-4269 \\ LANL Contact: D.M. Parkin, (505) 667-8455}

The objective of the thrust is to apply high magnetic fields to the solution of unresolved fundamental problems in many body physics of condensed matter. Particular attention is given to electronic structure and many-body phenomena in $5 f$ systems, with special emphasis on plutonium. There are two major components of the thrust: (1) an examination of static or mean-field properties of correlated-electron systems and (2) an examination of rapid femtosecond dynamics of electron-electron correlations (many-body phenomena) in high magnetic fields.

The world's longest-pulse, high-field magnet, funded by DOE, will be collocated with the other components of the Los Alamos NHMFL Pulsed-Field Facility, funded by the National Science Foundation (NSF). This interagency DOE/NSF collaboration will provide a unique user facility to users from DOE laboratories, industry, and universities. The magnet, when completed in 2000 , will provide nondestructive 100 -tesla magnetic fields for periods lasting up to 10 milliseconds, which is a thousand times longer than is available anywhere else. The magnet is a uniquely powerful tool for studying high-temperature superconductors and the electronic structure of materials at unprecedented resolution.

Keywords: High Magnetic Fields, Electronic Structure, Electron-electron Correlations, Plutonium

\section{NEUTRON DIFFRACTION $\$ 1,500,000$ \\ DOE Contact: B.B.Agrawal, (301) 903-2057 \\ LANL Contact: E.M.Farnum, (505) 665-5523}

Neutron scattering is being applied to the characterization of weapons materials in the realms of electronic structure, crystallography, chemical reaction dynamics and residual strain distribution. The primary materials of interest are high explosives, plutonium, uranium, beryllium and organic salts.

The local structure of Pu and its alloys is being studied using neutron pair-distribution-function (PDF) techniques. Neutron resonance Doppler broadening experiments are being performed to understand the phonon behavior of Pu alloys and phonon densities of states (PDOS) measurements will be made across the phase boundaries of Pu. The ability to measure crystallographic texture in plutonium has been demonstrate. The intent is to correlate texture measurements with elastic properties.

Keywords: Neutron Scattering, Pair-distributionfunction, Phonon Densities, High Explosives, Plutonium, Uranium, Beryllium and Organic Salts

\section{MATERIALS PROPERTIES, BEHAVIOR,} CHARACTERIZATION OR TESTING

\section{DYNAMIC MECHANICAL PROPERTIES OF WEAPONS MATERIALS \\ $\$ 2,000,000$ \\ DOE Contact: B.B. Agrawal, (301) 903-2057 \\ LANL Contact: G.T. Gray III, (505) 667-5452}

This program is focused on experimental measurements and computer modeling of dynamic stress-strain and fracture behavior of polymers, high explosives, actinides, beryllium, and common structural materials. Development of constitutive relationships and fracture models for the prediction of material performance.

Keywords: Dynamic Properties, Fracture, Microstructure

\section{DEFORMATION CHARACTERIZATION AND MODELING \\ $\$ 5,000,000$ \\ DOE Contact: Yok Chen, (301) 903-4174 \\ LANL Contact: D.M. Parkin, (505) 667-8455}

This program is focused on experimental measurements and computer modeling of elastic-plastic deformation paths incorporating dislocation dynamic and crystallographic texture to define multi-dimensional yield surfaces. Program success will result in an improved understanding of materials properties incorporating theories and modeling to extrapolate from microscopic to mesoscopic properties of materials.

Keywords: Elastic-Plastic Deformation, Dislacations, Crystallographic Texture

\section{MATERIALS AGING \\ $\$ 11,000,000$ \\ DOE Contact: D.V. Feather, (301) 903-5815 \\ LANL Contact: L. Salazar, (505) 667-7485}

The materials aging program is developing tools, techniques, and procedures to advance our capability to measure, analyze, and predict the aging of materials within nuclear weapons. Experimental work is proceeding in high explosives, polymers, plutonium, 
uranium, salts, and beryllium. Experimental investigations are proceeding at the atomistic level to examine radiolytic-induced structural changes, molecular levels for polymer degradation, microstructure and bulk levels for mechanical property changes or corrosion.

Keywords: High Explosives, Polymers, Plutonium, Uranium, Salts, Beryllium, Atomistic Bonding, Molecular Dynamics, Mechanical Properties, Corrosion

\section{POWDER CHARACTERIZATION} $\$ 300,000$

DOE Contact: B.B. Agrawal, (301) 903-2057

LANL Contact: J.K. Bremser, (505) 667-1179

Synthesis; and processing of ceramic or metal powders depends critically on the physical characterization of the starting powders being used. Typical starting powders include commercial powders of thoria, magnesia, alumina, tungsten, copper, tungsten carbide, and boron carbide. In the past year, considerable effort has been expended on characterizing palladium alloy powders. Physical properties of interest include particle size and distribution, surface area, bulk and packed densities, morphology, pore size and distribution, and zeta potential. The crystalline-phase composition of the starting powders and processed powders can be determined by $X$-ray diffraction.

Keywords: Ceramic Powder, Metal Powder, Particle Size, Superconducting Powder, X-ray Diffraction, Surface Area

\section{DEVICE OR COMPONENT FABRICATION, BEHAVIOR OR TESTING}

\section{MANUFACTURING PROCESS DEVELOPMENT $\$ 8,000,000$ \\ DOE Contact: G.S. Hearron, (505) 845-5311 \\ LANL Contact: T.R. Neal, (505) 665-5568}

The Advanced Design and Process Technology program, ADAPT, has taken the role of catalyst for manufacturing-related goals and for integrating the weapons complex manufacturing activities. This program includes the development of manufacturing process improvements, agile manufacturing techniques, enterprise integration focusing on material resource modeling, and hedge planning for the rapid reconstitution of large-scale production. Investments in the later three categories have been modest because of the intensity of needs in process development. ADAPT is directly integrated with core R\&D for specific studies of materials performance, models-based engineering, and manufacturing specifications.

Keywords: Radioactive Materials, Plutonium Alloys, Beryllium, Uranium, Lithium Salts, Polymers High Explosives, Tritium, Welding, Forming, Casting, Uranium Purification

\section{ADVANCED ENGINEERING METHODS DEVELOPMENT \\ $\$ 1,100,000$ \\ DOE Contact: $R$. Jones (301) 903-6688}

LANL Contact: C.A. Spirio, (505) 667-4772

The project is focused on developing tools and methods to support a models-based engineering-manufacturing (MBE-M) approach (solid models, assembly animation, spline algorithms, sensitivity analysis of secondaries, and manufacturing applications) to both the above ground experimental program, and as-built or remanufactured stockpile systems.
Keywords: Solid Model, Spline, Model-based Engineering, As-built, Remanufacturing, Stockpile

\section{COMPONENT FABRICATION}

$\$ 10,000,000$

DOE Contact: R. Jones (301) 903-6688

LANL Contact: R. Mah, (505) 667-3238

Component fabrication includes the development and modeling of process technologies coupled with extensive materials characterization for the manufacture of demonstration and test components. Processing capabilities cover casting, forming, atomization, rapid solidification processing, powder consolidation, plasma spray, heat treatment, sintering, welding and joining. Characterization includes $\mathrm{X}$-ray diffraction, microscopy, mechanical properties and physical properties determinations. Materials fabricated include uranium, beryllium, stainless steels, refractory metals, palladium, and special alloys.

Keywords: Casting, Forming, Atomization, Rapid Solidification Processing, Powder Consolidation, Plasma Spray, Heat Treatment, Sintering, Welding, Joining, X-ray Diffraction, Microscopy, Mechanical Properties, Physical Properties, Uranium, Beryllium, Stainless Steels, Refractory Metals, Palladium, Special Alloys

\section{LASER TARGET FABRICATION $\$ 5,000,000$ \\ DOE Contact: C. Keane , (301) 903-4323 \\ LANL Contact: L.R. Foreman, (505) 667-1846}

The fabrication of complex and ultra-precision targets, mm-sized, for laser drive experiments related to inertial confinement fusion and nuclear weapons research. Efforts include the development and characterization of special alloys and tritium loading techniques along with the application of manufacturing processes of rapid solidification, powder consolidation, physical vapor deposition, chemical vapor deposition, polymer and polymer foam synthesis, precision machining and micro-assembly. Characterization includes examinations of microstructure, mechanical properties, physical properties, nondestructive examinations 
(radiography and ultrasonic), dimensional inspection, and optical interferometry.

Keywords: Physical Vapor Deposition, Chemical Vapor Deposition, Polymer Chemistry, Polymer Foam Synthesis, Precision Machining, Micro-assembly, Beryllium, Tritium, Plastics

\section{PULSED POWER TARGET FABRICATION} $\$ 3,000,000$

DOE Contact: C. Keane, (301) 903-4323

LANL Contact: W.E. Anderson, (505) 665-3981

Fabrication and characterization of precision liners for high explosive or capacitive discharge pulsed power experiments. Technologies employed include ingot metallurgy processing, physical deposition of coatings, precision machining and micro-assembly. Characterization techniques include microscopy, mechanical properties, nondestructive examinations (radiography and ultrasonic), dimensional inspection, and optical interferometry.

Keywords: Aluminum, Platinum, Gold, Physical Deposition of Coatings, Precision Machining and Micro-assembly

\section{ADVANCED STRATEGIC COMPUTING} INITIATIVE MATERIALS MODELING $\$ 2,000,000$

DOE Contact: G.G. Weigand, (202) 586-0568

LANL Contact: R.A. LeSar, (505) 665-0420

The development and bench-marking of advanced computer codes for the prediction of materials performance or processing technology influences on product quality. Models are being developed utilizing a full-three-dimensional first-principles approach to explore sensitivities to performance or processing variables. This includes the demonstration and baseline of engineering analysis codes to predict the engineering performance and reliability margin of the nuclear explosives package to satisfy its stockpile to target sequence requirements.

Keywords: Modeling, Constitutive Relationships, Fracture, Casting, Reliability Margin, Nuclear Explosives Package 
Coating Process Development for $\mathrm{Cr}-\mathrm{Nb}$ Alloys

Procurement of Advanced Austenitic and Aluminide Alloys

50,000

Development of Iron Aluminides

Development of $\mathrm{Cr}-\mathrm{Nb}$ Alloys

High-Strength Iron Aluminide Alloys

Low-Aluminum Content Iron-Aluminum Alloys

Mo-Si Alloy Development

Development of Improved and Corrosion Resistant Surfaces for Fossil Power System Components

Commercial-Scale Melting and Processing of Low-Aluminum Content Alloys

Development of a Modified 310 Stainless Steel

Application of Advanced Austenitic Alloys to Fossil Power System Components

Development of Recuperator Materials

Influence of Processing on Microstructure and Properties of Aluminides

Investigation of Electrospark-Deposited Coatings for Protection of Materials in Sulfidizing Atmospheres

Technology Transfer of Electrospark-Deposited Coatings for Protection of Materials in Sulfidizing Atmospheres

Fabrication of Fiber-Reinforced Composites by Chemical Vapor Infiltration and Deposition

Compliant Oxide Coating Development

Development of Oxidation/Corrosion-Resistant Composite Materials and interfaces

Optimization of the Chemical Vapor Infiltration Technique for Ceramic Composites

Transport Properties of Ceramic Composites

Modeling of Fibrous Preforms for CVD Infiltration

Corrosion Protection of SiC-Based Ceramics with CVD Mullite Coatings

Feasibility of Synthesizing Oxide Films on Ceramic and Metal Substrates

Ceramic Coating and Native Oxide Scales Evaluation

Carbon Fiber Composite Molecular Sieves

Activation of Carbon Fiber Composite Molecular Sieves

Carbon Fiber Composite Molecular Sieves Technology Transfer

105,000

105,000

PYF $^{1}$

54,000

47,000

35,000

PYF $^{1}$

84,000

135,000

51,000

175,000

100,000

50,000

150,000

100,000

150,000

PYF'

50,000

50,000

30,000

44,000

70,000

150,000

PYF ${ }^{1}$

100,000

Materials Properties, Behavior, Characterization or Testing

$\$ 1,202,000$

Investigation of the Weldability of Polycrystalline Iron Aluminides

40,000

Friction Welding of Iron Aluminides

20,000

Aluminides

Investigation of Iron Aluminide Weld Overlays

44,000

6,000

Fireside Corrosion Tests of Candidate Advanced Austenitic Alloys, Coatings, and Claddings 
OFFICE OF FOSSIL ENERGY (continued)

Office of Advanced Research (continued)

Fossil Energy AR\&TD Materials Program (continued)

Materials Properties, Behavior, Characterization or Testing (continued)

Joining Techniques for Advanced Austenitic Alloys

Fatigue and Fracture Behavior of $\mathrm{Cr}-\mathrm{Nb}$ Alloys

Corrosion and Mechanical Properties of Alloys in FBC and Mixed-Gas Environments

High Temperature Environmental Effects on Iron Aluminides

Investigation of Moisture-Induced Embrittlement of Iron Aluminides

Reduction of Defect Content in ODS Aloys

Corrosion Protection of Ultrahigh Temperature Intermetallic Alloys

Oxide Dispersion Strengthened (ODS) Iron Aluminides

Materials Support for HITAF

Support Services for Ceramic Fiber-Ceramic Matrix Composites

Development of Nondestructive Evaluation Methods and Effects of Flaws on the Fracture Behavior of Structural Ceramics

180,000

170,000

9,000

30,000

130,000

295,000

PYF $^{1}$

30,000

180,000

Device or Component Fabrication, Behavior or Testing

$\$ 1,361,000$

Materials and Components in Fossil Energy Applications Newsletter

Development of Ceramic Membranes for Gas Separation and Fuel Cells

Extrusion Press Equipment

High-Temperature Heat Exchanger and Hot-Gas Filter Development

Investigation of the Mechanical Properties and Performance of

Ceramic Composite Components

Solid State Electrolyte Systems

Oxide-Dispersion-Strengthened $\mathrm{Fe}_{3} \mathrm{Al}-\mathrm{Based}$ Alloy Tubes

ODS $\mathrm{Fe}_{3} \mathrm{Al}$ Tubes for High-Temperature Heat Exchangers

Iron Aluminide Filters for IGCCs

Iron Aluminide Filters for PFBCs

Ceramic Tubesheet Design Analysis

Dense Ceramic Tube Development

50,000

450,000

75,000

PYF $^{1}$

PYF'

553,000

33,000

50,000

PYF $^{1}$

50,000

PYF $^{1}$

100,000

Instrumentation and Facilities

$\$ 446,000$

Management of the Fossil Energy AR\&TD Materials Program

406,000

General Technology Transfer Activities

35,000

Gordon Research Conference Support

1PYF denotes that funding for this project, active in FY 1997, was provided from prior year allocations. 


\section{OFFICE OF FOSSIL ENERGY}

The Office of Fossil Energy responsibilities include management of the Department's fossil fuels (coal, oil and natural gas) research and development program. This research is generally directed by the Office of Coal Technology (OCT), the Office of Gas and Petroleum Technology, and the Office of Advanced Research and Special Technologies in support of the National Energy Strategy Goals for Increasing Energy Efficiency, Securing Future Energy Supplies, Respecting the Environment, and Fortifying our Foundations. Three specific fossil energy goals are currently being pursued:

1. The first is to secure liquids supply and substitution. This goal targets the enhanced production of domestic petroleum and natural gas, the development of advanced, cost-competitive alternative fuels technology, and the development of coal-based, end-use technology to substitute for oil in applications traditionally fueled by liquid and gaseous fuel forms.

2. The second is to develop power generation options with environmentally superior, high-efficiency technologies for the utility, industrial, and commercial sectors. This goal targets the development of super-clean, high-efficiency power generation technologies.

3. The third is to pursue a global technology strategy to support the increased competitiveness of the U.S. in fossil fuel technologies, to maintain world leadership in our fossil fuel technology base, and provide expanded markets for U.S. fuels and technology. This crosscutting goal is supported by the activities in the above two technology goals.

\section{OFFICE OF ADVANCED RESEARCH}

\section{FOSSIL ENERGY AR\&TD MATERIALS PROGRAM}

Fossil Energy (FE) materials-related research is conducted under an Advanced Research and Technology Developrnent (AR\&TD) Materials sub-activity and is an integral part of the R\&D conducted by the Office of Advanced Research and Special Technologies. The AR\&TD Materials program includes cross-cutting research to obtain a fundamental understanding of materials and how they perform in fossil-based process environments and the development of new classes of generic materials that will allow the development of new fossil energy systems or major improvements in existing systems. The present program is focused on ceramics (composite structural ceramics, catalyst supports, solid state electrolytes, membranes, and ceramic filters), new alloys (aluminides, filters, advanced austenitic steels, and coatings and claddings), corrosion research, and technology development and transfer.

The AR\&TD research is carried through development and technology transfer to industry. Special emphasis is given to technology transfer to ensure that the materials will be available for subsequent fossil commercial applications. This also enhances U.S. technological competitiveness not only in the fossil area but in the materials industry in general and other technology application areas as well. The research is conducted in industry, universities, not-for-profit agencies, and national laboratories. This widespread participation also helps maintain the U.S. materials technology capabilities.

\section{MATERIALS PREPARATION, SYNTHESIS,} DEPOSITION, GROWTH OR FORMING

\author{
396. COATING PROCESS DEVELOPMENT FOR \\ Cr-Nb ALLOYS \\ $\$ 20,000$ \\ DOE Contacts: F. M. Glaser, (301) 903-2784 and \\ M. H. Rawlins, (423) 576-4507 \\ Oak Ridge National Laboratory Contact: \\ R. R. Judkins, (423) 574-4572 \\ Ohio State University Contact: R. A. Rapp, \\ (614) 292-6178
}

$\mathrm{Cr}$-Nb alloys are being developed for high temperature service, but require protection from high temperature environments, such as oxidation. Previously developed $\mathrm{MoSi}_{2}$-base coatings have shown some promise for protecting $\mathrm{Nb}$, and the principles learned may have applicability for protective coatings of $\mathrm{Cr}-\mathrm{Nb}$. The purpose of this work is to examine the protection of $\mathrm{Cr}-\mathrm{Nb}$ alloys with either silicides or aluminides.

Keywords: Alloys, Aluminizing, Chromizing, Corrosion, Coatings

\section{PROCUREMENT OF ADVANCED AUSTENITIC AND ALUMINIDE ALLOYS $\$ 50,000$ \\ DOE Contacts: F. M. Glaser, (301) 903-2784 and M. H. Rawlins, (423) 576-4507 \\ Oak Ridge National Laboratory Contact: R. R. Judkins, (423) 574-4572}

This task provides funds for the procurement of alloys necessary for alloy development and testing activities of the AR\&TD Materials Program.

Keywords: Alloys, Aluminides, Austenitic 
398. DEVELOPMENT OF IRON ALUMINIDES $\$ 105,000$

DOE Contacts: F. M. Glaser, (301) 903-2784 and M. H. Rawlins, (423) 576-4507

Oak Ridge National Laboratory Contact:

G. M. Goodwin, (423) 574-4809

The objective of this task is to develop low-cost and low-density intermetallic alloys based on $\mathrm{Fe}_{3} \mathrm{Al}$ with an optimum combination of strength, ductility, weldability, and corrosion resistance for use as components in advanced fossil energy conversion systems. Emphasis is on the development of iron aluminides for heat recovery applications in coal gasification systems.

Keywords: Alloys, Aluminides, Intermetallic Compounds

399. DEVELOPMENT OF Cr-Nb ALLOYS $\$ 105,000$

DOE Contacts: F. M. Glaser, (301) 903-2784 and M. H. Rawlins, (423) 576-4507

Oak Ridge National Laboratory Contact: C. T. Liu, (423) $574-4459$

The objective of this task is to develop high-strength, corrosion-resistant intermetallic alloys for use as hot components in advanced fossil energy conversion and power generation systems. The successful development of these alloys is expected to improve the thermal efficiency of fossil energy conversion systems through increased operating temperatures and to increase the service life of hot components exposed to corrosive environments at elevated temperatures $\left(1000^{\circ} \mathrm{C}\right)$. The work is focused on in situ composite alloys based on the $\mathrm{Cr}_{-} \mathrm{Cr}_{2} \mathrm{Nb}$ system.

Keywords: Alloys, Chromium-Niobium, Corrosion, Intermetallic Compounds

400. HIGH-STRENGTH IRON ALUMINIDE ALLOYS SO - PYF'

DOE Contacts: F. M. Glaser, (301) 903-2784 and M. H. Rawlins, (423) 576-4507

Oak Ridge National Laboratory Contact:

C. G. McKamey, (423) 574-6917

The objective of this task is to use microalloying techniques to further develop the $\mathrm{Fe}_{3} \mathrm{Al}-$ based alloys. Emphasis is on producing a low-cost, low-density, precipitation-strengthened $\mathrm{Fe}_{3} \mathrm{Al}$-based intermetallic alloy with improved high-temperature creep resistance while maintaining an optimum combination of roomtemperature and high-temperature $\left(600-700^{\circ} \mathrm{C}\right)$ tensile properties, weldability, and corrosion resistance for use

'PYF denotes that funding for this project, active in FY 1997, was provided from prior year allocations. as structural components of advanced fossil energy conversion systems.

Keywords: Alloys, Aluminides, Microalloy

\section{LOW-ALUMINUM CONTENT IRON-ALUMINUM ALLOYS $\$ 54,000$ DOE Contacts: F. M. Glaser, (301) 903-2784 and} M. H. Rawlins, (423) 576-4507

Oak Ridge National Laboratory Contact: V. K. Sikka, (423) 574-5112

The objective of this task is to develop a conventionally-fabricable low-cost and lower density iron-aluminum-based alloy with a good combination of strength, ductility, weldability, and corrosion resistance for use as components in advanced fossil energy systems. Initial emphasis is on the development of iron-aluminum alloys for heat-recovery applications in coal gasification systems.

Keywords: Alloys, Iron-Aluminum

\section{MO-Si ALLOY DEVELOPMENT \\ $\$ 47,000$}

DOE Contacts: F. M. Glaser, (301) 903-2784 and M. H. Rawlins, (423) 576-4507

Oak Ridge National Laboratory Contact:

J. H. Schneibel, (423) 574-4644

The objective of this task is to develop new-generation corrosion-resistant Mo-Si alloys for use as hot components in advanced fossil energy conversion and power generation systems. The successful development of Mo-Si alloys is expected to improve the thermal efficiency and performance of fossil energy systems through increased operating temperature and to increase the service life of hot components exposed to corrosive environments at high temperatures (to $1600^{\circ} \mathrm{C}$ ). The initial effort is devoted to $\mathrm{Mo}_{5} \mathrm{Si}_{3}$-base alloys containing boron additions.

Keywords: Alloys, Molybdenum, Silicon

\section{DEVELOPMENT OF IMPROVED AND} CORROSION RESISTANT SURFACES FOR FOSSIL POWER SYSTEM COMPONENTS $\$ 35,000$

DOE Contacts: F. M. Glaser, (301) 903-2784 and M. H. Rawlins, (423) 576-4507

Oak Ridge National Laboratory Contact: V. K. Sikka, (423) 574-5112

A Cooperative Research and Development Agreement (CRADA) has been established with ABB Combustion Engineering for the development of corrosion-resistant surface protection for fossil power systems.

Keywords: Alloys, Iron-Aluminum, Corrosion, Technology Transfer 
404. COMMERCIAL-SCALE MELTING AND PROCESSING OF LOW-ALUMINUM CONTENT ALLOYS

$\$ 0$ - PYF 1

DOE Contacts: F. M. Glaser, (301) 903-2784 and M. H. Rawlins, (423) 576-4507

Oak Ridge National Laboratory Contact: V. K. Sikka, (423) 574-5112

The purpose of this activity is the preparation and evaluation of castings of low-aluminum content, iron-aluminum alloys. The castings will be prepared in several types of molds including: (1) graphite, (2) sand, and (3) investment. Castings will be prepared primarily from the air-induction-melted material. Selected graphite and investment castings will also be prepared from the vacuum-induction-melted material. The graphite and sand castings will be prepared at ORNL and will also be procured from the commercial foundries. The castings will be evaluated for porosity, grain structure, mechanical properties, and weldability. The mechanical property evaluation will consist of Charpy impact, tensile, and creep testing.

Keywords: Alloys, Iron-Aluminum, Melting, Casting

\section{DEVELOPMENT OF A MODIFIED 310 STAINLESS STEEL \\ $\$ 84,000$ \\ DOE Contacts: F. M. Glaser, (301) 903-2784 and M. H. Rawlins, (423) 576-4507 \\ Oak Ridge National Laboratory Contact: \\ R. W. Swindeman, (423) 574-5108}

The purpose of this task is to evaluate structural alloys for improved performance of high-temperature components in advanced combined-cycle and coal-combustion systems.

Keywords: Materials, Mechanical Properties, Austenitics, Hot-Gas

\section{APPLICATION OF ADVANCED AUSTENITIC} ALLOYS TO FOSSIL. POWER SYSTEM COMPONENTS

$\$ 135,000$

DOE Contacts: F. M. Glaser, (301) 903-2784 and M. H. Rawlins, (423) 576-4507

Oak Ridge National Laboratory Contact:

R. W. Swindeman, (423) 574-5108

A Cooperative Research and Development Agreement (CRADA) has been established with ABB Combustion Engineering for the development of advanced austenitic alloys for fossil power systems.

Keywords: Alloys, Austenitics, Technology Transfer

\section{DEVELOPMENT OF RECUPERATOR MATERIALS \\ $\$ 51,000$}

DOE Contacts: F. M. Glaser, (301) 903-2784 and M. H. Rawlins, (423) 576-4507

Oak Ridge National Laboratory Contact: R. W. Swindeman, (423) 574-5108

A Cooperative Research and Development Agreement (CRADA) has been signed with Solar Turbines, Inc. to develop a materials technology for recuperators operating at gas inlet temperatures to $730^{\circ} \mathrm{C}$

Keywords: Alloys, Austenitics, Technology Transfer

408. INFLUENCE OF PROCESSING ON MICROSTRUCTURE AND PROPERTIES OF ALUMINIDES

$\$ 175,000$

DOE Contacts: F. M. Glaser, (301) 903-2784 and M. H. Rawlins, (423) 576-4507

Oak Ridge National Laboratory Contact: I. G. Wright, (423) 574-4451

Idaho National Engineering and Environmental Laboratory Contact: R. N. Wright, (208) 526-6127

The purpose of this program is to determine the influence of processing on the properties of alloys based on the intermetallic compound $\mathrm{Fe}_{3} \mathrm{Al}$. Thermomechanical processing of these alloys is pursued to improve their properties. The response of the microstructure to elevated temperature deformation and subsequent annealing is characterized in terms of the establishment of equilibrium phases and equilibrium degree of long-range order. The role of dislocation and antiphase boundary structures in enhancing ductility of $\mathrm{Fe}_{3} \mathrm{Al}$ is investigated. The tensile properties are determined at room and elevated temperature and related to the microstructure. Reaction synthesis is investigated as a novel joining method and as a process to fabricate porous iron aluminides for filter applications. Oxide dispersion strengthened alloys, fabricated by reaction synthesis, are developed for improved high temperature strength. Compositions of the $\mathrm{Fe}_{3} \mathrm{Al}$ alloys and details of the processing are determined in collaboration with the program at Oak Ridge National Laboratory (ORNL).

Keywords: Aluminides, Processing, Microstructure

${ }^{1}$ PYF denotes that funding for this project, active in FY 1997, was provided from prior year allocations. 
409. INVESTIGATION OF ELECTROSPARKDEPOSITED COATINGS FOR PROTECTION OF MATERIALS IN SULFIDIZING ATMOSPHERES $\$ 100,000$

DOE Contacts: F. M. Glaser, (301) 903-2784 and M. H. Rawlins, (423) 576-4507

Oak Ridge National Laboratory Contact: R. R. Judkins, (423) 574-4572

Pacific Northwest National Laboratory Contact: R. N. Johnson, (509) 375-6906

The purpose of this task is to examine the use of the electrospark deposition coating process for the application of corrosion-, erosion-, and wear-resistant coatings to candidate heat exchanger (including superheater and reheater) alloys. Materials to be deposited may include MCrAl, MCrAlY, highly wear-resistant carbides, and other hardsurfacing materials.

Keywords: Coatings, Materials, Deposition

410. TECHNOLOGY TRANSFER OF ELECTROSPARK DEPOSITED COATINGS FOR PROTECTION OF MATERIALS IN SULFIDIZING ATMOSPHERES

$\$ 50,000$

DOE Contacts: F. M. Glaser, (301) 903-2784 and M. H. Rawlins, (423) 576-4507

Oak Ridge National Laboratory Contact: I. G. Wright, (423) 574-4451

Pacific Northwest National Laboratory Contact: R. N. Johnson, (509) 375-6906

The purpose of this task is to transfer to industry the electrospark deposition coating process technology for the application of corrosion-, erosion-, and wear-resistant coatings to candidate heat exchanger (including superheater and reheater) alloys.

Keywords: Coatings, Materials, Deposition

411. FABRICATION OF FIBER-REINFORCED COMPOSITES BY CHEMICAL VAPOR INFILTRATION AND DEPOSITION $\$ 150,000$

DOE Contacts: F. M. Glaser, (301) 903-2784 and M. H. Rawlins, (423) 576-4507

Oak Ridge National Laboratory Contact:

T. M. Besmann, (423) 574-6852

The purpose of this task is to develop a process for the fabrication of fiber-reinforced ceramic composites having high fracture toughness and high strength. This process utilizes a steep temperature gradient and a pressure gradient to infiltrate low-density fibrous structures with gases, which deposit solid phases to form the matrix of the composite. Further development of this process is needed to fabricate larger components of more complex geometry, and to optimize infiltration for shortest processing time, greatest density and maximum strength.

Keywords: Composites, Fiber-Reinforced, Ceramics

412. COMPLIANT OXIDE COATING DEVELOPMENT $\$ 100,000$

DOE Contacts: F. M. Glaser, (301) 903-2784 and M. H. Rawlins, (423) 576-4507

Oak Ridge National Laboratory Contact:

D. P. Stinton, (423) 574-4556

Monolithic SiC heat exchangers and fiber-reinforced $\mathrm{SiC}$-matrix composite heat exchangers and filters are susceptible to corrosion by alkali metals at elevated temperatures. Protective coatings are currently being developed to isolate the $\mathrm{SiC}$ materials from the corrodents. Unfortunately, these coatings typically crack and spall when applied to SiC substrates. The purpose of this task is to determine the feasibility of using a compliant material between the protective coating and the substrate. The low-modulus compliant layer could absorb stresses and eliminate cracking and spalling of the protective coatings.

Keywords: Ceramics, Oxides, Coatings

413. DEVELOPMENT OF

OXIDATION/CORROSION-RESISTANT COMPOSITE MATERIALS AND INTERFACES $\$ 150,000$

DOE Contacts: F. M. Glaser, (301) 903-2784 and M. H. Rawlins, (423) 576-4507

Oak Ridge National Laboratory Contact:

R. A. Lowden, (423) 576-2769

Fiber-reinforced SiC-matrix composites have been observed to fail in fossil energy applications for two reasons. First, the mechanical properties of composites deteriorate under stressed oxidation because oxidants such as steam penetrate cracks formed in the SiC matrix and react with the carbon or boron nitride interface. The mechanical properties of composites may degrade because of corrosion due to sodium species typically present in fossil systems. Therefore, the purposes of this task are to first, develop fiber-matrix interfaces that are resistant to oxidation and yet optimize the mechanical behavior of composites, and second, to develop protective overcoats or oxide matrices that are resistant to oxidation and corrosion.

Keywords: Composites, Ceramics, Fiber-Reinforced, Interfaces 


\section{OPTIMIZATION OF THE CHEMICAL VAPOR INFILTRATION TECHNIQUE FOR CERAMIC COMPOSITES \\ $\$ 0$ - PYF ${ }^{1}$}

DOE Contacts: F. M. Glaser, (301) 903-2784 and

M. H. Rawlins, (423) 576-4507

Oak Ridge National Laboratory Contact:

D. P. Stinton, (423) 574-4556

University of Tennessee Contact: P. K. Liaw, (423) 974-6356

This project is focused on an optimization of the forced chemical vapor infiltration technique for fabrication of ceramic matrix composites (CMCs) using process models. In particular, a process model developed at the Georgia Tech Research Institute shall be thoroughly investigated. Experimental verification of the process model shall be conducted in light of microstructural characterization using both destructive and nondestructive evaluation techniques. An optimized process for manufacturing $\mathrm{CMCs}$ shall be demonstrated. Moreover, mechanistic understanding regarding the effects of processing parameters on microstructural features, and fatigue and fracture behavior of CMCs shall be provided.

Keywords: Composites, Fiber-Reinforced, Ceramics

\section{TRANSPORT PROPERTIES OF CERAMIC COMPOSITES \\ $\$ 50,000$}

DOE Contacts: F. M. Glaser, (301) 903-2784 and M. H. Rawlins, (423) 576-4507

Oak Ridge National Laboratory Contact: D. P. Stinton, (423) 574-4556

Georgia Institute of Technology Contact: T. L. Starr, (404) 894-0579

The purpose of this research effort is to conduct a theoretical and experimental program to identify new compositions and processing methods to improve the physical and mechanical properties of selected fiber-reinforced ceramics. The ceramic matrix material is amorphous fused silica or modified silica glass, and the focus is the development of fiber-reinforced silica. Parameters studied include: (1) differences in elastic modulus between matrix and fiber, (2) differences in thermal expansion, (3) nature of interfacial bond, (4) densification of matrix, (5) nature of fiber fracture/pull-out, (6) fiber diameter and fiber length-to-diameter ratio, (7) fiber loading, and (8) fiber dispersion and orientation. A model will be developed based on the information generated in the experimental phase of the program.

Keywords: Ceramics, Composites, Fiber-Reinforced

'PYF denotes that funding for this project, active in FY 1997, was provided from prior year allocations.

\section{MODELING OF FIBROUS PREFORMS FOR CVD INFILTRATION}

$\$ 50,000$

DOE Contacts: F. M. Glaser, (301) 903-2784 and M. H. Rawlins, (423) 576-4507

Oak Ridge National Laboratory Contact: D. P. Stinton, (423) 574-4556

Georgia Institute of Technology Contact: T. L. Starr, (404) 894-0579

The purpose of this project is to conduct a theoretical and experimental program to develop an analytical model for the fabrication and infiltration of fibrous preforms. The analytical model will: (1) predict preform structure (density, porosity, fiber orientation, etc.) based on fabrication technique and fundamental fiber parameters (diameter, aspect ratio, etc.), and (2) predict permeation and heat conduction through the preform structure and, thus, predict the CVD infiltration performance.

Keywords: Ceramics, Composites, Modeling

\section{CORROSION PROTECTION OF SIC-BASED CERAMICS WITH CVD MULLITE COATINGS $\$ 30,000$}

DOE Contacts: F. M. Glaser, (301) 903-2784 and M. H. Rawlins, (423) 576-4507

Oak Ridge National Laboratory Contact: D. P. Stinton, (423) 574-4556

Boston University Contact: Vinod Sarin, (617) 353-6451

This project involves the growth of dense mullite coatings on $\mathrm{SIC}$-based substrates by chemical vapor deposition. SiC and SiC-based composites have been identified as the leading candidate materials for stringent elevated temperature applications. At moderate temperatures and pressures, the formation of a thin self-healing layer of $\mathrm{SiO}_{2}$ is effective in preventing catastrophic oxidation by minimizing the diffusion of $\mathrm{O}_{2}$ to the substrate. The presence of impurities can increase the rate of passive oxidation by modifying the transport rate of oxygen through the protective scale, can cause active oxidation via formation of SiO which accelerates the degradation process, or can produce compositions such as $\mathrm{Na}_{2} \mathrm{SO}_{3}$ which chemically attack the ceramic via rapid corrosion. There is therefore a critical need to develop adherent oxidation/corrosionresistant, and thermal-shock-resistant coatings that can withstand such harsh environments. Mullite has been identified as an excellent candidate material due to its desirable properties of toughness, corrosion resistance, and a good coefficient of thermal expansion match with $\mathrm{SiC}$.

Keywords: Ceramics, Coatings 


\section{FEASIBILITY OF SYNTHESIZING OXIDE FILMS ON CERAMIC AND METAL SUBSTRATES $\$ 44,000$ \\ DOE Contacts: F. M. Glaser, (301) 903-2784 and M. H. Rawlins, (423) 576-4507 \\ Oak Ridge National Laboratory Contact: D. P. Stinton, (423) 574-4556 \\ Lawrence Berkeley National Laboratory Contact: Ian Brown, (510) 486-4174}

The objective of this project is the study of the feasibility of synthesizing metal oxide ceramic films on ceramic and metal substrates. This feasibility will be demonstrated by use of plasma-based deposition and ion mixing techniques. The films shall be characterized for properties such as composition, structure, hardness, high temperature oxidation resistance, adhesion to the substrate, and stability to high temperature cycling. The value of intermediate transition or buffer layers, composed of materials with suitably matched thermal expansion characteristics and atomically graded interfaces, as a technique for improving the high temperature survivability of the films, shall be explored. Samples shall be formed on substrates of various shapes and sizes, including perhaps on the inside and outside of pipes, as well as on small flat coupons. The issue of deposition onto and atomic mixing into substrates which are insulating shall be addressed experimentally. The work is divided into two parts:

(1) $\mathrm{Al}_{2} \mathrm{O}_{3}$ films on alumina-forming alloy substrates, and (2) oxides on $\mathrm{SiC}$.

Keywords: Ceramics, Films, Oxides

\section{CERAMIC COATING AND NATIVE OXIDE SCALES EVALUATION \\ $\$ 70,000$ \\ DOE Contacts: F. M. Glaser, (301) 903-2784 and M. H. Rawlins, (423) 576-4507 \\ Oak Ridge National Laboratory Contact: P. F. Tortorelli, (423) 574-5119}

The purpose of this work is to generate the information needed for the development of improved (slow growing, adherent, sound) protective oxide coatings and scales. The specific objectives are to systematically investigate the relationships among substrate composition and surface oxide structure, adherence, soundness, and micromechanical properties, (2) use such information to predict scale and coating failures, and (3) identify and evaluate compositions and synthesis routes for producing materials with damage-tolerant scales and coatings.

Keywords: Coatings, Corrosion

\section{CARBON FIBER COMPOSITE MOLECULAR SIEVES \\ $\$ 150,000$ \\ DOE Contacts: F. M. Glaser, (301) 903-2784 and \\ M. H. Rawlins, (423) 576-4507 \\ Oak Ridge National Laboratory Contact: \\ T. D. Burchell, (423) 576-8595}

Hydrogen recovery technologies are required to allow the upgrading of heavy hydrocarbons to transport fuels, thus reducing the amount of carbon rejected during the conversion of fossil resources into hydrocarbon products. The purpose of this work is to develop carbon molecular sieves (CMS) starting with porous carbon fiber composites (CFC) manufactured from petroleum pitch derived carbon fibers. The carbon fiber composite molecular sieves (CFCMS) will be utilized in pressure swing adsorption units for the efficient recovery of hydrogen from synthesis gas, refinery purge gases, and for other gas separation operations associated with hydrogen recovery.

Keywords: Carbon Fibers, Sieves, Composites

\section{ACTIVATION OF CARBON FIBER COMPOSITE MOLECULAR SIEVES $\$ O-$ PYF $^{1}$ \\ DOE Contacts: F. M. Glaser, (301) 903-2784 and}

M. H. Rawlins, (423) 576-4507

Oak Ridge National Laboratory Contact:

R. R. Judkins, (423) 574-4572

University of Kentucky Contact: Frank Derbyshire, (606) 257-0305

A novel monolithic adsorbent carbon, manufactured from carbon fibers, has been invented jointly by researchers at Oak Ridge National Laboratory (ORNL) and the University of Kentucky Center for Applied Energy Research. The novel material, referred to as a carbon-fiber composite molecular sieve (CFCMS) is fabricated at ORNL in the Carbon Materials Technology Group. The purpose of this activity is to activate samples of the CFCMS and to perform subsequent analyses of the surface area, pore width distributions, and micropore volume. Activities are directed toward an understanding of the relationships between the activation process and the micro- or mesopore structure that develops.

Keywords: Carbon Fibers, Sieves, Composites
'PYF denotes that funding for this project, active in FY 1997, was provided from prior year allocations. 
422. CARBON FIBER COMPOSITE MOLECULAR SIEVES TECHNOLOGY TRANSFER $\$ 100,000$

DOE Contacts: F. M. Glaser, (301) 903-2784 and

M. H. Rawlins, (423) 576-4507

Oak Ridge National Laboratory Contact:

T. D. Burcheil, (423) 576-8595

Hydrogen and methane gas recovery technologies are required to: (1) allow the upgrading of heavy hydrocarbons to transport fuels, thus reducing the amount of carbon rejected during crude oil refining and (2) to improve the yield and process economics of natural gas wells. The purpose of this work is to develop carbon fiber composite molecular sieves (CFCMS) from porous carbon fiber composites manufactured from solvent extracted coal tar pitch derived carbon fibers. The work will be performed in collaboration with other members of the Cooperative Research Partnership on Carbon Products and the Non Fuel Uses of Coal.

Keywords: Consortium, Carbon Products

MATERIALS PROPERTIES, BEHAVIOR, CHARACTERIZATION OR TESTING

\section{INVESTIGATION OF THE WELDABILITY OF POLYCRYSTALLINE IRON ALUMINIDES $\$ 40,000$ \\ DOE Contacts: F. M. Glaser, (301) 903-2784 and M. H. Rawlins, (423) 576-4507 \\ Oak Ridge National Laboratory Contact: \\ R. W. Swindeman, (423) 574-5108 \\ Colorado School of Mines Contact: \\ G. R. Edwards, (303) 273-3773}

The purpose of this project is the investigation of the weldability of polycrystalline aluminides. The major thrust of the project is to determine the role of microstructure in the intergranular cracking of aluminides, with special emphasis on weld cracking susceptibility. The weldability of polycrystalline $\mathrm{Fe}_{3} \mathrm{Al}-\mathrm{X}$ alloys is being evaluated, and the weldability is correlated with composition, phase equilibria, grain size and morphology, domain size, and degree of long-range order.

Keywords: Joining, Welding

\section{FRICTION WELDING OF IRON ALUMINIDES $\$ 20,000$ \\ DOE Contacts: F. M. Glaser, (301) 903-2784 and M. H. Rawlins. (423) 576-4507 \\ Oak Ridge National Laboratory Contact: I. G. Wright, (423) 574-4451 \\ The Welding Institute Contact: P. L. Threadgill, 8-0-11-44-1223-891162}

The purpose of this project is to establish that friction welding is a feasible method for joining iron aluminide tubes to other iron aluminide tubes, and to austenitic alloys. A companion objective is to establish optimized procedures for making welds, based on ambient temperature properties.

Keywords: Joining, Welding

425. EVALUATION OF THE INTRINSIC AND EXTRINSIC FRACTURE BEHAVIOR OF IRON ALUMINIDES

$\$ 44,000$

DOE Contacts: F. M. Glaser, (301) 903-2784 and M. H. Rawlins, (423) 576-4507

Oak Ridge National Laboratory Contact: I. G. Wright, (423) 574-4451

West Virginia University Contact: B. R. Cooper, (304) 293-3423

The purpose of this activity is the evaluation of the intrinsic and extrinsic fracture behavior of iron aluminides and the study of atomistic simulations of defect concentrations, dislocation mobility, and solute effects in $\mathrm{Fe}_{3} \mathrm{Al}$. The work also involves an experimental study of environmentally-assisted crack growth of $\mathrm{Fe}_{3} \mathrm{Al}$ at room and at elevated temperatures. The combined modeling and experimental activities are expected to elucidate the mechanisms controlling deformation and fracture in $\mathrm{Fe}_{3} \mathrm{Al}$ in various environments.

Keywords: Alloys, Aluminides, Fracture

\section{INVESTIGATION OF IRON ALUMINIDE WELD OVERLAYS \\ $\$ 6,000$}

DOE Contacts: F. M. Glaser, (301) 903-2784 and M. H. Rawlins, (423) 576-4507

Oak Ridge National Laboratory Contact: R. W. Swindeman, (423) 574-5108 Lehigh University Contact: J. N. DuPont, (610) $758-3942$

The objective of this activity is the investigation of iron aluminide weld overlays. Specific tasks include: (1) filler wire development, (2) weldability, (3) oxidation and sulfidation studies, (4) erosion studies, (5) erosioncorrosion studies, and (6) field exposures.

Keywords: Alloys, Aluminides, Overlay, Welding, Joining

427. FIRESIDE CORROSION TESTS OF CANDIDATE ADVANCED AUSTENITIC ALLOYS, COATINGS, AND CLADDINGS

$\$ 33,000$

DOE Contacts: F. M. Glaser, (301) 903-2784 and M. H. Rawlins, (423) 576-4507

Oak Ridge National Laboratory Contact: R. W. Swindeman, (423) 574-5108

Foster Wheeler Development Corporation Contact: J. L. Blough, (201) 535-2355

The purpose of this project is to provide comprehensive corrosion data for selected advanced austenitic tube alloys in simulated coal ash environments. ORNL- 
modified alloys and standard comparison alloys have been examined. The variables affecting coal ash corrosion and the mechanisms governing oxide breakdown and corrosion penetration are being evaluated. Corrosion rates of the test alloys are determined as functions of temperature, ash composition, gas composition, and time.

Keywords: Austenitics, Alloys, Corrosion

\section{JOINING TECHNIQUES FOR ADVANCED AUSTENITIC ALLOYS}

\$O - PYF ${ }^{1}$

DOE Contacts: F. M. Glaser, (301) 903-2784 and M. H. Rawlins, (423) 576-4507

Oak Ridge National Laboratory Contact: R. W. Swindeman, (423) 574-5108 University of Tennessee Contact: C. D. Lundin, (423) $974-5310$

Weldability is an important consideration in the selection of a suitable alloy for the fabrication of boiler components such as superheaters and reheaters. It is often a challenge to select joining materials and establish procedures that will allow advanced materials to function at their full potential. The purpose of this research is to examine important aspects of newly developed austenitic tubing alloys intended for service in the temperature range $550-700^{\circ} \mathrm{C}$.

Keywords: Alloys, Austenitics, Joining, Welding

\section{FATIGUE AND FRACTURE BEHAVIOR OF Cr-Nb ALLOYS \\ $\$ 35,000$ \\ DOE Contacts: F. M. Glaser, (301) 903-2784 and M. H. Rawlins, (423) 576-4507 \\ Oak Ridge National Laboratory Contact: I. G. Wright, (423) $574-4451$ \\ University of Tennessee Contact: Peter Liaw, (423) $974-6356$}

The objective of this research is to characterize the fatigue and fracture behavior of $\mathrm{Cr}_{2} \mathrm{Nb}$-based alloys and other intermetallic materials at ambient and elevated temperatures in controlled environments. These studies are expected to lead to mechanistic understanding of the fatigue and fracture behavior of these alloys. Fatigue tests shall be conducted for the purpose of evaluating crack initiation and fatigue life of $\mathrm{Cr}_{2} \mathrm{Nb}$-based alloys as well as other intermetallic alloys. The fatigue properties shall be evaluated as functions of test environment, cyclic frequency and test temperature. Additional tensile tests will be required to characterize the fracture behavior of these structural alloys. Mechanical tests shall be performed to determine the fatigue and fracture behavior of $\mathrm{Cr}_{2} \mathrm{Nb}$-based alloys.

'PYF denotes that funding for this project, active in FY 1997, was provided from prior year allocations.
The microstructure of the alloys shall be characterized and correlated with the mechanical properties.

Keywords: Fracture, Fatigue, Alloys

\section{CORROSION AND MECHANICAL PROPERTIES OF ALLOYS IN FBC AND MIXED-GAS ENVIRONMENTS \\ $\$ 180,000$ \\ DOE Contacts: F. M. Glaser, (301) 903-2784 and M. H. Rawlins, (423) 576-4507 \\ Oak Ridge National Laboratory Contact: I. G. Wright, (423) $574-4451$ \\ Argonne National Laboratory Contact: K. Natesan, (708) $252-5103$}

The purposes of this task are to: (1) evaluate the corrosion mechanisms for chromia- and aluminaforming alloys in mixed-gas environments, (2) develop an understanding of the role of several microalloy constituents in the oxidation/sulfidation process, (3) evaluate transport kinetics in oxide scales as functions of temperature and time, (4) characterize surface scales that are resistant to sulfidation attack, and (5) evaluate the role of deposits in corrosion processes.

Keywords: Corrosion, Gasification, Creep Rupture, Fluidized-Bed Combustion

\section{HIGH-TEMPERATURE ENVIRONMENTAL EFFECTS ON IRON ALUMINIDES $\$ 170,000$ \\ DOE Contacts: F. M. Glaser, (301) 903-2784 and M. H. Rawlins, (423) 576-4507 \\ Oak Ridge National Laboratory Contact: P. F. Tortorelli, (423) 574-5119}

The purpose of this task is to evaluate the hightemperature corrosion behavior of iron-aluminum alloys as part of the effort to develop highly corrosion-resistant iron-aluminide alloys and coatings for fossil energy applications. A primary objective is to investigate the resistance of the alloys to mixed-oxidant (oxygensulfur-chlorine-carbon) environments that arise in the combustion or gasification of coal. This includes the determination of the influence of sulfur and other reactive gaseous species on corrosion kinetics and oxide microstructures and the effects of alloying additions and oxide dispersoids on sulfidation and oxidation resistance.

Keywords: Corrosion, Aluminides, Mixed-Gas, Scales 


\section{INVESTIGATION OF MOISTURE-INDUCED EMBRITTLEMENT OF IRON ALUMINIDES $\$ 9,000$ \\ DOE Contacts: F. M. Glaser, (301) 903-2784 and M. H. Rawlins, (423) 576-4507 \\ Oak Ridge National Laboratory Contact: I. G. Wright, (423) 574-4451 \\ Rensselaer Polytechnic Institute Contact: N. S. Stoloff, (518) 276-6371}

The purpose of this work is to study hydrogen embrittlement of iron aluminide alloys. Moisture in air can significaritly reduce the room-temperature tensile ductility of $\mathrm{Fe}_{3} \mathrm{Al}$-based alloys by combining with the aluminum in the alloys to form atomic hydrogen. The atomic hydrogen diffuses rapidly into the material causing embrittlement. Experiments are being conducted on selected $\mathrm{Fe}_{3} \mathrm{Al}$ alloys that will lead to an understanding of the phenomenon. The work focuses on the effects of moisture on relevant mechanical properties such as fatigue and tensile strengths, and correlates important microstructural variables such as degree of order, grain size, and phases present with the alloy's susceptibility to embrittlement.

Keywords: Aluminides, Embrittlement, Moisture

\section{REDUCTION OF DEFECT CONTENT IN ODS ALL.OYS \\ $\$ 30,000$ \\ DOE Contacts: F. M. Glaser, (301) 903-2784 and M. H. Rawlins, (423) 576-4507 \\ Oak Ridge National Laboratory Contact: I. G. Wright, (423) 574-4451 \\ The University of Liverpool Contact: A. R. Jones}

The purpose of this work is to assess the sources of defects in oxide-dispersion-strengthened [ODS] alloys. Experiments to confirm key features of defects in ODS alloys shall be devised and performed, and recommendations shall be made for the reduction of defects in these alloys.

Keywords: Aluminides, Defects

\section{CORROSION PROTECTION OF ULTRAHIGH TEMPERATURE INTERMETALLIC ALLOYS $\$ 130,000$ \\ DOE Contacts: F. M. Glaser, (301) 903-2784 and M. H. Rawlins, (423) 576-4507 \\ Oak. Ridge National Laboratory Contact: P. F. Tortorelli, (423) 574-5119}

The objective of this task is to develop high-strength, corrosion-resistant intermetallic alloys for use as hot components in advanced fossil energy conversion and combustion systems. The successful development of these alloys is expected to improve the thermal efficiency of fossil energy conversion systems through increased operating temperatures and to increase the service life of hot components exposed to corrosive environments at elevated temperatures $\left(1000^{\circ} \mathrm{C}\right)$. The initial effort will be devoted to in situ composite alloys based on the $\mathrm{Cr}-\mathrm{Cr}_{2} \mathrm{Nb}$ system.

Keywords: Corrosion, Chromium-Niobium, Mixed-Gas, Scales

\section{OXIDE DISPERSION STRENGTHENED (ODS) IRON ALUMINIDES $\$ 295,000$ \\ DOE Contacts: F. M. Glaser, (301) 903-2784 and M. H. Rawlins, (423) 576-4507 \\ Oak Ridge National Laboratory Contact: I. G. Wright, (423) 574-4451}

The purpose of this task is to develop fabrication procedures for making oxide dispersion-strengthened (ODS) iron-aluminum alloys based on $\mathrm{Fe}_{3} \mathrm{Al}$. The suitability of the procedures is measured in terms of the highemperature oxidation and sulfidation resistance and creep strength of the ODS alloys compared with $\mathrm{Fe}_{3} \mathrm{Al}$ alloys fabricated by conventional ingot and powder processes.

Keywords: Aluminides

\section{MATERIALS SUPPORT FOR HITAF}

\$O - PYF

DOE Contacts: F. M. Glaser, (301) 903-2784 and M. H. Rawlins, (423) 576-4507

Oak Ridge National Laboratory Contact: K. Breder, (423) 574-5089

This task involves the measurement of selected mechanical and physical properties of structural ceramics which are proposed for use in the construction of the High Temperature Advanced Furnace (HITAF) air heater design being developed under the Combustion 2000 Program. The purpose of the research is to evaluate candidate structural ceramics for this application by studying the fast fracture and fatigue (both dynamic and interrupted static) properties at temperatures from 1100 to $1400^{\circ} \mathrm{C}$ in air, their corrosion behavior, property uniformity of components and long term degradation of ceramic properties due to exposure in prototype HITAF systems.

Keywords: Furnace, Materials, HITAF

'PYF denotes that funding for this project, active in FY 1997, was provided from prior year allocations. 
437. SUPPORT SERVICES FOR CERAMIC FIBER-CERAMIC MATRIX COMPOSITES $\$ 30,000$

DOE Contacts: F. M. Glaser, (301) 903-2784 and M. H. Rawlins, (423) 576-4507

Oak Ridge National Laboratory Contact: D. P. Stinton, (423) 574-4556

University of North Dakota Energy and Environmental Research Center Contact: J. P. Hurley, (701) 777-5159

This task will review and, if appropriate, propose modifications to plans, materials, and tests planned by researchers on the AR\&TD Materials Program in work to test materials for coal-fueled energy systems. The changes shall be suggested in order to make the corrosion experiments more reflective of the actual conditions that will be encountered by the materials in the energy systems. UNDEERC shall accomplish this task by reviewing the major advanced energy system projects being funded by the DOE, and by working with the company's technical monitor and staff to prepare a summary of the expected corrosion problems. Both gasification and combustion systems will be included. Ceramic materials in two subsystems will be the focus of this work: (1) hot gas cleanup systems and

(2) high-temperature heat exchangers. UNDEERC shall review and suggest improvements to materials testing procedures that are used to determine material behavior when used in hot-gas cleanup or heat exchanger applications. A limited amount of computer modeling and laboratory experimentation shall be a part of this effort.

Keywords: Composites, Ceramics, Fibers

\section{DEVELOPMENT OF NONDESTRUCTIVE} EVALUATION METHODS AND EFFECTS OF FLAWS ON THE FRACTURE BEHAVIOR OF STRUCTURAL CERAMICS

$\$ 180,000$

DOE Contacts: F. M. Glaser, (301) 903-2784 and M. H. Rawlins, (423) 576-4507

Oak Ridge National Laboratory Contact: D. P. Stinton, (423) 574-4556

Argonne National Laboratory Contacts: W. A. Ellingson, (708) 252-5068 J. P. Singh, (708) 252-5123

The purpose of this project is to study and develop acoustic and radiographic techniques and possible novel techniques such as nuclear magnetic resonance, to characterize structural ceramics with regard to presence of porosity, cracking, inclusions, amount of free silicon, and mechanical properties, and to establish the type and character of flaws that can be found by nondestructive evaluation (NDE) techniques. Both fired and unfired specimens are being studied to establish correlations between NDE results and failure of specimens.

Keywords: Nondestructive Evaluation, Ceramics, Flaws, Fracture

\section{DEVICE OR COMPONENT FABRICATION, BEHAVIOR OR TESTING}

\section{MATERIALS AND COMPONENTS IN FOSSIL ENERGY APPLICATIONS NEWSLETTER $\$ 50,000^{\dagger}$ \\ DOE Contacts: F. M. Glaser, (301) 903-2784 and M. H. Rawlins, (423) 576-4507 \\ Oak Ridge National Laboratory Contact: I. G. Wright, (423) $574-4451$}

The purpose of this task is to publish a bimonthly, joint DOE-Electric Power Research Institute (EPRI) newsletter to address current developments in materials and components in fossil energy applications. Matching funding is provided by EPRI.

Keywords: Materials, Components

\section{DEVELOPMENT OF CERAMIC MEMBRANES FOR GAS SEPARATION AND FUEL CELLS $\$ 450,000$ \\ DOE Contacts: F. M. Glaser, (301) 903-2784 and M. H. Rawlins, (423) 576-4507 \\ Oak Ridge National Laboratory Contact: R. R. Judkins, (423) 574-4572 \\ East Tennessee Technology Park Contact: D. E. Fain, (423) 574-9932}

The purpose of this activity is to fabricate inorganic membranes for the separation of gases at high temperatures and/or in hostile environments, typically encountered in fossil energy conversion processes such as coal gasification. This work is performed in conjunction with a separate research activity that is concerned with the development and testing of the ceramic membranes.

Keywords: Ceramics, Membranes, Filters, Separation, Fuel Cells

${ }^{1}$ Matching funding provided by EPRI. 


\section{EXTRUSION PRESS EQUIPMENT}

$\$ 75,000$

DCE Contacts: F. M. Glaser, (301) 903-2784 and

M. H. Rawlins, (423) 576-4507

Oak Ridge National Laboratory Contact:

R. R. Judkins, (423) 574-4572

East Tennessee Technology Park Contact:

D. E. Fain, (423) 574-9932

This task provides funds for the procurement of major equipment items, necessary for AR\&TD Materials Program activities.

Keywords: Equipment

\section{HIGH-TEMPERATURE HEAT EXCHANGER AND HOT-GAS FILTER DEVELOPMENT \$O - PYF' \\ DOE Contacts: F. M. Glaser, (301) 903-2784 and M. H. Rawlins, (423) 576-4507 \\ Oak Ridge National Laboratory Contact: \\ D. P. Stinton, (423) 574-4556 \\ Pennsylvania State University Contact: \\ R. E. Tressler, (814) 865-7961}

This project addresses the development of ceramic heat exchanger materials with chromia surface treatments for corrosion resistance. High chromia-content refractories have been demonstrated to be resistant to corrosion by coal slags. This project will focus on improving the corrosion resistance of ceramics by incorporating chromia into the surface layers. This work has two principal parts: (1) screening analysis of candidate ceramic hot-gas filter materials, and (2) internal pressure testing of ceramic tubes exposed to coal combustion environments.

Keywords: Ceramics, Corrosion, Filters

\section{INVESTIGATION OF THE MECHANICAL PROPERTIES AND PERFORMANCE OF CERAMIC COMPOSITE COMPONENTS $\$ 0$ - PYF ${ }^{4}$ \\ DOE Contacts: F. M. Glaser, (301) 903-2784 and \\ M. H. Rawlins, (423) 576-4507 \\ Oak Ridge National Laboratory Contact: \\ D. P. Stinton, (423) 574-4556 \\ Virginia Polytechnic Institute Contact: \\ K. L. Reifsnider, (703) 231-5259}

The purpose of this project is to develop a test system and test methods to obtain information on the properties and performance of ceramic composite materials. The work involves a comprehensive mechanical characterization of composite engineering components such as tubes, plates, shells, and beams subjected to

'PYF denotes that funding for this project, active in FY 1997, was provided from prior year allocations static and cyclic multiaxial loading at elevated temperatures for extended time periods.

Keywords: Ceramics, Composites, Mechanical Properties, Testing

444. SOLID STATE ELECTROLYTE SYSTEMS $\$ 553,000$

DOE

DOE Contacts: F. M. Glaser, (301) 903-2784 and M. H. Rawlins, (423) 576-4507

Oak Ridge National Laboratory Contact: R. R. Judkins, (423) 574-4572

Pacific Northwest National Laboratory Contact: L. R. Pederson, (509) 375-2579

The purpose of this project is to develop functional ceramic materials that will ultimately lead to the broader, cleaner, and more efficient utilization of fossil fuels, particularly coal and natural gas. This project is composed of three principal tasks:

1. Stability of Solid Oxide Fuel Cell Materials The purpose of this task is to evaluate the stabilities of materials and interfaces in SOFCs in order to identify features that would limit system performance.

2. Mixed Oxygen lon/Electron-Conducting Ceramics for Oxyoen Separation Compositions and physical forms are being developed that simultaneously conduct oxygen ions and electrons. Such mixed conducting ceramics can function as highly selective oxygen separation membranes, allowing high purity oxygen to be separated from air.

3. Proton-Conducting Solid Electrolytes - This task will develop perovskite compositions and physical forms, which will be used as the electrolyte in small-scale solid oxide fuel cells operating at intermediate temperatures.

Keywords: Fuel Cells, SOFC

\section{OXIDE-DISPERSION-STRENGTHENED Fe Al- $_{3}$ BASED ALLOY TUBES \\ $\$ 33,000$ \\ DOE Contacts: F. M. Glaser, (301) 903-2784 and M. H. Rawlins, (423) 576-4507 \\ Oak Ridge National Laboratory Contact: I. G. Wright, (423) 574-4451 \\ University of California at San Diego Contact: B. K. Kad, (619) 534-7059}

The goal of the work is to explore experimental and computational means by which inherent material and processing-induced anisotropies of ODS $\mathrm{Fe}_{3} \mathrm{Al}$-base alloys can be exploited to meet in-service mechanical and creep-life requirements of the power generation industry. The research shall examine microscopic and 
microstructural issues with a view to addressing optimum material design for macroscopic components under well prescribed in-service loading criteria. The economic incentive is the low cost of $\mathrm{Fe}_{3} \mathrm{Al}$-based alloys and its superior sulfidation resistance, in comparison to the competing $\mathrm{Fe}-\mathrm{Cr}-\mathrm{Al}$ base alloys and the Ni-base superalloys currently in service.

Keywords: Aluminide, Tubes

\section{ODS Fe $\mathrm{Al}_{3}$ TUBES FOR HIGH-TEMPERATURE HEAT EXCHANGERS $\$ 50,000$ \\ DOE Contacts: F. M. Glaser, (301) 903-2784 and M. H. Rawlins, (423) 576-4507 \\ Oak Ridge National Laboratory Contact: I. G. Wright, (423) 574-4451 \\ PM Hochtemperatur-Metall. GmbH Contact: Dieter Sporer, 011-43-5672-70-2923}

The goal of the work is to produce tubes of $\mathrm{Fe}_{3} \mathrm{Al}-0.5 \mathrm{wt}$. percent $\mathrm{Y}_{2} \mathrm{O}_{3}$ which have properties suitable for application as heat transfer surfaces in very hightemperature heat exchangers. The alloy is produced by a powder metallurgical (mechanical alloying) process, the main purpose of which is to obtain a uniform distribution of sub-micron $\mathrm{Y}_{2} \mathrm{O}_{3}$ particles in the $\mathrm{Fe}_{3} \mathrm{Al}$ matrix. The required high-temperature creep strength is derived largely by developing very large, elongated grains which are effectively pinned by the oxide dispersion. Development of the necessary grain structure is dependent on the characteristics of the mechanically-alloyed powder, and on thermomechanical processing of the consolidated powder.

Keywords: Aluminide, Tubes, Heat Exchangers

\section{IRON ALUMINIDE FILTERS FOR IGCCs \$O - PYF'}

DOE Contacts: F. M. Glaser, (301) 903-2784 and M. H. Rawlins, (423) 576-4507

Oak Ridge National Laboratory Contact: P. F. Tortorelli, (423) 574-5119

The purpose of this project is to provide technical support to the Pall Corporation in its development of porous sintered iron-aluminide filters for hot-particle removal from product streams in coal gasification systems. The ORNL role is to provide specialized expertise in the areas of corrosion analysis, microstructural characterization, alloy selection, and processing based on extensive experience with iron aluminides and materials performance in fossil energy systems. ORNL's contribution via this project should aid the success and timely completion of Pall's development and demonstration efforts.

Keywords: Filters, Aluminides

'PYF denotes that funding for this project, active in FY 1997, was provided from prior year allocations.
448. IRON ALUMINIDE FILTERS FOR PFBCs $\$ 50,000$

DOE Contacts: F. M. Glaser, (301) 903-2784 and M. H. Rawlins, (423) 576-4507

Oak Ridge National Laboratory Contact: P. F. Tortorelli, (423) 574-5119

The goal of this project is to determine the suitability of particular iron aluminides as materials of construction for hot-gas filters in advanced first- and second-generation PFBCs.

Keywords: Filters, Aluminides

\section{CERAMIC TUBESHEET DESIGN ANALYSIS} \$O - PYF

DOE Contacts: F. M. Glaser, (301) 903-2784 and M. H. Rawlins, (423) 576-4507

Oak Ridge National Laboratory Contact:

R. W. Swindeman, (423) 574-5108

The purpose of this task is to perform thermal and mechanical analyses of critical regions in a ceramic tubesheet support for barrier filters in a hot gas cleanup vessel designed for use in gasifier, carbonizer, and pressurized fluidized bed combustion gas streams.

Keywords: Ceramics, Tubesheet

\section{DENSE CERAMIC TUBE DEVELOPMENT} $\$ 100,000$

DOE Contacts: F. M. Glaser, (301) 903-2784 and M. H. Rawlins, (423) 576-4507

Oak Ridge National Laboratory Contact: T. M. Besmann, (423) 574-6852

The goal of this project is to demonstrate that composite materials of high interest to the fossil energy community can be fabricated by chemical vapor infiltration (CVI). Earlier work demonstrated that composites could be fabricated in simple geometries (thick-walled plates). However, more complex geometries were identified as important in a recent Continuous Fiber Ceramic Composite (CFCC) Initiative report. Potentials applications for CFCCs include air heaters or recuperators, heat exchangers, catathermal or porous combustors, components for filtration systems, gas turbine components (primarily combustors), and radiant burner tubes. Nearly all of these applications require tubular composites; therefore, the process will be developed for the fabrication of tubular shapes.

Keywords: Ceramics, Tubesheet 


\title{
INSTRUMENTATION AND FACILITIES
}

\author{
451. MANAGEMENT OF THE FOSSIL ENERGY \\ ARIRTD MATERIALS PROGRAM \\ $\$ 406,000$ \\ DOE Contacts: F. M. Glaser, (301) 903-2784 and \\ M. H. Rawlins, (423) 576-4507 \\ Oak Ridge National Laboratory Contact: \\ R. R. Judkins, (423) 574-4572
}

The overall objective of the Fossil Energy Advanced Research and Technology Development (AR\&TD) Materials program is to conduct a fundamental, long-range research and development program that addresses, in a generic way, the materials needs of fossil energy systems and ensures the development of advanced materials and processing techniques. The purpose of this task is to manage the Fossil. Energy AR\&TD Materials program in accordance with procedures described in the Program Management Plan approved by DOE. This task is responsible for preparing the technical program implementation plan for DOE approval; submitting budget proposals for the program; recommending work to be accomplished by subcontractors, other national laboratories, and by Oak Ridge National Laboratory (ORNL); placing and managing subcontracts for fossil energy materials development at industrial research centers, universities, and other government laboratories; and for reporting the progress of the program.

Keywords: Management, Materials Program

\section{GENERAL TECHNOLOGY TRANSFER ACTIVITIES \\ $\$ 35,000$ \\ DOE Contacts: F. M. Glaser, (301) 903-2784 and M. H. Rawlins, (423) 576-4507 \\ Oak. Ridge National Laboratory Contact: R. R. Judkins, (423) $574-4572$}

The task provides funds for the initiation of technology transfer activities to identify and develop relationships with industrial partners for the transfer of AR\&TD Materials Program technologies to industry.

Keywords: Technology Transfer

\section{GORDON RESEARCH CONFERENCE SUPPORT \\ $\$ 5,000$}

DOE Contacts: F. M. Glaser, (301) 903-2784 and

M. H. Rawlins, (423) 576-4507

Oak Ridge National Laboratory Contact:
R. R. Judkins, (423) 574-4572

The task provides funds for partial support of the annual Gordon Research Conference.

Keywords: Technology Transfer 


\section{DIRECTORY}

J. D. Achenbach

Department of Civil Engineering

Northwestern University

Evanston, IL 60201

(847) 491-5527

lqbal Anmad

Associate Professor

Far East Liaison Office

ONRIAFOSRIARO

7-23-17, Roppongi

Minato-ku, Tokyo 106

(03) 3401-8924, 3423-1374

L. F. Allard

ORNL

P.O. Box 2008

Bldg. 4515, MS 064

Oak Ridge, TN 37831

(423) $574-4981$

Richard Anderson

Kroftt-Brakston International, Inc.

5836 Sunrise Avenue

Claendon Hills, IL 60514

(708) 655-3207

P. Angelini

ORNL

P.O. Box 2008

Bldg. 4515, MS 6065

Oak Ridge, TN 37830-6065

(423) $574-4565$

C. Arnold, Jr.

Division 1811

Sandia National Laboratories

Albuqeurque, NM 87185

(505) 844-8728

T. W. Arrigoni

U.S. Dept. of Energy

P.O. Box 10940

Pittsburgh, PA 15236

(412) $972-4450$

\section{J. S. Arzigian}

Division 1815

Sandia National Laboratories

Albuquerque, NM 87185

(505) 844-2465

R. A. Assink

Division 1811

Sandia National Laboratories

Abuquerque, NM 87185

(505) 844-6372
D. G. Austin

1060 Sun Valley Drive

Annapolis, MD 21401

(410) 626-7826

V. Saimasarma Awa

N. Carolina State Univ.

Grahm Hall \#8

Greensboro, NC 27411

(919) $379-7620$

Walter C. Babcock

Bend Research, Inc.

64550 Research Road

Bend, OR 97701-8599

(503) $382-4100$

Samuel J. Barish

ER-32/GTN

U.S. Dept. of Energy

19901 Germantown Road

Germantown, MD 20874-1290

(301) 903-3054

W. Barnett

NE-53/GTN

U.S. Dept. of Energy

19901 Germantown Road

Germantown, MD 20874-1290

(301) 903-3097

Harold N. Barr

Hittman Mat. \& Med. Components, Inc. 9190 Red Branch Road

Columbia, MD 21045

(301) $730-7800$

Bulent Basol

Internl. Solar Electric Tech., Inc.

8635 Aviation Boulevard

Inglewood, CA 90301

(310) 216-4427

J. L. Bates

Pacific Northwest Laboratories

P.O. Box 999

Richland, WA 99352

(509) $375-2579$

S. Bauer, Division G314

Sandia National Laboratory

P.O. Box 5800

Albuquerque, NM 87185

(505) 846-9645 
M. B. Beardsley

Caterpillar, Inc.

100 N.E. Adams Street

Peoria, IL. 61629

(309) 578-8514

R. L. Beatty

ORNL

P.O. Box 2008

Bldg. 4508, MS 088

Oak Ridge, TN 37831

(423) $574-4536$

B. Beaudry

Ames Laboratory

lowa State University

Ames, lowa 50011

(515) 294-1366

P. F. Becher

ORNL

P.O. Box 2008

Bldg. 4515, 068, Room 275

Oak Ridge, TN 37831-6088

(423) 574-5157

David J. Beecy

FE-72/FORS

U.S. Dept. of Energy

Washington, DC 20585

(301) 903-2787

James A. Begley

Packer Engineering, Inc.

200 Fleet Street

Pittsburgh, PA 15220

(412) 921-6441

Mohamad M. Behravesh

Nuclear Plant Corrosion Control

Electric Power Research Institute

3412 Hillview Avenue

Palo Alto, CA 94303

(650) 855 -2388

R. G. Behrens

LANL

Los Alamos, NM 87545

(505) 667-8327

William L. Bell

TDA Research, Inc

12345 West 52nd Avenue

Wheat Ridge, CO 80033

(303) 940-2301
John Benner

Solar Electric Conversion Div.

NREL

1617 Cole Blvd.

Golden, CO 80401

(303) 231-1396

Dave Benson

NREL

1617 Cole Blvd

Golden, CO 80401

(303) 384-6462

Clifton G. Bergeron

University of lllinois

105 South Goodwin Avenue

204 Ceramics Building

Urbana, IL 61801

(217) $333-1770$

Sam Berman

Bldg. 90, Rm. 3111

Lawerence Berkeley Laboratory

University of California

Berkeley, CA 94720

(510) 486-5682

Theodore M. Besmann

Metals and Ceramics Division

Oak Ridge National Laboratory

P.O. Box 2008

Oak Ridge, TN 37831

(423) 574-6852

Fritz Bien

Spectral Sciences, Inc.

99 South Bedford Street, \#7

Burlington, MA 01803-5169

(617) 273-4770

L. Blair

Los Alamos National Lab

P.O. Box 1663

Los Alamos, NM 87545

(505) 667-6250

J. Bockris

Texas A\&M University

College Station TX 77843-3255

(713) 845-5335

Robert Boettner

EE-112/FORS

U.S. Dept. of Energy

Washington, DC 20585

(202) 252-9136 
W. D. Bond

Oak Ridge National Laboratory

P.O. Box 2008

Bldg. 7920, 384, Room 0014

Oak Ridge, TN 37831-6088

(423) 574-7071

\section{J. A. M. Boulet}

University of Tennessee

310 Perkins Hall

Knoxville, TN 37996

(423) 974-8376

R. J. Bourcier

Division 1832

Sandia National Laboratories

Albuquerque, NM 87185

(505) 844-6638

H. K. Bowen

Dept. of Mat. Science \& Eng.

MIT

77 Massachusetts Avenue

Cambridge, MA 02139

(617) 253-6892

\section{J. Bradley}

Pacific Northwest National Laboratory

Richland, WA 99352

(509) 375-2587

R. A. Bradley

ORNL

P.O. Box 2008

Bldg. 4515

Oak Ridge, TN 37831-6067

(423) 574-6094

Joyce $M$. Brien

Research International, Inc

18706-142nd Avenue, NE

Woodinville, WA 98072

(206) 486-7831

C. R. Brinkman

ORNL

P.O. Box 2008

Bldg. 4500-S, MS 154

Oak Ridge, TN 37831

(423) 574-5106

Leslie Bromberg

Plasma Fusin Center

MA Institute of Tech.

Cambridge, MA 02139

(617) 253-6919

S. E. Bronisz

LANL

Los Alamos, NM 87545

(505) 667-4665
J. A. Brooks

Division 8312

Sandia National Laboratories

Livermore, CA 94550

(925) 422-2051

Alexander Brown

Chesapeake Composites Corporation

239 Old Churchman's Road

New Castle, DE 19720

(302) 324-9110

Ian G. Brown

Lawrence Berkeley Laboratory

Berkeley, CA 94720

(510) 486-4147

J. J. Brown, Jr.

Materials Engineering

Virginia Polytechnic Inst.

Blacksburg, VA 24061

(703) $961-6777$

S. T. Buljan

GTE Laboratories, Inc.

40 Sylvan Road

Waltham, MA 02254

(617) $890-8460$

R. F. Bunshah

Mat. Science \& Eng. Dept.

Univ. of CA, Los Angeles

6532 Boelter Hall

Los Angeles, CA 90024

(213) $825-2210$

R. J. Buss

Division 1812

Sandia National Laboratories

Albuquerque, NM 87185

(505) 844-7494

Kenneth R. Butcher

Selee Corporation

700 Shepherd Street

Hendersonville, NC 28792

(704) 697-2411

J. F. Butler

Aurora Technologies Corporation

7408 Trade Street

San Diego, CA 92121-2410

(619) $549-4645$

Oral Buyukozturk

MIT

77 Massachussetts Avenue

Cambridge, MA 02139

(617) 253-7186 


\section{E. Buzzeli}

Westinghouse R\&D Center

1310 Beulah Rd

Pittsbugh, PA 15235

(412) 256-1952

\section{Elton Cairns}

Lawrence Berkeley Laboratory

University of California

Berkeley, CA 94720

(510) 486-5028

Juan Carbajo

ORNL

P.O. Box Y

Oak Ridge, TN 37831

(423) $57.4-3784$

R. W. Carling, Div. 8313

Sandia National Laboratories

Livermore, CA 94550

(925) 42:2-2206

P. T. Carison

Oak Ridge National Laboratory

P.O. Box 2008

Oak Ridge, TN 37831

(423) 574-5135

D. W. Carroll

LANL

Los Alamos, NM 87545

(505) 667-2145

D. H.W. Carstens

LANL

Los Alamos, NM 87545

(505) 667-5849

G. M. Caton

ORNL

P.O. Box 2008

Bidg. 4515

Oak Ridge, TN 37831-6065

(423) 574-7782

Ken Chacey

EM-34/GTN

U.S. Dept. of Energy

Washington, DC 20545

(301) 903-7186

\section{A. T. Chapman}

Georgia Institute of Technology

Georgia Tech Research Institute

Atlanta, GA 30332-0420

(404) $894-4815$
Yok Chen

ER-131/GTN

U.S. Dept. of Energy

Washington, DC 20585

(301) $903-3428$

Lalit Chhabildas

Org. 1433 Mail Stop 0821

P.O. Box 5800

Sandia National Laboratory

Albuquerque, NM 87185

(505) 844-4147

Russell Chou

Materials Research Center

Lehigh University

Bethlehem, PA 18015

(215) 861-4235

D. C. Christensen

LANL

Los Alamos, NM 87545

(505) 667-2556

Richard Christensen

LLNL

University of California

P.O. Box 808

Livermore, CA 94550

(925) 422-7136

L. Christophorou

ORNL

P.O. Box 2008

Bldg. 4500S, 122, Rm. H156

Oak Ridge, TN 37831

(423) 574-6199

Russel J. Churchill

American Research Corp. of Va.

642 First Street

P.O. Box 3406

Radford, VA 24143-3406

(703) 731-0836

M. J. Cieslak

Division 1833

Sandia National Laboratories

Albuquerque, NM 87185

(505) $846-7500$

D. E. Clark

Materials Technology Div

Idaho National Eng. Laboratory

Idaho Falls, ID 83415

FTS 583-2627 
S. K. Clark

Dept. of Mech. Eng. \& App. Mech.

University of Michigan

Ann Arbor, MI 48109

(313) 764-4256

David Clarke

Univ. of California

Materials Department

Engineering III

Santa Barbara, CA 93106

(805) 893-8275

A. H. Claver

Battelle-Columbus Labs

505 King Avenue

Columbus, $\mathrm{OH} 43201$

(614) 424-4377

R. L. Clough

Sandia National Laboratories

Albuquerque, NM 87185

(505) 844-3492

Joe K. Cochran, Jr.

School of Ceramic Eng.

Georgia Inst. of Technology

Atlanta, GA 30332

(404) $894-2851$

Robert Cook

LLNL

University of California

P.O. Box 808

Livermore, CA 94550

(925) 422-6993

lastair N. Cormack

NYS College of Ceramics

Alfred University

Alfred, NY 14802

(607) $871-2180$

J. E. Costa

Division 8314

Sandia National Laboratories

Livermore, CA 94550

(925) 422-2352

Bruce Cranford

EE-21/FORS

U.S. Dept. of Energy

Washington, DC 20585

(202) 586-9496

Frederick A. Creswick

ORNL

P.O. Box 2009

Oak Ridge, TN 37831

(423) $574-2009$
James V. Crivello

Department of Chemistry

Rensselaer Polytechnic institute

Troy, NY 12180-3590

(518) 276-6825

Randy Curlee

ORNL

P.O. Box 2008

Oak Ridge, TN 37831

(423) $576-4864$

David I. Curtis

NE-60/NR

U.S. Dept of Energy

(703) 603-5565

Steinar Dale

ORNL

P.O. Box 2008

Bldg. 5500, 366, Room A217

Oak Ridge, TN 37831

(423) $574-4829$

G. J. D'Alessio

DP-242/GTN

U.S. Dept. of Energy

Washington, DC 20585

(301) 903-6688

S. J. Dapkunas

National Institute of Standards and Technology

Gaithersburg, MD 20899

(301) 975-6119

John Davis

McDonnell Douglas Astro. Co.

Fusion Energy Program

P.O. Box 516, Bldg 278

St. Louis, MO 63166

(314) 234-4826

Robert F. Davis

Dept. of Materials Eng.

North Carolina State University

232 Riddick Lab, Box 7907

Raleigh, NC 27695

(919) 737-3272

Victor Der

ER-531/FORS

U.S. Dept. of Energy

Washington, DC 20585

(301) 903-5736

R. Diegle

Division 1841

Sandia National Labs

Albuquerque, NM 87185

(505) 846-3450 
R. Diercks

Mat. Science \& Tech. Div.

Argonne National Labs

9700 South Cass Ave

Argonne, Illinois 60439

(630) $972-5032$

Joseph A. Dodson

Space Power, Inc.

621 River Oaks Parkway

San Jose, CA 95134

(408) 434-9500

Larry A. Dominey

Covalent Associates, Inc.

10 State Street

Woburn, MA 01801

(617) $938-1140$

Alan Dragoo

ER-131, G236/GTN

U.S. Dept of Energy

Washington, DC 20585

(301) 903.4895

Elaine Drew

Supercon, Inc.

830 Boston Turnpike

Shrewsbuly, MA 01545

(508) 842-0174

W. D. Drotning

Division 1824

Sandia National Laboratories

Albuquerque, NM 87185

(505) 844-7934

T. J. Drummond

Division 1150

Sandia National Laboratories

Albuquerque, NM 87185

(505) 844-9677

C. Duffy

LANL P.O. Box 1663

Los Alamos, NM 87545

(505) 843-5154

Keith F. Dufrane

Battelle-Columbus Labs

505 King Avenue

Columbus, OH 43201

(614) 424-4618

E. M. Dunn

GTE Laboratories, Inc.

40 Sylvan Road

Waltham, MA 02254

(617) 466-2312
Sunil Dutta

NASA Lewis Research Center

21000 Brookpark Road, MS 49-3

Cleveland, $\mathrm{OH} 44135$

(216) $433-3282$

Christopher A. Ebel

Norton Company

Goddard Road

Northboro, MA 01532-1545

(617) 393-5950

James J. Eberhardt EE-34/FORS

U.S. Dept. of Energy

Washington, DC 20585

(202) 586-9837

G. R. Edwards

Colorado School of Mines

Golden, CO 80401

(303) 273-3773

Mr. Paul Eggerstedt

Ind. Filter \& Pump Man. Co.

5900 Ogden Avenue

Cicero, IL 60650

(708) 656-7800

W. A. Ellingson

Argonne National Laboratories Mat. Science Div., Bldg. 212

9700 South Cass

Argonne, Illinois 60439

(630) $972-5068$

Mr. Norbert B. Elsner

Hi-Z Technology, Inc.

6373 Nancy Ridge Drive

San Diego, CA $92121-2247$

(619) $535-9343$

James Ely, Thermophys. Prop.

Ctr. for Chemical Engineering

National Eng. Laboratory

NIST

Boulder, CO 80303

(303) 320-5467

Gerald Entine

Radiation Monitoring Devices, Inc.

44 Hunt Street

Watertown, MA 02172

(617) 926-1167

Mike Epstein

Battelle-Columbus Labs

505 King Avenue

Columbus, OH 43201

(614) 424-6424 
R. H. Ericksen

Division 1813

Sandia National Laboratories

Albuquerque, NM 87185

(505) 844-8333

\section{Bob Evans}

NASA Lewis Research Center 21000 Brookpark Road, MS 77-6 Cleveland, $\mathrm{OH} 44135$

(216) 433-3400

John Fairbanks

EE-33/FORS

U.S. Dept. of Energy

Washington, DC 20585

(202) 586-8066

P. D. Fairchild

ORNL

P.O. Box $Y$

Bldg. 9102-2, 001, Room 0210

Oak Ridge, TN 37831

(423) 574-2009

\section{A. Farkas}

Virginia Polytechnic Institute and University

Blacksburg, VA 24061

(703) $961-4742$

Cynthia K. Farrar

Montec Associates, Inc

P.O. Box 4182

Butte, MT 59702

(406) 494-2596

G. C. Farrington

University of Pennsylvania

Philadelphia, PA 19104

(215) 898-8337

W. Feduska

Westinghouse Electric Corp.

R\&D Center

1310 Beulah Road

Pittsburgh, PA 15235

(412) 256-1951

Robert S. Feigelson

Center for Materials Research

Stanford University

Stanford, CA 94305

(650) 723-4007

Mattison K. Ferber

ORNL

P.O. Box 2008

Building 4515

Oak Ridge, TN 37831-6064

(423) $576-0818$
Nicholas Fiore

Carpenter Technology Corp.

101 West Bern Street

P.O. Box 14662

Reading, PA 19612

(215) $371-2556$

Ronald J. Fiskum

EE-422/FORS

U.S. Dept. of Energy

Washington, DC 20585

(202) $586-9130$

Timothy J. Fitzsimmons

ER-131, G-236/GTN

U.S. Dept. of Energy

Washington, DC 20585

(301) 903-9830

D. M. Follstaedt

Division 1110

Sandia National Laboratories

Albuquerque, NM 87185

(505) 844-2102

Christopher A. Foster

Cryogenic Applications $F_{\text {, Inc. }}$

450 Bacon Springs Lane

Clinton, TN 37716

(423) $435-5433$

Mark Frei

EM-34/FORS

U.S. Dept. of Energy

Washington, DC 20585

(301) 903-7201

Ehr-Ping Huang Fu

Thermal Science

EE-232/FORS

U.S. Dept. of Energy

Washington, DC 20585

(202) 586-1493

P. W. Fuerschbach

Division 1833

Sandia National Laboratories

Albuquerque, NM 87185

(505) 846-2464

E. R. Fuller

National Institute of Standards and Technology

Gaithersburg, MD 20899

(301) 921-2942

F. D. Gac

LANLMS G771

Los Alamos, NM 87545

(505) 667-5126 
G. F. Gallegos

LLNL

University of California

P.O. Box 808

Livermore, CA 94550

(925) 42:2-7002

Yogendra S. Garud

S. Levy, Inc.

3425 Soluth Bascom Avenue

Campbell, CA 95008

(408) $377-4870$

F. P. Gerstle, Jr.

Sandia National Laboratories

Albuquerque, NM 87185

(505) 844-4304

C. P. Geltz

Yucca Mountain Project Mgr.

U.S. Dept. of Energy

P.O. Box 98518

Las Vegas, NV 89193

(702) 794-7920

Larry Gestaut

Eltech Systems Corp.

Painsville, OH 44077

(216) 357-4041

R. Glass

LLNL

University of California

P.O. Box 808

Livermore, CA 94550

(925) 423-7140

Leon Glicksman

MIT

77 Massachussetts Avenue

Cambridge, MA 02139

(617) 253-2233

Martin Glicksman

Rensselear Polytechnic Inst.

Materials Research Ctr. - 104

8th Street

Troy, NY 12180-3690

(518) 276-6721

Robert L. Goldsmith

CeraMem Corporation

12 Clematis Avenue

Waltham, MA 02154

(617) 899-0467
Mark Goldstein

Quantum Group, Inc

11211 Sorrento Valley Road

San Diego, CA 92121

(619) 457-3048

B. Goodman

NREL

1617 Cole Blvd

Golden, CO 80401

(303) 231-1005

S. H. Goods

Divison 8314

Sandia National Laboratories

Livermore, CA 94550

(925) 422-3274

Paul D. Gorsuch

Space Systems Division

General Electric Company

P.O. Box 8555

Philadelphia, PA 19101

(215) 354-5047

R. J. Gottschall

ER-13/GTN

U.S. Dept. of Energy

Washington, DC 20585

(301) 903-3427

R. A. Graham

Division 1130

Sandia National Laboratories

Albuquerque, NM 87185

(505) 844-1931

Anton C. Greenwald

Spire Corporation

One Patriots Park

Bedford, MA 01730-2396

(617) 275-6000

N. Grossman

NE-42/FORS

U.S. Dept. of Energy

Washington, DC 20585

(301) 903-3745

Dieter M. Gruen

Materials Science Division

Argonne National Laboratory

9700 South Cass Avenue

Argonne, IL 60439

(630) 252-3513 
T. R. Guess

Division 1812

Sandia National Laboratories

Albuquerque, NM 87185

(505) 844-5604

Marvin E. Gunn

EE-60/FORS

U.S. Dept. of Energy

Washington, DC 20585

(202) 586-2826

M. Gurevich

EE-332/FORS

U.S. Dept. of Energy

Washington, DC 20585

(202) 586-6104

Adi R. Guzdar

Foster-Miller, Inc.

350 Second Avenue

Waltham, MA 02154

(617) $890-3200$

John P. Gyeknyesi

NASA Lewis Research Center

2100 Brookpark Road, MS 49-7

Cleveland, $\mathrm{OH} 44135$

(216) $433-3210$

J. S. Haggarty

MIT

77 Massachussetts Avenue

Cambridge, MA 02139

(617) 253-2129

Phil Haley

Allison Turbine Operations

P.O. Box 420

Indianapolis, IN 46206-0420

(317) 230-2272

David G. Hamblen

Advanced Fuel Research, Inc.

87 Church Street

P.O. Box 380379

East Hartford, CT 06138-0379

(203) 528-9806

Edward P. Hamilton

American Superconductor Corp.

2 Technology Drive

Westboro, MA 01581

(508) 836-4200
Michael T. Harris

Chemical Tech. Div.

Oak Ridge National Lab

P.O. Box 2008

Oak Ridge, TN 37831

(423) 574-5962

Pat Hart

Pacific Northwest Labs

P.O. Box 999

Richland, WA 99352

(504) 375-2906

Debbie Haught

EE-23/FORS

U.S. Dept. of Energy

Washington, DC 20585

(202) $586-2211$

Jeff Hay

Chem.-Mat. Science Div.

Los Alamos National Lab

Los Alamos, NM 87545

(505) 843-2097

A. K. Hays

Division 1831

Sandia National Labs

Albuquerque, NM 87185

(505) 844-9996

Norman L. Hecht

University of Dayton

300 College Park, KL165

Dayton, OH 45469-0001

(513) 229-4343

Richard L. Heestand

ORNL

P.O. Box 2008

Bldg. 4508, 083, Room 128

Oak Ridge, TN 37831

(423) 574-4352

Kamithi Hemachalam

Intermagnetics General Corp.

1875 Thomaston Avenue

Waterbury, CT 06704

(203) 753-5215

Mary T. Hendricks

Alabama Cryogenic Engineering, Inc.

P.O. Box 2470

Huntsville, AL 35804

(205) 536-8629 
Carolyn J. Henkens

Andcare, Inc.

2810 Meridian Parkway

Suite 15 ?

Durham, NC 27713

(919) $544-8220$

Carl Henning

Lawrence Livermore Nat. Lab

P.O. Box 5511

Livermore, CA 94550

(925) 532-0235

Thomas P. Herbell

NASA Lewis Research Center 21000 Brookpark Road, 105-1

Cleveland, $\mathrm{OH} 44135$

(216) 433-3246

Carl B. Hilland

DP-28/GTN

U.S. Dept. of Energy

Washington, DC 20545

(301) 903-3687

G. Duncan Hitchens

Lynntech, Inc.

7610 Eastmark Drive

Suite 105

College Station, TX 77840

(409) 693-0017

Kai-Ming Ho

Inst. for Physical

Research and Technology

Ames Laboratory

Ames, IA 50011

(515) 294-1960

J. M. Hobiday

METC

P.O. Box 880

Morgantown, WV 26505

(304) 291-4347

D. M. Hotfman

Lawrence Livermore Nat. Lab

University of California

P.O. Box 808

Livermore, CA 94550

(510) 422-7759

E. E. Hoffman

U.S. Dept. of Energy

P.O. Box 2001

Oak Ridge, TN 37831-8600

(423) 576-0735
Linda L. Horton

Oak Ridge National Laboratory

Box 2008, Bldg. 4500-S

Oak Ridge, TN 37831-6118

(423) 574-5081

E. Philip Horwitz

Chemistry Division

Argonne National Laboratory

9700 South Cass Avenue

Argonne, IL 60439

(630) 252-3653

Charles R. Houska

Dept. of Materials Eng.

Holden Hall

Virginia Polytechnic Institute

Blacksburg, VA 24061

(703) $961-5652$

Stephen M. Hsu

Center for Materials Science

National Measurements Lab

NIST

Gaithersburg, MD 20899

(301) 975-6119

W. J. Huber

FETC

P.O. Box 880

Morgantown, WV 26505

(304) 291-4663

Donald R. Huffman

Dept. of Physics

University of Arizona

Tucson, AZ 85721

(520) 621-4804

Robert A. Huggins

Dept. of Mat. Science \& Eng.

Peterson 550l

Stanford University

Stanford, CA 94305

(925) $497-4110$

Arlon Hunt

Lawrence Berkeley Laboratory

University of California

Berkeley, CA 94720

(925) 486-5370

Thomas K. Hunt

Advanced Modular Power Systems, Inc.

4667 Freedom Drive

Ann Arbor, MI 48108

(313) $677-4260$ 
George F. Hurley

Chemistry-Materials Sci. Div.

Los Alamos National Laboratory

Los Alamos, NM 87545

(505) 667-9498

Mallika D. Ilindra

Sumi Tech, Inc.

3006 McLean Court

Blacksburg, VA 24060

(703) 552-8334

D. David Ingram

Universal Energy Systems, Inc.

4401 Dayton-Xenia Road

Dayton, OH 45432

(513) 426-6900

L. K. Ives

National Institute of Standards

and Technology

Gaithersburg, MD 20899

(301) 921-2843

David A. Jackson

Energy Photovoltaics, Inc.

276 Bakers Basin Road

Lawrenceville, NJ 08648

(609) 587-3000

Jonah Jacob

Science Research Lab, Inc.

15 Ward Street

Somerville, MA 02143

(617) $547-1122$

N. S. Jacobson

NASA Lewis Research Center

21000 Brookpark Road

Cleveland, OH 44135

(216) $433-5498$

Radha Jalan

ElectroChem, Inc.

400 West Cummings Park

Woburn, MA 01801

(617) $932-3383$

Mark A. Janney

ORNL

P.O. Box 2008

Bldg. 4515, 069, Room 228

Oak Ridge, TN 37831-6088

(423) $574-4281$

J. L. Jellison

Division 1833

Sandia National Laboratories

Albuquerque, NM 87185

(505) 844-6397
M. M. Jenior

EE-41/FORS

U.S. Dept. of Energy

Washington, DC 20585

(202) $586-2998$

J. E. Jensen

CVI Inc.

P.O. Box 2138

Columbus, $\mathrm{OH} 43216$

(614) 876-7381

Carl E. Johnson

Chemical Technology Division

Argonne National Laboratory

9700 Cass Ave, Bldg. 205

Argonne, IL 60439

(630) $972-7533$

Curtis A. Johnson

GE Research Laboratory

P.O. Box 8

Bldg. 31 \#3C7

Schenectady, NY 12301

(518) 387-6421

D. L. Johnson, Chairman

Dept. of Mat. Science \& Eng.

2145 Sheridan Road, Rm 1034

Northwestern University

Evanston, IL 60201

(312) 492-3537

D. Ray Johnson

ORNL, Metals \& Ceramics Div.

P.O. Box 2008

Bldg. 4515, 066, Room 206

Oak Ridge, TN 37831-6088

(423) $576-6832$

R. J. Johnson

Hanford Eng. Dev. Lab.

P.O. Box 1970

Richland, WA 99352

(509) 376-0715

Robert Jones

Los Alamos National Lab.

P.O. Box 1663, M/S J577

Los Alamos, NM 87545

(505) 667-6441

Robert A. Jones

DP-28/GTN

U.S. Dept. of Energy

Washington, DC 20545

(301) $903-4236$ 
Chris Karig

EE-142/FORS

U.S. Dept. of Energy

Washington, DC 20585

(202) 586-4563

Landis Kannberg

Pacific Northwest Lab

Battlelle Blvd.

P.O. Box 999

Richland, WA 99352

(509) $375-3919$

Michael E. Karpuk

TDA Research, Inc.

12345 West 52nd Avenue

Wheat Ridge, CO 80033

(303) 940-2301

M. E. Kassner

Oregon State University

Dept. Of Mechanical Engineering

Rogers 204

Corvallis, OR 97331-5001

(541) 737-7023

Carlos Katz

Cable Technology Lab

P.O. Box 707

New Brunswick, NJ 08903

(201) $846-3220$

Joel Katz

LANL

P.O. Box 1663/MS G771

Los Alamos, NM 87545

(505) 665-1424

Robert N. Katz

Worcester Polytechnical inst.

Dept. of Mechanical Eng.

100 Institute Street

Worcester, MA 01609

(508) 831-5336

Larry Kazmerski

Solar Electric Conv. Div.

NREL

1617 Cole Blvd.

Golden, CO 80401

(303) 231-1115

M. R. Keenan

Division 1813

Sandia National Laboratories

Albuquerque, NM 87185

(505) 844-6631
J. R. Keiser

ORNL

P.O. Box 2008

Bidg. 4500-S, 156, Room 0734

Oak Ridge, TN 37830

(423) $574-4453$

Rudolf Keller

EMEC Consultants

4221 Roundtop Road

Export, PA 15632

(412) 325-3260

Paul T. Kerwin

NASA Lewis Research Center

21000 Brookpark Road, MS 77-6

Cleveland, $\mathrm{OH} 44135$

(216) 433-3409

Lawrence W. Kessler

Sonoscan, Inc.

530 East Green Street

Bensenville, IL 60106

(213) 766-7088

Han Kim

GTE Labs

40 Sylvan Road

Waltham, MA 02254

(617) 466-2742

Christopher N. King

Planar Systems, Inc.

1400 Northwest Compton Drive

Beaverton, OR 97006

(503) 690-1100

Richard King

EE-131/FORS

U.S. Dept. of Energy

Washington, DC 20585

(202) 586-1693

J. H. Kinney

LLNL

University of California

P.O. Box 808

Livermore, CA 94550

(925) 422-6669

G. S. Kino

Edward Ginzton Laboratory

Stanford University

Stanford, CA 94305

(925) 497-0205

Thomas Kitchens

ER-31/GTN

U.S. Dept. of Energy

Washington, DC 20585

(301) 903-5152 
E. E. Klaus

Penn State

Room 108, Fenske Laboratory

Univ Park, PA 16802

(814) 865-2574

Paul Klemmens

University of Connecticut

Box U-46

Storrs, CT 06268

(860) 486-3134

\section{S. J. Klima}

NASA Lewis Research Center MS 106-1

21000 Brookpark Road

Cleveland, $\mathrm{OH} 44135$

(216) 433-6020

J. A. Knapp

Division 1110

Sandia National Laboratories

Albuquerque, NM 87185

(505) 844-2305

G. A. Knorovsky

Division 1833

Sandia National Laboratories

Albuquerque, NM 87185

(505) 844-1109

Timothy R. Knowles

Energy Science Labs, Inc.

6888 Nancy Ridge Drive

San Diego, CA 92121-2232

(619) 552-2034

C. C. Koch

Materials Eng. Department

North Carolina State University

Raliegh, NC 27650

(919) 737-2377

Victor R. Koch

Covalent Associates, Inc.

10 State Street

Woburn, MA 01801

(617) 938-1140

K. G. Kreider

National Institute of Standards and Technology

Gaithersburg, MD 20899

(301) 975-2619

L. E. Kukacka

Brookhaven National Laboratory

Upton, NY 11973

(516) 282-3065
David Kurtz

Advanced Technology Materials, Inc.

7 Commerce Drive

Danbury, CT 06810

(203) $794-1100$

S. R. Kurtz

Division 1811

Sandia National Laboratories

Albuquerque, NM 87185

(505) 844-5436

Richard J. Lagow

Department of Chemistry

The Univ. of Texas at Austin

Austin, TX 78712

(512) 471-1032

C. M. Lampert

Lawerence Berkeley Laboratory

University of California

Berkeley, CA 94720

(925) 486-6093

A. Landgrebe

EE-32/FORS

U.S. Dept. of Energy

Washington, DC 20585

(202) 586-1483

P. M. Lang

NE-45/FORS

U.S. Dept. of Energy

Washington, DC 20585

(301) $903-3313$

James Lankford

Southwest Research Inst.

6220 Culebra Road

P.O. Drawer 28510

San Antonio, TX 78284

(512) 684-5111

Herbert J. Larson

Caterpillar, Inc.

Building $F$

100 N.E. Adams

Peoria, IL 61629

(309) 578-6549

R. LaSala

EE-122/FORS

U.S. Dept. of Energy

Washington, DC 20585

(202) 586-4198

W. N. Lawless

CeramPhysics, Inc.

921 Eastwind Drive, Suite 110

Westerville, OH 43081

(614) $882-2231$ 
Ed LeBaker

425 Lakeside Drive

Sunnyvale, CA 94086

(408) $733-7780$

S. R. Lee

U.S. Dept. of Energy

P.O. Box: 10940

Pittsburgh, PA 15236

(412) 675-6137

Franklin D. Lemkey

United Tech. Research Ctr.

Silver Lane

East Hartford, CT 06108

(860) $727-7318$

Douglas Lemon

Pacific Northwest Labs

P.O. Box 999

Richland, WA 99352

(509) 375-2306

Alexander Lempicki

ALEM Associates/Radiation

Monitoring Devices

303A Commonwealth Avenue

Boston, MA 02115

(617) 353-9581

S. R. Levine

NASA Lewis Research Center

21000 Brookpart Road

Cleveland, $\mathrm{OH} 44135$

(216) 433-3276

\section{A. V. Levy}

Lawerence Berkley Lab

University of California

One Cyclotron Road

Berkley, CA 94720

(510) 486-5822

John Lewellen

NE-46/FORS

U.S. Dept. of Energy

Washington, DC 20585

(301) 903-2899

\section{Patrick Lin}

Chemat Technology, Inc.

19365 Business Center Drive

Suite 8

Northridge, CA 91324

(818) 727-9786

J. Lipkin

Sandia National Laboratories

Livermore, CA 94550

(925) 42:-2417
C. T. Liu, Mtl. Ceram. Div.

ORNL

P.O. Box 2008

Bldg. $4500-S, 115$, Rm. $\$ 280$

Oak Ridge, TN 37831

(423) 574-5516

K. C. Liu

ORNL

P.O. Box 2008

Bldg. 4500-S, MS 155

Oak Ridge, TN 37831

(423) 574-5116

Earl L. Long, Jr.

ORNL, Metals \& Ceramics Div. P.O. Box 2008

Bldg. 4515, 069, Room 229

Oak Ridge, TN 37831

(423) 574-5127

Richard W. Longsderff

Thermacore, Inc.

780 Eden Road

Lancaster, PA 17601

(717) 569-6551

R. O. Loutfy

Mat. \& Electro. Research Corp.

7960 South Kolb Road

Tucson, AZ 85706

(602) 574-1980

T. C. Lowe

Divison 8316

Sandia National Laboratories

Livermore, CA 94550

(925) 422-3187

C. D. Lundin

307 Dougherty Eng. Bldg.

University of Tennessee

Knoxville, TN 37996

(423) $974-5310$

MAJ Ross E. Lushbough

DP-225.2/FORS

U.S. Dept. of Energy

Washington, DC 20585

(301) 903-3912

E. A. Maestas

West Valley Project Office

U.S. Dept. of Energy

P.O. Box 191

West Valley, NY 14171-0191

(716) $942-4314$ 
Richard Mah

Los Alamos National Lab

P.O. Box 1663

Los Alamos, NM 87545

(505) 607-3238

Mokhtas S. Maklad EOTEC Corporation 420 Frontage Road West Haven, CT 06516 (203) 934-7961

Frederick M. Mako

FM Technologies 10529-B Braddock Road Fairfax, VA 22032 (703) 425-5111

A. C. Makrides EIC Laboratories, Inc. 111 Downey Street Norwood, MA 02062 (617) $769-9450$

Subhas G. Malghan

NIST

A-258/223

Gaithersburg, MD 20899

(301) 975-6101

Mark K. Malmros

MKM Research/Ohmicron

P.O. Box I

Washington Crossing, PA 18977

(609) $737-9050$

Matthew Marrocco

Maxdem, Inc.

140 East Arrow Highway

San Dimas, CA 91773

(909) 394-0644

R. G. Martin

Analysis Consultants

21831 Zuni Drive

El Toro, CA 92630

(714) 380-1204

H. Maru

Energy Research Corporation.

3 Great Pasture Road

Danbury, CT 06810

(203) $792-1460$

K. Masubuchi

Lab for Manuf. and Prod.

MIT

Cambridge, MA 02139

(617) 255-6820
Ronald D. Matthews

Dept. of Mechanical Engineering

The University of Texas at Austin

Austin, TX 78712

(512) $471-3108$

W. A. May, Jr.

LANL:

Los Alamos, NM 87545

(505) 667-6362

Douglas McAllister

BIODE, Inc.

2 Oakwood Road

Cape Elizabeth, ME 04107

(207) 883-1492

James W. McCauley, Dean

New York State College of Ceramics

Alfred University

Alfred, NY 14802

(607) $871-2411$

Robert W. McClung

ORNL

P.O. Box 2008

Bldg. 4500-S, 151, Rm. D63

Oak Ridge, TN 37831-6088

(423) 574-4466

Scott B. McCray

Bend Research, Inc.

64550 Research Road

Bend, OR 97701-8599

(503) $382-4100$

D. McCright

LLNL

University of California

Livermore, CA 94550

(213) 423-7051

Roger J. McDonald

Brookhaven National Laboratory

Bldg. 475

Upton, NY 11973

(515) 282-4197

Patrick N. McDonnell

Spire Corporation

One Patriots Park

Bedford, MA 01730-2396

(617) $275-6000$

David L. McElroy

ORNL

P.O. Box 2008

Bldg. 4508, 092, Rm. 239

Oak Ridge, TN 37831-6088

(423) 574-5976 
A. J. McEvily

Metallurgy Dept., U-136

University of Connecticut

Storas, CT 06268

(860) 486-2941

T. D. MaGee

Mat. Science \& Engineering

110 Engineering Annex

lowa State University

Ames, IA 50011

(515) 294-9619

R. R. McGuire

Lawrence Livermore Nat. Lab

University of California

P.O. Box 808

Livermore, CA 94550

(925) 42:2-7792

Carl McHargue

University of Tennessee

Materials \& Eng. Dept.

434 Doughtery Eng. Bldg.

Knoxville, TN 37996-2200

(423) 974-8013

M. J. McMonigle

EE-234/FORS

U.S. Dept. of Energy

Washington, DC 20585

(202) 586-2082

Arthur S. Mehner

NE-53/GTN

U.S. Dept. of Energy

Washington, DC 20585

(301) 90:3-4474

G. H. Meier

848 Benevum Hall

University of Pittsburgh

Pittsburgh, PA 15261

(412) 624-5316

A. Meyer

International Fuel Cells

P.O. Box 739

195 Governors Hwy.

South Windsor, CT 06074

(203) 727-2214

B. E. Mills

Sandia National Laboratories

Livermore, CA 94550

(925) $422-3230$
Andrew Morrison

M/S 238-343

Flat Plate Solar Array Project

Jet Propulsion Laboratory

Pasadena, CA 91109

(213) 354-7200

Craig Mortenson

BPAFORS

U.S. Dept. of Energy

Washington, DC 20585

(202) 586-5656

Jack Mofett

Library of Congress

101 Independence Avenue, SW

Washington, DC 20540-7490

(202) $707-1435$

Leszek R. Motowidlo

IGC Advanced Superconductors

1875 Thomaston Avenue

Waterbury, CT 06704

(203) 753-5215

Arnulf Muan

Pennsylvania State University

EMS Experiment Station

415 Walker Bldg.

University Park, PA 16802

(814) 865-7659

L. Marty Murphy

NREL

1617 Cole Blvd

Golden, CO 80401

(303) 231-1050

\section{J. Narayan}

Materials Science \& Eng.

North Carolina State Univ. Box 7916

Raleigh, NC 27695-7916

(919) 515-7874

J. E. Nasise

LANL

Los Alamos, NM 87545

(505) 667-1459

Michael Nastasi

Los Alamos National Lab

Los Alamos, NM 87545

(505) 667-7007 


\section{K. Natesan}

Argonne National Lab.

Materials Science Division

9700 South Cass

Argonne, IL 60439

(312) $972-5068$

M. Naylor

Cummins Engine Co., Inc.

Box 3005

Mail Code 50183

Columbus, IN 47202-3005

(812) $377-5000$

Fred Nichols

Argonne National Laboratory

9700 South Cass

Argonne, IL 60439

(630) $972-8292$

M. C. Nichols

Sandia National Laboratories

Livermore, CA 94550

(925) 422-2906

\section{P. J. Nigrey}

Division 1150

Sandia National Laboratories

Albuquerque, NM 87185

(505) 844-8985

F. B. Nimick, Division G313

Sandia National Laboratory

P.O. Box 5800

Albuquerque, NM 87185

(505) 844-6696

D. A. Nissen

Sandia National Laboratories Livermore, CA 94550

(925) 422-2767

R. Gerald Nix

NREL

1617 Cole Bivd

Golden, CO 80401

(303) 231-1757

\section{T. A. Nolan}

ORNL

P.O. Box 2008

Bldg. 4515, MS 064

Oak Ridge, TN 37831

(423) 574-0811

Paul C. Nordine

Containerless Research, Inc.

910 University Place

Evanston, IL 60201-3149

(708) 467-2678
P. C. Odegard

Divison 8216

Sandia National Laboratories

Livermore, CA 94550

(925) 422-2789

G. R. Odette

Dept. of Chem. \& Nuclear Eng.

University of California

Santa Barbara, CA 93106

(805) 961-3525

Thomas Ohlemiller

Center for Bldg. Technology

National Institute of Standards and Technology

Gaithersburg, MD 20899

(301) 921-3771

Ben Oliver

Materials Science \& Eng.

421 Dougherty Hall

Knoxville, TN 37996

(423) 974-5326

Randall B. Olsen

Chronos Research Labs, Inc.

3025 Via de Caballo

Olivenhaim, CA 92024

(619) 756-1447

G. C. Osbourn

Division 1130

Sandia National Laboratories

Albuquerque, NM 87185

(505) 844-8850

Roland Otto

Lawrence Berkeley Lab.

Bldg 73, 106A

Berkeley, CA 94720

(510) 486-5289

G. M. Ozeryansky

IGC Superconductors, Inc.

1875 Thomaston Avenue

Waterbury, CT 06704

(203) 753-5215

Richard H. Pantell

Electrical Engineering Dept

Stanford University

Stanford, CA 94305

(650) 723-2564

E. R. Parker

456 Hearst

Univ. of Ca., Berkeley

Berkeley, CA 24720

(510) 642-0863 
Bill Parks

EE-221/FORS

U.S. Dept. of Energy

Washington, DC 20585

(202) 586-2093

D. O. Patten

Norton Company

High Performance Ceramics

Goddard Road

Northboro, MA 01532

(617) 39.3-5963

Ahmad Fiesaran

NREL

1617 Cole Blvd.

Golden, CO 80401

(303) 231-7636

John Petrovic

Chemistry-Mat. Science Div.

Los Alamos National Laboratory

Los Alamos, NM 87545

(505) 667-5452

S. T. Picraux

Division 1110

Sandia National Laboratories

Albuquerque, NM 87185

(505) 844-7681

R. D. Pierce

Argonne National Laboratories

Chemical Tech Division

Bldg. 205, Room W-125

Argonne, IL 60439

(630) $972-4450$

Melvin A. Piestrup

Adelphi Technology

13800 Skyline BIvd.

Woodside, CA 94062

(925) 851-0633

James E. Plank

Charles Evans and Associates

301 Chesapeake Drive

Redwood City, CA 94063

(925) 369-4567

L. E. Pope

Division 1834

Sandia National Laboratories

Albuquerque, NM 87185

(505) 844-5041

Joseph Prahl

Case Western Reserve Univ.

Cleveland, $\mathrm{OH} 44106$

(216) 368-2000
Mark A. Prelas

Nuclear Engineering Program

University of Missouri

Columbia, MO 65211

(314) 882-3550

Peter Pronko

Universal Energy Systems

4401 Dayton-Xenia Road

Dayton, OH 45432

(513) $426-6900$

Herschel Rabilz

Dept. of Chemistry

Princeton University

Princeton, NJ 08544-1009

(609) 258-3917

P. B. Rand

Division 1813

Sandia National Labs

Albuquerque, NM 87185

(505) 844-7953

Robert Rapp

Dept. of Metal. Eng.

Ohio State University

Columbus, $\mathrm{OH} 43210$

(614) 422-2491

Bhakta B. Rath, Assoc. Dir. Res.

Naval Research Laboratory

Mat. Science \& Component Tech.

Building 43, Room 212 - Code 6000

Washington, DC 20375-5000

(202) 767-3566

Rod Ray

Bend Research, Inc.

64550 Research Road

Bend, OR 97701-8599

(503) 382-4100

Richard Razgaitis

Battelle-Columbus Labs

505 King Avenue

Columbus, $\mathrm{OH} 43201$

(614) 424-4212

Brian Rennex

Natl. Institute of Standards

and Technology

Center of Bldg. Technology

Gaithersburg, MD 20899

(301) 921-3195

W. G. Reuter

Materials Technology Div.

Idaho National Eng. Lab

Idaho Falls, ID 83415

(205) 526-0111 
S. Richlen EE-221/FORS

U.S. Dept. of Energy Washington, DC 20585 (202) 586-2078

R. O. Ritchie 456 Hearst University of Cal., Berkeley Berkeley, CA 24720 (510) 642-0863

P. L. Rittenhouse ORNL

P.O. Box 2008

Bldg. 45005, 138, Rm. A158

Oak Ridge, TN 37831

(423) $574-5103$

H. F. Rizzo

Lawrence Livermore Nat. Lab University of California

P.O. Box 808

Livermore, CA 94550

(925) 422-6369

\section{R. B. Roberto}

ORNL

Solid State Division

P.O. Box 2008

Oak Ridge, TN 37831-6030

(423) 574-6151

\section{I. Roberts}

GA Technologies

P.O. Box 81608

San Diego, CA 92138

(619) $455-2560$

\section{S. L. Robinson}

Division 8314

Sandia National Laboratories Livermore, CA 94550

(925) 422-2209

A. D. Romig
Division 1832

Sandia National Laboratories Albuquerque, NM 87185

(505) 844-8358

Timothy L. Rose

EIC Laboratories, Inc.

111 Downing Street

Norwood, MA 02062

(617) 764-9450
R. S. Rosen

LLNL

University of California

P.O. Box 808

Livermore, CA 94550

(925) 422-9559

John H. Rosenfeld

Thermacore, Inc.

780 Eden Road

Lancaster, PA 17601

(717) 569-6551

P. N. Ross

Mat. \& Metal. Research Div.

Lawrence Berkeley Labs

University of Berkeley

Berkeley, CA 94720

(510) 486-4000

Giulio A. Rossi

Norton Company

Goddard Road

Northboro, MA 01532-1545

(617) 393-5829

Walter Rossiter

Center for Bldg. Technology

National Institute of Standards and Technology

Gaithersburg, MD 20899

(301) 921-3109

Arthur Rowcliffe, Met/Ceram Div.

ORNL

P.O. Box 2008

Bidg. 5500, 376, Rm. A111

Oak Ridge, TN 37831

(423) 576-4864

M. Rubin

Lawrence Berkeley Laboratory

University of California

Berkeley, CA 94720

(510) 486-7124

E. Russell

LLNL

University of California

Livermore, CA 94550

(925) 423-6398

C. O. Ruud

159 MRL

University Park, PA 16802

(814) 863-2843 
John Ryan

EE-422/FORS

U.S. Dept. of Energy

Washington, DC 20585

(202) $586-9130$

\section{J. R. Sadoway}

MIT

77 Massachussetts Avenue

Cambridge, MA 02139

(617) 253-3300

Djordjiji R. Sain

Nuclear Con. Services, Inc.

P.O. Box 29151

Columbus, OH 43229

(614) 846-5710

Peter H. Salmon-Cox

Dir. of Olfice Ind. Processes

EE-23/FORS

U.S. Dept. of Energy

Washington, DC 20585

(202) $586-2380$

R. J. Salzbbrenner

Division 1832

Sandia National Laboratories

Albuquerque, NM 87185

(505) 844-5041

Stuart Samuelson

Deltronic Crystal Industries, Inc.

60 Harding Avenue

Dover, NJ 07801

(201) 361-2222

\section{J. Sankar}

Dept of Mechanical Engineering

North Carolina A\&T University

Greensboro, NC 27411

(919) 379-7620

Mike L. Santella

ORNL

P.O. Box 2008

Oak Ridge, TN 37831-6088

(423) 574--4805

Srinivasan Sarangapani

ICET, Inc.

916 Pleasant Street

Unit 12

Norwood, MA 02062

(617) 679-6064

V. K. Sarin

GTE

40 Sylvan Road

Waltham, MA 02254

(617) $890-8460$
Suri A. Sastri

Surmet Corporation

33 B Street

Burlington, MA 01803

(617) 272-3250

Y. Schienle

Garrett Turbine Engine Co.

111 South 34th Street

P.O. Box 5217

Phoenix, AZ 85034

(602) 231-4666

Jerome J. Schmidt

Jet Process Corporation

25 Science Park

New Haven, CT 06511

(203) $786-5130$

S. J. Schneider

National Institute of Standards and Technology

Gaithersburg, MD 20899

(301) 921-2901

G. D. Schnittgrund

Rockwell International

Rocketdyne Division

6633 Canoga Avenue

Canoga Park, CA 91304

(818) 710-5972

W. K. Schubert

Division 1815, SNL

Albuquerque, NM 87185

(505) 846-2466

Erland M. Schulson

33 Haskins Road

Hanover, NH 03755

(603) 646-2888

James Schwarz

Dept. Chem. Eng/Mat Science

Syracuse University

320 Hinds Hall

Syracuse, NY 13244

(315) 423-4575

James L. Scott

Metals and Ceramics Div.

ORNL

P.O. Box 2008, Bldg. 4508

Oak Ridge, TN 37831-6091

(423) 624-4834 
Timothy C. Scott

Chemical Technology Division

Oak Ridge National Laboratory

P.O. Box 2008

Oak Ridge, TN 37831

(423) 574-5962

\section{R. E. Setchell}

Division 1130

Sandia National Labs

Albuquerque, NM 87185

(505) 844-5459

\section{J. A. Seydel}

Materials Science Division

Idaho National Eng. Lab

Idaho Falls, ID 84315

(208) 526-0111

D. J. Sharp

Division 1831

Sandia National Laboratories

Albuquerque, NM 87185

(505) 844-8604

Suzanne C. Shea

Praxis Engineers, Inc.

852 North Hillview Drive

Milpitas, CA 95035

(408) $945-4282$

D. E. Shelor

RW-3/FORS

U.S. Dept. of Energy

Washington, DC 20585

(202) 586-9433

\section{K. Sikka}

ORNL

P.O. Box 2008

Bldg. 4508, 083, Rm. 129

Oak Ridge, TN 37831

(423) 574-5112

Richard Silberglitt

FM Technologies, Inc.

Patriot Square

10529-B Braddock Road

Fairfax, VA 22032

(703) 425-5111

T. B. Simpson

FE-34/GTN

U.S. Dept. of Energy

Washington, DC 20585

(301) 903-3913
J. P. Singh

Argonne National Labs

9700 South Cass

Argonne, IL 60439

(630) $972-5068$

Maurice J. Sinnott

Chemical and Metall. Eng.

University of Michigan

$\mathrm{H}$ Dow Building

Ann Arbor, MI 48109-2136

(313) 764-4314

Piran Sioshamsi

Spire Corporation

Patriots Park

Bedford, MA 02173

(617) 275-6000

Kurt D. Sisson

EE-222/FORS

U.S. Dept. of Energy

Washington, DC 20585

(202) 586-6750

Hal Sliney

NASA Lewis Research Center 21000 Brookpark Road

MS 23-2

Cleveland, $\mathrm{OH} 44135$

(216) 433-6055

Jerry Smith

ER-132/GTN

U.S. Dept. of Energy

Washington, DC 20545

(301) $903-3426$

M. F. Smith

Division 1834

Sandia National Laboratories

Albuquerque, NM 87185

(505) $846-4270$

Paul Smith

Materials Dept

Univ. of CA, Santa Barbara

Santa Barbara, CA 93103

(805) 893-8104

Peter L. Smith

Newton Optical Technologies

167 Valentine Street

Newton, MA 02165

(617) 495-4984

J. E. Smugeresky

Division 8312

Sandia National Laboratories

Livermore, CA 94550

(925) 422-2910 
N. R. Sorensen

Division 1841

Sandia National Laboratories

Albuquerque, NM 87185

(505) 84.4-1097

Charles A. Sorrell

AlM Program

EE-232/FORS

U.S. Dept. of Energy

Washington, DC 20585

(202) $586-1514$

R. F. Sperlein

U.S. Dept. of Energy

P.O. Box 10940

Pittsburgh, PA 15236

(412) $972-5985$

Bernard F. Spielvogel

Boron Biologicals, Inc.

533 Pylon Drive

Raleigh, NC 27606

(919) 832-2044

J. R. Springarn

Division 8312 , SNL

Livermore, CA 94550

(925) 422-3307

Mark B. Spitzer

Spire Corporation

Patriots Park

Bedford, MA 01730

(617) 275-6000

Gregory $C$. Stangle

School of Cer. Eng.

2 Pine Street

Alfred University

Alfred, NY 14802

(607) 871-2798

T. L. Starr

Georgia Tech Res. Inst

Georgia Inst. of Technology

Atlanta, GA 30332

(404) $894-3678$

Carl A. Stearns

NASA Lewis Research Center MS 106-1

21000 Brookpark Road

Cleveland, $\mathrm{OH} 44135$

(216) 433-5504
Wayne S. Steffier

Hyper-Therm, Inc.

18411 Gothard Street

Units B \& C

Huntington Beach, CA 92648

(714) 375-4085

Helmut F. Stern

Arcanum Corporation

P.O. Box 1482

Ann Arbor, MI 48106

(313) 665-4421

George Stickford

Battelle-Columbus Labs

505 King Avenue

Columbus, OH 43201

(614) 424-4810

Thomas J. Stiner

AstroPower, Inc.

Solar Park

Newark, DE 19716

(302) 366-0400

Robert J. Stinner

ISM Technologies, Inc.

9965 Carroll Canyon Road

San Diego, CA 92131

(619) $530-2332$

D. P. Stinton

ORNL

P.O. Box 2008

Bldg. 4515, 063, Rm. 111

Oak Ridge, TN 37831

(423) $574-4556$

Thomas G. Stoebe

Chairman, Mak. Sci. \& Eng.

University of Washington

Roberts Hall, FB-10

Seattle, WA 98195

(206) $543-2600$

Norman Stoloff

Materials Engineering Dept.

Rensselaer Polytechnic Inst.

Troy, NY 12181

(518) 266-6436

Paul D. Stone

The Dow Chemical Company

1776 Eye Street, NW, \#575

Washington, DC 20006

J. E. Stoneking

Dept. of Eng. Science \& Mech.

310 Perkins Hall

Knoxville, TN 37996

(423) 974-2171 
G. Stoner

University of Virginia

Charlottesville, VA 22901

(804) 924-3277

Edwin E. Strain

Garrett Corporation

$111 \mathrm{~S}$. 34th Street

P.O. Box 5217, MS 301-2N

Phoenix, AZ 85010

(602) 231-2797

Reinhold N. W. Strnot

KJS Associates

1616 Hillrose Place

Fairborn, OH 45324

(513) 879-0114

Thomas N. Strom

NASA Lewis Research Center

21000 Brookpark Road, MS 77-6

Cleveland, OH 44135

(216) $433-3408$

David Sutter

ER-224/GTN

U.S. Dept. of Energy

Washington, DC 20585

(301) 903-5228

Patrick Sutton

EE-32/FORS

U.S. Dept. of Energy

Washington, DC 20585

(202) $586-8058$

Richard Swanson

SunPower Corporation

435 Indio Way

Sunnyvale, CA 94086

(408) $991-0900$

R. W. Swindeman

ORNL

P.O. Box 2008

Bldg. 4500-S, 155, Rm. 0040

Oak Ridge, TN 37831

(423) 574-5108

W. Tabakoff

Dept. of Aerospace Eng.

M/L 70

University of Cincinnati

Cincinnati, OH 45221

(513) 475-2849

C. A. Thomas

U.S. Dept. of Energy

P.O. Box 10940

Pittsburgh, PA 15236

(412) $972-5731$
Iran L. Thomas

ER-10/GTN

U.S. Dept. of Energy

Washington, DC 20545

(301) 903-3426

D. O. Thompson

Ames Laboratory

lowa State University

Ames, IA 50011

(515) 294-5320

T. Y. Tien

Mat. and Metal. Eng.

University of Michigan

Ann Arbor, MI 48109

(813) $764-9449$

T. N. Tiegs

ORNL

Bldg. 4515, 069, Rm. 230

P.O. Box 2008

Oak Ridge, TN 37831-6088

(423) 574-5173

Jyh-Ming Ting

Applied Sciences, Inc.

141 West Xenia Avenue

P.O. Box 579

Cedarville, $\mathrm{OH} 45314$

(513) $766-2020$

R. H. Titran

NASA Lewis Research Center

21000 Brookpark Road, MS 49-1

Cleveland, OH 44135

(216) 433-3198

Zygmunt Tomczuk

Chemical Technology Division

Argonne National Laboratory

9700 South Cass Avenue

Argonne, IL 60439

(708) 252-7294

Micha Tomkiewicz

Physics Department

Brooklyn College of City

University of New York

Brooklyn, NY 11210

(718) 951-5357

John J. Tomlinson

ORNL

Bldg. 9204-1, MS 8045

P.O. Box 2009

Oak Ridge, TN 37831-8045

(423) 574-0768 
J. A. VanDenAvyle

Division 1832

Sandia National Laboratories

Albuquerque, NM 87185

(505) 844-1016

D. van Rooyen

Brookhaven National Lab.

Upton, NY 11973

(516) $28: 2-4050$

Carl R. Vander Linden

Vander Linden \& Associates

AIC Materials Program

5 Brassie Way

Littleton, CO 80123

(303) 794-8309

William VanDyke

NE-46/GTN

U.S. Dept. of Energy

Washington, DC 20545

(301) 903-4201

Richard D. Varjian

Dow Chemical Company, Inc.

Central Research - Catalysis

1776 Building

Midland, MI 49675

(517) 636-6557

Alex Vary'

NASA Lewis Research Center

21000 Brookpark Road

Cleveland, $\mathrm{OH} 44135$

(216) $433-6019$

Krishna Vedula

Dept. of Metal. \& Mat. Science

Case Western Reserve University

10900 Euclid Avenue

Cleveland, OH 44115

(216) 368-4211

Ted Vojnovich

ER-32/GTN

U.S. Dept. of Energy

Washington, DC 20585

(301) 903-7484

Brian G. Volintine

EE-232

5F-059/FORS

U.S. Dept. of Energy

Washington, DC 20585

(202) 586-1739
Robert W. Vukusich

UES, Inc

4401 Dayton-Xenia Road

Dayton, $\mathrm{OH} 45432-1894$

(513) 426-6900

David Waksman

National Institute of Standards

and Technology

Building 226

Gaithersburg, MD 20899

(301) 921-3114

J. B. Walter

Materials Technology Div.

Idaho National Eng. Lab

Idaho Falls, ID 83415

(208) 526-2627

John Walter

IntraSpec, Inc.

P.O. Box 4579

Oak Ridge, TN 37831

(423) 483-1859

William K. Warburton

$X$-ray Instrumentation Associates

1300 Mills Street

Menlo Park, CA 94025-3210

(925) $903-9980$

Craig N. Ward

Uitramet

12173 Montague Street

Pacoima, CA 91331

(818) 899-0236

Gary S. Was

Dept. of Nuclear Eng.

University of Michigan

Ann Arbor, MI 48109

(313) 763-4675

Michael R. Wasielewski

Chemistry Division

Argonne National Laboratory

9700 South Cass Avenue

Argonne, IL 60439

(708) 252-3538

Rolf Weil

Dep. of Mat. \& Metal. Eng.

Stevens Inst. of Technology

Castle Point Station

Hoboken, NJ 07030

(201) 420-5257 
Roy Weinstein

Instit. for Particle Beam Dynamics

University of Houston

Houston, TX 77204-5502

(713) $743-3600$

\section{Elizabeth $\mathbf{G}$. Weiss}

Membrane Technology and Research, Inc. 1360 Willow Road, Suite 103

Menlo Park, CA 94025

(925) 328-2228

James Wert

Dept. of Mat. Science \& Eng.

Vanderbilt University

Station B, P.O. Box 1621

Nashville, TN 37235

(423) $322-3583$

\section{J. B. Whitley}

Sandia National Laboratories

Albuquerque, NM 87185

(505) 844-5353

Sheldon M. Wiederhorn

National Institute of Standards

and Technology

Bldg. 223, \#A329

Gaithersburg, MD 20899

(301) $975-2000$

\section{F. W. Wiffen}

ER-52/GTN

U.S. Dept. of Energy

Washington, DC 20545

(301) $903-4963$

Daniel E. Wiley

Dir. of Improved Energy Prod.

EE-231/FORS

U.S. Dept. of Energy

Washington, DC 2085

(202) 586-2099

Frank Wilkins

EE-11/FORS

U.S. Dept. of Energy

Washington, DC 20585

(202) 586-1684

\section{A. D. Wilks}

Signal UOP Research Center

50 UOP Plaza

Des Plaines, IL 60016

(312) 492-3179

Ward 0 . Winer

Mechanical Eng. Department

Georgia Inst. of Technology

Atlanta, GA 30332

(404) 894-3270
C. E. Witherell

LLNL

University of California

P.O. Box 808

Livermore, CA 94550

(925) 422-8341

J. C. Withers

Mat. \& Electro. Res. Corp.

7960 South Kolb Road

Tucson, AZ 85706

(602) 574-1980

D. E. Wittmer

S. Illinois Univ./Carbondale

Dept. of Mech. Eng. \& Egy Pro.

Carbondale, IL 62901

(618) 536-2396, ext. 21

T. Wolery

LiNL

University of California

Livermore, CA 94550

(925) $423-5789$

Stanley M. Wolf

EM-54/GTN

U.S. Dept. of Energy

Washington, DC 20545

(301) 903-7962

James C. Wood

NASA Lewis Research Center

MS 500-210

21000 Brookpark Road

Cleveland, $\mathrm{OH} 44135$

(216) 433-4000

J. R. Wooten

Rocketdyne

6633 Canoga Avenue

Mail Code BA-26

Canoga Park, CA 91303

(818) 710-5972

John D. Wright

TDA Research, Inc.

12345 West 52nd Avenue

Wheat Ridge, CO 80033

(303) 940-2301

R. N. Wright

Materials Technology Div.

Idaho National Eng. Laboratory

Idaho Falls, ID 83415

(208) 526-6127 
David Yarbrough

Department of Chem. Eng.

Tennessee Tech. University

1155 N. Dixie Ave.

Cookville, TN 38505

(423) 528-3494

H. C. Yeh

Air Research Casting Co.

19800 VanNess Avenue

Torrance, CA 90509

(213) 618-7449

Thomas M. Yonushonis

Cummins Engine $\mathrm{Co}$., Inc.

Box 3005

Mail Code 50183

Columbus, IN 47202-3005

(812) 377-7078

J. Yow

LLNL

University of California

Livermore, CA 94550

(925) 423-3521

Dingan $Y_{I J}$

Supercon, Inc.

830 Boston Turnpike

Shrewsbury, MA 01545

(508) 842-0174

Charlie Yust

ORNL

P.O. Box 2008

Bldg. 4515, 063, Rm. 106

Oak Ridge, TN 37830

(423) $574-4812$

\section{F. J. Zanner}

Division 1833

Sandia National Laboratories

Albuquerque, NM 87185

(505) 844-7073

C. M. Zeh

FETC

P.O. Box 380

Morgantown, WV 26505

(304) $291-4265$

R. M. Zimmerman, Division 6313

Sandia National Laboratory

P.O. Box 5800

Albuquerque, NM 87185

(505) 846-0187
Kenneth Zwiebel

NREL

1617 Cole Blvd

Golden, CO 80401

(303) 231-7141 


\section{INDEX}

A

Ablator (173)

Accelerometer (107)

Acid Condensate (61)

Actinides (146)

Adhesion (61)

Adhesive $(44,164)$

Adhesive Bonding (45)

Adsorption Mechanisms (93)

Advanced Batteries (48)

Advanced Heat Engines $(42,54)$

Advanced Sheet Metal Forming (115)

Aerogel (159)

Aging (161)

AGT (54)

Air Conditioning (104)

Air Separation (105)

Al-Metal Composites (118)

AlGaAs (121)

$\mathrm{AlGalnP}_{2}$ (121)

Alkaline Electrolytes (110)

Alloy Design (103)

Alloy Development (136)

Alloy Homogeneity (173)

Alloys $(31,32,52,53,87,102,104,179-181,185,186)$

Alumina Reduction (21)

Aluminides $(179-181,185-187,189,190)$

Aluminizing (179)

Aluminosilicate Minerals (93)

Aluminum $(19,22,23,25,27,29,31,42,43,45,176)$

Aluminum Bridge Decks (103)

Aluminum Casting Explosion (116)

Aluminum Electrolysis Cell (117)

Aluminum Fluoride (20)

Aluminum Melting (20)

Aluminum Oxide (Alumina) $(19,32,51$ )

Aluminum Production $(21,116)$

Aluminum Scrap (21)

Aluminum Smelting (20)

Amorphous Materials (58)

Analyses (106)

Annealing (50)

Applications (102, 107, 109, 118)

Artery (170)

As-built (175)

ASICs (109)

AT-STM (160)

Atomic Force Microscopy $(94,169,172)$

Atomic Scale Structures (118)

Atomistic Bonding (175)

Atomization $(173,175)$

Austenitics (181, 185, 186)

Automated Process Control (115)
Automation (40)

Automotive (42-45)

Automotive Applications (44)

Backfill (62)

Bandgap (162)

Batteries $(46,47,101,108)$

Bearing (64)

Behavior (170)

Berthierine (94)

Beryllium (138, 173, 175, 176)

Beryllium and Organic Salts (174)

Bioceramics (107)

Biochemical Processes (61)

Biocompatible (103)

Biological Polymers (105)

Biologically Suitable Metallic Devices (118)

Biomaterials (170)

Biomedical (102)

Biomineralization (94)

Bismuth Conductor (63)

Blue Emitting Diodes (111)

Bonding (169)

Bone $(107,170)$

Borosilicate Glass (143)

Brazing (42)

Bridge Decks (19)

Brittle Failure (97)

Brittle Materials (85)

Broadband Light Emitters (122)

Bronze (26)

Building Envelope (14)

Building Materials (14)

Buildings (13)

Burner (20)

\section{C-O-H Fluids (99)}

CAD (107)

Calcium Carbonate (94)

Capacitors (30)

Carbon $(46,47)$

Carbon Electrodes (49)

Carbon Fibers $(45,54,184)$

Carbon Products (184) 
Carbon Steel (147)

Carbon-Fiber Composite (138)

Carbonate Minerals $(93,96,97)$

Carbonation (60)

Cast Iron (27)

Cast Metals (43)

Casting $(28,175,176,181)$

CAT Scarns (107)

Catalysis $(93,103,162)$

Catalyst Performance (53)

Catalysts (53)

Catalytic Electrodes (111)

Catalytic Production (103)

Cathode (22)

Cathode Protection (61)

Cation Diffusion (96)

CdZnTe (102)

CdZnTe Detector Arrays (109)

Cementation (97)

Cementitious Grouts (62)

Cements (60)

Centrifugal Casting (118)

Ceramic Composites $(13,28,29,34)$

Ceramic Electrolytes (111)

Ceramic Membranes (101)

Ceramics $(30,33,39,40,52,53,61,112-114,137$,

$138,148,158,160,163,171,182-184,187-190)$

Cermets (53)

Chain Silicates (95)

Chamosite (94)

Characterization $(32,44,108,167,170)$

Chemical Analysis $(53,115,167)$

Chemical Reaction (170)

Chemical Sensing (115)

Chemical Vapor Deposition $(23,31,42,55,58,59,176)$

Chemicals (33)

Chlorofluorocarbons (110)

Chromium-Niobium $(180,187)$

Chromizing (179)

Claddings (30)

Clay Minerals (97)

Cluster (170)

CMOS Process (109)

CMZP (54)

Coated Conductors $(63,114)$

Coatings $\{24,30,31,33,42,52,53,55,58,100,107$,

$114,162,169,179,182-184)$

Cogeneration (28)

Cold Spray Processing (160)

Combinatorial Synthesis (124)

Combustion $(20,84)$

Compatibility $(33,136,137)$

Competitiveness of U.S. Industry (115)

Complex Ceramic Structures (105)

Components $(40,42,52-54,188)$

Composite Electrodes (101)

Composite Tubes (32)

Composites $(24,33,44,45,51,60,61,100,106,126$,

$137,158,160,182-184,187,189)$
Computation (162)

Computed Tomography $(54,98)$

Computer Displays (100)

Conduit (139)

Conservation (158)

Consortium $(103,184)$

Constitutive Description $(98,176)$

Consumable Arc Melt (151)

Contacts (88)

Continuous Fiber (29)

Continuum Mechanics (85)

Convection (84)

Coordination $(42,54)$

Copper $(26,31,138)$

Corrosion $(23-26,30,31,60,116,175,179,180$, 184-187, 189)

Corrosion Control (127)

Corrosion Inhibitors $(116,127)$

Corrosion Protection (61)

Corrosion Resistance $(42,102)$

Corrosion-Gaseous (34)

Cost (44)

Cost Effective (103)

Cost Reduction (56)

Cost-Effective Ceramics $(50,52,55,56)$

Crack Growth (91)

Crash (45)

Creep $(41,53,152)$

Creep Damage (28)

Creep Rupture (186)

Cryogenics (171)

Cryolite (19)

Crystal (170)

Crystal Chemistry Structural Topology (95)

Crystal Silicon (59)

Crystal Surfaces (172)

Crystalline Waste Forms (145)

Crystallization $(142,168)$

Crystallographic Texture (174)

Cupola (27)

Current Collectors (48)

Cutting Fluids (114)

CVD $(42,55,83)$

Cyclic Fatigue $(40)$

Damage (85)

Data Collection and Transmissions (109)

Defects $(96,187)$

Deformation (89)

Dehydrogenation (123)

Densification (142)

Deposition (182) 
<smiles>[2H]</smiles>

Damage (85)

Data Collection and Transmissions (109)

Defects $(96,187)$

Deformation (89)

Dehydrogenation (123)

Densification (142)

Deposition (182)

Design Codes (40)

Design Rules (26)

Design Synthesis and Characterization (105)

Detonation (172)

Device Fabrication (166)

Diagenetic Reactions (94)

Diamond $(83,100,107)$

Die Casting $(26,43)$

Die Design (115)

Die Life (43)

Die Wear (43)

Dies (32)

Diesel (52-55)

Diffusion $(95,96,149)$

Diffusion Mechanism (96)

Diffusivity (99)

Direct Fabrication (160)

Dislocations (174)

Dissociation (171)

Dissolution and Precipitation Mechanisms $(93,94)$

Dissolution Mechanism (98)

Dissolution Rates (98)

Distribution and Transmission (114)

Drill Cores (98)

Drilling (60)

Dual Laser Ablation (126)

Ductile Materials (91)

Durability (44)

Dye-Sensitive Semiconductors (121)

Dynamic Failure (91)

Dynamic Properties (174)

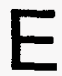

Elastic-Plastic Deformation (174)

Electric Motors (103)

Electric Vehicles $(46,47,49,110)$

Electrical (100)

Electrical Conductivities (171)

Electrical Equipment (114)

Electrical Properties $(137,138)$
Electrically Conducting Polymers (30)

Electro-Optical Devices (112)

Electrocatalysts $(50,108,109)$

Electrochemical Capacitors (49)

Electrochemical Cell (97)

Electrochemistry $(48,109,161)$

Electrodeposition $(58,167)$

Electrodes $(47,48,109)$

Electrodialysis (22)

Electrolyte Decomposition (47)

Electrolytes and Glazings (104)

Electromagnetic Shielding (127)

Electron Beam Melting (173)

Electron-electron Correlations (174)

Electronic Structure $(169,174)$

Electronics $(42,112)$

Electrooxidation (50)

Embrittlement (186)

Energetic Materials $(169,172)$

Energy Efficiency (14)

Energy Management (45)

Energy Transfer (163)

Energy Up Conversion (121)

Engineered Barrier System (154)

Engines (42, 52-55)

Environmental Effects $(41,114)$

Environmental Monitoring (115)

Epitaxy (162)

Equation of State (171)

Equipment (188)

Erosion (31, 138)

Etching (170)

Ethylene (34)

Ettinhausen Effect (120)

EXAFS (47)

Examination (169)

Experimental Rock Deformation (97)

Explosive $(21,169)$

Extrusion $(19,42,151)$

$F$

Fabrication $(60,158)$

Failure Analysis $(41,42,53)$

Failure Testing $(41,42,53)$

Fatigue $(41,186)$

Fault Current Limiter (65)

Feldspar (96)

Ferric Hydroxides (96)

Ferric Oxides (96)

Ferromagnetic Features (124)

Fiber Optic Probe, (19)

Fiber-Reinforced $(182,183)$ 
Fibers $(23,151,187)$

Film Deposition (104)

Films $(107,184)$

Filters $(20,188-190)$

Filtration (33)

Flat Glass (23)

Flaws (188)

Floatation Melter (21)

Fluidized-Bed Combustion (186)

Fluids (88)

Flux Flow (92)

Flywheels (64)

Foam Insulation (13)

Forming $(39,40,151,175)$

Fouling Coefficient (60)

Fractal Lattice and Chirped Quantum Wells (122)

Fractals (B5)

Fracture $(40,44,53,91,137,174,176,185,186,188)$

Fracture Evolution (98)

Fracture Mechanics (85-87, 91)

Fracture Toughness $(41,103)$

Free Machining Steel (45)

Freeform Fabrication $(112,113)$

Freeforming (160)

Fuel Cells (50, 108, 188, 189)

Functionally Gradient Materials (82)

Furnace $(24,187)$

Fuzzy Logic (86)

GaAs (121)

GaAs/AlGaAs (120)

GalnP $_{2}$ (121)

Gallium Nitride (111)

Galvanostatic Charge/Discharge (48)

Gamma Detectors (102)

Gas Gun (171)

Gas Phases (143)

Gas Separation (30)

Gas Turbines $(28,105)$

Gas-Metal Arc (83)

Gas-Phase Chemistry (23)

Gasification (186)

Gatings (25)

Gelcasting (32, 39, 40, 113)

Geologic Repository (145)

Geothermal Heat Pumps (62)

Giant Magnetoresistance (118)

Glass $(24,31,94,142,143,148,149,171)$

Glass Fiber $(20,45)$

Gold (176)

Gold Sulfides (97)
Graduate Fellowship (44)

Gray Iron (27)

Green Emitting Diodes (111)

Ground Heat Exchanger (62)

$\mathrm{H}$

H13 Steel (32)

HCFC (13)

Health-Related Technology Devices (118)

Heat Exchanger Tubes (60)

Heat Exchangers $(34,189)$

Heat Transfer $(13,60,116)$

Heat Treat Distortion (44)

Heat Treating $(23,29,175)$

Heating Elements (122)

HEED (166)

Heteroepitaxial Growth (111)

High Energy Density Materials (172)

High Explosives $(172,174,175)$

High Level Waste $(143,144,146,147)$

High Magnetic Fields (174)

High Temperature $(24,33,104,108,114)$

High Temperature Materials (122)

High Temperature Properties $(40,41)$

High Temperature Service $(53,151)$

High Temperature Solution Calorimetry (146)

High Temperature Superconductors $(88,90,124)$

High-Resolution Transmission Electron Microscopy (94, 95)

HITAF (187)

Hollow-Cathode Discharge (125)

Hot-Gas (181)

HR Coatings (168)

Hydrodechlorination (110)

Hydrogel Polymers (103)

Hydrogen $(30,103,171)$

Hydrogen Production (121)

Hydrogen Storage $(49,50)$

IEA (54)

Illite (94)

Image Processing (123)

Imaging Arrays (109)

Imaging Materials (114)

In-Line Sensors (117)

Inclusions (27) 
Incoloy (139)

Indium-Aluminum-Gallium-Phosphide (122)

Induction Hardening (44)

Industrial Process Control (115)

Industrial Waste Heat Recovery (34)

Industry (32)

Inert Anode (21)

Information Storage (110)

Infrared $(114,162)$

Infrared Spectroscopy $(94,146)$

Infrastructure (44)

InGaAs/InP (120)

Injuries and Fatalities (116)

Inorganic Coatings (30)

Inspection (115)

Insulation $(13,14)$

Insulation Sheathing (13)

Insulators/Thermal (151)

Integrated Circuits $(109,112)$

Intelligent Control (27)

Interace Reactions (99)

Intercalation (47)

Intercalation Electrodes (46)

Interfaces $(90,164,169,182)$

Interfacial Interactions (105)

Intermetallics $(24,31,52,53,180)$

Ion Beam (167)

Ion Beam Processing (125)

Ion Implantation $(48,112)$

Ion Processing (31)

Ion Exchange (149)

Ionic Hydrogenation (103)

IR Imaging (164)

Iron (27)

Iron Aluminides (30)

Iron Phosphate Glasses (145)

Iron-Aluminum $(180,181)$

Irradiation Effects (136-138)

Joining $(32,42,44,138,159,175,185,186)$

Josephson Junctions (92)

$\operatorname{KDP}(168,170)$

Kerogen (94)

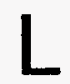

"Lab-on-a-Chip Devices" (115)

LaNi4.27Sno.24 Alloy (49)

Laser Ablation (126)

Laser Damage (169)

Laser Fusion Targets (173)

Laser-Assisted Arc Welding (161)

Laves Phase (174)

Leaching $(143,147)$

LEDs $(111,121)$

LEEM (160)

Li Batteries $(46,47)$

Li intercalation $(46,47)$

Life Prediction $(40-42,53)$

Light Emitting Diodes (121)

Light Emitting Mechanisms (111)

Lighting Tubes (32)

Lightweight Al Alloy Sheets (115)

Lightweight Materials (44)

Lightweight Systems (103)

Liquid Matrix Composites (121)

Lithiated Metal Oxides (104)

Lithium $(108,113,136)$

Lithium Ceramics $(137,138)$

Lithium Salts (175)

Long Length Conductor (64)

Lost Foam Casting (25)

Lubricants (163)

Machining $(25,39,54-56,114)$

Macro-inclusions (26)

Magnesium (43, 45)

Magnetic Imaging (110)

Magnetic Multilayers (118)

Magnetic Processing (34)

Magnetic Separation (64)

Magnetics (100, 138, 139, 171)

Magnetostrictive Materials (119)

Management $(42,54,190)$

Manufacturing $(104,114,115,117)$

Material Degradation (60)

Materials $(32,103,181,182,187,188)$

Materials Program (190)

Materials Properties $(29,101,170,171)$

MBE (166)

Measurements (32) 
Mechanical Properties $(26,34,40,42,53,54,170,175$, 181, 189)

Mechanical Testing (27)

Mechanical Thermophysical (24)

Melt Decontamination (147)

Melt Spinning (173)

Melting (181)

Membranes $(30,111,162,188)$

Meniscus Coater (168)

Mesoporous Silica (106)

Metal Flow $(24,26)$

Metal Matrix Composites $(27,30,43,114,126)$

Metal Matrix Processing (118)

Metal Powder (175)

Metal Transport (97)

Metal-Hydrogen Electrodes (101)

Metalcasting $(23-27,29,31)$

Metallization (171)

Metalorganic Molecular Beam Epitaxy $(119,120)$

Metals $(32,42,144,158)$

Metalworking (114)

Methane ( 30 )

Methanol Oxidation (108)

$\mathrm{MH} / \mathrm{NiOOH}$ Batteries (49)

$\mathrm{MH} / \mathrm{NiOOH}$ Batteries Ab5 and Ab2 Electrodes (50)

$\mathrm{MH} / \mathrm{NiOOH}$ Batteries Modeling (48)

Micro-assembly (176)

Micro-spectroscopy (114)

Microalloy (180)

Microcircuits (109)

Microelectronics (112)

Microencapsulation $(49,173)$

Microfabricated Instrumentation (115)

Microfabrication (107)

Micromachines $(163,165,167)$

Micromagnetics (110)

Micromechanical (162)

Micron-Scale Magnets (124)

Microscopy $(53,175)$

Microshells (173)

Microstructure $(48,53,59,96,174,181)$

Microwave Joining (33)

Microwave Processing $(33,50)$

Microwave Sintering (50)

Minerals (95)

Mixed Metal Oxides (104)

Mixed-Gas $(186,187)$

Mixture (84)

MMC (45)

$\mathrm{Mo}_{5} \mathrm{Si}_{3} \mathrm{~B}(122)$

Model Surfaces (105)

Model-based Engineering (175)

Modeling $(23,32,56,106,115,136,137,149,161$, $176,183)$

Moisture (186)

Molding (45)

Molecular Design (172)
Molecular Dynamics (175)

Molecule-Based Magnets (127)

Molten Aluminum $(20,21,116)$

Molten Metal Catalysts (123)

Molybdenum (180)

MOMBE $(119,120)$

Monazite (142)

Monomers (103)

Monte Carlo (92)

Morphology (172)

$\mathrm{MoSi}_{2}(24,122)$

Motor (65)

MPC (160)

Mullite $(42,52)$

Multilayer Coatings (105)

Multilayer Technology $(163,168)$

Mutli-Component Oxides (112)

N

Nano-indentation (170)

Nanoclusters $(146,165)$

Nanocrystalline Si (171)

Nanodevices (165)

Nanoscale $(161,164,166)$

Nanoseparation (164)

Nanostructures $(159,167)$

Natural Gas (101)

$\mathrm{Nb}_{3} \mathrm{Sn}(138)$

$\operatorname{NDE}(41,170)$

NDT (45)

Near Net Shape Forming (31)

Near-field (145)

Neodymium Magnets, (103)

Neural Networks $(86,115)$

Neutron Absorbers (149)

Neutron Residual Stress (32)

Neutron Scattering (174)

Ni-Based Superalloys $(104,117)$

$\mathrm{Ni}_{3} \mathrm{Al}$ (31)

$\mathrm{Ni}_{3} \mathrm{Si}$ (31)

Nickel Aluminide $(23,29,33)$

NiO Electrodes (49)

Nitrite (147)

NMR (50)

Noble Metal (151)

Nondestructive Evaluation $(27,41,44,54,56,59,86$, 188)

Nonlinear Behavior (98)

Nonlinear Crystals (168)

Nonlinear Optical Materials (123)

Nozzle Vane (39)

Nuclear Explosives Package (176) 
Nuclear Waste (145)

Olefins (30)

Optical Metrology (115)

Optical Waveguides (92)

Optics $(104,163)$

Ordered Alloys (31)

Organic Polymers (34)

Organic Transformations (103)

Organometallic CVD (124)

Overlay (185)

Oxidation (117)

Oxides $(112,182,184)$

Oxy-Fuel $(24,84)$

Oxygen (111)

Oxygen Generators (111)

Oxygen-Permeable Membranes (101)

Pair-distribution-function (174)

Palladium (175)

Particle Reinforced Aluminum (43)

Particle Size (175)

Passivation (116)

Pd Catalysts (110)

Peltier Devices (120)

Permanent Magnets (101)

Permanent Mold Casting (25)

Petroleum (93)

Phase Separation $(25,142)$

Phase Stability (173)

Phase Transformations (87)

Phonon Densities (174)

Photochemical Solar Cells (121)

Photoelectron Emissions (110)

Photonics $(112,162)$

Photooxidation (146)

Photorefractive Liquid Crystals $(123,126)$

Photovoltaics $(119,120)$

Phyllosilicates (95)

Physical Properties (175)

Physical Vapor Deposition $(58,176)$

Physical/Mechanical Properties $(39,51,54)$

Piezoelectrics (90)

Piping $(61,91,144)$

Pitting Corrosion (147)
Plasma (83)

Plasma Arc Melting (174)

Plasma Etching (143)

Plasma Processing (82)

Plasma Sources (125)

Plasma Spray (175)

Plasma-Facing Components, (138)

Plastic Deformation $(95,97)$

Plastics (176)

Platinum (176)

Plutonium $(143,149,174,175)$

Polyimide (173)

Polymer Chemistry (176)

Polymer Composites (45)

Polymer Foam Synthesis (176)

Polymer Magnets (127)

Polymer Multilayer Films (104)

Polymer Systems (104)

Polymeric Electrolytes $(46,47)$

Polymers $(44,45,60,61,100,158,164,165,173,175)$

Pore Structure (98)

Porosity Structure (99)

Porous Media (89)

Porous Silicon (123)

Potliner (20)

Powder Characterization $(52,54)$

Powder Consolidation (175)

Powder Metallurgy $(43,45)$

Powder Synthesis (174)

Powders $(31,33,52)$

Power Supplies (123)

Power Transmission Cable (64)

Precision Machining (176)

Preforming (45)

Pressure Infiltration Casting (114)

Pressure Vessels (91)

Probe (20)

Process Control (52)

Processing $(23,29,32,45,56,101,158,181)$

Properties $(24,32)$

Property Characterization (40)

Proton Adsorption (96)

Prototypes (108)

Pulp and Paper $(23,32)$

Pulsed Ion Beams (125)

Pyroxenes (96)

Quantum Dot (165)

Quantum Well (120)

Quartz (96) 


\section{$\mathrm{R}$}

Radiation $(102,142)$

Radiation Damage (144)

Radiation Effects $(145,148)$

Radioactive Materials (175)

Radioactive Scrap Metal (147)

Radionuclides (149)

Raman Probe (19)

Raman Spectroscopy (146)

Rapid Manufacturing $(112,113)$

Rapid Prototyping $(43,45,107)$

Rapid Solidification $(125,173,174,175)$

Reaction Mechanisms (110)

Reactive Metal Infiltration (30)

Rechargeable Batteries $(46,48)$

Recovery Boilers $(23,32)$

Recycling (22)

Red Emitting Diodes (111)

Reference Material (54)

Reflectivity (152)

Reforming (123)

Refractories (24)

Refractory Metals (175)

Refrigeration (13, 104)

Reliability $(42,161,165,176)$

Remanufacturing (175)

Remote Siensing (159)

REMS (166)

Residual Stress $(25,26)$

Resistance Heaters (122)

Resistive Fault Current Limiter (64)

Retarders (60)

Reverse Engineering (107)

Rheology (26)

Rhodium Plate (152)

Rock Permeability (99)

Rocks (96)

Rolling (151)

Roofs (13)

Salt Cake (22)

Salts $(20,175)$

Sand Mold (27)

Scale-Resistant (60)

Scales $(186,187)$

Scanning Electron Microscopy (53)

Scrap Sorting (43)

Secondary Batteries (104)
Semi-Solid (26)

Semi-solid Casting (27)

Semiconductor Manufacturing (112)

Semiconductors $(58,59,111)$

Sensors $(19,100,109,162)$

Separation $(30,105,111,188)$

Shape Casting (173)

Shape Memory Alloy (126)

Shear Strain Localization (98)

Sheet (22)

Sheet Forming $(42,115)$

Shock Pressures (171)

Shock Temperatures (171)

SiAION (51-53)

Sieves (184)

Silicate Liquids (94)

Silicate Minerals $(94,96,98)$

Silicide (174)

Silicon $(167,180)$

Silicon Carbide $(33,51,137)$

Silicon Nitride $(39-42,50,52,53,55,56)$

Silicotitanate (148)

Sintering $(50,142,175)$

Slurry Preforming (45)

Smart Contact Lens (103)

Smart Materials (159)

Smectite (94)

SMMC (123)

Smog (14)

SOFC (189)

Sol-Gel $(32,33,158,168)$

Solar Cells $(58,59,119,120)$

Solar Energy Conversion (100)

Solar Reflectivity (14)

Solid Acid Catalyst (106)

Solid Model (175)

Solid State Detectors (109)

Solid State Cells (46)

Solid State Electrodes (49)

Solid State Refrigeration (120)

Solubility $(97,99,149)$

Solution Calorimetry (97)

Special Alloys (175)

Speciation (94)

Spectrographic Analysis (50)

Spent Fuel (147)

Spin Forming (173)

Spin-Dependent Tunneling Electron Transport (118)

Spline (175)

Spray Forming (22)

Sputtering $(30,58,173)$

Squeeze Casting (27)

SRBSN (50)

Stability $(54,162,168)$

Stainless Steel $(25,27,175)$

Stamping Process (115)

Statistics (40) 
Steel $(23,25,26,29,31,44,137,138)$

Steel-Reinforced Concrete (116)

$\operatorname{STM}(159,166)$

Stockpile (175)

Stockpile Stewardship (170)

Stoichiometric Evaporation (126)

Strain (170)

Strength (60)

Stress Analysis (90)

Structural Ceramics $(28,34,40-42,51-56)$

Sulfated Zirconia (106)

Sulfur Electrode (46)

Sunsoft Corp. (103)

Superconducting Powder (175)

Superconducting Tape (64)

Superconducting Wires $(108,114)$

Superconductors $(63,86,92,101,124,138)$

Superlattices (88)

Surface Characterization $(55,56,59,98)$

Surface Complexation $(97,99)$

Surface Films (144)

Surface Modification $(125,127)$

Surface Reactions $(93-96,98)$

Surface Roughness (88)

Surface Structure (96)

Surfaces $(90,168,175)$

Surge Protectors (121)

Sustainability (14)

Synchrotron Beamline (114)

Synchrotron Radiation $(98,145)$

Synchrotron X-ray Absorption Spectroscopy (99)

Synthesis (112)

Synthesis Gas (syngas) (101)

$\mathrm{T}$

Tailor Welded Blanks (43)

Tantalum Alloy (152)

Tape Calendering of Oxide Membranes (105)

TATB (169)

Technology Transfer $(180,181,191)$

Tensile Testing $(41,53)$

Terfenol-D (119)

Testing $(29,54,189)$

Testing of Membranes (101)

Thallium Conductor (63)

Thermal Barriers $(28,55,105)$

Thermal Conductivity (62)

Thermal Fatigue (138)

Thermochemistry (97)

Thermoelectric Cooling (120)

Thermoelectric Devices (104)

Thermophysical Properties $(30,88)$
Thin Films $(88,90,100,108,112,164,168)$

Thin-Film Batteries $(49,112,113)$

TiAl (31)

Time-Dependent $(40,41)$

Tissue Regeneration (118)

Titanium (43)

Titanium Diboride (22)

Tooth (170)

Torque Sensors (119)

Toughened Ceramics $(39-41,51)$

Transformation (41)

Transformer (64)

Transition Metals (93)

Transmission Cable (65)

Transmutation (145)

Transport Properties $(89,147)$

Tritium $(123,175,176)$

Tritium Release $(137,138)$

Tubes $(33,189)$

Tubesheet $(190)$

Tungsten (138)

Tungstophosphoric Acid (106)

Turbine Blade (39)

Turbine Components (61)

Turbine Rotor (39)

Turbines (117)

Ultra-low Expansion $(51,52)$

Ultra-Precision Measurements (115)

Ultrahard (163)

Ultrasonics (41)

Uranium (173-175)

Uranium Casting (172)

Uranium Hydriding (170)

Uranium Oxide Dissolution (170)

Uranium Oxide Hydrates (95)

Uranium Purification (175)

User Center (32)

Vacuum (13)

Vacuum Arc Melting (174)

Vanadium (136-138)

Vapor Deposition (105)

Varistors (121)

Viscoplasticity (89)

Vitrification (145) 


\section{W}

Waste Form $(142,148,149)$

Waste Incineration (34)

Waste Package (154)

Waste Tanks (144)

Water (21)

Wear (168)

Weibull (40)

Welding $(23,29,83,86,87,175,185,186)$

Well Casing (61)

Well Completions (60)

Wettable Cathodes (21)

Wetting (162)

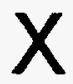

X-ray (102)

$X$-ray Absorption Spectroscopy (50)

$X$-ray Detector (107)

$\mathrm{X}$-ray Diffraction (175)

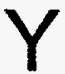

Yttrium Alloying (117)

Yucca Mountain Repository (154)

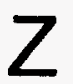

Zeolites (97)

Zirconia $(51,52)$

$\mathrm{Zn}$ and Ni Electrodes (110)

Zn/Air Batteries (109)

$\mathrm{Zn} / \mathrm{Ni}$ Batteries (110)

$\mathrm{ZnO}(121)$ 